\title{
Developing a self-consistent AGB wind model: II. Non-classical, non-equilibrium polymer nucleation in a chemical mixture
}

\author{
Jels Boulangier ${ }^{1 \star}$, D. Gobrecht ${ }^{1}$, L. Decin ${ }^{1,2} \dagger$, A. de Koter ${ }^{1,3}$ and J. Yates ${ }^{4}$ \\ ${ }^{1}$ Institute of Astronomy, KU Leuven, Celestijnenlaan 200D, 3001 Leuven, Belgium \\ ${ }^{2}$ University of Leeds, School of Chemistry, Leeds LS2 9JT, United Kingdom \\ ${ }^{3}$ Anton Pannenkoek Institute for Astronomy, Universiteit van Amsterdam, Science Park 904, NL-1098 XH Amsterdam, The Netherlands \\ ${ }^{4}$ Department of Physics and Astronomy, University College London, Gower St., London WC1E 6BT, United Kingdom
}

Accepted 22/08/2019

\begin{abstract}
Unravelling the composition and characteristics of gas and dust lost by asymptotic giant branch (AGB) stars is important as these stars play a vital role in the chemical life cycle of galaxies. The general hypothesis of their mass loss mechanism is a combination of stellar pulsations and radiative pressure on dust grains. However, current models simplify dust formation, which starts as a microscopic phase transition called nucleation. Various nucleation theories exist, yet all assume chemical equilibrium, growth restricted by monomers, and commonly use macroscopic properties for a microscopic process. Such simplifications for initial dust formation can have large repercussions on the type, amount, and formation time of dust. By abandoning equilibrium assumptions, discarding growth restrictions, and using quantum mechanical properties, we have constructed and investigated an improved nucleation theory in AGB wind conditions for four dust candidates, $\mathrm{TiO}_{2}, \mathrm{MgO}, \mathrm{SiO}$ and $\mathrm{Al}_{2} \mathrm{O}_{3}$. This paper reports the viability of these candidates as first dust precursors and reveals implications of simplified nucleation theories. Monomer restricted growth underpredicts large clusters at low temperatures and overpredicts formation times. Assuming the candidates are present, $\mathrm{Al}_{2} \mathrm{O}_{3}$ is the favoured precursor due to its rapid growth at the highest considered temperatures. However, when considering an initially atomic chemical mixture, only $\mathrm{TiO}_{2}$-clusters form. Still, we believe $\mathrm{Al}_{2} \mathrm{O}_{3}$ to be the prime candidate due to substantial physical evidence in presolar grains, observations of dust around AGB stars at high temperatures, and its ability to form at high temperatures and expect the missing link to be insufficient quantitative data of Al-reactions.
\end{abstract}

Key words: stars: AGB and post-AGB - stars: winds, outflows - astrochemistry methods: numerical

\section{INTRODUCTION}

Low and intermediate mass (initially 0.8 to $8 \mathrm{M}_{\odot}$ ) stars evolve through the asymptotic giant branch (AGB) phase at the end of their life time. During this phase, AGB stars lose vast amounts of material to their surroundings via a stellar wind and thereby contribute significantly to the chemical enrichment of the interstellar medium. As low (and intermediate) mass stars dominate the initial mass function, AGB stars are one of the main contributors of this chemical enrichment. The generally accepted hypothesis is that the mechanism triggering the onset of the AGB stellar

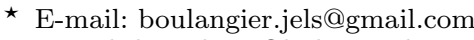

$\dagger$ E-mail: leen.decin@kuleuven.be wind is a combination of stellar pulsations and radiation pressure on newly formed dust grains (Habing \& Olofsson 2004). While dynamic models incorporating this scenario can explain observed wind mass loss rates and velocities of carbon-rich winds (Woitke 2006a), a substantial fine-tuning is needed for oxygen-rich winds (Woitke 2006b) and a model from first principles incorporating all physics and chemistry does not yet exist.

Current AGB wind models implement dust growth by accretion of gas onto tiny solid particles, so-called seeds, based on the prescription of Gail \& Sedlmayr (1999). Such seed particles are either predicted using a nucleation theory (e.g. Gail \& Sedlmayr 1988; Helling \& Winters 
2001; Woitke 2006a), or are assumed to pre-exist, typically chosen to consist of 1000 monomers or to have a radius of $1 \mathrm{~nm}$ (e.g. Ferrarotti \& Gail 2006; Höfner et al. 2016; Dell'Agli et al. 2017). To understand the wind formation mechanism from first principles, it is essential to use a nucleation theory. However, the most complex nucleation theories still assume chemical equilibrium, restrict growth of nucleation clusters to addition of monomers, and apply macroscopic properties of solids to describe clusters of a few molecules. Nonetheless, progress has been made regarding these assumptions, in a range of astrophysical fields where understanding dust formation crucial (e.g. in supernovae, brown dwarf atmospheres, and the interstellar medium). First, the assumption of chemical equilibrium is discarded by e.g. Sarangi \& Cherchneff (2015); Gobrecht et al. (2016); Sluder et al. (2018) who treat nucleation as consecutive chemical reactions. From a chosen cluster size, they allow dust growth by coagulation of clusters, controlled by van der Waals forces (Jacobson 2013). The chosen cluster size is typically less than 5 monomer units. As nucleation reaction rate coefficients are rarely known, these coefficients are often estimated and usually neglect the temperature dependence of the reaction. The latter is crucial to infer dust formation rates as a function of the radial distance from the AGB star. Second, the use of bulk solid properties for molecular clusters is abandoned by e.g. Köhler et al. (1997); Goumans \& Bromley (2012); Lee et al. (2015); Bromley et al. (2016); Lee et al. (2018) by adopting chemical potential energies from detailed quantum mechanical calculations. When describing the clustering of gas phase molecules it is inaccurate to use extrapolated bulk properties, such as binding energy and surface tension, firstly because cluster binding energies are generally significantly reduced with respect to the bulk one, and secondly because microscopic clusters do not resemble the shape/structure of the solid (Johnston 2002; Lamiel-Garcia et al. 2017; Gobrecht et al. 2017). E.g., small clusters do not have well-defined surfaces like solids, rendering the use of surface tension meaningless. Third, as far as we know, no astrophysical models exist where the nucleation and the growth are not restricted by specific cluster size additions (e.g. monomers or dimers). Yet polymer and more complex nucleation theories have been developed in non-astrophysics disciplines, e.g. nano and solid-state physics. Clouet (2009, and references therein) provides a good overview of different complexity levels of nucleation theory from a non-astrophysical perspective.

Presolar grains can be identified in meteorites, interplanetary particles, and cosmic dust by isotopic anomalies that cannot be explained by physical or chemical processes within the Solar System. The origin of the grains can be traced by isotopic ratios of atoms in the grains (Nittler et al. 1997) and point to other nucleosynthetic environments such as AGB stars or supernovae (McSween \& Huss 2010). Here we focus on grains with an AGB origin. Since the first discovery of a presolar $\mathrm{Al}_{2} \mathrm{O}_{3}$ grain by Hutcheon et al. (1994), several presolar oxides have been found of which the majority are $\mathrm{Al}_{2} \mathrm{O}_{3}$ grains (corundum) and only a few are $\mathrm{MgAl}_{2} \mathrm{O}_{4}$ (spinel) (e.g. Nittler et al. 1994; Choi et al. 1998; Nittler et al. 2008). Note that $\mathrm{Al}_{2} \mathrm{O}_{3}$ grains are often referred to as corundum, which is the thermodynamically most stable solid bulk form, yet $\mathrm{Al}_{2} \mathrm{O}_{3}$ exists in a variety of structural forms in presolar grains (Stroud et al. 2004, 2007). Subsequently, Nittler et al. (2008) identified the first Ti-oxides in presolar grains, however they did not have any crystallographic data that would allow to determine the structure of the grains or even conclude if they were $\mathrm{TiO}_{2}$-grains. Later, Bose et al. (2010b) claim to have found a $\mathrm{TiO}_{2}$-grain. The occurrence of Ti-bearing presolar grains is low and their rarity is often explained by the low $\mathrm{Ti}$ abundance in AGB stars. Additionally, presolar silicate grains (containing Si-oxides) have been found (Nguyen \& Messenger 2009; Bose et al. 2010a, 2012). A more extended summary of discovered presolar grains can be found in the Presolar Grain Database ${ }^{1}$ (Hynes \& Gyngard 2009). Besides physical evidence of presolar grains, there is also observational evidence for different dust precursors in AGB winds. Notably the $13 \mu \mathrm{m}$ feature, which is found in spectra of half of all AGB stars (Sloan et al. 1996; Speck et al. 2000; Sloan et al. 2003), is thought to be caused by $\mathrm{Al}_{2} \mathrm{O}_{3}$-grains (Zeidler et al. 2013; Takigawa et al. 2015; Depew et al. 2006), or $\mathrm{MgAl}_{2} \mathrm{O}_{4}$ (Posch et al. 1999), or by $\mathrm{SiO}_{2}$ or polymerised silicates (Speck et al. 2000). Since there is no consensus on what causes this feature, there is still a large uncertainty on the composition of dust in AGB winds.

We investigated the viability of $\mathrm{TiO}_{2}, \mathrm{MgO}, \mathrm{SiO}$ and $\mathrm{Al}_{2} \mathrm{O}_{3}$ as candidates of oxygen-rich AGB dust precursors with a revised nucleation theory. We have improved on the current nucleation theories by abandoning equilibrium assumptions, discarding growth restrictions, and using quantum mechanical properties of cluster molecules. Firstly, we evolve a nucleation system kinetically, therefore it is time dependent and not in equilibrium. Secondly, the revised theory also allows polymer nucleation, not just interactions via monomers. Thirdly, quantum mechanical properties of molecular clusters are calculated with high accuracy density functional theory. Subsequently, these are used in chemical interactions between the nucleation clusters instead of using extrapolations from bulk material. The abundances and formation times of the largest nucleation clusters are examined in a closed nucleating system (no interaction with other chemical species) and in a large chemical mixture. The former assumes the monomer to be a priori present and is unable to be destroyed into smaller species. The latter allows chemical interactions between all species and starts from a purely atomic composition. To describe the chemical interactions, we used the reduced chemical reaction network of Boulangier et al. (2019) and extended this with additional reactions required to chemically couple to the nucleation candidates.

Section 2 describes the chemical evolution of a closed system and presents the improved nucleation theory. Section 3 justifies the chosen nucleation candidates and explains two different nucleation models. Firstly, a closed nucleating model which only considers one nucleating species without interaction with other chemical species. Secondly, a comprehensive nucleating model which considers all nucleating species simultaneously in a large chemical

1 https://presolar.physics.wustl.edu/ presolar-grain-database 
mixture. Additionally, it elaborates on the used nucleation networks, the construction thereof, and the details of the used quantum mechanical data. Section 4 presents the results of the evolution of all nucleation candidates for the different model setups. Section 5 focuses on the implications of the model results. Section 6 discusses the limitations of the revised nucleation, the model setups, and compares the results to previous studies. Finally, section 7 summarises this work. The appendix consists of detailed description of used calculations (Apps. A-C) and an overview of all quantum mechanical data sources (App. D). Additional figures of the model results and the used chemical network are available as appendices $\mathrm{E}$ and $\mathrm{F}$.

\section{METHODS}

This section covers the general theory of chemical reactions and how to evolve such a system, i.e. chemical kinetics (Sec. 2.1), and the construction of our improved non-classical, non-equilibrium polymer nucleation theory (Sec. 2.2).

\subsection{Chemistry}

The evolution of the composition of a system is dictated by a set of chemical formation and destruction reactions. Mathematically, this is a set of coupled ordinary differential equations where the change in number density of the $i$ th species is given by,

$\frac{\mathrm{d} n_{i}}{\mathrm{~d} t}=\sum_{j \in F_{i}}\left(k_{j} \prod_{r \in R_{j}} n_{r}\right)-\sum_{j \in D_{i}}\left(k_{j} \prod_{r \in R_{j}} n_{r}\right)$.

Here, the first term, within the summation, represents the rate of formation of the $i$ th species by a single reaction $j$ of a set of formation reactions $F_{i}$. The second term is the analogue for a set of destruction reactions $D_{i}$. Each reaction $j$ has a set of reactants $R_{j}$, where $n_{r}$ is the number density of each reactant. The rate coefficient of this reaction is represented by $k_{j}$ and has units $\mathrm{m}^{3(N-1)}$ $\mathrm{s}^{-1}$ where $N$ is the number of reactants involved. To solve the chemical evolution of a system, we use the open source KROME $^{2}$ package (Grassi et al. 2014), that is developed to model chemistry and microphysics for a wide range of astrophysical applications.

In general, the rate coefficient of a two body reaction

$\mathrm{A}+\mathrm{B} \longrightarrow \mathrm{C}+\mathrm{D}$

is given by

$k=\int_{0}^{\infty} \sigma v_{r} f\left(v_{r}\right) \mathrm{d} v_{r}$,

where $\sigma$ is the total cross section of an A-B collision, $v_{r}$ is the relative speed between $\mathrm{A}$ and $\mathrm{B}$, and $f\left(v_{r}\right)$ is a (relative) speed distribution. The total cross section of a two-particle collision depends on the kinetic energy of both particles and

2 http://kromepackage.org/ their microphysical interactions. However, the reaction is often reduced to an inelastic collision of two hard spheres due to lack of detailed chemical information. In this case, the total cross section is the geometrical cross section of both spheres, $\sigma=\pi\left(r_{A}+r_{B}\right)^{2}$ where $r_{A}$ and $r_{B}$ are the radii of both species. The speed distribution can be represented by the Maxwell-Boltzmann relative speed distribution, that considers the motion of particles in an ideal gas,

$f\left(v_{r}\right)=\left(\frac{\mu}{2 \pi k_{\mathrm{B}} T}\right)^{3 / 2} 4 \pi v_{r}^{2} e^{-\frac{\mu v_{r}^{2}}{2 k_{\mathrm{B}} T}}$,

where $\mu=\frac{m_{A} m_{B}}{m_{A}+m_{B}}$ is the reduced mass of the system, $k_{\mathrm{B}}$ is the Boltzmann constant, and $T$ is the temperature of the gas. Note that when the reaction requires an activation energy $E_{a}$, the integral in equation (3) should be evaluated from the equivalent speed $v_{a}=\sqrt{2 E_{a} / \mu}$, rather than zero. Using the geometrical cross section and the Maxwell-Boltzmann distribution, equation (3) results in

$k=\pi\left(r_{A}+r_{B}\right)^{2} \sqrt{\frac{8 k_{\mathrm{B}} T}{\pi \mu}}\left(1+\frac{E_{a}}{k_{\mathrm{B}} T}\right) e^{-\frac{E_{a}}{k_{\mathrm{B}} T}}$.

In the limit where $E_{a} \gg k_{\mathrm{B}} T$ this reduces to

$k=\pi\left(r_{A}+r_{B}\right)^{2} \sqrt{\frac{8 k_{\mathrm{B}}}{\pi \mu}} \frac{E_{a}}{k_{\mathrm{B}}} T^{-0.5} e^{-\frac{E_{a}}{k_{\mathrm{B}} T}}$,

and has the form of a modified Arrhenius' equation,

$k_{\mathrm{Ar}}=\alpha T^{\beta} e^{-\frac{\gamma}{T}}$,

where $\alpha, \beta$, and $\gamma$ are constants. In the limit where there is no activation energy or when $E_{a} \ll k_{\mathrm{B}} T$, the last two terms in equation (5) reduce to 1 and the rate coefficient is given by

$k=\pi\left(r_{A}+r_{B}\right)^{2} \sqrt{\frac{8 k_{\mathrm{B}} T}{\pi \mu}}$,

which also has the modified Arrhenius' form. Here, the last factor denotes the average relative speed, often quoted as thermal velocity ${ }^{3}$.

\subsection{Nucleation theory}

We assume that the nucleation process is homogeneous and homomolecular. The former states that there are no preferential sites for nucleation to start, and the latter means that nucleation happens by addition of the same molecular type of clusters. Heteromolecular nucleation is omitted since in this case the number of possible reactions would increase exponentially. Additionally, nucleation occurs in a pure gas-phase condition and as such no preferential nucleation sites exist. This is different compared to nucleation that can occur on solid-state surfaces which can act as a catalyst or where crystal lattice defects can reduce the energy needed for nucleation to start.

3 This is, however, not a vector quantity and naming this a velocity is therefore confusing and should be avoided. The correct terminology is average relative speed. 
In general, a nucleation/cluster growth reaction is represented by,

$$
\mathrm{C}_{\mathrm{N}}+\mathrm{C}_{\mathrm{M}} \longrightarrow \mathrm{C}_{\mathrm{N}+\mathrm{M}}
$$

where $C_{N}$ and $C_{M}$ are clusters ${ }^{4}$ of size $N$ and $M$, respectively. Due to a lack of reaction rate coefficients in the literature, the rate coefficient is determined via equation (8) by assuming an inelastic collision where the activation energy of the reaction is much smaller than $k_{\mathrm{B}} T$ and is given by

$k_{N, M}^{+}=\pi\left(r_{N}+r_{M}\right)^{2} \sqrt{\frac{8 k_{\mathrm{B}} T}{\pi \mu_{N, M}}}$,

where $\mu_{N, M}$ is the reduced mass of the $(N, M)$-system, and $r_{N}$ and $r_{M}$ are the radii of clusters of size $N$ and $M$, respectively. Assuming that the volume scales linearly with the size of the clusters, the radii can be written as function of the monomer radius ${ }^{5} r_{1}$

$k_{N, M}^{+}=\pi\left(N^{1 / 3} r_{1}+M^{1 / 3} r_{1}\right)^{2} \sqrt{\frac{8 k_{\mathrm{B}} T}{\pi \mu_{N, M}}}$.

Note that the assumption of a spherical cluster can be generalised to a fractal cluster with a fractal radius $r_{f, N}=N^{1 / D_{f}} r_{1}$, where $D_{f}$ is the fractal dimension, which equals 3 for spheres.

A cluster destruction process of an $(N+M)$-sized cluster is represented by

$\mathrm{C}_{\mathrm{N}+\mathrm{M}} \longrightarrow \mathrm{C}_{\mathrm{N}}+\mathrm{C}_{\mathrm{M}}$,

The rate coefficient can be derived from the principle of detailed balance which states that, at equilibrium, each elementary process is equilibrated by its reverse process. Hereby, we assume that the destruction rate is an intrinsic property of the cluster and does not depend on the embedding system (i.e. no collisional dissociation). We therefore assume that the cluster has enough time to relax to the lowest energy configuration between its formation and spontaneous break-up. This assumption is consistent with the fact that we describe a cluster solely by its size and minimal energy configuration. With the principle of detailed balance, the destruction rate coefficient can be determined via,

$n_{N+M}^{\mathrm{eq}} k_{N, M}^{-}=n_{N}^{\mathrm{eq}} n_{M}^{\mathrm{eq}} k_{N, M}^{+}$

$$
k_{N, M}^{-}=\frac{n_{N}^{\mathrm{eq}} n_{M}^{\mathrm{eq}}}{n_{N+M}^{\mathrm{eq}}} k_{N, M}^{+},
$$

where $n_{N}^{\text {eq }}$ is the equilibrium number density of the $N$-sized cluster and $k_{N, M}^{+}$is the growth rate coefficient of the reversed reaction (Eq. 10). For a system at constant pressure and temperature, the equilibrium number distribution is determined by minimising its Gibbs free energy (App. A). Consequently, the ratio of the clusters is given by

$\frac{n_{N}^{\mathrm{eq}} n_{M}^{\mathrm{eq}}}{n_{N+M}^{\mathrm{eq}}}=n_{\text {tot }} \exp \left(\frac{G_{N+M}-G_{M}-G_{N}}{k_{\mathrm{B}} T}\right)$,

4 A cluster $C_{N}$ of specific size $N$ denotes a molecule that exists of $N$-times molecule $C$, e.g. $(\mathrm{SiO})_{2}$ is an $\mathrm{SiO}$-cluster of size 2 .

5 This assumption reduces the amount of needed information, i.e. just one molecule radius instead of $N$ radii. It does, however, also decrease the accuracy of the description. where $G_{N}$ is the Gibbs free energy of an $N$-sized cluster and $n_{\text {tot }}$ is the total number density of the gas ${ }^{6}$. It is more convenient to use the Gibbs free energies at standard pressure $\left(P^{\circ}=1\right.$ bar $\left.=10^{5} \mathrm{~Pa}=1 \cdot 10^{6} \mathrm{dyne} / \mathrm{cm}^{2}\right)$. Here, the superscript ${ }^{\circ}$ refers to a quantity evaluated at this standard pressure. Using equation (A25) this ratio is given by

$\frac{n_{N}^{\mathrm{eq}} n_{M}^{\mathrm{eq}}}{n_{N+M}^{\mathrm{eq}}}=\frac{P^{\circ}}{k_{\mathrm{B}} T} \exp \left(\frac{G_{N+M}^{\circ}-G_{M}^{\circ}-G_{N}^{\circ}}{k_{\mathrm{B}} T}\right)$.

Substituting this ratio into equation (13) yields a cluster destruction rate coefficient

$k_{N, M}^{-}=k_{N, M}^{+} \frac{P^{\circ}}{k_{\mathrm{B}} T} \exp \left(\frac{G_{N+M}^{\circ}-G_{M}^{\circ}-G_{N}^{\circ}}{k_{\mathrm{B}} T}\right)$.

Note that the standard Gibbs free energies are often given in $\mathrm{kJ} \mathrm{mol}^{-1}$, in which case the Boltzmann constant $k_{\mathrm{B}}$ in the exponential has to be replaced with the universal gas constant $R$ in $\mathrm{kJ} \mathrm{K}^{-1} \mathrm{~mol}^{-1}$.

\section{MODEL SETUP}

This section explains the two different nucleation descriptions that have been used, a monomer and polymer one (Sec. 3.1). Next, it justifies the choice of nucleation candidates that have been considered, namely $\mathrm{TiO}_{2}, \mathrm{MgO}, \mathrm{SiO}$ and $\mathrm{Al}_{2} \mathrm{O}_{3}$ (Sec. 3.2). Additionally, it describes the two different types of chemical nucleation networks, a closed one and a comprehensive one (Secs. 3.3 and 3.4). The closed nucleating network assumes the monomer to be a priori present and is unable to be destroyed into smaller species. No assumptions have been made on how the monomer has been formed or its possible existence. The comprehensive nucleating network does not assume the existence of the nucleating monomers and starts from a purely atomic composition. The (possible) formation of the nucleating monomers and other chemical species is determined by a large chemical reaction network. Finally, this section summarises all the additionally gathered data and performed calculations prior to running the nucleation models (Sec. 3.6).

\subsection{Nucleation description}

We consider two different nucleation descriptions, polymer and monomer nucleation. The former is the most general and uses growth and destruction of the corresponding clusters described by equations (11) and (16), whereas the latter uses those same equation but with $M=1$ reducing it to a monomer. We make this distinction because, to our knowledge, most homomolecular nucleation studies assume monomer nucleation (e.g. Köhler et al. 1997; Lee et al. 2015; Bromley et al. 2016; Lee et al. 2018). However, the monomer assumption is only valid when the number of monomers is much larger than that of any other cluster. There is no quantitative evidence to support this assumption and it turns out to be invalid in our parameter space $^{7}$ (Sec. 4). Sarangi

${ }^{6}$ Note that this is only valid in the dilute limit, i.e. the number of clusters is small compared to the total number of particles.

7 For higher densities this will be even less valid, e.g. brown dwarfs and planetary atmospheres. 
\& Cherchneff (2015); Gobrecht et al. (2016); Sluder et al. (2018), however, do allow polymer nucleation but limit it to small clusters $(N<5)$.

\section{$3.2 \quad$ Nucleation candidates}

In oxygen-rich atmospheres $(\mathrm{C} / \mathrm{O}<1)$, carbon is predominantly locked-up in $\mathrm{CO}$, strongly inhibiting the formation of carbonaceous dust. Highly stable molecules in an carbon-deficient gas such $\mathrm{CO}, \mathrm{N}_{2}$, and $\mathrm{CN}$ only have a solid form (ice) at temperatures well below $500 \mathrm{~K}$. Also solid oxygen only forms at extremely cold temperatures. Hence, nucleation at high temperatures must proceed via hetero-atomic species such as composite metal ${ }^{8}$ oxides. Monomers with high bond energies ${ }^{9}$ are preferential candidates for first nucleation because higher energies generally allow for easier formation and more difficult destruction at higher temperatures. Therefore, bond energies of simple metal oxides give a hint for which molecules will play a predominant role. Considering the most abundant atomic metals in $\mathrm{AGB}$ winds, $\mathrm{SiO}, \mathrm{TiO}$, and $\mathrm{AlO}$ are the metal oxides with the highest bond energy (Fig. 1). Even though the amount of $\mathrm{Ti}$ is almost a factor 40 and 400 lower than $\mathrm{Al}$ and $\mathrm{Si}$, respectively, it can still be an important molecule due to its high bond energy. Similarly, $\mathrm{MgO}$, and $\mathrm{FeO}$ have lower bond energies but the high atomic abundance of $\mathrm{Mg}$ and Fe can make them important nucleation candidates.

Although the metal oxides hint at the engaged species, the most compelling evidence for nucleation building blocks comes from presolar grains. Considering all the presolar grains that originated from AGB stars, $\mathrm{Al}_{2} \mathrm{O}_{3}$ grains are the most frequently occurring oxygen-bearing ones. (Hutcheon et al. 1994; Nittler et al. 1994; Choi et al. 1998; Nittler et al. 2008). In these grains, $\mathrm{Al}_{2} \mathrm{O}_{3}$ is the basic building block (repeating formula unit) that forms the bulk grains with a variety of structural forms (Stroud et al. 2004, 2007). The repetition of such a basic building block strengthens our assumption of homomolecular nucleation. The second most frequently found grains, roughly a factor 7 less abundant, are the ones with $\mathrm{MgAl}_{2} \mathrm{O}_{4}$ as repeating formula unit (Nittler et al. 1994; Choi et al. 1998; Nittler et al. 2008). Additionally, there is some evidence for silicon and titanium oxides in presolar grains (Nguyen \& Messenger 2009; Bose et al. 2010b; Nittler et al. 2008; Bose et al. 2010a). However, as only little amount of this material is detected, it is unclear what the repeating basic building block is.

Considering the occurrence in presolar grains, the atomic metal abundance, and the bond energy of simple metal oxides, we choose $\mathrm{Al}_{2} \mathrm{O}_{3}$ to be our primary nucleation candidate. Next, we do not consider $\mathrm{MgAl}_{2} \mathrm{O}_{4}$ as a candidate as this molecule consist of three different atoms, making it more complex to characterise its molecular features. We include $\mathrm{MgO}$ as a candidate because it (and its clusters) might play a role in the formation of $\mathrm{MgAl}_{2} \mathrm{O}_{4}$ grains. Additionally, we take $\mathrm{TiO}_{2}$ as a nucleation candidate. Even

\footnotetext{
${ }^{8}$ We refer to the chemical use of metals and not the astronomical one.

9 Bond energy is a measure of the strength of a chemical bond.
}

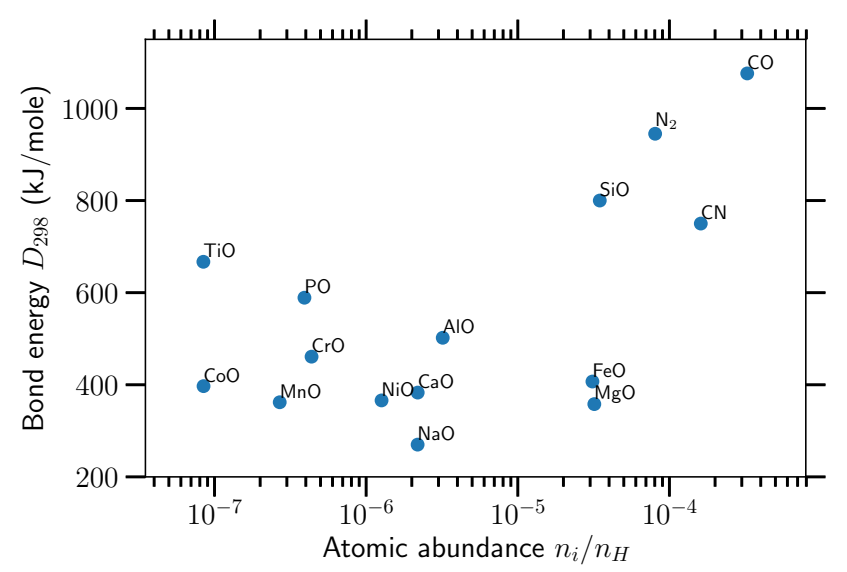

Figure 1. Simple molecules (mainly oxides) with high bond energies at $298 \mathrm{~K}$ (Luo 2007) and/or a high atomic abundance provide hints at which species play a dominant role in the initial dust formation in AGB winds.

though there is no substantial evidence for $\mathrm{TiO}_{2}$ to be the repeating formula unit in presolar grains containing titanium oxides, it is, however, the repeating basic building block in other commonly found titanium minerals on Earth (e.g. rutile and anatase). Lastly, we select $\mathrm{SiO}$ as a candidate. Although there is no physical evidence in presolar grains that $\mathrm{SiO}$ is the repeating formula unit, it does have the highest bond energy of the most abundant atomic metals and it most likely will play an important role in the formation of silicate grains. We exclude $\mathrm{FeO}$ from this study because, so far, only one potential detection of $\mathrm{FeO}$ in AGB circumstellar environment has been reported (Decin et al. 2018), nor has there been proof of FeO-containing particles in pre-solar grains. Additionally, Fe-containing nanoparticles can display various magnetic behaviours such as ferromagnetic, antiferromagnetic, ferrimagnetic, and nonmagnetic, and are therefore challenging to characterise.

A typical interstellar dust grains of radius $0.1 \mu \mathrm{m}$ contains $10^{9}$ monomer units with a typical radius of roughly $0.1 \mathrm{~nm}$ (Table D1). Hence, in order to construct a dust grain via reaction rate equations, one needs of the order of $10^{9}$ equations. As this is computationally impossible, we limit the maximum cluster size so the largest clusters roughly consist of 20 to 40 atoms, making it still feasible to perform high accuracy density functional theory calculations (Sec. 3.6.2). We take the largest cluster to be $\left(\mathrm{TiO}_{2}\right)_{10}$, $(\mathrm{SiO})_{10},(\mathrm{MgO})_{10}$, and $\left(\mathrm{Al}_{2} \mathrm{O}_{3}\right)_{8}$. Note that these cluster sizes are not necessarily the threshold from which the species can be considered as a macroscopic, solid dust grain (Sec. 6).

\subsection{Closed nucleation networks}

A closed nucleation model corresponds to the evolution of a cluster system according to growth and destruction rate coefficients (Eqs. 11 and 16) with the monomer as the smallest and the maximally considered cluster size as the largest allowed clusters. Such a model starts with an initial monomer abundance and follows the growth of this monomer over 
Table 1. Initial chemical composition. This is equal to the timeaveraged mass fractions in the wind for a nucleosynthetic AGB evolutionary model with an initial mass of $1 \mathrm{M}_{\odot}$ and metallicity $\mathrm{Z}=0.02$ of Karakas (2010). The mass fraction of Ti is that of solar abundance (Asplund et al. 2009).

\begin{tabular}{lll} 
Element $i$ & Mass fraction $X_{i}$ & $n_{i} / n_{H}$ \\
\hline $\mathrm{He}$ & $3.11 \cdot 10^{-1}$ & $1.16 \cdot 10^{-1}$ \\
$\mathrm{C}$ & $2.63 \cdot 10^{-3}$ & $3.26 \cdot 10^{-4}$ \\
$\mathrm{~N}$ & $1.52 \cdot 10^{-3}$ & $1.61 \cdot 10^{-4}$ \\
$\mathrm{O}$ & $9.60 \cdot 10^{-3}$ & $8.92 \cdot 10^{-4}$ \\
& & \\
$\mathrm{~F}$ & $4.06 \cdot 10^{-7}$ & $3.18 \cdot 10^{-8}$ \\
$\mathrm{Na}$ & $3.38 \cdot 10^{-5}$ & $2.18 \cdot 10^{-6}$ \\
$\mathrm{Mg}$ & $5.16 \cdot 10^{-4}$ & $3.19 \cdot 10^{-5}$ \\
$\mathrm{Al}$ & $5.81 \cdot 10^{-5}$ & $3.20 \cdot 10^{-6}$ \\
& & \\
$\mathrm{Si}$ & $6.54 \cdot 10^{-4}$ & $3.47 \cdot 10^{-5}$ \\
$\mathrm{P}$ & $8.17 \cdot 10^{-6}$ & $3.92 \cdot 10^{-7}$ \\
$\mathrm{~S}$ & $3.97 \cdot 10^{-4}$ & $1.84 \cdot 10^{-5}$ \\
$\mathrm{Ti}$ & $2.84 \cdot 10^{-6}$ & $8.44 \cdot 10^{-8}$ \\
& & \\
$\mathrm{Fe}$ & $1.17 \cdot 10^{-3}$ & $3.16 \cdot 10^{-5}$ \\
$\mathrm{e}^{-}$ & 0 & 0 \\
$\mathrm{H}$ & $1-\sum_{i}^{N} X_{i}$ & 1 \\
& $=6.72 \cdot 10^{-1}$ &
\end{tabular}

time at a fixed temperature. We construct a model grid in temperature and density that is primarily applicable to an AGB wind (but that is also valid in other environments) and evolve each model over a timescale of one year. The latter corresponds to the longest dynamically stable period (between pulsation-induced consecutive shocks), resulting in a roughly constant local temperature and density in that period. For the initial abundance of the monomer we assume all of the available atomic metal ${ }^{8}$ to be locked-up in the monomer (Table 1). For the available atomic metal abundance we choose the same composition as Boulangier et al. (2019) who take the time-averaged elemental mass fractions in the wind from $1 \mathrm{M}_{\odot}$ and $Z=0.02 \mathrm{AGB}$ evolution model of Karakas (2010) (defined as $\langle X(i)\rangle$ in Karakas \& Lattanzio (2007)). For Ti we take the solar abundance because this element is not considered in the nucleosynthesis networks of Karakas $(2010)^{10}$.

\subsection{Comprehensive chemical nucleation network}

A comprehensive nucleation model corresponds to the evolution of nucleation clusters in a large chemical network according to growth and destruction rate coefficients (Eqs. 11 and 16) until a specified maximum cluster size. Such a model starts from the atomic composition rather than the initial monomer abundance which is used in a closed nucleation

10 The abundance of Ti is not affected by the slow neutron capture process because of low neutron capture cross sections for elements below iron, and burning temperatures are not high enough for higher burning processes to affect Ti. Hence, $\langle X(i)\rangle$ of Ti does not change between birth and death of low and intermediate mass stars. model (Sec. 3.3). This is a more realistic prescription as is removes the assumption of the monomer being (abundantly) present. Moreover, it allows for more chemical interaction between species and the creation of other metalbearing molecules besides the nucleation candidate clusters. In practice, the reaction network consists of the closed nucleation networks of $\mathrm{TiO}_{2}, \mathrm{MgO}, \mathrm{SiO}$, and $\mathrm{Al}_{2} \mathrm{O}_{3}$ (Sec. 3.3) extended with the reduced AGB wind network of Boulangier et al. (2019). However, because their reduced network does not consider any $\mathrm{Ti}, \mathrm{Al}$, and only a few $\mathrm{Mg}$ reactions, we have added all reactions that include these elements available in the literature. Additionally, where necessary and possible, we have included the reversed reaction based on the assumption of detailed balance ${ }^{11}$. As with the closed nucleation models, we compute the same grid of models in temperature and density over a one year period but with an initial atomic composition (Table 1).

\subsection{Justification of nucleation networks}

It is instructive to investigate the nucleation of chemical species in a closed system with the assumption of an a priori monomer existence to gain insight in the efficiency of the nucleation process different species. Such preliminary nucleation investigations can already exclude candidates as viable AGB dust precursors based on inefficient nucleation at high temperatures. This pre-selection of nucleation candidates leads to a considerable reduction of the computational cost when coupling the reaction network to a hydrodynamical framework. Moreover, a closed nucleation investigation reduces the number of uncertainties when interpreting the nucleation process. For example, the nucleation of clusters in a large chemical network might not occur due to an insufficient or incorrect description of the gas-phase chemistry prior to the monomer formation rather than the nucleation process itself, which can be very effective. By ignoring the disentanglement between monomer formation and the nucleation process, the nucleation species can be wrongly discarded as a good dust candidate. Additionally, the closed nucleation system allows us to investigate the impact of using the improved nucleation description, such as monomer versus polymer nucleation and using molecular energies compared to bulk energies.

\subsection{Construction of nucleation networks}

This section covers the additional chemical reactions, quantum mechanical properties and calculations needed to construct valuable nucleation reaction networks. The first section describes the addition of chemical reactions and the second section the collection and calculation of quantum mechanical properties of molecules and clusters necessary for certain reversed reactions.

11 The reversed rate coefficient depends on the difference in Gibbs free energy of reactants and products (i.e. the Gibbs free energy of reaction). If there was insufficient data in the literature to calculate these energy values, we did not include the reversed reaction. 


\subsubsection{Additional reactions}

In order to construct a reaction network for the comprehensive nucleation models, reactions from atomic $\mathrm{Ti}, \mathrm{Al}, \mathrm{Si}$, and $\mathrm{Mg}$ up to the corresponding nucleation monomer have to be included. Additionally, to increase the accuracy of chemical interactions, as many as possible other nucleation-related metal-bearing molecules should be added to the network with corresponding reactions. Even though some species or reactions might not be important and could be omitted, such filtering is beyond the scope of this paper because computation time is currently not an issue as we only perform grids of models rather than coupling it in real-time to a hydrodynamical framework.

Ti-bearing molecules are not well studied and corresponding reaction rate coefficients are lacking in astrochemical databases. We could only find 9 reactions of which only one had a reversed reaction. For the remaining 8 reversed reactions we assumed detailed balance. We did, however, ignore reactions for the Ti-Cl-H system (Teyssandier \& Allendorf 1998) due to the low abundance of both $\mathrm{Cl}$ and Ti in AGB stars.

Apart from the $\mathrm{SiO}$-nucleation reactions, just one other Si-reaction is added relative to Boulangier et al. (2019), whose network is mainly constructed from the astrochemical databases UMIST (McElroy et al. 2013) and KIDA (Wakelam et al. 2012) in which Si-bearing molecules are well-studied. The destruction of $\mathrm{SiO}_{2}$ by atomic hydrogen, calculated via detailed balance, is added to the chemical network to equilibrate the forward reaction. Previously, the only incorporated $\mathrm{SiO}_{2}$ destruction reaction was the collision of $\mathrm{He}^{+}$, which requires very high temperatures.

Additionaly, 15 Mg-related reactions are added. Only for 7 of them we added a reversed detailed balance reaction. However, due to a lack of quantum chemical data on $\mathrm{MgO}_{2}, \mathrm{MgO}_{3}$, and $\mathrm{MgO}_{4}$ no reversed reactions for reactions including such species are added. Reactions with ionised Mg-bearing molecules can be found in the literature (Whalley \& Plane 2010; Martínez-Núñez et al. 2010; Whalley et al. 2011) but are ignored because ionisation is unlikely at the low temperatures of our grid.

In total 51 Al-related reactions and their reversed detailed balance reactions are added, that mostly originate from combustion chemistry.

\subsubsection{Quantum mechanical properties}

In order to calculate the reversed reaction rate coefficient under the assumption of detailed balance, one needs the Gibbs free energy (GFE) of all reactants and products, as a function of temperature at a specific pressure ${ }^{12}$ (Eq. (16) for nucleation and e.g. equations (73) - (76) in Grassi et al. (2014) in general). In principle, one can also use the difference in Gibbs free energy of formation (GFEoF) because

\footnotetext{
12 One only needs to determine the GFE at a single pressure to be used in reversed rate coefficients. Often a standard pressure of $1 \mathrm{bar}=1 \cdot 10^{5} \mathrm{~Pa}$ is used.
}

the additional contribution of individual atoms cancels out (App. C). On one hand, using the GFEoF has the advantage of being calculated for numerous species and being included in different databases, e.g. so-called NASA-polynomials ${ }^{13}$ (Burcat \& Ruscic 2005) and NIST-JANAF Thermochemical Tables ${ }^{14}$ (Chase 1998). On the other hand, there are inconsistencies between both databases such as the same species having different GFEoF values. By benchmarking, Tsai et al. (2017) also came to this conclusion and assign the discrepancies between the databases to a differently defined reference level that corresponds to zero energy. Another reason might be that the GFEoF values rely on experimentally determined values of quantities at room temperature which can have large error bars. Moreover, the details of the calculations or experiments are often unclear as these have been performed decades ago and frequently lack detailed descriptions. For consistency, we use (and strongly encourage to use) GFE rather than GFEoF. Because the GFE is an intrinsic property of a species, it does not rely on any experimental value at a reference temperature (e.g. room temperature) but can be calculated from first principles with absolute zero as a reference point (App. B). In short, to calculate the GFE as a function of temperature, one only needs the total partition function and the electronic potential energy at zero Kelvin (Eq. B9).

We calculate the GFE of all clusters of the four nucleation species $\mathrm{TiO}_{2}, \mathrm{MgO}, \mathrm{SiO}$ and $\mathrm{Al}_{2} \mathrm{O}_{3}$ by first gathering the most recent structural information (i.e. atomic coordinates) of the lowest energy isomers, i.e. the so-called global minima (Table D1). Subsequently, using Gaussian09 (Frisch et al. 2013), we perform density functional theory (DFT) calculations including a vibrational analysis to determine the GFE. For consistency, we always use the same functional and basis set, namely the B3LYP functional (Becke 1993) and $6-311+\mathrm{G}^{* 15}$ basis set. Other functionals and/or basis sets might be more accurate for specific properties or species, yet B3LYP is well established and suitable for inorganic oxides (Corà 2005), and $6-311+\mathrm{G}^{*}$ is a good compromise between accuracy and computation time.

For all non-cluster species participating in reversed reactions, we have collected the electronic potential energies when available (Table D2). All energies originate from DFT calculations by the Computational Chemistry Comparison and Benchmark DataBase ${ }^{16}$ (CCCBDB, Johnson 2018). For consistency we always use results of the same functional and basis set, namely B3LYP and 6-31+G**17. We perform DFT calculations for the species of which no electronic potential energies are present in any database, using the same DFT setup as for the nucleation clusters (Table D2).

\footnotetext{
13 http://garfield.chem.elte.hu/Burcat/burcat.html

14 https://janaf.nist.gov/

15 This basis set is spanned by 6 primitive Gaussians, includes diffusion $(+)$ and polarisation $(*)$.

16 https://cccbdb.nist.gov/

17 CCCBDB does not contain calculations with $6-311+\mathrm{G}^{*}$, the one we used for the nucleation clusters. The $6-31+\mathrm{G}^{* *}$ basis set is slightly smaller but also includes diffusion and polarisation, and most closely resembles $6-311+\mathrm{G}^{*}$
} 
When possible, we have gathered partition functions ${ }^{18}$ of the non-cluster species participating in reversed reactions (Table D2). These values originate from detailed calculations and/or experiments. If no literature partition functions could be found, we have calculated them from internal energy levels (rotational, vibration, and electronic ${ }^{19}$ ) found in the CCCBDB (App. B). Note that this method is less precise due to approximations such as considering the species as a rigid rotor and harmonic oscillator. Again, when no energy levels were available in the literature, we have calculated them via a vibrational analysis as a follow-up on the DFT calculations (Table D2).

\section{RESULTS}

This section presents the simulation results of the two main model setups, one with closed nucleation networks and one with a comprehensive chemical nucleation network. The closed nucleation network setup considers four nucleation species, $\mathrm{TiO}_{2}, \mathrm{MgO}, \mathrm{SiO}$ and $\mathrm{Al}_{2} \mathrm{O}_{3}$. Additionally, each of these sub-setups will use the monomer nucleation (MN) and the polymer nucleation (PN) approach. The comprehensive chemical nucleation network setup will encompass all four mentioned nucleation species but only use the polymer nucleation approach.

Because our results include four parameters (temperature, gas density, cluster number density, and time), we reduce the dimensionallity to analyse the outcome. The analysis of the cluster size distributions in $(T, \rho)$-space is limited to the end of the simulation, i.e. after one year. Subsequently, to infer temporal effects, we choose a benchmark constant total mass density of $1 \cdot 10^{-9} \mathrm{~kg} \mathrm{~m}^{-3}$, which is a typical value we expect in an AGB wind (Boulangier et al. 2019, fig. 10). Note that we use the total mass density of the gas as a parameter since this value remains constant as compared to the total number density.

\subsection{Closed nucleation networks}

This section covers the evolution of four nucleation species $\mathrm{TiO}_{2}, \mathrm{MgO}, \mathrm{SiO}$ and $\mathrm{Al}_{2} \mathrm{O}_{3}$ for a closed nucleation network setup with both the monomer nucleation $(\mathrm{MN})$ and the polymer nucleation (PN) description. To ensure the overview, we mainly discuss the largest clusters because they are most interesting to understand formation of macroscopic dust grains. Additional figures for all clusters can be found in Appendix E1.

\footnotetext{
18 Note that this excludes the translational part because that depends on the number of particles and the pressure for which one wants to calculate the total partition function.

19 The number of electronic energy levels is truncated to be valid below $\sim 10000 \mathrm{~K}$, which is more than sufficient for the purpose of this paper.
}

\subsection{1 $\mathrm{TiO}_{2}$}

$\left(\mathrm{TiO}_{2}\right)_{10}$ forms when the temperature drops below the sharp threshold at 1000 to $1200 \mathrm{~K}$, where the low (high) temperature threshold is for the lowest (highest) densities (Fig. 2). At temperatures above $1200 \mathrm{~K}$, its abundance drops orders of magnitude (Figs. E1, E10). As expected, a higher density leads to more collisions facilitating nucleation at higher temperatures. Between roughly $950 \mathrm{~K}$ and the upper temperature threshold for both $\mathrm{MN}$ and $\mathrm{PN}$, almost all of the available monomers end up in $\left(\mathrm{TiO}_{2}\right)_{10}$ ( $>80$ per cent). However, using MN or PN yields vastly different results at low temperatures. In this regime, roughly below $950 \mathrm{~K}$, the abundance of $\left(\mathrm{TiO}_{2}\right)_{10}$ drops orders of magnitude in the case of MN in contrast to PN, where its abundance is nearly identical and accounts for 40 to 50 per cent of the available titanium. The low abundance in the MN case is caused by a relatively rapidly developing lack of monomers in this temperature range, because, by design, growth is only allowed by the addition of monomers. Once the bulk of the material is clustered in $N=2$ to 4 chains, the monomer population becomes depleted and further growth is quenched (Fig. E1). At our benchmark density of $1 \cdot 10^{-9} \mathrm{~kg} \mathrm{~m}^{-3}$, this typically happens in less than a day. This bottleneck does not occur in the case of PN since, by design, all clusters are allowed to participate in the growth process (Fig. E10). Therefore, even in the case of a lack of monomers other small clusters can interact and form larger clusters. In this low temperature regime, this occurs so efficiently that the small clusters $(N=2$ to 4$)$ are completely depleted and turned into large clusters. The fact that clusters of intermediate $(N>6)$ size are still present is somewhat artificial since they are only allowed to grow by addition of smaller ones due to the limitation of a maximum size of $N=10$. As these small clusters are already depleted, the intermediate growth is quenched. In reality clusters of size $N=6$ and $N=7$ can interact to form an $N=13$ sized cluster.

Using $\mathrm{MN}$, the abundance of the largest molecules converges $^{20}$ slowest, roughly after 20 and $60 \mathrm{~d}$ for $\left(\mathrm{TiO}_{2}\right)_{9}$ and $\left(\mathrm{TiO}_{2}\right)_{10}$, respectively. All smaller molecules roughly converge after $20 \mathrm{~d}$ or less (Fig. E2). Using PN, the convergence of $\left(\mathrm{TiO}_{2}\right)_{10}$ occurs faster, already after $20 \mathrm{~d}$, even in less than $1 \mathrm{~d}$ for the slightly smaller clusters. All small clusters are also formed within $1 \mathrm{~d}$ but continue to steadily grow into larger ones (Fig. E11).

\subsection{2 $\mathrm{MgO}$}

Unlike for $\mathrm{TiO}_{2}$ clusters, the conditions that determine the presence of the largest $\mathrm{MgO}$ cluster differ strongly between the different nucleation descriptions, being more complex in the MN case. Yet both nucleation descriptions reveal that the second largest cluster $(\mathrm{MgO})_{9}$, rather than the largest cluster $(\mathrm{MgO})_{10}$, is the most stable and therefore most abundant cluster (Figs. E3, E12). Hence, we mainly discuss $(\mathrm{MgO})_{9}$. In the MN case, between 1100 and $1500 \mathrm{~K}$ and at the highest densities all available monomers end up

20 This happens over the entire temperature range unless stated otherwise. 

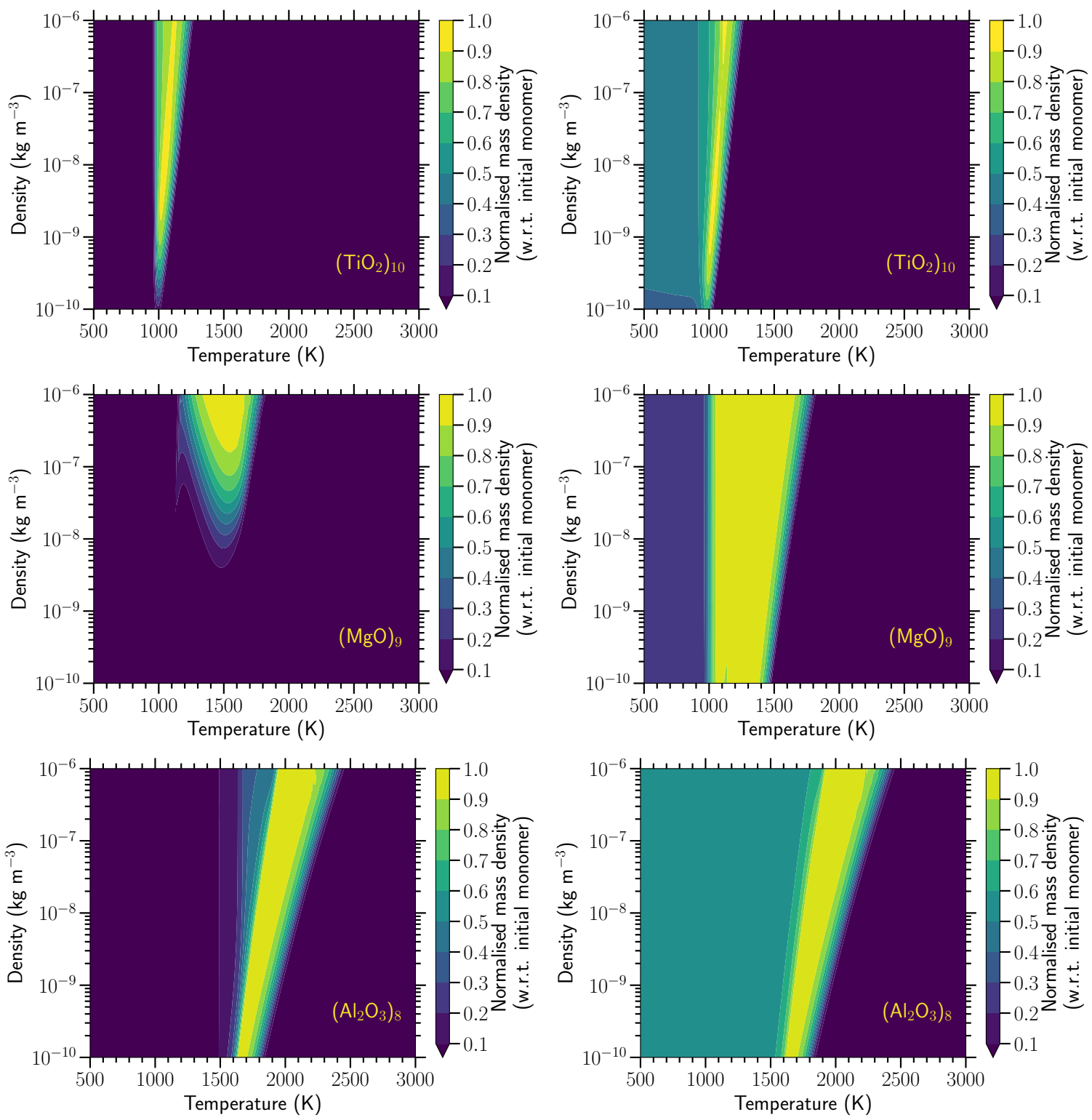

Figure 2. Normalised mass density (or mass fraction) w.r.t. the initially available monomers after one year of $(\mathrm{TiO})_{10},\left(\mathrm{MgO}_{9}\right.$, and $\left(\mathrm{Al}_{2} \mathrm{O}_{3}\right)_{8}$ for the closed nucleation models with left monomer and right polymer nucleation description. We refrain from showing $(\mathrm{SiO})_{10}$ since its abundance is zero in the entire parameter space. Note that $(\mathrm{MgO})_{9}$ is the second largest cluster, but most stable and more abundant one. Monomer nucleation under predicts the amount of large clusters at low temperature, as compared to polymer nucleation. This under prediction is due to the limitation of growth-by-monomers in the monomer nucleation description. In the most favourable nucleation conditions, more than 90 per cent of the initial monomers end up in the largest cluster. $\mathrm{Al}_{2} \mathrm{O}_{3}$-clusters are the primary candidate for first dust precursors because $\left(\mathrm{Al}_{2} \mathrm{O}_{3}\right)_{8}$ forms at the highest temperature as compared to the other candidates. Normalised number densities w.r.t. the initially available monomers can easily be found by dividing the normalised mass density by the cluster size, i.e. divide by 8 in the case of $\left(\mathrm{Al}_{2} \mathrm{O}_{3}\right)_{8}$. An overview of all clusters of all candidates can be found in Appendix E1 with an in-depth analysis in Sections 4.1 and 5.2 .

in $(\mathrm{MgO})_{9}$ (Fig. 2). But, within this temperature range, this amount strongly decreases with decreasing density where at $1 \cdot 10^{-8} \mathrm{~kg} \mathrm{~m}^{-3}$ just 10 per cent ends up in $(\mathrm{MgO})_{9}$ and at the lowest densities this amount reduces to 0.01 per cent (Fig. E3). Note that below $1100 \mathrm{~K}(\mathrm{MgO})_{9}$ clusters can also exist but maximally take up 1 per cent of the available monomers. In the $\mathrm{PN}$ case, $(\mathrm{MgO})_{9}$-clusters already form below 1500 to $1700 \mathrm{~K}$ and above $1000 \mathrm{~K}$ they contain over 90 per cent of the available monomers (Fig. 2). Below $1000 \mathrm{~K}$, they are less abundant but still encompass between 20 to
30 per cent of the monomers. Note that below $1000 \mathrm{~K}$, there is more $(\mathrm{MgO})_{10}$ than $(\mathrm{MgO})_{9}$, making the largest cluster the most stable one at low temperatures (Fig. E12). Similar to the other nucleation candidates, the lack of large $\mathrm{MgO}$-clusters at low temperatures, below $1000 \mathrm{~K}$, in the MN case is due to the construction of this nucleation description, that limits growth by addition of monomers. It is also interesting to note that in both nucleation cases and above $1000 \mathrm{~K}$, cluster sizes $N=2,4,6$, and 9 are more abundant than their direct size-neighbours. This 

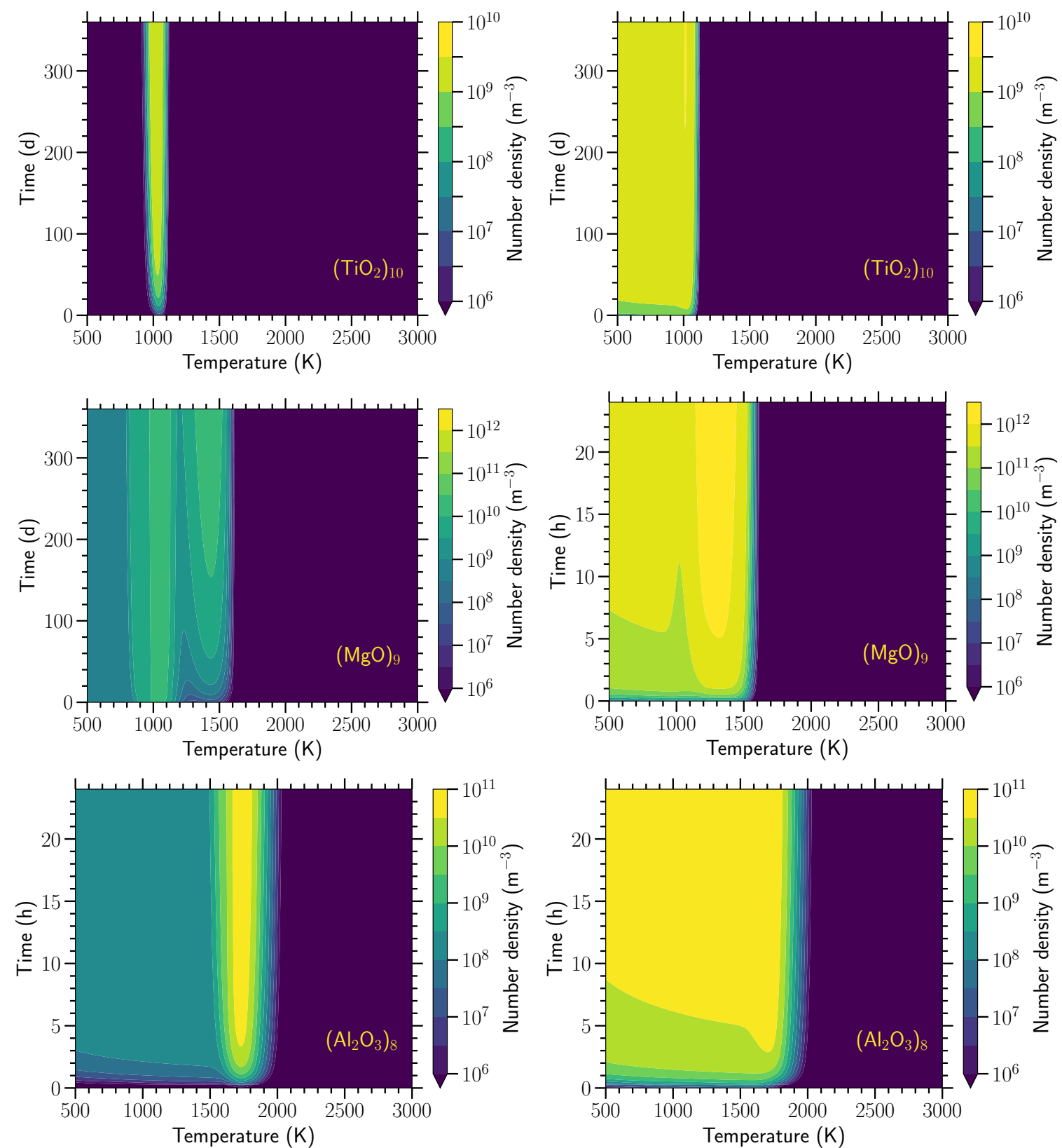

Figure 3. Temporal evolution of the absolute number density of $\left(\mathrm{TiO}_{2}\right)_{10},(\mathrm{MgO})_{9}$, and $\left(\mathrm{Al}_{2} \mathrm{O}_{3}\right)_{8}$ at the benchmark total gas density $\rho=1 \cdot 10^{-9} \mathrm{~kg} \mathrm{~m}^{-3}$ with left monomer and right polymer nucleation description. Be aware of the different time scales between species. Overall, convergence with monomer nucleation description takes slightly longer than using the polymer nucleation one. It can also yield vastly different final abundances which is most noticeable for $(\mathrm{MgO})_{9}$. We refrain from showing $(\mathrm{SiO})_{10}$ since its abundance is zero in the entire parameter space. An overview of all clusters of all candidates can be found in Appendix E1 with an in-depth analysis in Secs. 4.1 and 5.2 .

is a consequence of the energetic stability of these $\mathrm{MgO}$ cluster sizes. This phenomenon would not arise when using extrapolated bulk properties for the clusters (i.e. classical nucleation), but only when calculating the energy on a microscopic level (i.e. quantum mechanically).

Determining the time scale of abundance convergence for $\mathrm{MgO}$-clusters is problematic, due to the complex behaviour in temperature-space. We give a rough convergence time scale below and above $1000 \mathrm{~K}$. Below $1000 \mathrm{~K}$ and in the case of $\mathrm{MN}$, all clusters converge in just a few hours
(Fig. E5). In the case of PN, the largest clusters do converge in a few hours but smaller clusters form in less than a few hours and then gradually get destroyed again over the course of a few days before reaching convergence (Fig. E14). $(\mathrm{MgO})_{5}$ stands out as its abundance still gradually changes on time scales of 10 to $100 \mathrm{~d}$ (Fig. E13). Because the evolution above $1000 \mathrm{~K}$ is less straightforward, we limit the analysis to the largest most stable cluster $(\mathrm{MgO})_{9}$, and refer the reader to figures E4, E5 and E13, E14 for more details on all clusters. In the case of MN, the abundance of 
$(\mathrm{MgO})_{9}$ converges after roughly $180 \mathrm{~d}$, whereas using PN this happens in only a few hours (Fig. 3).

\subsection{3 $\mathrm{SiO}$}

In both nucleation cases, the largest $\mathrm{SiO}$-clusters do not form significantly in our $(T, \rho)$-range (Figs. E6, E15). Between 500 to $700 \mathrm{~K}$ most monomers end up in $(\mathrm{SiO})_{3}$ and remain in the monomer above this temperature. Note that sizes $N=5$ to 9 do not form at all. Since no large clusters form in our $(T, \rho)$-range, we refrain from analysing any time dependence.

\section{$4.1 .4 \mathrm{Al}_{2} \mathrm{O}_{3}$}

For both nucleation descriptions, the largest $\mathrm{Al}_{2} \mathrm{O}_{3}$-clusters already form at temperatures as high as 1800 to $2400 \mathrm{~K}$, depending on the total gas density (Fig. 2), i.e. in hotter regimes than any of the other nucleation candidates. Moreover, between 1600 to $1700 \mathrm{~K}$ and 1900 to $2200 \mathrm{~K}$ more than 90 per cent of the available monomers are locked-up in the largest cluster $\left(\mathrm{Al}_{2} \mathrm{O}_{3}\right)_{8}$. Between the lower limits and $1500 \mathrm{~K},\left(\mathrm{Al}_{2} \mathrm{O}_{3}\right)_{8}$ encompasses between 10 and 90 per cent of the available material for the $\mathrm{MN}$ description. Below $1500 \mathrm{~K}, \mathrm{MN}$ again impedes a subsequent growth because the monomers are depleted once small clusters have formed, resulting in a pile-up of small clusters unable to continue to grow (Fig. E7). PN does not have this limitation and $\left(\mathrm{Al}_{2} \mathrm{O}_{3}\right)_{8}$ contains more than 50 per cent of the available monomers in the entire temperature range below the formation threshold. Additionally $\mathrm{PN}$ growth is so efficient that the bulk of the material grows to sizes above $N=5$, removing all smaller clusters (Fig. E16).

In both nucleation cases, the formation of $\left(\mathrm{Al}_{2} \mathrm{O}_{3}\right)_{8}$ happens so fast that it is invisible on a time scale of days (Figs. E8, E17). Refining the time sampling reveals that, in both nucleation cases, convergence of the abundance of $\left(\mathrm{Al}_{2} \mathrm{O}_{3}\right)_{8}$ already occurs after roughly 5 to $10 \mathrm{~h}$ (Fig. 3). For $\mathrm{MN}$, convergence happens even faster for smaller clusters (Fig. E9). For PN, however, there is a gradual creation and destruction of the smaller clusters, on a time scale of hours (Fig. E18). Even on a time scale of 100 d, the smallest clusters do not converge but gradually get converted to larger ones (Fig. E17).

\subsubsection{Comparison with equilibrium compositions}

The equilibrium abundance ratio of two clusters with different sizes w.r.t to the equilibrium abundance ratio of two other cluster sizes can be calculated via Eq. (15). Such ratio of ratios can be used to more quantitatively discuss if clusters distributions have reached the equilibrium composition. Since it is most meaningful to compare ratios if nucleation is feasible, the ratios of two smaller clusters w.r.t. the ratio of the two largest clusters are discussed in the favourable temperature range. The results, shown for comparison with the equilibrium abundances, correspond to the closed PN models for the benchmark total gas density $\rho=1 \cdot 10^{-9} \mathrm{~kg} \mathrm{~m}^{-3}$ at the final time step (one year). Note that if the number density of any of the four clusters species is below the numerical solver accuracy of $1 \cdot 10^{-20} \mathrm{~cm}^{-3}$, the ratios are not shown.

The relative abundances ratios of $\mathrm{TiO}_{2^{-}}$and $\mathrm{MgO}-$ clusters do not reach the equilibrium ratios in the entire temperature range (Figs. E19 and E20). At the highest temperatures, at which the nucleation is feasible, the model results correspond to the equilibrium ratios. However, at lower temperatures, the clusters need more time to reach the equilibrium ratios since the interaction probability is lower. This transition is visible between 900 to $1000 \mathrm{~K}$ and 1000 to $1300 \mathrm{~K}$ for the $\mathrm{TiO}_{2^{-}}$and $\mathrm{MgO}$-clusters, respectively. The fact that the clusters have not yet reached equilibrium ratios is also visible from the temporally changing abundances in Figs. (E11) and (E13). The relative abundance ratios of $\mathrm{Al}_{2} \mathrm{O}_{3}$-clusters deviate more from the equilibrium ratios (Fig. E21). Due to the large variation in number densities of the clusters in different temperature regimes (order of magnitude), it is often impossible to compare ratios of the $\mathrm{Al}_{2} \mathrm{O}_{3}$-clusters. This variation is more clearly visible in Fig. (E17). SiO-clusters are not discussed since they do not significantly form in the temperature range of interest.

\subsection{Comprehensive chemical nucleation network}

This section covers the evolution of the four nucleation species $\mathrm{TiO}_{2}, \mathrm{MgO}, \mathrm{SiO}$ and $\mathrm{Al}_{2} \mathrm{O}_{3}$ for a comprehensive chemical nucleation network with the polymer nucleation (PN) description. To ensure the overview, we mainly discuss the species that also contain the cluster metals ( $\mathrm{Ti}$, $\mathrm{Mg}, \mathrm{Si}$, and $\mathrm{Al}$ ) because they are most interesting to understand formation of macroscopic dust grains. In analogy with Section 4.1, only the temporal evolution of the nucleation clusters is presented. Additional figures for all species of interest can be found in Appendix E2.

\subsection{1 $\mathrm{TiO}_{2}$}

The formation of $\left(\mathrm{TiO}_{2}\right)_{10}$ occurs at the same temperature and density conditions as in the closed nucleation model with the PN approach, i.e. when the temperature drops below the sharp threshold at 1000 to $1200 \mathrm{~K}$ (Fig. 4). Above this threshold, Ti resides in either $\mathrm{TiO}_{2}$, TiO, or remains atomic, with the atomic state preferred at the highest temperatures (above $2000 \mathrm{~K}$ or higher for higher densities). (Fig. E22) The convergence of $\left(\mathrm{TiO}_{2}\right)_{10}$ happens within roughly $40 \mathrm{~d}$, similar to the closed nucleation model with PN (Fig. 4). The convergence of other $\mathrm{TiO}_{2}$-clusters is also similar to the closed PN case (Fig. E23).

\subsection{2 $\mathrm{MgO}$}

All available $\mathrm{Mg}$ remains atomic. Neither $\mathrm{MgO}$, nor the $\mathrm{MgO}$-clusters, nor any Mg-bearing molecules are formed. Hence we refrain from showing the abundance figures.

\subsection{3 $\mathrm{SiO}$}

The abundance evolution of all SiO-clusters, in temperature, density, and time, is the same as for the closed nucleation PN model, i.e. the large clusters do not form in the 
considered temperature-density range and the smallest clusters only form at the lowest temperatures (Fig. E24). Above roughly $700 \mathrm{~K}$, all $\mathrm{Si}$ is locked-up in the $\mathrm{SiO}_{2}$ molecule (except at the highest temperatures and lowest densities, which is due to time constraints of the simulation). This finding is somewhat in contrast to the higher binding energies of $\mathrm{SiO}$ compared to $\mathrm{SiO}_{2}$ (Section 6.1.2). Below $700 \mathrm{~K}$, the most abundant molecules are $\mathrm{SiO}$ and $(\mathrm{SiO})_{3}$. Note that in the entire $(T, \rho)$-grid, Si does not remain atomic.

\section{$4.2 .4 \mathrm{Al}_{2} \mathrm{O}_{3}$}

Most of the $\mathrm{Al}$ remains atomic except for some specific $(T, \rho)$-combinations. Overall creation of Al-molecules is up to maximally 1 per cent of the total available $\mathrm{Al}$, except at the lowest temperatures for both extremes in the considered density range where it can be up to roughly 50 per cent (Fig. 5). The most abundant molecules are $\mathrm{AlO}, \mathrm{AlH}$, $\mathrm{Al}(\mathrm{OH})_{2}$, and $\mathrm{Al}(\mathrm{OH})_{3}$. Their formation regimes can be recovered in the abundance figure of $\mathrm{Al}$, and only $\mathrm{AlO}$ forms in the entire temperature range. Note that the figures of less abundant Al-bearing molecules are only shown in Appendix E2 since their abundance never exceeds the chosen threshold (Fig. E25).

\section{IMPLICATIONS OF RESULTS}

This section interprets the nucleation model results and what they implicate for AGB dust precursors. Be aware that conclusions drawn from closed nucleation networks are based on the underlying assumption that the monomer exists and that all of the nucleation-related metal is turned into the monomer. The reader should be cautious when using these results as they are not necessarily physical. They are, however, useful in their own right to investigate the efficiency of individual nucleation species and the improved nucleation description.

\subsection{Closed nucleation networks}

The most prominent result is that large $\mathrm{Al}_{2} \mathrm{O}_{3}$-clusters can form fast $(<1 \mathrm{~d}$ ) at high temperatures (around 1800 to $2400 \mathrm{~K}$ ). This makes $\mathrm{Al}_{2} \mathrm{O}_{3}$ the favoured candidate to become the first dust particles in the inner AGB wind. The second favoured candidates are $\mathrm{MgO}$-clusters, which can form fast $(<1 \mathrm{~d})$ around $1500 \mathrm{~K}$. We find, that $(\mathrm{MgO})_{9}$ forms more easily than the largest considered cluster $(\mathrm{MgO})_{10}$ thanks to its higher stability. This is a consequence of the used non-classical nucleation description that relies on the Gibbs free energy of the clusters, which is lower for $(\mathrm{MgO})_{9}$ than for $(\mathrm{MgO})_{10}$, making the former more energetically stable. Another consequence of the non-classical description is the preferred cluster sizes $N=2,4,6$, and 9 , a situation that would never occur when using a classical nucleation theory (also noted by Köhler et al. 1997). The third preferred dust candidates are $\mathrm{TiO}_{2}$-clusters, which only form below $1000 \mathrm{~K}$ at a relatively slow rate (time scale of tens of days compared to hours for $\mathrm{MgO}-$ and $\mathrm{Al}_{2} \mathrm{O}_{3}$-clusters). Finally, we discard SiO-clusters to be important as first dust species as their growth requires conditions that are too cold and too dense compared to the conditions in an inner
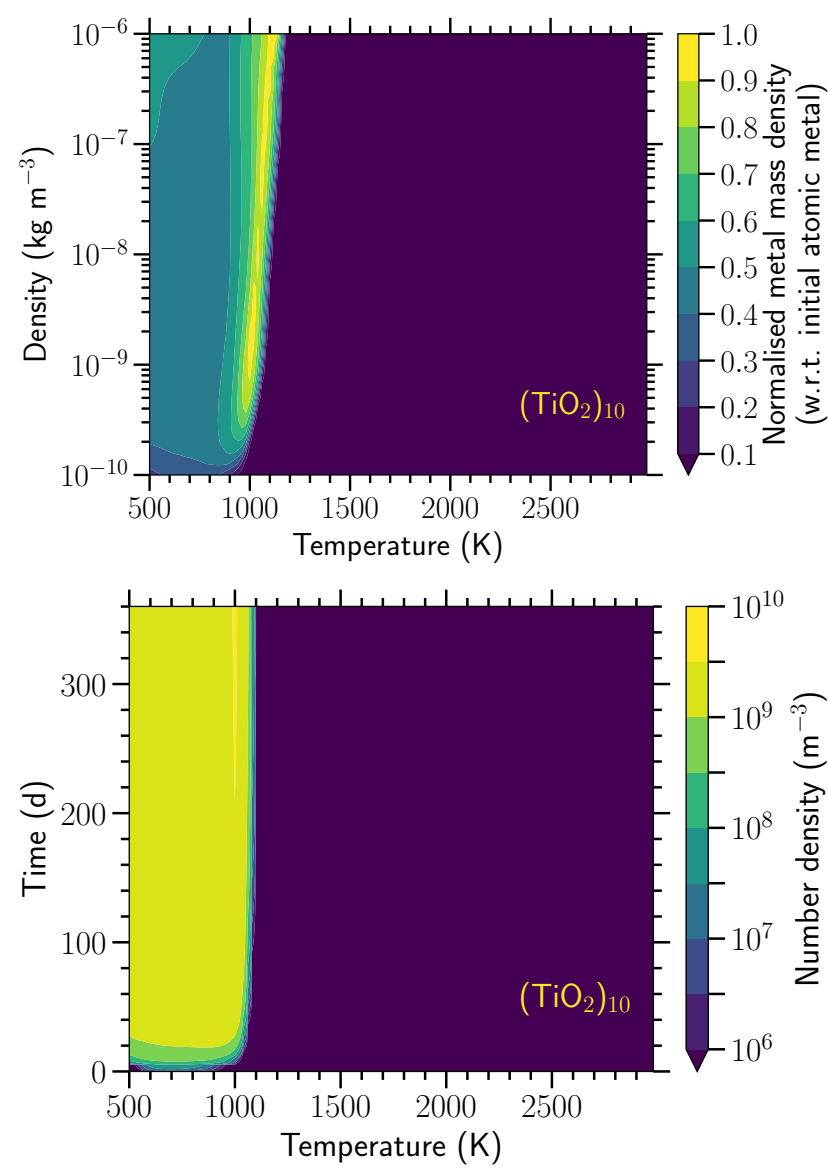

Figure 4. Normalised mass density after one year (top) and temporal evolution of the absolute number density at the benchmark total gas density $\rho=1 \cdot 10^{-9} \mathrm{~kg} \mathrm{~m}^{-3}$ (bottom) of $\left(\mathrm{TiO}_{2}\right)_{10}$ for the comprehensive chemical nucleation models using the polymer nucleation description. The results are similar to the closed nucleation model (Fig. 2) where $\left(\mathrm{TiO}_{2}\right)_{10}$ forms from 1000 to $1200 \mathrm{~K}$ and converges within roughly $20 \mathrm{~d}$. The largest cluster encompasses more than 90 per cent of the available $\mathrm{Ti}$, in the most favourable nucleation conditions. This implies that all atomic Ti quickly forms $\mathrm{TiO}_{2}$ which subsequently starts to nucleate, in favourable conditions. An overview of all Ti-bearing molecules can be found in Appendix E2 with an in-depth analysis in Sections 4.2 and 5.2 .

AGB wind. SiO-clusters might form dust grains further out in the wind, where the temperature is below $500 \mathrm{~K}$.

Using the monomer or polymer nucleation description can result in substantial differences in typical formation times of the nucleation products, hence in their abundances after one year (Figs. 2, 3). The most striking difference is the absence of large clusters at low temperatures when using the MN description. This can have profound implications while the wind is cooling down, underestimating the total number of large clusters. Using the abundance of the largest clusters as a gauge of dust formation, the $\mathrm{MN}$ description will yield less dust, which can delay or even hamper wind-driving. The formation time of large clusters can be several times larger when using the MN description. E.g. the convergence of $\left(\mathrm{TiO}_{2}\right)_{10}$ takes $60 \mathrm{~d}$ as compared to less than $20 \mathrm{~d}$ when 

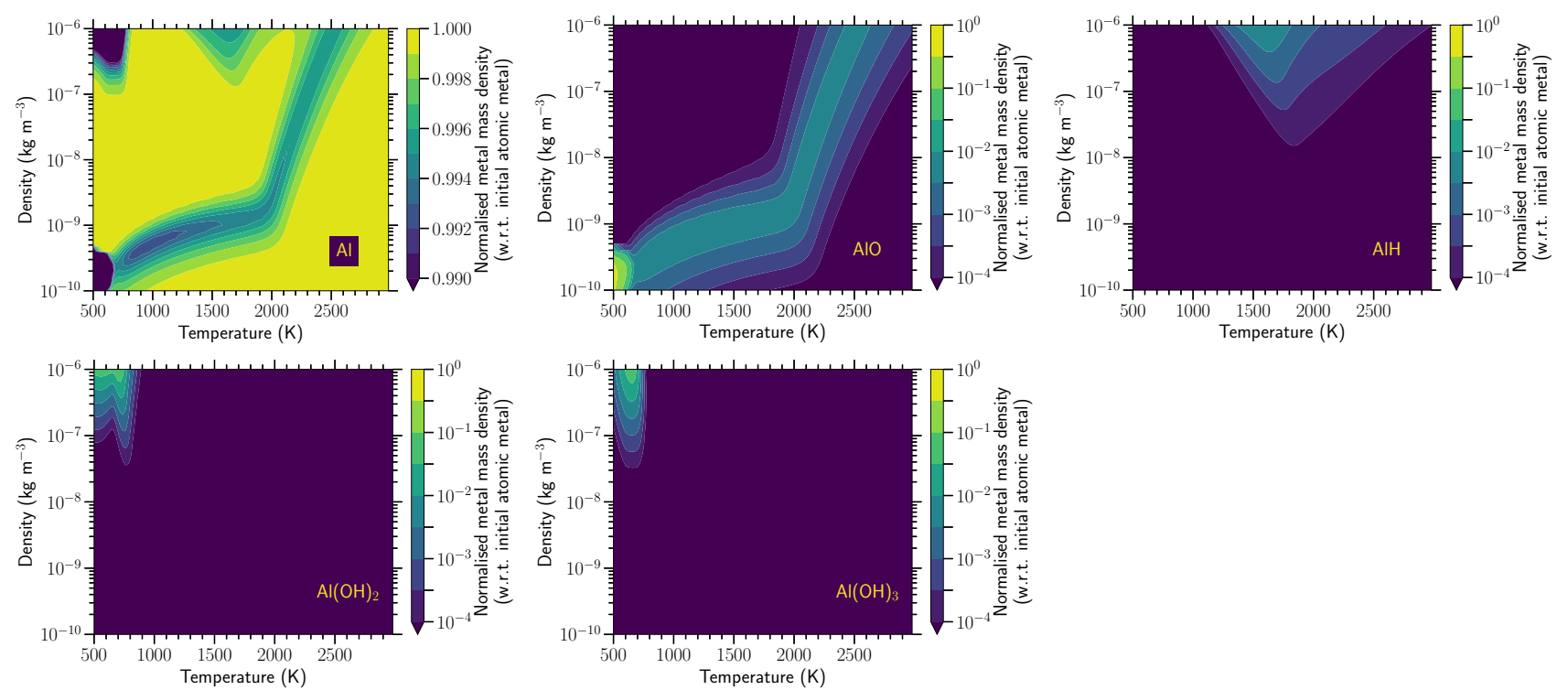

Figure 5. Normalised mass density after one year of the most abundant Al-bearing molecules for the comprehensive chemical nucleation models using the polymer nucleation description. Most $\mathrm{Al}$ remains atomic with up to 1 per cent in Al-bearing molecules. $\mathrm{Al}_{2} \mathrm{O}_{3}$, nor its precursors $\mathrm{Al}_{2} \mathrm{O}_{2}, \mathrm{AlO}_{2}$ are able to form anywhere in the considered $(T, \rho)$-grid. Hence, no $\mathrm{Al}_{2} \mathrm{O}_{3}$-clusters can form either. We believe this issue is due to incomplete rate coefficients of Al-molecule formation reactions. An overview of all Al-bearing molecules plus a temporal evolution of $\mathrm{Al}$ and $\mathrm{AlO}$ can be found in Appendix E2 with an in-depth analysis in Sections 4.2 and 5.2.

using the $\mathrm{PN}$ description. For $(\mathrm{MgO})_{9}$ the difference is $180 \mathrm{~d}$ compared to a few hours (Fig. 3). Additionally, at our benchmark density of $10^{-9} \mathrm{~kg} \mathrm{~m}^{-3}$ the abundance of $(\mathrm{MgO})_{9}$ converges to roughly $10^{12} \mathrm{~m}^{-3}$ in mere hours in the polymer case whereas in the monomer case it takes almost $200 \mathrm{~d}$ to converges to only $10^{10} \mathrm{~m}^{-3}$ (Fig. 3).

Although the abundance of some clusters converges, this does not happen for all clusters over the entire temperature regime. This result implies that no all clusters have reached equilibrium abundances yet. Hence, the assumption of a steady state nucleation is generally not valid in the entire temperature range. Therefore, it is necessary to use a time dependent nucleation description to accurately trace the nucleation process.

\subsection{Comprehensive chemical nucleation network}

Although $\mathrm{Al}_{2} \mathrm{O}_{3}$-clusters are the primary dust precursor candidate according to the closed nucleation models (Sec 5.1), no $\mathrm{Al}_{2} \mathrm{O}_{3}$-clusters form in the comprehensive nucleation models since the smallest building block, the monomer, cannot be created. Most $\mathrm{Al}$ remains atomic, though up to maximally 1 per cent can form molecules (AlO, $\mathrm{AlH}, \mathrm{Al}(\mathrm{OH})_{2}$, and $\mathrm{Al}(\mathrm{OH})_{3}$, Fig. 5). The second favoured candidates, $\mathrm{MgO}$-clusters, do not exist either because all the available $\mathrm{Mg}$ remains atomic. The third favoured candidates according to the closed nucleation model, $\mathrm{TiO}_{2}$-clusters, form equally efficient in the comprehensive nucleation model. Lastly, as in the closed nucleation models, SiO-clusters are discarded as first dust precursors in the considered temperature-density regime.

These results suggest that, of the considered candi- dates, $\mathrm{TiO}_{2}$-clusters are the only possible dust precursors. However, firstly there is ample evidence that pre-solar AGB grains mainly encompass $\mathrm{Al}_{2} \mathrm{O}_{3}$-grains rather than $\mathrm{TiO}_{2}$-grains (Hutcheon et al. 1994; Nittler et al. 1994; Choi et al. 1998; Nittler et al. 2008; Bose et al. 2010b). Secondly, dust has been observed to exist close to AGB stars, at $\sim 1.5 R_{\star}$ for R Dor (Khouri et al. 2016), at $<2 R_{\star}$ for R Dor, W Hya and R Leo (Norris et al. 2012), and at $<2 R_{\star}$ for W Hya (Zhao-Geisler et al. 2015; Ohnaka et al. 2016). The temperature corresponding to those spatial regions is roughly 1500 to $2000 \mathrm{~K}$, which is higher than the formation temperature of $\left(\mathrm{TiO}_{2}\right)_{10}$, that is around 1000 to $1200 \mathrm{~K}$ (Figs. 2, 4). Large $\mathrm{MgO}$ and $\mathrm{Al}_{2} \mathrm{O}_{3}$-clusters, however, are able to form at such high temperatures (Fig. 2). Both observational arguments question the viability of $\mathrm{TiO}_{2}$ clusters as first dust species and favour $\mathrm{Al}_{2} \mathrm{O}_{3}$-clusters, yet our comprehensive model does not predict this. This discrepancy indicates that our current model lacks chemical reaction physics to form $\mathrm{Al}_{2} \mathrm{O}_{3}$ monomers. Since we cannot form any of the two $\mathrm{Al}_{2} \mathrm{O}_{3}$ precursors either $\left(\mathrm{Al}_{2} \mathrm{O}_{2}\right.$ and $\mathrm{AlO}_{2}$, Tab. 2), we believe that the current reaction rate coefficients involving Al-oxides are incorrect and need revision or that alternative small $\mathrm{Al}_{2} \mathrm{O}_{3}$-cluster formation pathways are missing.

\section{DISCUSSION}

This section discusses the limitations of our models (Sec. 6.1) and compares our model results with other literature studies (Sec. 6.2). 


$$
\begin{aligned}
& a \mathrm{AlO}+\mathrm{AlO}+\mathrm{M} \longrightarrow \mathrm{Al}_{2} \mathrm{O}_{2}+\mathrm{M} \\
& a \mathrm{Al}+\mathrm{AlO}_{2}+\mathrm{M} \longrightarrow \mathrm{Al}_{2} \mathrm{O}_{2}+\mathrm{M} \\
& \text { a } \mathrm{Al}_{2} \mathrm{O}+\mathrm{O}+\mathrm{M} \longrightarrow \mathrm{Al}_{2} \mathrm{O}_{2}+\mathrm{M} \\
& { }^{b} \mathrm{AlO}+\mathrm{O}+\mathrm{M} \longrightarrow \mathrm{AlO}_{2}+\mathrm{M} \\
& { }^{b} \mathrm{AlO}+\mathrm{O}_{2} \longrightarrow \mathrm{AlO}_{2}+\mathrm{O} \\
& a \mathrm{AlO}+\mathrm{CO}_{2} \longrightarrow \mathrm{AlO}_{2}+\mathrm{CO} \\
& \text { a } \mathrm{Al}_{2} \mathrm{O}_{2}+\mathrm{O}+\mathrm{M} \longrightarrow \mathrm{Al}_{2} \mathrm{O}_{3}+\mathrm{M} \\
& { }^{a} \mathrm{AlO}_{2}+\mathrm{AlO}+\mathrm{M} \longrightarrow \mathrm{Al}_{2} \mathrm{O}_{3}+\mathrm{M}
\end{aligned}
$$

Rate coefficients are determined by: a) Reversed of Catoire et al. (2003); Washburn et al. (2008) via detailed balance. b) Sharipov et al. (2012).

Table 2. Formation of $\mathrm{Al}_{2} \mathrm{O}_{3}$ can only occur via $\mathrm{Al}_{2} \mathrm{O}_{2}$ or $\mathrm{AlO}_{2}$, according to the reactions available in the literature. $\mathrm{M}$ is by convention a third body which can be any chemical species.

\subsection{Limitations}

This section focuses on the limitations of the improved nucleation theory (Sec 6.1.1), the used chemical reactions (Sec 6.1.2), and the inference of dust properties (Sec 6.1.3).

\subsubsection{Nucleation theory}

Our non-classical, non-equilibrium nucleation theory has some limitations. The most prominent one is most likely that it describes the growth of clusters as an inelastic collision between rigid spheres. This assumption does not account for the shape of the clusters nor mutual interaction forces. Using detailed chemical reaction coefficients for each cluster reaction, which account for possible energy barriers, would be a large improvement. Unfortunately, such information does not yet exist. Recently, Sharipov \& Loukhovitski (2018) have calculated rate coefficients of the dimerisation of $\mathrm{Al}_{2} \mathrm{O}_{3}$ based on Rice-Ramsperger-Kassel-Marcus (RRKM) theory, which is a more realistic apprximation than the using the rigid spheres. We show both approximations as an example on how much the coefficients can differ (Fig. 6). Similarly, Suh et al. (2001) and Bromley et al. (2016) have determined SiO-clustering rate coefficients with RRMK theory. Additionally, in the cluster growth coefficient (Eq. 11), we write the radius of each cluster as a function of the monomer radius. However, since we know the shape of each cluster, it is possible to calculate an effective radius for each cluster, yielding a more correct geometrical cross-section between cluster collisions. Another limitation is set by using spontaneous clusters destruction reactions that rely on detailed balance. Incorporating chemical or collisionally induced destruction reactions would increase the accuracy of the model. Furthermore, the entire nucleation process is assumed to be homomolecular. There is, however, no good reason that it cannot be heteromolecular. Heteromolecular nucleation is most likely necessary to create $\mathrm{MgAl}_{2} \mathrm{O}_{4}$-clusters, which are abundant in pre-solar AGB grains, or Mg-containing silicates (Goumans \& Bromley 2012). Including heteromolecular nucleation will increase the number of possible reactions exponentially and will increases the amount of detailed quantum mechanical calculation and data needed for those reaction rate coefficients.

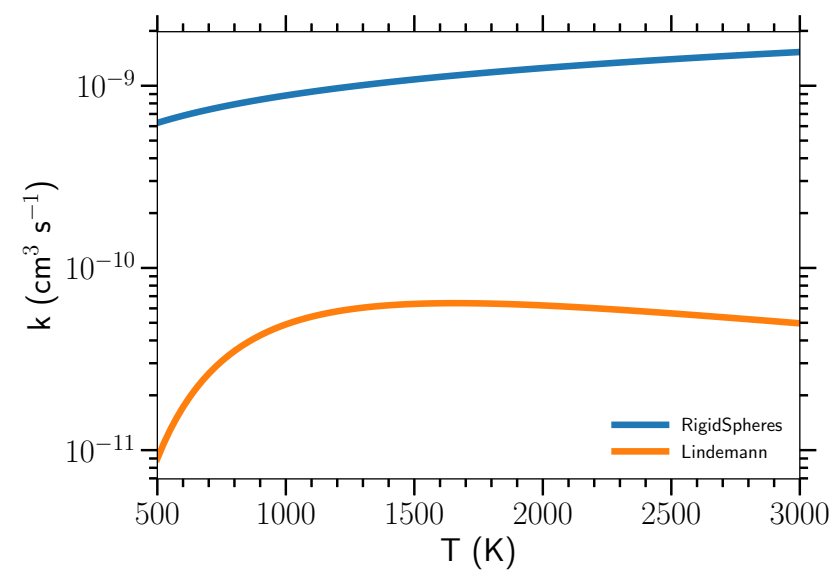

Figure 6. The reaction rate coefficients of $\mathrm{Al}_{2} \mathrm{O}_{3}+\mathrm{Al}_{2} \mathrm{O}_{3} \longrightarrow$ $\left(\mathrm{Al}_{2} \mathrm{O}_{3}\right)_{2}$ with the approximation of a collision of rigid spheres, used in this work, and calculated with Rice-Ramsperger-KasselMarcus theory plus a Lindemann fit by Sharipov \& Loukhovitski (2018). As this latter also depends on the total number density, we have chosen a typical value for the inner AGB wind, $n_{\text {tot }}=$ $10^{18} \mathrm{~m}^{-3}$. Our approximation over predicts the dimerisation by roughly an order of magnitude compared to the more realistic coefficient using the Lindemann fit. Therefore, using a rigid sphere approximation, as in this work, will most likely overestimate the efficiency of the nucleation process.

The assumption that nucleation starts with the formation of the monomer is not yet established. Small clusters might be formed via pathways which bypass the monomer molecule. This could possibly solve the issue of not forming $\mathrm{Al}_{2} \mathrm{O}_{3}$-monomer in our models. Additionally, the fact that nucleation occurs via the addition of monomer-multiples with a fixed stoichiometry is not established either. Clusters could possibly grow via the addition of other stoichiometric ratios, as investigated by Patzer et al. (2005) for small aluminium oxide clusters.

Note that the used nucleation description considers the process as a statistical ensemble of particles which all have the same mean temperature. However, as this is a process of molecular interactions, the notion of 'temperature' can become unclear. In reality, the particles have a temperature distribution around a mean kinetic temperature. Molecular dynamics simulations, which do not rely on a mean temperature, reveal that small temperature fluctuations amongst particles initiate the nucleation process (Tanaka et al. 2011; Diemand et al. 2013; Toxvaerd 2015).

A last limitation is the artificial maximum cluster size. In reality, the clusters would continue to grow to form solid material. This material can then, on its turn, sublimate and return nucleation species to the gas phase. Whether the sublimation process returns small clusters, monomers, atoms, or simple molecules is unclear. Additionally, to estimate the sublimation rate one needs the binding energies of the surface layer of the solid material. However, the phase transition process to a solid dust grain is often described by one fast reaction (e.g. Huang et al. 2009; Bojko et al. 
2014). A better approach would be to evolve the nucleation of clusters until a chosen maximal cluster size is reached, after which it can be considered as a solid particle and can grow via grain-grain interactions such a coagulation.

\subsubsection{Chemical reactions}

To infer abundances of the largest nucleation clusters, it is crucial to correctly predict the creation of its fundamental building block, the monomer. Hence, the chemical reaction path ways from atoms to monomers have to be accurate. However, astrochemical databases lack the necessary monomer formation reactions. Yet, there are individual studies that provide some reactions, but they are scarce depending on the nucleation candidate. To determine the AGB dust precursors, we believe that Ti and $\mathrm{Al}$ reactions are the most pressing. There are hardly any Ti-related reactions (App. F) and most Al-related reactions have extremely high reaction barriers. The latter mainly originate from combustion studies and are therefore often only determined in the high density limit. Moreover, most Al-related reaction rate coefficients are determined from destruction of larger molecules, which is the opposite of what is actually needed. Therefore, the growth coefficients rely on the assumption of detailed balance.

It is important that the entire chemical network contains sufficient reactions with accurate rates. As pointed out by Boulangier et al. (2019), we are largely dependent on the astrochemical databases which do not contain all the reactions that are necessary. Due to the lack of reactions rate coefficients and especially the unknown temperature dependence, caution is advised when interpreting chemical evolution results and the existence of certain molecules based on the gas temperature.

\subsubsection{Inference of dust properties from clusters}

This work focuses on nucleation clusters to infer AGB dust properties such as abundance, composition and formation times. However, the largest clusters that we consider are only a fraction of the size of a dust grain nor do they resemble the bulk geometry. The largest clusters' radii range from 0.16 to $0.71 \mathrm{~nm}$ whereas dust grains can be as large as a few micron. Lamiel-Garcia et al. (2017) predict that $\mathrm{TiO}_{2^{-}}$ clusters only resemble the bulk geometry from $N \geq 125$. For highly ionically bonded materials such as $\mathrm{MgO}$-clusters this can already be at $N=20$ due to the strong electrostatic interactions between atoms. Therefore, one has to be careful when using nucleation clusters as a gauge for dust grains. Yet, due to computational constraints a small cross-over size, from clusters to dust, has to be chosen. From this crossover size, the particles should not be considered as molecular clusters any more but as tiny grains which can numerically be binned in size and can grow via various physical processes (e.g. Jacobson 2013; Grassi et al. 2017; McKinnon et al. 2018; Sluder et al. 2018). Because of our artificial maximum cluster-size, one has to be cautious when interpreting the abundances of the largest clusters in this work since in reality these will most likely continue to grow to actual dust grains.

\subsection{Comparison with literature}

This section compares our model results with other nucleation models (Sec. 6.2.1), with seed particle requirements of dynamical wind models (Sec. 6.2.2), and with molecular observations of AGB stars (Sec. 6.2.3).

\subsubsection{Nucleation models}

In contrast to Gobrecht et al. (2016), our most complete model (comprehensive network with polymer nucleation) does not produce any $\mathrm{Al}_{2} \mathrm{O}_{3}$-clusters. However, unlike this work, Gobrecht et al. (2016) used a simplified formulation to determine reversed formation rates for Al-bearing molecules resulting in a temperature independent rate coefficients. Some key formation reactions reveal that the used rate coefficients can differ by up to 10 orders of magnitude (e.g. $\mathrm{AlO}+\mathrm{AlO}+\mathrm{M} \longrightarrow \mathrm{Al}_{2} \mathrm{O}_{2}+\mathrm{M}$, Fig. 7. Note that Sluder et al. (2018) use an even higher rate coefficient for this reaction.). Such large differences could explain different results of Gobrecht et al. (2016), as compared to this work. Moreover, we give a more realistic rate description by incorporating a temperature dependence in addition to the strong density dependence which is crucial to investigate the existence of large clusters and dust grain as a function of temperature (e.g. $\mathrm{Al}_{2} \mathrm{O}_{2}+\mathrm{O}+\mathrm{M} \longrightarrow \mathrm{Al}_{2} \mathrm{O}_{3}+\mathrm{M}$, Fig. 7). Compared to observations, Gobrecht et al. (2016) overpredict the abundance of Al-bearing molecules (AlO and $\mathrm{AlOH}$ ), whereas our models agree better with the most recent observations (Sec. 6.2.3).

An approach similar to this work has recently been used by Savel'ev \& Starik (2018) who investigated the nucleation of $\mathrm{Al}_{2} \mathrm{O}_{3}$-clusters up to a cluster size of 75 during the combustion of aluminized fuels. Similarly, they also model the nucleation kinetically with a set a chemical reactions. Their nucleation reactions, however, only consider monomer interactions. They do consider much larger clusters than we do. However, the authors rely on estimates (interpolations) of the Gibbs free energies for $N=5-75$ and do not perform DFT calculations of the global minima candidates. The authors do not provide the geometries of these larger sized $\mathrm{Al}_{2} \mathrm{O}_{3}$-clusters. Therefore, we cannot verify these isomers with the lowest-energy structures used in the present study. Moreover, it is difficult to compare results since their environment has a density of several orders of magnitude higher making the nucleation occur on milli- and microsecond time scales. See Starik et al. (2015) for a recent review of modelling aluminium nanoparticles in the fuel combustion community.

The nucleation efficiency of species is often determined by the steady state nucleation rate, $J_{*} / n_{\mathrm{H}}$, which represents the number of dust seed particles formed per second per total number of hydrogen. However, this rate relies on two main assumptions. Firstly, growth of clusters only occurs via addition of monomers. Secondly, the system of clusters is in a steady state, i.e. the number densities of all clusters remain constant over time, ergo chemical equilibrium. This latter implies that the net formation of all clusters is the same and size independent. Detailed derivations for the steady state nucleation rate can be found in Patzer 
et al. (1998) but the notation used by Bromley et al. (2016) is clearer. The latter explicitly shows that $J_{*} / n_{\mathrm{H}}$ solely depends on the amount of monomers ${ }^{21}$ and all rate coefficients between clusters. To determine this equilibrium abundance, one has to know the Gibbs free energy of the lowest energy configuration for all cluster sizes (App. A). This data is unavailable for large clusters. It is often unclear how this abundance is determined in nucleation papers, either from the vapour pressure of the monomer and the solid form (as explained by Patzer et al. 1998; Helling \& Woitke 2006 $)^{22}$ or by chemical equilibrium calculations of the gas without considering the clusters (e.g. Jeong et al. 2003; Lee et al. 2015) ${ }^{23}$. Because the steady state monomer nucleation description differs significantly from ours and requires knowing the equilibrium abundance of the monomer, it is difficult to compare with. Using $J_{*} / n_{\mathrm{H}}$, it is often claimed that only $\mathrm{TiO}_{2}$ nucleates efficiently enough to form the first dust precursor. We limit the comparison to our monomer nucleation description since the steady state one also assumes nucleation by monomers. When comparing our results with Jeong et al. (2003, fig. 1), we note that both predictions of $\left(\mathrm{TiO}_{2}\right)_{2}$-clusters have a steep cut-off around $1000 \mathrm{~K}$ (Fig. 2). However, our time dependent description does not yield the high nucleation that the steady state one does at low temperatures since the availability of monomers decreases quickly hereby quenching the growth process. Additionally, the assumption of steady state is invalid since there is a clear time dependence in cluster growth (Fig. 3). Jeong et al. (2003) exclude $\mathrm{Al}_{2} \mathrm{O}_{3}$-clusters to be a primary dust precursor due to the low $J_{*} / n_{\mathrm{H}}$. One should be careful with interpreting this result since, as they point out, this is due to the low equilibrium abundance of the monomer and not necessarily the capability of nucleating $\mathrm{Al}_{2} \mathrm{O}_{3}$-clusters. They do not discuss the efficiency of $\mathrm{Al}_{2} \mathrm{O}_{3}$ vs $\mathrm{TiO}_{2}$-nucleation based on stability of the clusters. We find that, if $\mathrm{Al}_{2} \mathrm{O}_{3}$-monomers could exist, they will nucleate at much higher temperatures than $\mathrm{TiO}_{2}$ (Fig. 2). However, we are also unable to form the $\mathrm{Al}_{2} \mathrm{O}_{3}$-monomers with an initial atomic gas (Sec. 4.2.4).

Our results indicate that $\mathrm{Al}_{2} \mathrm{O}_{3}$-nucleation is dominant at high temperatures but the formation of the monomer via chemical reactions is unattainable with currently available data. Moreover, there is experimental evidence that small $\mathrm{Al}_{2} \mathrm{O}_{3}$-clusters do exist when vaporising the solid material

21 Since a steady state is assumed, this refers to the number of monomers at chemical equilibrium. A detail which is usually overlooked.

22 Determining the equilibrium monomer abundance from the phase equilibrium with the bulk material via the vaporisation pressure inherently assumes that the bulk material exists. However, since we are investigating the existence of bulk material can actually happen in certain conditions, such assumption should not be made.

23 Though we could not confirm which of these two methods Jeong et al. (2003) used, we note that if the vapour pressure was used than the nucleation of $\mathrm{Al}_{2} \mathrm{O}_{3}$ should be higher than that of $\mathrm{TiO}_{2}$ since the former has a lower vapour pressure. According to that method, this means less monomers thus all material is in the solid form. However, they find a smaller $J_{*} / n_{\mathrm{H}}$ for $\mathrm{Al}_{2} \mathrm{O}_{3}$ than for $\mathrm{TiO}_{2}$.

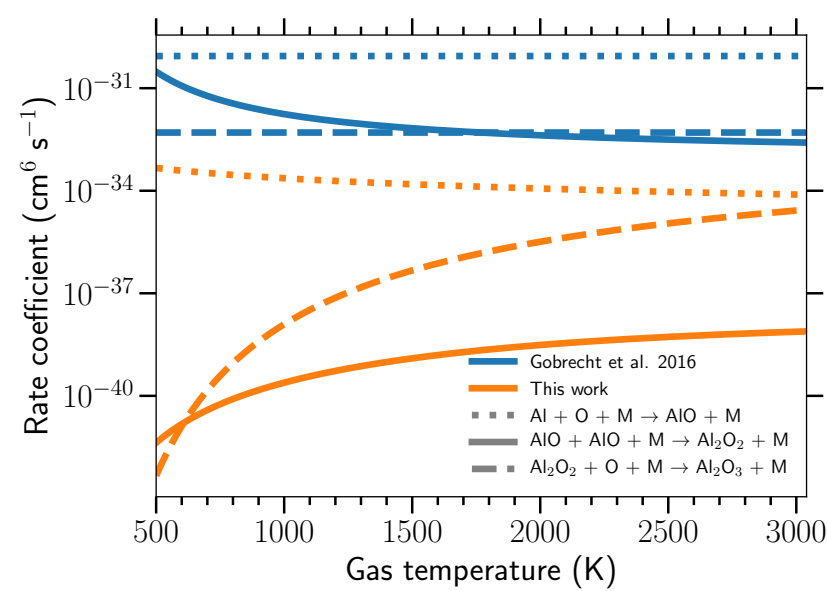

Figure 7. The reaction rate coefficients of some key $\mathrm{Al}_{2} \mathrm{O}_{3}$ formation reaction used by Gobrecht et al. (2016) are 2 to 10 orders of magnitude higher than the ones used is this work. These large differences could explain why Gobrecht et al. (2016) form $\mathrm{Al}_{2} \mathrm{O}_{3}$ and we do not. Moreover, they estimate the barrierless three-body reactions of the type $\mathrm{A}+\mathrm{B}+\mathrm{M} \longrightarrow \mathrm{AB}+\mathrm{M}$ to be temperature independent, hampering an investigating of the temperature dependence for $\mathrm{Al}_{2} \mathrm{O}_{3}$-cluster formation.

(van Heijnsbergen et al. 2003; Demyk et al. 2004; Sierka et al. 2007) This is a clear incentive for the scientific community to investigate rate coefficients of Al-bearing reactions at high temperatures. Without this data, it will remain unclear which species forms the first dust precursors in AGB winds.

\subsubsection{Dynamical models}

Höfner et al. (2016) show that the minimal normalised number of $\mathrm{Al}_{2} \mathrm{O}_{3}$ dust seed particles (assumed to be clusters of size $N=1000$ ) for driving an AGB wind is of the order of $n_{S} / n_{\mathrm{H}} \sim 10^{-16}$, with $n_{S}$ the seed particle number density. For comparison, we do a rough extrapolation of our results by assuming that all the largest $\mathrm{Al}_{2} \mathrm{O}_{3}$-clusters get turned into clusters of size $N=1000$. This is in line with rapid formation of the largest clusters and depletion of the smallest ones (Sec. 4.1.4). Since our largest cluster has roughly size $N=10$, the number of seed particles of $N=1000$ would be 100 times smaller. If we compare with $\mathrm{Al}_{2} \mathrm{O}_{3}$-clusters and assume that 1 per cent of the available $\mathrm{Al}$ turns into $\mathrm{Al}_{2} \mathrm{O}_{3}$ (Sec 4.2.4 and 5.2), then the total number of largest clusters is roughly 10 per cent of the initial number of monomers. This translates to $n_{\left(\mathrm{Al}_{2} \mathrm{O}_{3}\right)_{1000}} / n_{\mathrm{Al}} \approx 10^{-5}$. Using $n_{\mathrm{Al}} / n_{\mathrm{H}}$ from Table 1 , this yields a normalised number of seed particles $n_{\left(\mathrm{Al}_{2} \mathrm{O}_{3}\right)_{1000}} / n_{\mathrm{H}} \approx 3 \cdot 10^{-11}$, which is already 100000 times more than needed according to the models of Höfner et al. (2016). We can also compare this with the number of $\left(\mathrm{TiO}_{2}\right)_{10}$-clusters. Here no assumption on the number of monomers has to be made because the comprehensive network model with PN already predicts the amount of $\left(\mathrm{TiO}_{2}\right)_{10}$. This is roughly 10 per cent of the available number of Ti. Again assuming that the number of $\left(\mathrm{TiO}_{2}\right)_{1000}$-clusters is 100 times smaller than $\left(\mathrm{TiO}_{2}\right)_{10}$ and using the initial $n_{\mathrm{Ti}} / n_{\mathrm{H}}$ from Table 1 , 
yields $n_{\left(\mathrm{TiO}_{2}\right)_{1000}} / n_{\mathrm{H}} \approx 8 \cdot 10^{-11}$. This is in line with the

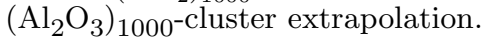

\subsubsection{Observations}

Our prediction of $\mathrm{TiO}_{2}$-clusters (Fig. 4) agrees with Kamiński et al. (2017) who state that there is no solid $\mathrm{TiO}_{2}$ close to the star $(T>1000 \mathrm{~K})$. They also claim that $\mathrm{TiO}$ and $\mathrm{TiO}_{2}$ are abundantly present in the extended envelope $(170$ to $500 \mathrm{~K})$ and therefore $\mathrm{TiO}_{2}$-clusters should not significantly exist to aid in wind driving. However, according to models of Höfner et al. (2016), a tiny faction of seed particles $\left(n_{S} / n_{H} \sim 10^{-16}\right)$ can be sufficient to aid in wind driving (Sec. 6.2.2). The lower left corner of our $(T, \rho)$-grid most closely resembles the extended envelope regime (i.e. cold and sparse), which shows that the $\mathrm{TiO}_{2}$ molecule and $\mathrm{TiO}_{2}$-clusters can simultaneously be present (Fig. E22). When intuitively extrapolating to lower temperatures and lower densities, as if moving further out into the extended envelope, we expect a higher $\mathrm{TiO}_{2}$ and $\mathrm{TiO}$ abundance and less $\mathrm{TiO}_{2}$-clusters.

Khouri et al. (2018) observe that for the oxygen-rich AGB star o Cet 4.5 per cent of the atomic Ti is locked-up in $\mathrm{TiO}_{2}$. It is however difficult to compare with our model grid since the presence of the molecule is extremely sensitive to gas temperature and its abundance ranges from 0 to 100 per cent of the intitial atomic Ti (Fig. E22). As it is unclear what the temperature coverage of the observation is, the derived abundance is most likely an average in a certain temperature range. Kamiński et al. (2016) discovered AlO, $\mathrm{AlOH}$, and $\mathrm{AlH}$ in oCet but could only determine the abundance of AlO. They find $n_{\mathrm{AlO}} / n_{\mathrm{H}}=10^{-9}-10^{-7}$, which agrees with our model predictions that maximally 1 per cent of all $\mathrm{Al}$ is turned into molecules, with $\mathrm{AlO}$ the most abundant molecule $\sim n_{\mathrm{AlO}} / n_{\mathrm{H}}<10^{-8}$. Kamiński et al. (2016) do state that $\mathrm{AlOH}$ is present in a gas temperature of $1960 \pm 170 \mathrm{~K}$, and that $\mathrm{AlH}$ is detected between 2.5 to $4 R_{\star}$. Both observational constraints comply with our model predictions (Fig. E25). Additionally, Decin et al. (2017) find that for AGB stars IK Tau and R Dor the amount of $\mathrm{AlO}, \mathrm{AlOH}$, and $\mathrm{AlCl}$ accounts for maximally 2 per cent of the total aluminium budget. Both observations are in line with our prediction that maximally 1 per cent of all $\mathrm{Al}$ is turned into molecules (Fig. 5). The amount of detected $\mathrm{AlOH}$ in $\mathrm{R}$ Dor only accounts for roughly 0.02 per cent, yet this is still significantly more than our models predict (Fig. E25). Lastly, Khouri et al. (2018) also deduce that less than 0.1 per cent of the atomic $\mathrm{Al}$ is converted into $\mathrm{AlO}$. In conclusion, all three observational studies agree with our prediction that maximally 1 per cent of all $\mathrm{Al}$ is turned into molecules. Our prediction also better supports the recent observations than the significantly higher abundances of Al-bearing molecules predicted by models of Gobrecht et al. (2016).

As both observations and our comprehensive model agree that maximally 1 per cent of all atomic $\mathrm{Al}$ turns into a molecule (Sec. 4.2.4), it is interesting to analyse the results of a closed nucleation model with only 1 per cent of
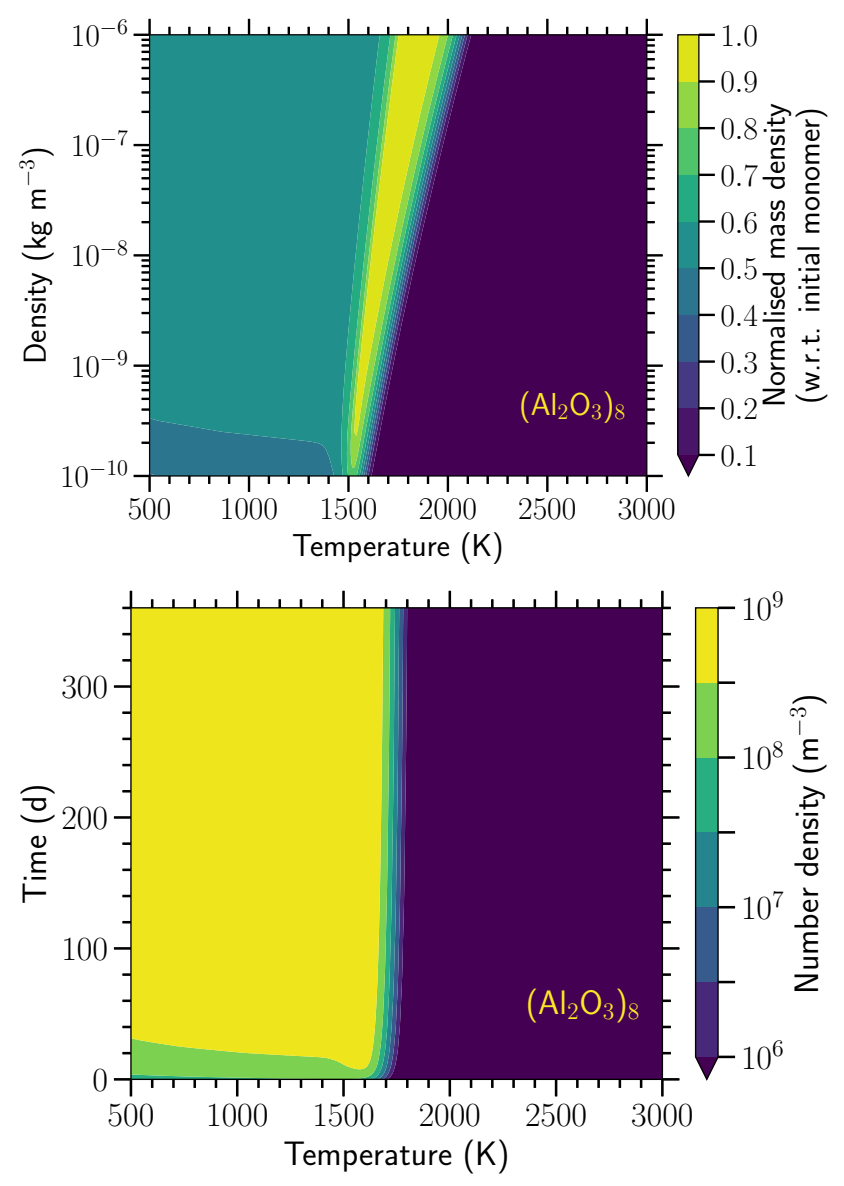

Figure 8. Normalised mass density after one year (top) and temporal evolution of the absolute number density at the benchmark total gas density $\rho=1 \cdot 10^{-9} \mathrm{~kg} \mathrm{~m}^{-3}$ (bottom) of $\left(\mathrm{Al}_{2} \mathrm{O}_{3}\right)_{8}$ for the closed nucleation model with an initial $\mathrm{Al}_{2} \mathrm{O}_{3}$ abundance of 1 per cent of the available $\mathrm{Al}$ using the polymer nucleation description. The results are similar to the closed nucleation model with all $\mathrm{Al}$ turned into $\mathrm{Al}_{2} \mathrm{O}_{3}$ (Figs. 2,3). Due to the lower amount of species the formation threshold is slightly lower at 1600 to $2100 \mathrm{~K}$ and convergence takes a little longer, roughly $20 \mathrm{~d}$.

the available $\mathrm{Al}$ as initial $\mathrm{Al}_{2} \mathrm{O}_{3}$ abundance. We choose to only use the polymer nucleation description. Compared to a 100 per cent initial abundance, the temperature formation threshold of $\left(\mathrm{Al}_{2} \mathrm{O}_{3}\right)_{8}$ has slightly lowered to 1600 to $2100 \mathrm{~K}$ (Fig. 8). This is expected as a lower density produces less collisions therefore making it more difficult to form clusters at higher temperatures. Similarly, $\left(\mathrm{Al}_{2} \mathrm{O}_{3}\right)_{8}$ converges only after roughly $20 \mathrm{~d}$ which is significantly longer than the 5 to $10 \mathrm{~h}$ for the 100 per cent initial abundance model (Fig. 8). Besides the temporal effects, the results are analogous to the 100 per cent case where $\left(\mathrm{Al}_{2} \mathrm{O}_{3}\right)_{8}$ also contains more than 90 per cent of the available monomers at the highest formation temperatures.

\section{SUMMARY AND PROSPECTS}

In this paper, we have constructed and investigated an improved nucleation theory by abandoning the assumption of chemical equilibrium, dropping the restriction of cluster 
growth by only monomers, and using accurate quantum mechanical properties of molecular clusters. We have examined the viability of $\mathrm{TiO}_{2}, \mathrm{MgO}, \mathrm{SiO}$ and $\mathrm{Al}_{2} \mathrm{O}_{3}$ as candidates of the first dust precursors in oxygen-rich AGB winds. The choice of candidates is based on rigorous theoretical and observational evidence (Sec. 3.2).

This work consists of two main nucleation descriptions, one that only allows cluster growth via monomers and one that allows polymer interaction. Both assume the nucleation processes to be homogeneous and homomolecular. With these descriptions, two main types of systems are evolved in a grid of temperature and density that is typical for AGB winds: a closed nucleation system and a comprehensive chemical nucleation system. The former considers the growth of one nucleation candidate species with the monomer as the smallest building block and assumes that all available atomic metal is locked-up in the monomer. The latter allows chemical interaction between species in a gas mixture which includes all nucleation species and starts with an atomic composition. The former provides insight in the nucleating efficiency of each candidate in temperature and density space, and the latter yields a more complete chemical nucleation model by removing the assumption of the a priori existence of the monomer (Sec. 3).

Constructing the nucleation reaction networks required quantum mechanical data of all clusters, which we calculated with high precision density functional theory. Since such calculations exponentially increase with cluster size, we limit the maximal size to roughly $N=10$. The comprehensive chemical reaction network is constructed by adding relevant chemical reactions to an already carefully designed reduced network for AGB winds (Boulangier et al. 2019). The extension includes all relevant and available reactions to form the nucleation monomers. Since a significant amount of reversed reactions is not present in the literature, quantum mechanical data for the participating species is needed to calculate those reaction rate coefficients. We have gathered as much as possible data from the literature and performed density functional theory calculations when this was unavailable (Sec. 3.6).

Overall, using the monomer nucleation description as compared to the polymer one, will underestimate the abundance and overestimate the formation time of the large clusters. Using the abundance of the largest clusters as a gauge of dust formation, the monomer nucleation scenario would underestimate the amount of dust and overestimate its formation time. This can lead to less efficient wind-driving or even the absence of a wind in theoretical simulations. The monomer description also inhibits the formation of large clusters at low temperatures due to a rapidly developing lack of monomers, which by design is the only growth mechanism. The polymer description does not suffer from this limitation and is therefore more realistic. Comparison with equilibrium abundance ratios reveals that the assumption of equilibrium is not valid over the entire temperature range for a period of one year. Hence, a time-dependent description in necessary to investigate the nucleation process in AGB winds.
The closed nucleation models, which assume that the nucleation monomers are present, predict that $\mathrm{Al}_{2} \mathrm{O}_{3}$ is the primary candidate to be the first AGB dust precursor. These clusters rapidly form at much higher temperatures than any other cluster, around 1800 to $2400 \mathrm{~K}$ and in less than a few days. Rapid dust formation at high temperatures will aid in driving the AGB wind, since the wind is cooling down from hot shocks ( $10000 \mathrm{~K}$, Boulangier et al. 2019). At around 1500 to $1700 \mathrm{~K}$, large $\mathrm{MgO}$-clusters can form and only at 1000 to $1200 \mathrm{~K}$ large $\mathrm{TiO}_{2}$-clusters arise. Formation of SiO-clusters is not favourable in the considered temperature range but requires colder conditions. Note that the above conclusions are drawn on the underlying assumption that the monomer exists (Sec. 4.1).

The comprehensive chemical nucleation model yields different results from the closed nucleation ones. Firstly, it does not predict any $\mathrm{Al}_{2} \mathrm{O}_{3}$-clusters, nor its monomer, nor its molecular precursors $\left(\mathrm{Al}_{2} \mathrm{O}_{2}\right.$ and $\left.\mathrm{AlO}_{2}\right)$ but most $\mathrm{Al}$ remains atomic with maximally 1 per cent in Al-bearing molecules which is mainly AlO. Secondly, all available $\mathrm{Mg}$ remains atomic and no $\mathrm{MgO}$-clusters can exist. Hence, the most favoured nucleation candidates, according to the closed models, are non-existent. Only $\mathrm{TiO}_{2}$-clusters exist in the comprehensive model, with similar formation conditions as in the closed model. SiO-clusters are again discarded due to their low formation temperature (Sec. 4.2).

The results from the comprehensive nucleation model suggest that $\mathrm{TiO}_{2}$ is the only possible AGB dust precursor of the considered nucleation candidates. However, this contradicts the substantial amount of $\mathrm{Al}_{2} \mathrm{O}_{3}$-favouring evidence. Firstly, the number of $\mathrm{Al}_{2} \mathrm{O}_{3}$-clusters found in pre-solar AGB grains far exceeds the amount of $\mathrm{TiO}_{2}$ clusters. Secondly, numerous AGB dust observations indicate that dust already exists close to the star and thus at temperatures as high as 1500 to $2000 \mathrm{~K}$, a regime in which, according to our model results, only $\mathrm{Al}_{2} \mathrm{O}_{3}$-clusters can exist. $\mathrm{TiO}_{2}$-clusters require temperatures below 1000 to $1200 \mathrm{~K}$. We believe that this discrepancy suggests that our current chemical reaction network is incomplete. Additionally, since there is experimental evidence that gaseous small $\mathrm{Al}_{2} \mathrm{O}_{3}$-clusters can exists, we believe that either the current reaction rate coefficients involving $\mathrm{AlO}$-bearing molecules are not accurate enough and need to be re-evaluated, or that alternative small $\mathrm{Al}_{2} \mathrm{O}_{3}$-cluster formation pathways are missing. Moreover, most Al-molecule formation rate coefficients are unavailable in the literature and rely on the assumption of detailed balance with their corresponding destruction process. We therefore urge the scientific community to investigate rate coefficients of formation reactions of Al-bearing molecules at high temperatures. Without this data, it will remain unclear which species will form the initial dust precursors in AGB winds.

This paper has constructed and investigated an improved nucleation theory for more accurate modelling of the formation of dust. The improved description is time-dependent, allows growth by polymers, and considers quantum mechanical molecular properties. This procedure is universal and can be applied to any astrophysical environment, where this paper focuses on AGB winds. 
This work serves as a initial model which will be extended with macroscopic dust formation processes such as gas accretion, gas sputtering, dust coagulation, dust shattering, and dust evaporation in a future paper. It is the second in a series where we strive for increased self-consistency regarding chemistry, dust creation, and dynamics. The developed and improved chemical nucleation description can be incorporated into a hydrochemical model such as the first paper in this series (Boulangier et al. 2019). Currently, the results indicate which species, how much, how fast, and under which conditions they nucleate in an AGB wind.

\section{ACKNOWLEDGEMENTS}

J.B., D.G., and L.D. acknowledge support from the ERC consolidator grant 646758 AEROSOL. This research made use of Matplotlib (Hunter 2007), NumPy (Oliphant 2006), and Astropy (Robitaille et al. 2013; The Astropy Collaboration et al. 2018), which are community-developed core Python packages for science and astronomy.

\section{REFERENCES}

Abel T., Anninos P., Zhang Y., Norman M. L., 1997, New Astron., 2,181

Archibong E. F., St-Amant A., 1999, J. Phys. Chem. A, 103, 1109 Asplund M., Grevesse N., Sauval A. J., Scott P., 2009, ARA\&A, 47,481

Atkinson R., et al., 2004, Atmos. Chem. Phys., 4, 1461

Bauschlicher C. W., Schwenke D. W., 2017, Chem. Phys. Lett., 683,62

Becke A. D., 1993, J. Chem. Phys., 98, 1372

Becker K., Fink E., Leiss A., Schurath U., 1978, Chem. Phys. Lett., 54, 191

Beckmann A., Böklen K. D., Bremer G., Elke D., 1975, Z. Phys. A Atoms Nucl., 272, 143

Bojko B. T., DesJardin P. E., Washburn E. B., 2014, Combust. Flame, 161, 3211

Bose M., Floss C., Stadermann F. J., Stroud R. M., Speck A. K., 2010a, in Lunar Planet. Sci. Conf.. p. 1812, https: //ui.adsabs. harvard.edu//\{\#\}abs/2010LPI ...41.1812B

Bose M., Floss C., Stadermann F. J., 2010b, ApJ, 714, 1624

Bose M., Floss C., Stadermann F. J., Stroud R. M., Speck A. K., 2012, Geochim. Cosmochim. Acta, 93, 77

Boulangier J., Clementel N., van Marle A. J., Decin L., de Koter A., 2019, MNRAS, 482, 5052

Bromley S. T., Gómez Martín J. C., Plane J. M. C., 2016, Phys. Chem. Chem. Phys., 18, 26913

Burcat A., Ruscic B., 2005, Technical report, Third millenium ideal gas and condensed phase thermochemical database for combustion (with update from active thermochemical tables)., http://www.osti.gov/servlets/purl/ 925269-199FK1/. Argonne National Laboratory (ANL), Argonne, IL, doi:10.2172/925269, http://www.osti.gov/ servlets/purl/925269-199FKl/

Campbell M. L., McClean R. E., 1993, J. Phys. Chem., 97, 7942

Capitelli M., Coppola C. M., Diomede P., Longo S., 2007, A\&A, 470,811

Catoire L., Legendre J.-F., Giraud M., 2003, J. Propuls. power, 19, 196

Chase M. W. J., 1998, Phys. Chem. Ref. Data, 9

Chen M., Felmy A. R., Dixon D. A., 2014, J. Phys. Chem. A, 118, 3136
Choi B. G., Huss G. R., Wasserburg G. J., Gallino R., 1998, Science, 282, 1284

Clouet E., 2009, in Furrer D., Semiatin S., eds, , Vol. 22, ASM Handb. Fundam. Model. Met. Process. Vol. 22A. ASM International, Chapt. Modeling o, pp 203-217, https://arxiv. org/pdf/1001.4131v2.pdf

Corà F., 2005, Mol. Phys., 103, 2483

DeMore W., et al., 1997, JPL Publ. 97-4, pp 1 - 266

Decin L., et al., 2017, A\&A, 608, 55

Decin L., Danilovich T., Gobrecht D., Plane J. M. C., Richards A. M. S., Gottlieb C. A., Lee K. L. K., 2018, ApJ, 855, 113

Dell'Agli F., García-Hernández D. A., Schneider R., Ventura P., La Franca F., Valiante R., Marini E., Di Criscienzo M., 2017, MNRAS, 467, 4431

Demyk K., van Heijnsbergen D., von Helden G., Meijer G., 2004, A\&A, 420, 547

Depew K., Speck A., Dijkstra C., 2006, ApJ, 640, 971

Diemand J., Angélil R., Tanaka K. K., Tanaka H., 2013, J. Chem. Phys., 139, 074309

Farrow M. R., Chow Y., Woodley S. M., 2014, Phys. Chem. Chem. Phys., 16, 21119

Ferrarotti A. S., Gail H.-P., 2006, A\&A, 447, 553

Forrey R. C., 2013, ApJ, 773, L25

Frisch M. J., et al., 2013, Gaussian 09, Revision E.01, http:// gaussian.com/

Furtenbacher T., Szidarovszky T., Hrubý J., Kyuberis A. A., Zobov N. F., Polyansky O. L., Tennyson J., Császár A. G., 2016, J. Phys. Chem. Ref. Data, 45, 043104

Gail H.-P., Sedlmayr E., 1988, A\&A, 206, 153

Gail H.-P., Sedlmayr E., 1999, A\&A, 347, 594

Gamache R. R., et al., 2017, J. Quant. Spectrosc. Radiat. Transf., 203, 70

Glover S. C., Abel T., 2008, MNRAS, 388, 1627

Glover S. C., Federrath C., Low M. M., Klessen R. S., 2010, MNRAS, 404, 2

Gobrecht D., Cherchneff I., Sarangi A., Plane J. M. C., Bromley S. T., 2016, A\&A, 585, A6

Gobrecht D., Cristallo S., Piersanti L., Bromley S. T., 2017, ApJ, 840,117

Gobrecht D., Decin L., Cristallo S., Bromley S. T., 2018, Chem. Phys. Lett., 711, 138

Gordon I., et al., 2017, J. Quant. Spectrosc. Radiat. Transf., 203, 3

Goumans T. P. M., Bromley S. T., 2012, MNRAS, 420, no

Grassi T., Bovino S., Schleicher D. R., Prieto J., Seifried D., Simoncini E., Gianturco F. A., 2014, MNRAS, 439, 2386

Grassi T., Bovino S., Haugbølle T., Schleicher D. R. G., 2017, MNRAS, 466, 1259

Habing H., Olofsson H., 2004, Asymptotic giant branch stars, doi:10.1007/978-1-4757-3876-6., https://ui.adsabs. harvard.edu/abs/2004agbs.book.....H

Haris K., Kramida A., 2017, ApJS, 233, 16

Helling C., Winters J. M., 2001, A\&A, 366, 229

Helling C., Woitke P., 2006, A\&A, 455, 325

Herzberg G., 1966, Molecular spectra and molecular structure. Vol.3: Electronic spectra and electronic structure of polyatomic molecules. Van Nostrand Reinhold Company, https: //ui.adsabs. harvard.edu/abs/1966msms. book..... H

Higuchi Y., Fukuda Y., Fujita Y., Yamakita N., Imajo T., 2008, Chem. Phys. Lett., 452, 245

Höfner S., Bladh S., Aringer B., Ahuja R., 2016, A\&A, 594, A108

Huang Y., Risha G. A., Yang V., Yetter R. A., 2009, Combust. Flame, 156, 5

Huber K. P., Herzberg G., 1979, in , Mol. Spectra Mol. Struct.. Van Nostrand Reinhold Company, New York, pp 8-689, doi:10.1007/978-1-4757-0961-2_2, https ://ui . adsabs. harvard.edu/\{\%\}5C $\{\#\}$ abs $/ 1966$ msms. book..... H

Hunter J. D., 2007, Comput. Sci. Eng., 9, 90 
Hutcheon I. D., Huss G. R., Fahey A. J., Wasserburg G. J., 1994, ApJ, 425, L97

Hynes K. M., Gyngard F., 2009, Technical report, The presolar grain database, http://presolar.wustl.edu/\{^\}pgd.. Laboratory for Space Sciences and Department of Physics, http: //presolar.wustl.edu/ $\left\{{ }^{\sim}\right\}$ pgd.

Jacobson M. Z., 2013, Fundamentals of Atmospheric Modeling, 2nd edn. Cambridge University Press, New York (arXiv: 1011.1669v3), doi:10.1017/CBO9781107415324.004

Janev R., Langer W., Evans K., 1987, Elementary processes in Hydrogen-Helium plasmas - Cross sections and reaction rate coefficients. Springer, Berlin

Jeong K. S., Chang C., Sedlmayr E., Sülzle D., 2000, J. Phys. B At. Mol. Opt. Phys., 33, 3417

Jeong K. S., Winters J. M., Le Bertre T., Sedlmayr E., 2003, A\&A, 407, 191

Johns J. W. C., Priddle S. H., Ramsay D. A., 1963, Discuss. Faraday Soc., 35, 90

Johnson R. D. I., 2018, NIST Computational Chemistry Comparison and Benchmark Database NIST Standard Reference Database Number 101, doi:10.18434/T47C7Z, http:// cccbdb.nist.gov/

Johnston R. L., 2002, Atomic and Molecular Clusters, 1st edn. Master's Series in Physics and Astronomy, CRC Press, doi:10.1201/9781420055771, https://www.taylorfrancis.com/books/9781420055771

Kamiński T., et al., 2016, A\&A, 592, A42

Kamiński T., et al., 2017, A\&A, 599, A59

Karakas A. I., 2010, MNRAS, 403, 1413

Karakas A., Lattanzio J. C., 2007, Publ. Astron. Soc. Aust., 24, 103

Khouri T., et al., 2016, A\&A, 591, A70

Khouri T., Vlemmings W. H. T., Olofsson H., Ginski C., De Beck E., Maercker M., Ramstedt S., 2018, A\&A, 620, 75

Köhler T. M., Gail H.-P., Sedlmayr E., 1997, A\&A, 320, 553

Kramida A., Ralchenko Y., Reader J., NIST ASD Team (2018) 2018, Natl. Inst. Stand. Technol.

Kurucz R., 1992, Rev. Mex. Astron. y Astrofis., 23

Lamiel-Garcia O., Cuko A., Calatayud M., Illas F., Bromley S. T., 2017, Nanoscale, 9, 1049

Langowski M. P., et al., 2015, Atmos. Chem. Phys, 15, 273

Lee G., Helling C., Giles H., Bromley S. T., 2015, A\&A, 575, A11

Lee G. K. H., Blecic J., Helling C., 2018, A\&A, 614, 126

Lepinoux J., 2006, Philos. Mag., 86, 5053

Li R., Cheng L., 2012, Comput. Theor. Chem., 996, 125

Li G., Gordon I. E., Rothman L. S., Tan Y., Hu S.-M., Kassi S., Campargue A., Medvedev E. S., 2015, ApJS, 216, 15

Luo Y., 2007, Comprehensive Handbook of Chemical Bond Energies. CRC Press, http://staff.ustc.edu.cn/\{ $\}$ luo971/ 2010-91-CRC-BDEs-Tables.pdf

Martin W. C., Zalubas R., 1979, J. Phys. Chem. Ref. Data, 8, 817

Martin W. C., Zalubas R., 1983, J. Phys. Chem. Ref. Data, 12, 323

Martínez-Núñez E., Whalley C. L., Shalashilin D., Plane J. M. C., 2010, J. Phys. Chem. A, 114, 6472

McElroy D., Walsh C., Markwick A. J., Cordiner M. A., Smith K., Millar T. J., 2013, A\&A, 550, A36

McKinnon R., Vogelsberger M., Torrey P., Marinacci F., Kannan R., 2018, MNRAS, 478, 2851

McSween H. J., Huss G. R., 2010, Cosmochemistry. Cambridge University Press, doi:10.1111/j.1945-5100.2011.01192.x, https: //books . google. be/books?id=385nPZOXmYAC

Moore C. E., 1993, in Gallagher J. W., ed., , CRC Ser. Eval. Data At. Phys.. CRC Press, Boca Raton, FL

Nguyen A. N., Messenger S., 2009, Identification of an Extremely 18O-rich Presolar Silicate Grain in Acfer 094, https://ui.adsabs.harvard.edu/\{\#\}abs/2009M\{\&\}PSA .

\section{$72.5376 \mathrm{~N} /$ abstract}

Nittler L. R., Alexander C. M. O., Gao X., Walker R. M., Zinner E. K., 1994, Nature, 370, 443

Nittler L. R., Alexander C. M. O., Gao X., Walker R. M., Zinner E., 1997, ApJ, 483, 475

Nittler L. R., Alexander C. M. O., Gallino R., Hoppe P., Nguyen A. N., Stadermann F. J., Zinner E. K., 2008, ApJ, 682, 1450 Norris B. R. M., et al., 2012, Nature, 484, 220

Ohnaka K., Weigelt G., Hofmann K.-H., 2016, A\&A, 589, A91

Oliphant T. E., 2006, A guide to NumPy

Patrascu A. T., Yurchenko S. N., Tennyson J., 2015, MNRAS, 449, 3613

Patzer A. B. C., Gauger A., Sedlmayr E., 1998, A\&A, 337, 847

Patzer A. B., Chang C., Sedlmayr E., Sülzle D., 2005, Eur. Phys. J. D, 32,329

Phillips J. G., 1971, ApJ, 169, 185

Plane J. M. C., 2013, Philos. Trans. A. Math. Phys. Eng. Sci., 371,20120335

Plane J. M. C., Helmer M., 1995, Faraday Discuss., 100, 411

Plane J. M. C., Whalley C. L., 2012, J. Phys. Chem. A, 116, 6240

Plane J. M. C., Feng W., Dawkins E. C. M., 2015, Chem. Rev., 115,4497

Popovas A., Jørgensen U. G., 2016, A\&A, 595, A130

Posch T., Kerschbaum F., Mutschke H., Fabian D., Dorschner J., Hron J., 1999, A\&A, 352, 609

Poulaert G., Brouillard F., Claeys W., McGowan J. W., Wassenhove G. V., 1978, J. Phys. B At. Mol. Phys., 11, L671

Ritter D., Weisshaar J. C., 1989, J. Phys. Chem, 93, 1576

Robitaille T. P., et al., 2013, A\&A, 558, A33

Rollason R. J., Plane J. M. C., 2001, Phys. Chem. Chem. Phys., 3,4733

Rothman L., et al., 2010, J. Quant. Spectrosc. Radiat. Transf., 111,2139

Saloman E. B., 2012, J. Phys. Chem. Ref. Data, 41, 013101

Sarangi A., Cherchneff I., 2015, A\&A, 575, A95

Savel'ev A. M., Starik A. M., 2018, Combust. Flame, 196, 223

Sharipov A. S., Loukhovitski B. I., 2018, Combust. Explos., 11

Sharipov A. S., Starik A. M., 2016, Chem. Phys., 465-466, 9

Sharipov A., Titova N., Starik A., 2011, J. Phys. Chem. A, 115, 4476

Sharipov A. S., Titova N. S., Starik A. M., 2012, Combust. Theory Model., 16, 842

Sierka M., et al., 2007, Angew. Chemie Int. Ed., 46, 3372

Sloan G. C., Levan P. D., Little-Marenin I. R., 1996, ApJ, 463, 310

Sloan G. C., Kraemer K. E., Goebel J. H., Price S. D., 2003, ApJ, 594,483

Sluder A., Milosavljević M., Montgomery M. H., 2018, MNRAS, 480, 5580

Speck A. K., Barlow M. J., Sylvester R. J., Hofmeister A. M., 2000, A\&AS, 146, 437

Starik A. M., Kuleshov P. S., Sharipov A. S., Titova N. S., Tsai C.-J., 2014, Combust. Flame, 161, 1659

Starik A. M., Savel'ev A. M., Titova N. S., 2015, Combust. Explos. Shock Waves, 51, 197

Stroud R. M., Nittler L. R., Alexander C. M. O., 2004, Science, 305, 1455

Stroud R. M., Nittler L. R., Alexander C. M. O., Zinner E., 2007, Lunar Planet. Sci. Conf., p. 2203

Suh S.-M., Zachariah M. R., Girshick S. L., 2001, J. Vac. Sci. Technol. A Vacuum, Surfaces, Film., 19, 940

Swihart M. T., Catoire L., Legrand B., Gökalp I., Paillard C., 2003, Combust. Flame, 132, 91

Takigawa A., Tachibana S., Nagahara H., Ozawa K., 2015, ApJS, 218

Tanaka K. K., Tanaka H., Yamamoto T., Kawamura K., 2011, J. Chem. Phys., 134, 204313 
Teyssandier F., Allendorf M. D., 1998, J. Electrochem. Soc., 145, 2167

The Astropy Collaboration T. A., et al., 2018, ArXiv, 156, 123

Toxvaerd S., 2015, J. Chem. Phys., 143, 154705

Tsai S.-M., Lyons J. R., Grosheintz L., Rimmer P. B., Kitzmann D., Heng K., 2017, ApJS, 228, 20

Verner D. A., Ferland G. J., 1996, ApJS, 103, 467

Vidler M., Tennyson J., 2000, J. Chem. Phys., 113, 9766

Wakelam V., et al., 2012, ApJS, 199, 21

Washburn E. B., Trivedi J. N., Catoire L., Beckstead M. W., 2008, Combust. Sci. Technol., 180, 1502

Whalley C. L., Plane J. M. C., 2010, Faraday Discuss., 147, 349

Whalley C. L., Martín J. C. G., Wright T. G., Plane J. M. C., 2011, Phys. Chem. Chem. Phys., 13, 6352

Woitke P., 2006a, A\&A, 452, 537

Woitke P., 2006b, A\&A, 460, 9

Wong A., Yurchenko S. N., Bernath P., Müller H. S. P., McConkey S., Tennyson J., 2017, MNRAS, 470, 882

Yurchenko S. N., Williams H., Leyland P. C., Lodi L., Tennyson J., 2018, MNRAS, 479, 1401

Zeidler S., Posch T., Mutschke H., 2013, A\&A, 553, 81

Zhao-Geisler R., Köhler R., Kemper F., Kerschbaum F., Mayer A., Quirrenbach A., Lopez B., 2015, Publ. Astron. Soc. Pacific, 127,732

van Heijnsbergen D., Demyk K., Duncan M. A., Meijer G., von Helden G., 2003, Phys. Chem. Chem. Phys., 5, 2515

\section{APPENDIX A: EQUILIBRIUM COMPOSITION IN THE DILUTE LIMIT}

This section describes, step by step, how to determine the equilibrium composition of a gas mixture. This allows to determine the equilibrium ratio of two species, which in needed in equation (13). We focus on a nucleating system as this is the main purpose of this work. Because the number densities of nucleating molecules are small compared to the total gas number density, a nucleating system can be considered as a dilute solution where the bulk gas is the solvent and the nucleation molecules are the solutes. The Gibbs free energy of a pure solvent of $N_{A}$ particles $A$, is just $N_{A}$ times the chemical potential,

$G=N_{A} \mu_{A}(T, P)$,

where $\mu_{A}(T, P)$ is the chemical potential of the pure solvent, that is a function of temperature and pressure, $T$ and $P$. Imagine, adding a single $B$ particle to this system while holding the temperature and pressure fixed. This changes the Gibbs free energy by

$\mathrm{d} G=\mathrm{d} U+P \mathrm{~d} V-T \mathrm{~d} S$,

where $U$ is the internal energy, $V$ the volume, and $S$ the entropy of the system. Note that $\mathrm{d} U$ nor $P \mathrm{~d} V$ depend on $N_{A}$ but on how the $B$ particle interacts with its nearby neighbours, regardless of the total number of $A$ particles. $\mathrm{d} S$ is partly independent of $N_{A}$, but part comes from the freedom of choosing where to put this $B$ particle. As this is proportional to the total number of $A$ particles, the entropy changes as

$\mathrm{d} S=k \ln N_{A}+\left(\right.$ terms independent of $\left.N_{A}\right)$.

We drop the $B$ subscript of the Boltzmann constant to avoid confusion with the $B$ particle. The total change in Gibbs free energy can then be written as

$\mathrm{d} G=G_{B}(T, P)-k T \ln N_{A}$,

where $G_{B}(T, P)$ is a function of temperature and pressure but independent of $N_{A}$. We shall call this the intrinsic Gibbs free energy of particle $B$. Generalising to adding $N_{B}$ particles results in a change

$\mathrm{d} G=N_{B} G_{B}(T, P)-N_{B} k T \ln N_{A}+k T \ln \left(N_{B} !\right)$

where the last term is introduced because all $B$ particles are identical and interchanging them does not result in a distinct state. Because $N_{B} \gg 1$, Stirling's approximation can be used to get rid of the factorial, leading to

$\mathrm{d} G=N_{B} G_{B}(T, P)-N_{B} k T \ln N_{A}+N_{B} k T \ln N_{B}-N_{B} k T$.

Generalising this to adding $\mathcal{M}-1$ different particles (so that $\mathcal{M}$ includes the solvent particle), the total Gibbs free energy of the system is given by

$G=N_{A} \mu_{A}(T, P)+\sum_{i=2}^{\mathcal{M}} N_{i} G_{i}(T, P)-N_{i} k T \ln N_{A}+N_{i} k T \ln N_{i}-N_{i} k T$.

Note that this expression is only valid in the limit $N_{i} \ll N_{A}$, that is when the solution is dilute. If not, then all $i$ particles would also interact with each other and the volume occupied by the particles will matter in the total Gibbs free energy determination (Lepinoux 2006). In order to determine the equilibrium composition of the system, its Gibbs free energy (Eq. A7) has to be minimised.

In general, when optimising a multivariate function $f\left(x_{1}, \ldots, x_{n}\right)$ with $m$ number of constraints $g_{k}\left(x_{1}, \ldots, x_{n}\right)=0$ with $k \in\{1, \ldots, m\}$, the Lagrangian that needs to be optimised (to each variable) takes the form

$\mathcal{L}\left(x_{1}, \ldots, x_{n}, \lambda_{1}, \ldots, \lambda_{m}\right)=f\left(x_{1}, \ldots, x_{n}\right)-\sum_{k=1}^{m} \lambda_{k} g_{k}\left(x_{1}, \ldots, x_{n}\right)$,

where each $\lambda_{k}$ is called a Lagrangian multiplier. Minimising the total Gibbs free energy of the nucleating system, eq. (A7), can be achieved under the constraint that the total number of atoms in the system is constant

$\sum_{i=1}^{\mathcal{M}} \sum_{j=1}^{\mathcal{A}} N_{i} x_{i j}=C$

where $C$ is the total number of atoms, $\mathcal{A}$ is the number of different atoms, and $x_{i j}$ is the number of $j$ atoms in molecule $i$. Since this one constraint is sufficient, $g_{k}=g_{1}=g$ and $\lambda_{k}=\lambda_{1}=\lambda$. Rewriting the constraint gives

$g\left(N_{1}, \ldots, N_{\mathcal{M}}\right)=\sum_{i=1}^{\mathcal{M}} \sum_{j=1}^{\mathcal{A}} N_{i} x_{i j}-C=0$

with $N_{1}=N_{A}$ (the solvent). The Lagrangian of the system can then be written as

$\mathcal{L}\left(N_{1}, \ldots, N_{\mathcal{M}}\right)=G\left(N_{1}, \ldots, N_{\mathcal{M}}\right)-\lambda\left(\sum_{i=1}^{\mathcal{M}} \sum_{j=1}^{\mathcal{A}} N_{i} x_{i j}-C\right)$. 
Minimising this Lagrangian to each variable leads to the set of $\mathcal{M}+1$ equations

$$
\begin{aligned}
\frac{\partial \mathcal{L}}{\partial N_{A}} & =\mu_{A}(T, P)-\frac{k T}{N_{A}} \sum_{i=2}^{\mathcal{M}} N_{i}-\lambda \sum_{j=1}^{\mathcal{A}} x_{A j} & & =0 \\
\frac{\partial \mathcal{L}}{\partial N_{i}} & =G_{i}(T, P)+k T \ln \left(\frac{N_{i}}{N_{A}}\right)-\lambda \sum_{j=1}^{\mathcal{A}} x_{i j} & & =0 \\
\frac{\partial \mathcal{L}}{\partial \lambda} & =\sum_{i=1}^{\mathcal{M}} \sum_{j=1}^{\mathcal{A}} N_{i} x_{i j}-C & & =0
\end{aligned}
$$

where eq. (A13) is valid for all $i \in\{2, \ldots, \mathcal{M}\}$. Solving this matrix will result in the equilibrium distribution of all molecules.

For our purpose (making use of detailed balance, eq. 13), we are interested in the ratio between molecules and by rewriting equation (A13) the number of solute molecules compared to the solvent is given by

$\frac{N_{i}}{N_{A}}=\exp \left(\frac{-G_{i}+\lambda \sum_{j}^{\mathcal{A}} x_{i j}}{k T}\right)$.

Note this represents the equilibrium values but we omit the "eq" superscript for clarity. As we consider a nucleating system, this equation can be simplified, because the number of atoms in a cluster scales linearly with the size of the cluster. Let $X$ be the number of atoms in the monomer, then for a cluster of size $n$ :

$\sum_{j}^{\mathcal{A}} x_{n j}=n \sum_{j}^{\mathcal{A}} x_{1 j}=n X$.

Then, according to equation (A15), the number fraction of an $n$-sized cluster is given by

$\frac{N_{n}}{N_{A}}=\exp \left(\frac{-G_{n}+\lambda n X}{k T}\right)$.

Consequently, the ratio of two different cluster sizes $n$ and $m$ is

$\frac{N_{n}}{N_{m}}=\exp \left(\frac{-G_{n}+G_{m}+(n-m) \lambda X}{k T}\right)$.

Introducing an $(n-m)$-sized cluster, with $n>m$, removes the $\lambda X$ term. I.e. using Eq. (A17), one can write

$\frac{N_{n-m}}{N_{A}}=\exp \left(\frac{-G_{n-m}+(n-m) \lambda X}{k T}\right)$,

and hence

$(n-m) \lambda X=k T \ln \left(\frac{N_{n-m}}{N_{A}}\right)+G_{n-m}$.

Substitution Eq. (A20) into equation (A17), results in the ratio,

$\frac{N_{n}}{N_{m}}=\frac{N_{n-m}}{N_{A}} \exp \left(\frac{-G_{n}+G_{m}+G_{n-m}}{k T}\right)$.

Remember that each $G_{i}=G_{i}(T, P)$ is temperature and pressure dependent. For convenience these values are often calculated at a so-called standard pressure of $P^{\circ}=1$ bar $\left(=1 \cdot 10^{5} \mathrm{~Pa}=1 \cdot 10^{6} \mathrm{dyne} / \mathrm{cm}^{2}\right)$. The superscript ${ }^{\circ}$ refers to a quantity at this standard pressure. The Gibbs free energy of a particle at any pressure can be written as a function of the standard one,

$G=G^{\circ}-k T \ln \left(\frac{P^{\circ}}{P}\right)$,

because only the translational partition function is a pressure dependent term (Eqs. B10-B9),

$Z_{t}=Z_{t}^{\circ} \frac{P^{\circ}}{P}$.

Using the standard Gibbs free energy and substituting equation (A22) in equation (A21), the ratio of cluster sizes becomes,

$$
\begin{aligned}
\frac{N_{n}}{N_{m}} & =\frac{N_{n-m}}{N_{A}} \exp \left(\frac{-G_{n}^{\circ}+G_{m}^{\circ}+G_{n-m}^{\circ}}{k T}\right) \frac{P}{P^{\circ}} \\
& =N_{n-m} \frac{k T}{P^{\circ} V} \exp \left(\frac{-G_{n}^{\circ}+G_{m}^{\circ}+G_{n-m}^{\circ}}{k T}\right)
\end{aligned}
$$

Hence, in equilibrium, the ratio of number densities of two clusters of sizes $N$ and $M$, with $N>M$, is described by,

$\frac{n_{N}^{\mathrm{eq}}}{n_{M}^{\mathrm{eq}}}=n_{N-M}^{\mathrm{eq}} \frac{k T}{P^{\circ}} \exp \left(\frac{-G_{N}^{\circ}+G_{M}^{\circ}+G_{N-M}^{\circ}}{k T}\right)$.

\section{APPENDIX B: GIBBS FREE ENERGY}

The Gibbs free energy of a system is defined as

$G=H-T S$,

where $H$ is the enthalpy, $S$ is the entropy, and $T$ is the temperature of the system. The enthalpy is defined as

$H=U+P V$,

where $U$ is the internal energy of the system, $P$ is the pressure of the system, and $V$ is the volume of the system. Both entropy and internal energy depend on the configurational freedom of the particles in the system. This configurational freedom or statistical properties of a particle is described by its partition function. When dealing with a system of $N$ non-interacting particles, the system's partition function is given by

$Z_{N}=\frac{1}{N !} Z_{1}^{N}$,

where $Z_{1}$ is the partition function of a single particle.

The entropy for a system consisting of $N$ particles is defined as

$$
\begin{aligned}
S_{N} & =\left.\frac{\partial k T \ln Z_{N}}{\partial T}\right|_{V, N} \\
& =k \ln Z_{N}+\left.k T \frac{\partial \ln Z_{N}}{\partial T}\right|_{V, N}
\end{aligned}
$$


Substituting $Z_{N}$ using equation (B3) yields,

$$
\begin{aligned}
S_{N} & =N k \ln Z_{1}-k \ln (N !)+\left.k T \frac{\partial N \ln Z_{1}-k \ln (N !)}{\partial T}\right|_{V, N} \\
& =N k \ln Z_{1}+\left.N k T \frac{\partial \ln Z_{1}}{\partial T}\right|_{V}-k \ln (N !) \\
& =N S_{1}-k \ln (N !) \\
& \approx N S_{1}-N k \ln N+k N,
\end{aligned}
$$

where the last transition uses Stirling's approximation which is valid for $N \gg 1$. As this quantity is often calculated for one mole $\left(6.022140758 \cdot 10^{23}\right.$ particles $)$, this is a valid approximation.

The internal energy of a system consisting of $N$ particles is defined as

$U_{N}=\left.k T^{2} \frac{\partial \ln Z_{N}}{\partial T}\right|_{V, N}$

Again, substituting $Z_{N}$ with equation (B3), this reduces to

$$
\begin{aligned}
U_{N} & =\left.N k T^{2} \frac{\partial \ln Z_{1}}{\partial T}\right|_{V} \\
& =N U_{1} .
\end{aligned}
$$

Typically, the partition function is calculated with respect to the bottom of the particle's energy well (Sec. B1.4) Therefore this energy value, $U_{0}{ }^{24}$, is separated from the partition function and equation (B7) becomes,

$$
\begin{aligned}
U_{N} & =\left.N k T^{2} \frac{\partial \ln Z_{1}}{\partial T}\right|_{V}+N U_{0} \\
& =N\left(U_{1}+U_{0}\right) .
\end{aligned}
$$

Substituting equations (B2), (B5), and (B8) into (B1), combined with the ideal gas law, yields the Gibbs free energy of a system of $N$ particles,

$G_{N}=N U_{0}-N k T \ln Z_{1}+N k T \ln N$,

which only depends on the total partition function of a single particle and $U_{0}$ of that particle.

\section{B1 Partition functions of one particle}

According to the Born-Oppenheimer approximation rotational, vibrational, and electronic energies are independent of each other, and the partition function of one particle can be written as the product of separate contributors namely translational, rotational, vibrational, and electronic degrees of freedom, $Z_{1}=Z_{\mathrm{tr}} Z_{\mathrm{rot}} Z_{\mathrm{vib}} Z_{\mathrm{el}}$. This section contains a summary of all different partition function for the most general case of a non-linear poly atomic ideal gas, a linear poly atomic ideal gas, and a mono atomic ideal gas.

\footnotetext{
${ }^{24} U_{0}$ is the sum of the electronic ground state and nuclear-nuclear repulsion energies, isolated in vacuum, without vibration at $0 \mathrm{~K}$.
}

\section{B1.1 Translation}

The translational part is always given by

$$
\begin{aligned}
Z_{\mathrm{tr}} & =\left(\frac{2 \pi m k T}{h^{2}}\right)^{3 / 2} V \\
& =\left(\frac{2 \pi m k T}{h^{2}}\right)^{3 / 2} \frac{N k T}{P},
\end{aligned}
$$

where $m$ is the mass of the particle and $h$ is the Planck constant Note that $V$ is the volume of the embedding system meaning that $N$ is the total number of particles of the system in which this one particle resides.

\section{B1.2 Rotation}

(I) Non-linear poly atomic

$$
Z_{\text {rot }}=\frac{1}{\sigma}\left(\frac{\pi T^{3}}{\Theta_{x} \Theta_{y} \Theta_{z}}\right)^{1 / 2},
$$

where $\sigma$ is the molecule's symmetry number ${ }^{25}$, and $\Theta_{i}$ the rotational temperature related to the moments of inertia, $I_{x}, I_{y}, I_{z}$, via

$$
\Theta_{i}=\frac{\hbar^{2}}{2 I_{i} k} \quad i \in\{x, y, z\}
$$

(II) Linear poly atomic

$$
Z_{\text {rot }}=\frac{T \Theta_{\mathrm{rot}}}{\sigma}
$$

where $\Theta_{\text {rot }}$ is the rotational temperature related to the moment of inertia, $I$ via

$$
\Theta=\frac{\hbar^{2}}{2 I k}
$$

(III) Mono atomic

$$
Z_{\text {rot }}=0
$$

Note that this is a high temperature approximation which is valid when the temperature is much larger than rotational temperature, which is the case in all our simulations.

\section{B1.3 Vibration}

A molecules consisting of $N$ atoms has $3 N$ degrees of freedom, where the factor " 3 " corresponds to the possible movements of a particle in three-dimensional space. In the most general case, a molecule has $3 N-3-3=3 N-6$ vibrational degrees of freedom where the " -3 " terms are the translational and rotational degrees of freedom of the molecule. We choose the zero-energy reference point as the bottom of the potential well and not the vibrational ground state.

(1) Non-linear poly atomic

$$
Z_{\mathrm{vib}}=\prod_{\Theta_{v} \in \mathcal{T}_{v}} \frac{e^{-\Theta_{v} / 2 T}}{1-e^{-\Theta_{v} / T}},
$$

25 A molecule's symmetry number is the number of different but indistinguishable views of the molecule to correct for counting equivalent views. 
where $\Theta_{v}$ is the vibrational temperature related to a vibrational frequency $v$ of the molecule via

$\Theta_{v}=\frac{h v}{k}$

when assuming that the vibrational modes of the molecule behave like harmonic oscillators. $\mathcal{T}_{v}$ is the set of all $3 N-6$ vibrational modes of the molecule.

(2) Linear poly atomic

$Z_{\mathrm{vib}}=\prod_{\Theta_{v} \in \mathcal{T}_{v}} \frac{e^{-\Theta_{v} / 2 T}}{1-e^{-\Theta_{v} / T}}$.

Note that $\mathcal{T}_{v}$ only contains $3 N-5$ vibrational modes due to a rotational symmetry of the molecule.

(3) Mono atomic

$Z_{\text {vib }}=0$

\section{B1.4 Electronic}

The electronic part is always given by

$Z_{\mathrm{el}}=\sum_{i=0}^{N_{e}} g_{i} e^{-\epsilon_{i} / k T}$

with $\epsilon_{i}$ the $i$ th electronic energy level w.r.t. the bottom of the electronic potential well, $g_{i}$ the degeneracy of the $i$ th level due to spin splitting and $N_{e}$ the number of energy levels. Each energy level can be scaled by choosing the bottom of the well to be $0^{26}$, giving $\varepsilon_{i}=\epsilon_{i}-\epsilon_{0}$. The number of levels can also be limited to the one where $\varepsilon_{N_{\mathrm{lim}}} \gg k T$.

$Z_{\mathrm{el}}=g_{0}+\sum_{i=1}^{N_{\mathrm{lim}}} g_{i} e^{-\varepsilon_{i} / k T}$

\section{APPENDIX C: GIBBS FREE ENERGY OF FORMATION}

Generally, the standard Gibbs free energy of formation (GFEoF), rather than the Gibbs free energy (GFE), is used to determine reversed reaction rate coefficients under the assumption of detailed balance. Although both can be used, we opt for GFE for reason explained in the main text (Sec. 3.6.2) but explain GFEoF for completeness and comparison. The GFEoF of a compound is the change in GFE that occurs when one mole of the compound is formed from its component elements in their most thermodynamically stable states under standard conditions (pressure of 1 bar $\left.=1 \cdot 10^{5} \mathrm{~Pa}\right)$. Note that this state, depending on the components can be gaseous, solid, or liquid.

Consider a molecule $m$ consisting of $N$ unique atoms with each atom $a$ occurring $v_{a}$ times in the molecule. Then, the set with unique atoms is defined as $\mathcal{A}=\left\{a_{1}, a_{2}, \ldots, a_{N}\right\}$. For an example molecule $m=\mathrm{H}_{2} \mathrm{O}$, this gives $N=2$,

\footnotetext{
26 This energy difference should be added again in the total internal energy of the molecule (Eq. B8.)
}

$\mathcal{A}=\{H, O\}, v_{H}=2$, and $v_{O}=1$. Following the documentation of GaUssian09 (Frisch et al. 2013), the standard GFEoF of molecule $m$ at a given temperature $T, \Delta_{f} G_{T, m}^{\circ}$, is described by

$\Delta_{f} G_{T, m}^{\circ}=\Delta_{f} H_{T, m}^{\circ}-T\left(S_{T, m}^{\circ}-\sum_{a \in \mathcal{A}} v_{a} S_{T, a}^{\circ}\right)$,

where $\Delta_{f} H_{T, m}^{\circ}$ is the standard enthalpy of formation ${ }^{27}$ of molecule $m$ at a given temperature, $S_{T, m}^{\circ}$ and $S_{T, a}^{\circ}$ are the entropy at a given temperature of molecule $m$ and atom $a$, respectively. The ${ }^{\circ}$ notation refers to the quantity at standard pressure of 1 bar $\left(=1 \cdot 10^{5} \mathrm{~Pa}\right)$. The standard enthalpy of formation of molecule $m$ at temperature $T$ is described by

$$
\Delta_{f} H_{T, m}^{\circ}=\Delta_{f} H_{0, m}^{\circ}+H_{T, m}^{\circ}-H_{0, m}^{\circ}-\sum_{a \in \mathcal{A}} v_{a}\left(H_{T, a}^{\circ}-H_{0, a}^{\circ}\right),
$$

where $H_{T}^{\circ}$ denotes the standard (thermal) enthalpy (Eq. B2) which excludes the electronic potential energy $U_{0}{ }^{24}$ of the species. The standard enthalpy of formation of a molecule at absolute zero is given by

$\Delta_{f} H_{0, m}^{\circ}=U_{0, m}+U_{\mathrm{zpve}, m}-\sum_{a \in \mathcal{A}} v_{a}\left(U_{0, a}-\Delta_{f} H_{0, a}^{\circ}\right)$,

where $U_{\mathrm{zpve}, m}$ is the zero point vibration energy of a molecule, which is the lowest vibrational energy (ground state) at $0 \mathrm{~K}$. Note that this is not the bottom of the vibrational potential well (when representing this as harmonic oscillator potential). Combining equations $\mathrm{C} 1, \mathrm{C} 2$, and $\mathrm{C} 3$, and rearranging some terms, the standard GFEoF is given by

$$
\begin{aligned}
\Delta_{f} G_{T, m}^{\circ} & =H_{T, m}^{\circ}-H_{0, m}^{\circ}+U_{0, m}+U_{\mathrm{zpve}, m}-T S_{T, m}^{\circ} \\
& -\sum_{a \in \mathcal{A}} v_{a}\left(H_{T, a}^{\circ}-H_{0, a}^{\circ}+U_{0, a}-\Delta_{f} H_{0, a}^{\circ}-T S_{T, a}^{\circ}\right) .
\end{aligned}
$$

When realising that $H_{0, m}^{\circ}=U_{\mathrm{zpve}, m}$ for a molecule and $H_{0, a}^{\circ}=0$ for an atom, the standard GFEoF reduces to

$$
\begin{aligned}
\Delta_{f} G_{T, m}^{\circ} & =H_{T, m}^{\circ}+U_{0, m}-T S_{T, m}^{\circ} \\
& -\sum_{a \in \mathcal{A}} v_{a}\left(H_{T, a}^{\circ}+U_{0, a}-\Delta_{f} H_{0, a}^{\circ}-T S_{T, a}^{\circ}\right) .
\end{aligned}
$$

\section{APPENDIX D: QUANTUM MECHANICAL DATA}

This section contains an overview of all quantum mechanical data that was collected and calculated (Table D1 for the nucleation species and Table D2 for all other species). All gathered data has been homogenised and is available as a JSON file. A collection of used literature input files (raw

27 The standard enthalpy of formation of a compound is the change of enthalpy during the formation of one mole of that substance from its constituent elements, with all substances in their standard states. For an atom, this is the standard enthalpy of phase transition w.r.t. the phase in its standard state, i.e. the energy that must be supplied as heat at constant pressure per mole to convert from one phase to the other. 
Table D1. Nucleation cluster specifications. All quantum mechanical properties of these clusters are calculated in this work $\left(U_{0}, Z_{1} / Z_{\mathrm{tr}}, \Theta_{\mathrm{rot}}, \Theta_{\mathrm{vib}}\right)$.

\begin{tabular}{llll} 
Cluster & Sizes & Global minimum & $r_{\text {monomer }}(\mathrm{nm})$ \\
\hline $\mathrm{TiO}_{2}$ & $1-10$ & Lamiel-Garcia et al. (2017) & $0.162^{a}$ \\
$\mathrm{SiO}$ & $1-10$ & Bromley et al. (2016) & $0.075765^{b}$ \\
$\mathrm{MgO}$ & $1-10$ & Chen et al. (2014) & $0.0865^{c}$ \\
$\mathrm{Al}_{2} \mathrm{O}_{3}$ & $1-7$ & Li \& Cheng (2012) & $0.3304^{d}$ \\
& 8 & Gobrecht et al. (2018) & \\
\hline
\end{tabular}

Notes: a) Inter atomic Ti-O distance from Jeong et al. (2000). b) Half a $\mathrm{Si}-\mathrm{O}$ bond length from Bromley et al. (2016). c) Half a $\mathrm{Mg}-\mathrm{O}$ bond length from Farrow et al. (2014). d) Inter atomic distance $\mathrm{O}-\mathrm{Al}-\mathrm{O}$ (linear geometry) from Archibong \& St-Amant (1999). All used monomer radii can be more accurate by accounting for the geometry of the non-linear molecules and using our re-evaluated structures (Sec. 6.1.1).

and cleaned versions), reference files, and info files is also available online ${ }^{28}$. All this data was used to calculate Gibbs free energies, which are also available online for the temperature range on our interest 500 to $3000 \mathrm{~K}$ at standard pressure of 1 bar, which also have been included in KROME. Adaptations of these tables can easily be produced with our open-source repository $^{29}$ and the provided data.

\section{APPENDIX E: RESULTS}

This appendix encompasses additional figures of the nucleation models. Figures which are not shown in this appendix are either already present in the main body or provide no added value.

\section{E1 Closed nucleation networks}

This section contains a more thorough overview of all closed nucleation models of all nucleation clusters results.

\section{E1.1 Monomer nucleation}

This section contains a more complete overview of the closed nucleation models using the monomer nucleation description of all nucleation clusters results.

$\mathrm{TiO}_{2}$-clusters: Figs. E1 to E2

MgO-clusters: Figs. E3 to E5

SiO-clusters: Fig. E6

$\mathrm{Al}_{2} \mathrm{O}_{3}$-clusters: Figs. E7 to E9

\section{E1.2 Polymer nucleation}

This section contains a more complete overview of the closed nucleation models using the polymer nucleation description of all nucleation clusters results.

$\mathrm{TiO}_{2}$-clusters: Figs. E10 to E11

MgO-clusters: Figs. E12 to E14

SiO-clusters: Fig. E15

$\mathrm{Al}_{2} \mathrm{O}_{3}$-clusters: Figs. E16 to E18

\section{E1.3 Polymer nucleation compared with equilibrium}

This section contains figures which compare the relative ratios of nucleation clusters of the closed nucleation models w.r.t. the equilibrium ratios (Figs. E19 to E21).

\section{E2 Comprehensive chemical nucleation networks}

This section contains a more complete overview of all nucleation clusters results in the comprehensive chemical nucleation model using the polymer nucleation description. No Mg-related figures are shown as it remains completely atomic.

\section{E2.1 Ti-bearing species}

This section contains a more complete overview of all Tibearing species results in the comprehensive chemical nucleation model using the polymer nucleation description (Figs. E22, E23).

\section{E2.2 Si-bearing species}

This section contains a more complete overview of all Sibearing species results in the comprehensive chemical nucleation model using the polymer nucleation description (Fig. E24).
28 Zenodo: https://zenodo.org/record/3356710

29 https://bitbucket.org/JelsB/thermochemistry 
Table D2. Overview of the sources of all quantum mechanical data, either gathered or calculated, as defined in Appendix B.

\begin{tabular}{|c|c|c|c|c|c|}
\hline Species & Global minimum & $U_{0}$ & $Z_{1} / Z_{\mathrm{tr}}$ & $\Theta_{\text {rot }}, \Theta_{\text {vib }}$ & $\varepsilon_{i}$ \\
\hline $\mathrm{TiO}$ & - & $\mathrm{CCCBDB}$ & Kurucz $(1992)^{a}$ & - & Phillips $(1971)^{c}$ \\
\hline $\mathrm{CO}_{2}$ & - & $\mathrm{CCCBDB}$ & Rothman et al. $(2010)^{a}$ & - & Herzberg $(1966)^{e}$ \\
\hline $\mathrm{OH}$ & - & CCCBDB & Rothman et al. $(2010)^{a}$ & - & Huber \& Herzberg $(1979)^{e}$ \\
\hline $\mathrm{AlO}$ & - & CCCBDB & Patrascu et al. $(2015)^{a}$ & - & - \\
\hline $\mathrm{AlH}$ & - & CCCBDB & Yurchenko et al. $(2018)^{a}$ & - & - \\
\hline NO & - & CCCBDB & Wong et al. $(2017)^{a}$ & - & Huber \& Herzberg $(1979)^{e}$ \\
\hline $\mathrm{CO}$ & - & CCCBDB & Li et al. $(2015)^{a}$ & - & - \\
\hline $\mathrm{SO}$ & - & $\mathrm{CCCBDB}$ & Gamache et al. $(2017)^{b}$ & - & $? c$ \\
\hline $\mathrm{SO}_{2}$ & - & CCCBDB & Gamache et al. $(2017)^{b}$ & - & Herzberg $(1966)^{e}$ \\
\hline $\mathrm{HO}_{2}$ & - & CCCBDB & Gamache et al. $(2017)^{b}$ & - & - \\
\hline $\mathrm{H}_{2} \mathrm{O}_{2}$ & - & CCCBDB & Gamache et al. $(2017)^{b}$ & - & - \\
\hline $\mathrm{O}_{2}$ & - & CCCBDB & Gamache et al. $(2017)^{b}$ & - & Huber \& Herzberg $(1979)^{e}$ \\
\hline $\mathrm{N}_{2}$ & - & CCCBDB & Gamache et al. $(2017)^{b}$ & - & - \\
\hline $\mathrm{N}_{2} \mathrm{O}$ & - & CCCBDB & Gamache et al. $(2017)^{b}$ & - & Herzberg $(1966)^{e}$ \\
\hline $\mathrm{NO}_{2}$ & - & $\mathrm{CCCBDB}$ & Gamache et al. $(2017)^{b}$ & - & $? e$ \\
\hline $\mathrm{H}_{2} \mathrm{O}$ & - & $\mathrm{CCCBDB}$ & Furtenbacher et al. $(2016)^{f}$ & - & - \\
\hline $\mathrm{H}_{2}$ & - & CCCBDB & Popovas \& Jørgensen (2016) & - & Huber \& Herzberg $(1979)^{e}$ \\
\hline $\mathrm{AlC}$ & - & $\mathrm{CCCBDB}$ & $V$ & CCCBDB & - \\
\hline $\mathrm{AlH}_{2}$ & - & CCCBDB & $\checkmark$ & CCCBDB & - \\
\hline $\mathrm{AlH}_{3}$ & - & $\mathrm{CCCBDB}$ & $\checkmark$ & CCCBDB & - \\
\hline $\mathrm{HCO}$ & - & CCCBDB & $\checkmark$ & CCCBDB & Johns et al. (1963) $)^{e, g}$ \\
\hline $\mathrm{HO}_{2}$ & - & $\mathrm{CCCBDB}$ & $\checkmark$ & CCCBDB & Becker et al. $(1978)^{e, h}$ \\
\hline $\mathrm{MgO}$ & - & $\mathrm{CCCBDB}$ & $\checkmark$ & CCCBDB & Bauschlicher \& Schwenke $(2017)^{i}$, Huber \& Herzberg \\
\hline $\mathrm{MgOH}$ & - & CCCBDB & $\checkmark$ & CCCBDB & - \\
\hline $\mathrm{Mg}(\mathrm{OH})_{2}$ & - & CCCBDB & $\checkmark$ & CCCBDB & - \\
\hline $\mathrm{MgCO}_{3}$ & - & $\mathrm{CCCBDB}$ & & CCCBDB & - \\
\hline $\mathrm{O}_{3}$ & - & $\mathrm{CCCBDB}$ & $\checkmark$ & CCCBDB & - \\
\hline $\mathrm{SiO}_{2}$ & - & CCCBDB & $V$ & CCCBDB & - \\
\hline $\mathrm{AlO}_{2}$ & Patzer et al. (2005) & & & $\checkmark$ & - \\
\hline $\mathrm{Al}_{2} \mathrm{O}$ & Patzer et al. (2005) & & & $\checkmark$ & - \\
\hline $\mathrm{Al}_{2} \mathrm{O}_{2}$ & Patzer et al. (2005) & & $\checkmark$ & $\checkmark$ & - \\
\hline $\mathrm{AlOH}$ & $V$ & & $\checkmark$ & $\checkmark$ & - \\
\hline $\mathrm{AlO}_{2} \mathrm{H}$ & $\checkmark$ & & $\checkmark$ & $\checkmark$ & - \\
\hline $\mathrm{Al}(\mathrm{OH})_{2}$ & $\checkmark$ & & $\checkmark$ & $\checkmark$ & - \\
\hline $\mathrm{Al}(\mathrm{OH})_{3}$ & $\checkmark$ & & $\checkmark$ & $\checkmark$ & - \\
\hline $\mathrm{H}$ & $x$ & CCCBDB & $x$ & $x$ & - \\
\hline $\mathrm{C}$ & $x$ & $\mathrm{CCCBDB}$ & $x$ & $x$ & Haris \& Kramida (2017); Beckmann et al. $(1975)^{d}$ \\
\hline $\mathrm{Mg}$ & $x$ & & $x$ & $x$ & - \\
\hline $\mathrm{N}$ & $x$ & & $x$ & $x$ & - \\
\hline $\mathrm{O}$ & $x$ & & $x$ & $x$ & Moore $(1993)^{d}$ \\
\hline $\mathrm{Si}$ & $x$ & 1 & $x$ & $x$ & Martin \& Zalubas $(1983)^{d}$ \\
\hline $\mathrm{Al}$ & $x$ & $\checkmark$ & $x$ & $x$ & Martin \& Zalubas $(1979)^{d}$ \\
\hline $\mathrm{Ti}$ & $x$ & & $x$ & $x$ & Saloman $(2012)^{d}$ \\
\hline
\end{tabular}

Legend: $\checkmark$ : This work, $\boldsymbol{x}$ : Not applicable, -: Unnecessary, ?: No references provided, CCCBDB: NIST Computational Chemistry Comparison and Benchmark Database (Johnson 2018).

a) via ExoMol (http://exomol.com/). b) via HITRAN (Gordon et al. 2017). c) via NIST chemistry WebBook (https://doi.org/ 10.18434/T4D303). d) via NIST Atomic Spectra Database (Kramida et al. 2018). e) via CCCBDB (Johnson 2018) f) Uses $g$ = 1 and $g=3$ as para-ortho degeneracy which is preferred over using $g=1 / 4$ and $g=3 / 4$ like Vidler \& Tennyson (2000). g) The most likely reference of list of the references provided by NIST chemistry WebBook (https://doi.org/10.18434/T4D303). h) Unclear reference for the second energy level. i) First level: improved theoretical value over the theoretical one of Huber \& Herzberg (1979). 
E2.3 Al-bearing species

This section contains a more complete overview of all Albearing species results in the comprehensive chemical nucleation model using the polymer nucleation description (Figs. E25, E26).

\section{APPENDIX F: CHEMICAL NETWORK}

This appendix lists all the used reactions with their reaction rate coefficient and the source of this data (Tab. F1). This is the comprehensive chemical network used in this paper. Subsets of this network are not explicitly listed, i.e. the closed nucleation networks. 

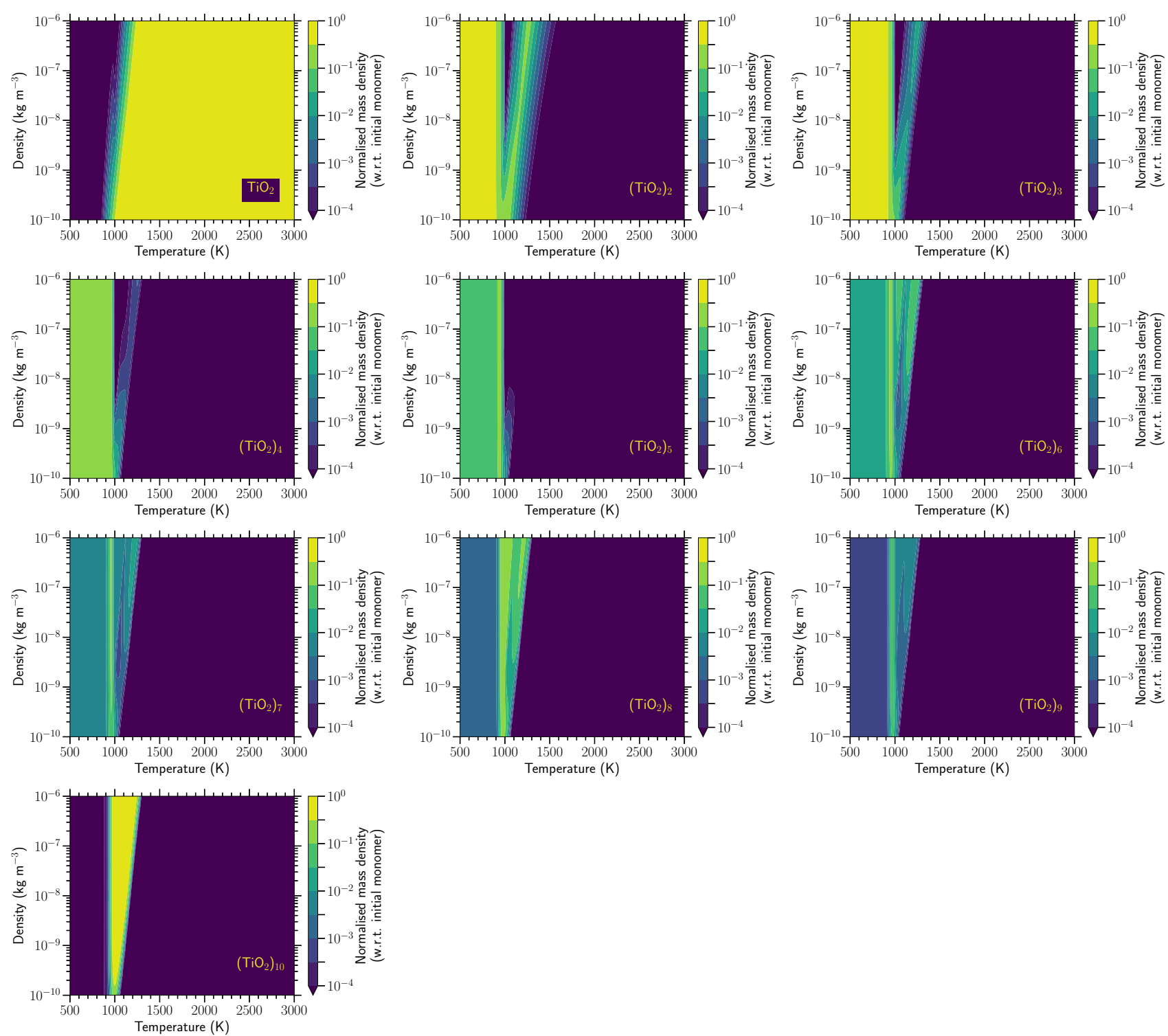

Figure E1. Overview of the normalised mass density after one year of all $\mathrm{TiO}_{2}$-clusters for a closed nucleation model using the monomer nucleation description. 

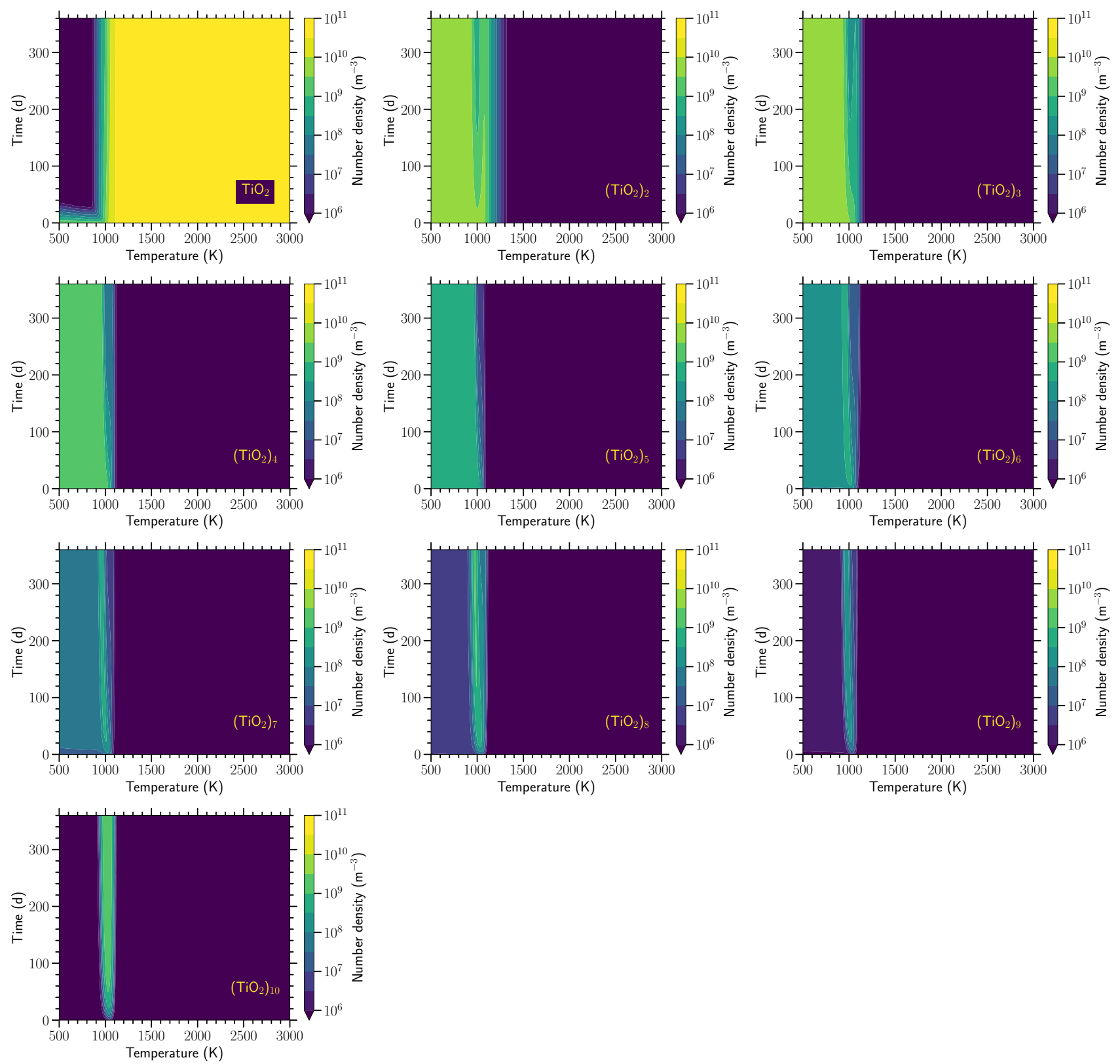

Figure E2. Temporal evolution of the absolute number density of all $\mathrm{TiO}_{2}$-clusters at the benchmark total gas density $\rho=1 \cdot 10^{-9} \mathrm{~kg} \mathrm{~m}^{-3}$ for a closed nucleation model using the monomer nucleation description. 

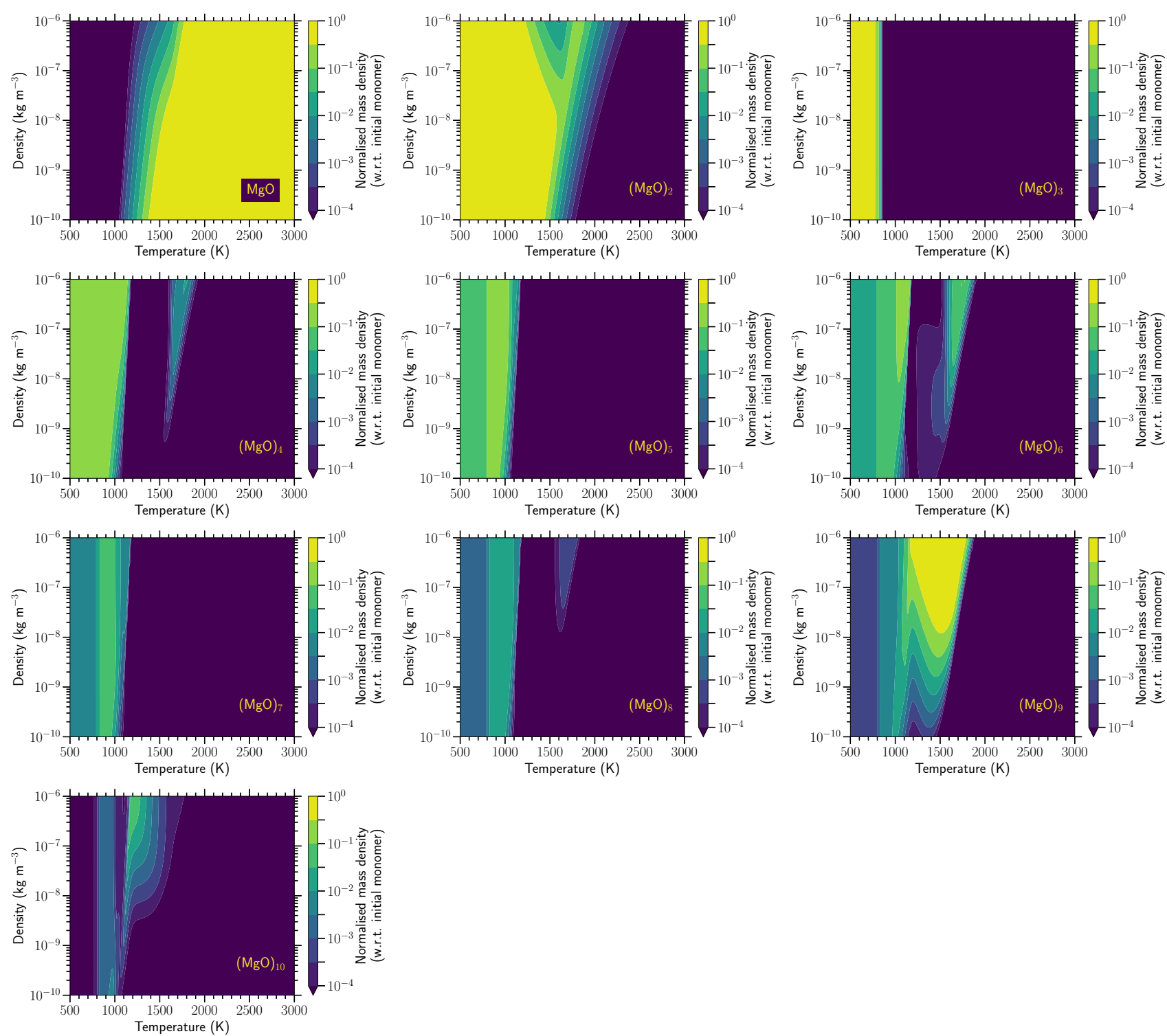

Figure E3. Overview of the normalised mass density after one year of all MgO-clusters for a closed nucleation model using the monomer nucleation description. 

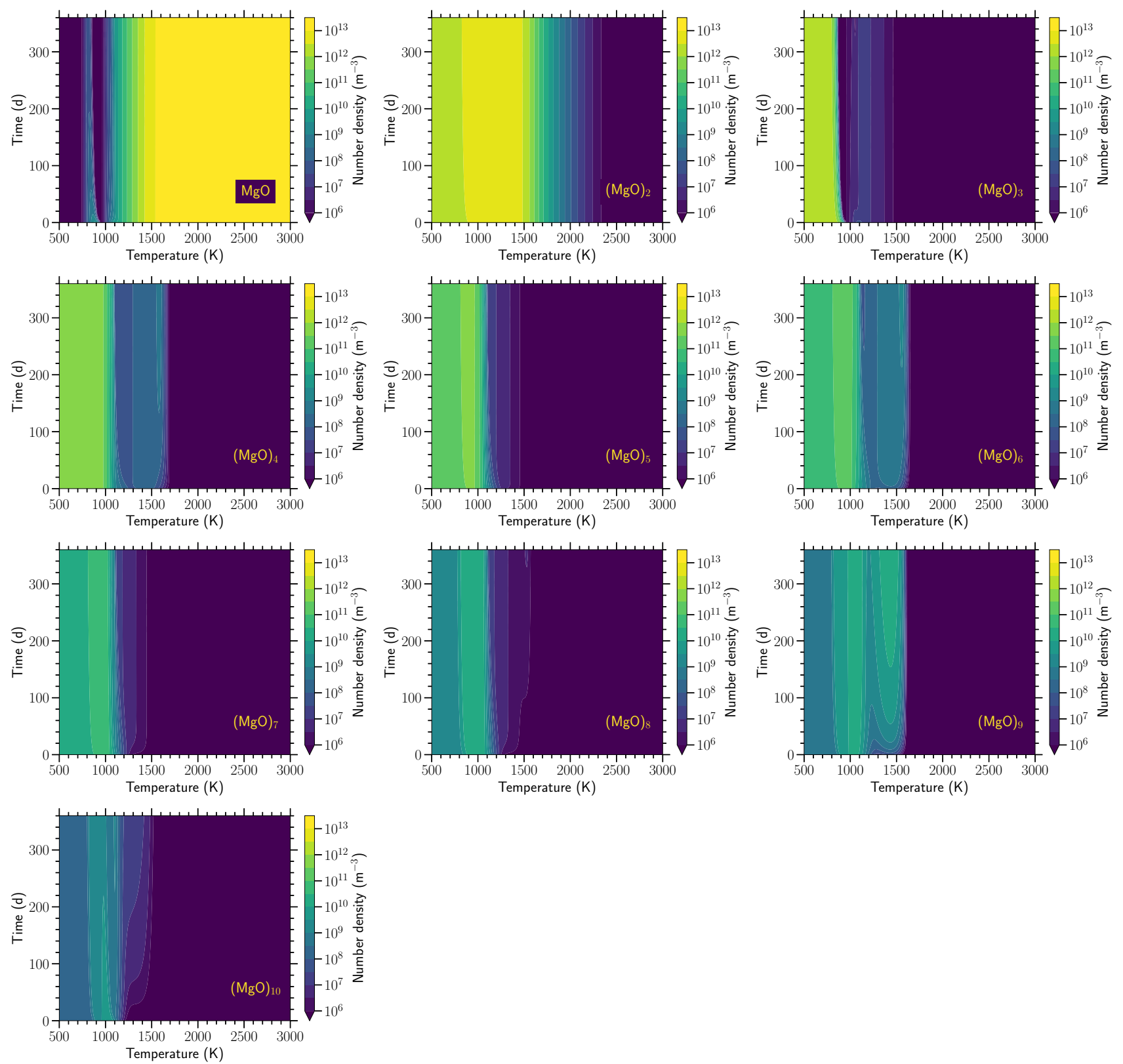

Figure E4. Temporal evolution of the absolute number density of all $\mathrm{MgO}$-clusters at the benchmark total gas density $\rho=1 \cdot 10^{-9} \mathrm{~kg} \mathrm{~m}^{-3}$ for a closed nucleation model using the monomer nucleation description. 

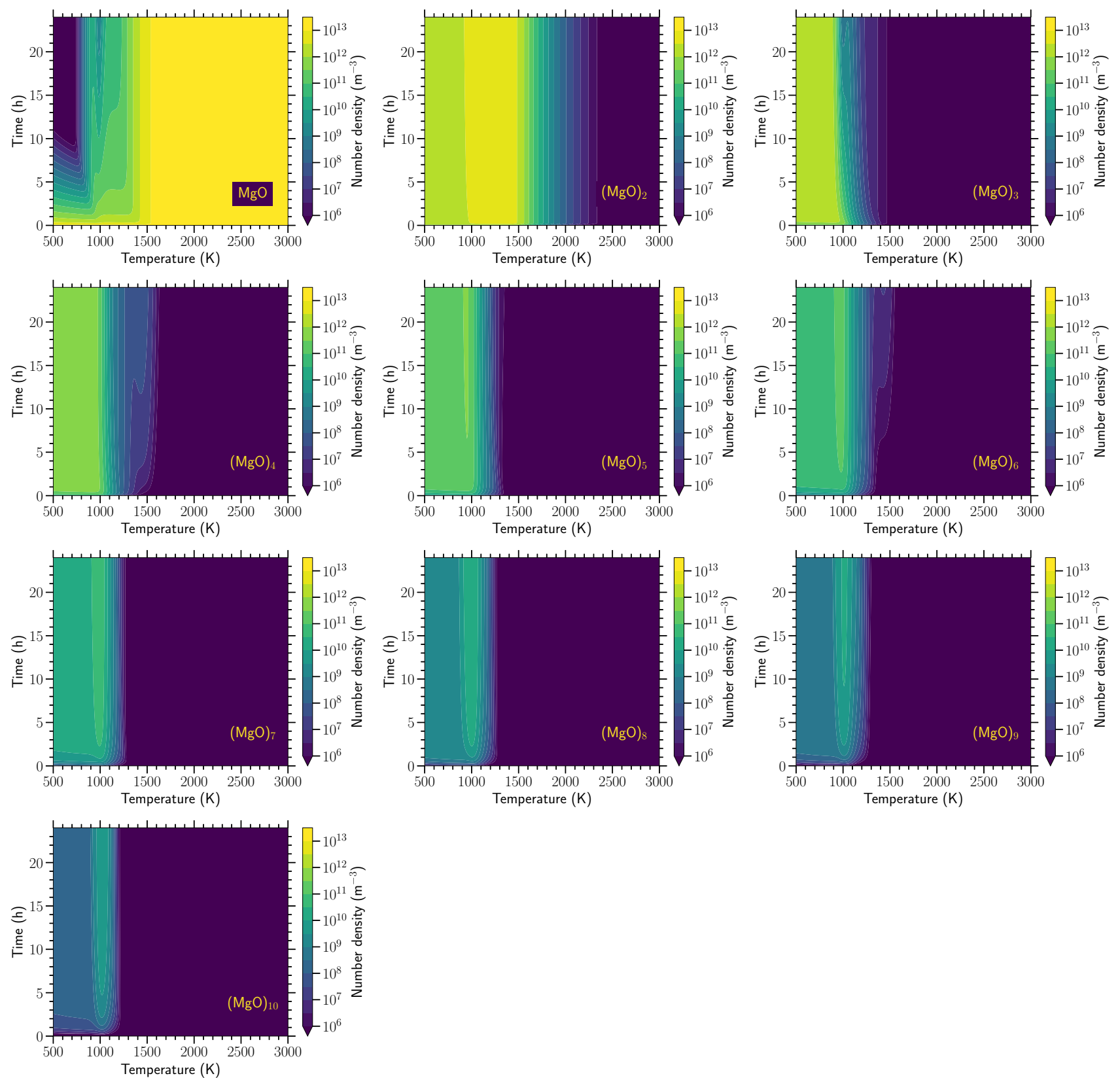

Figure E5. Refined temporal evolution of the absolute number density of all MgO-clusters at the benchmark total gas density $\rho=$ $1 \cdot 10^{-9} \mathrm{~kg} \mathrm{~m}^{-3}$ for a closed nucleation model using the monomer nucleation description. 

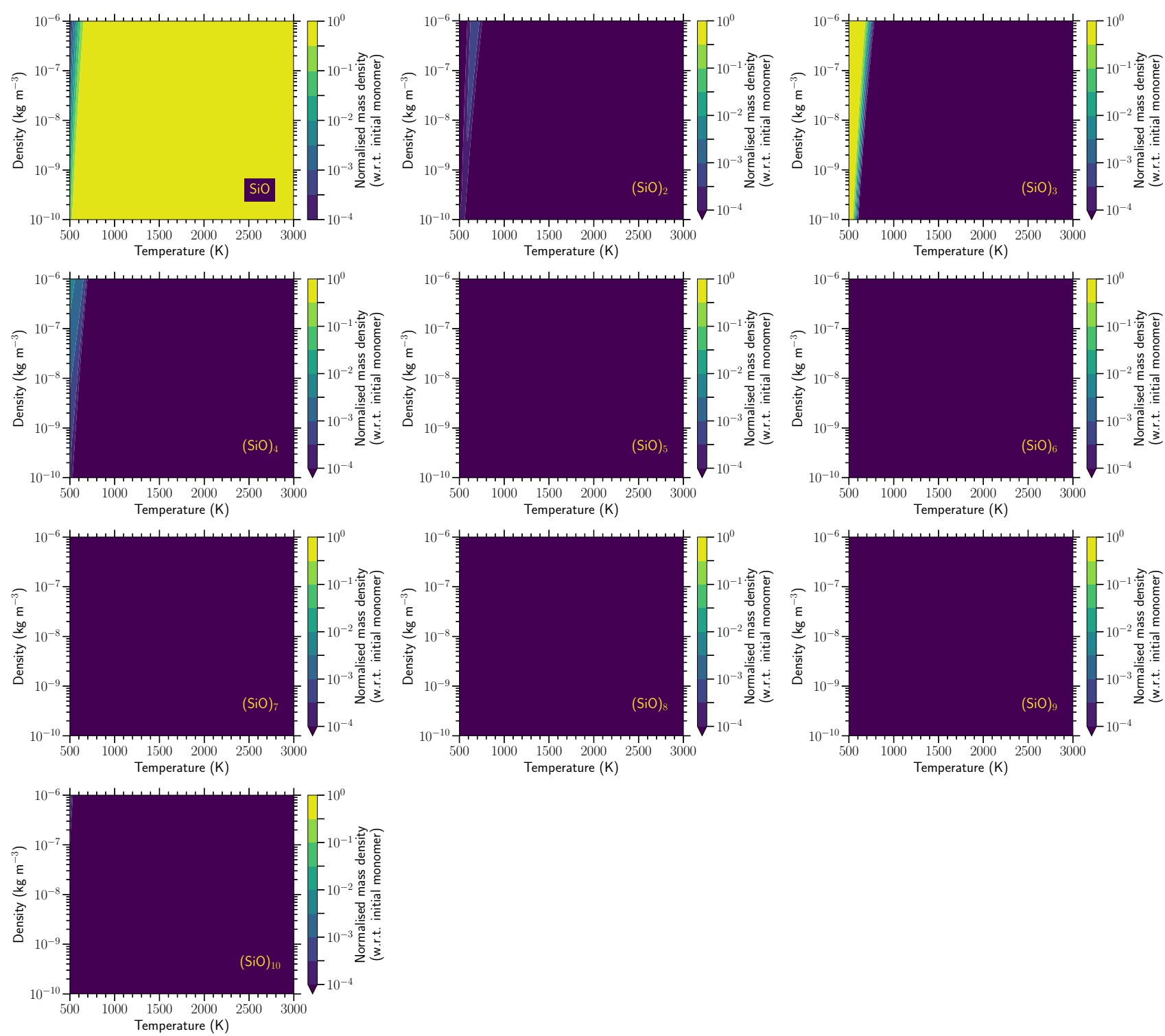

Figure E6. Overview of the normalised mass density after one year of all SiO-clusters for a closed nucleation model using the monomer nucleation description. 

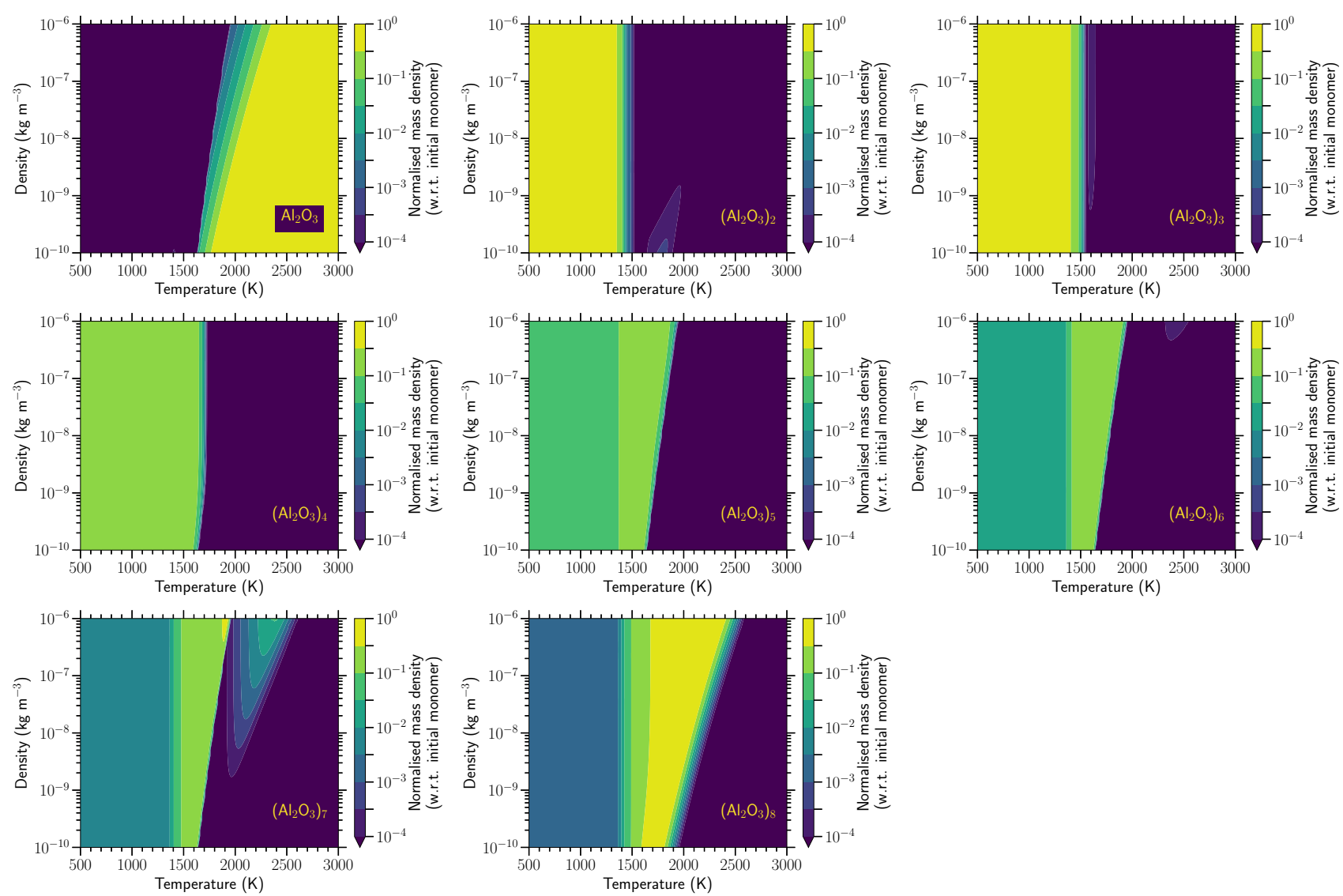

Figure E7. Overview of the normalised mass density after one year of all $\mathrm{Al}_{2} \mathrm{O}_{3}$-clusters for a closed nucleation model using the monomer nucleation description. 

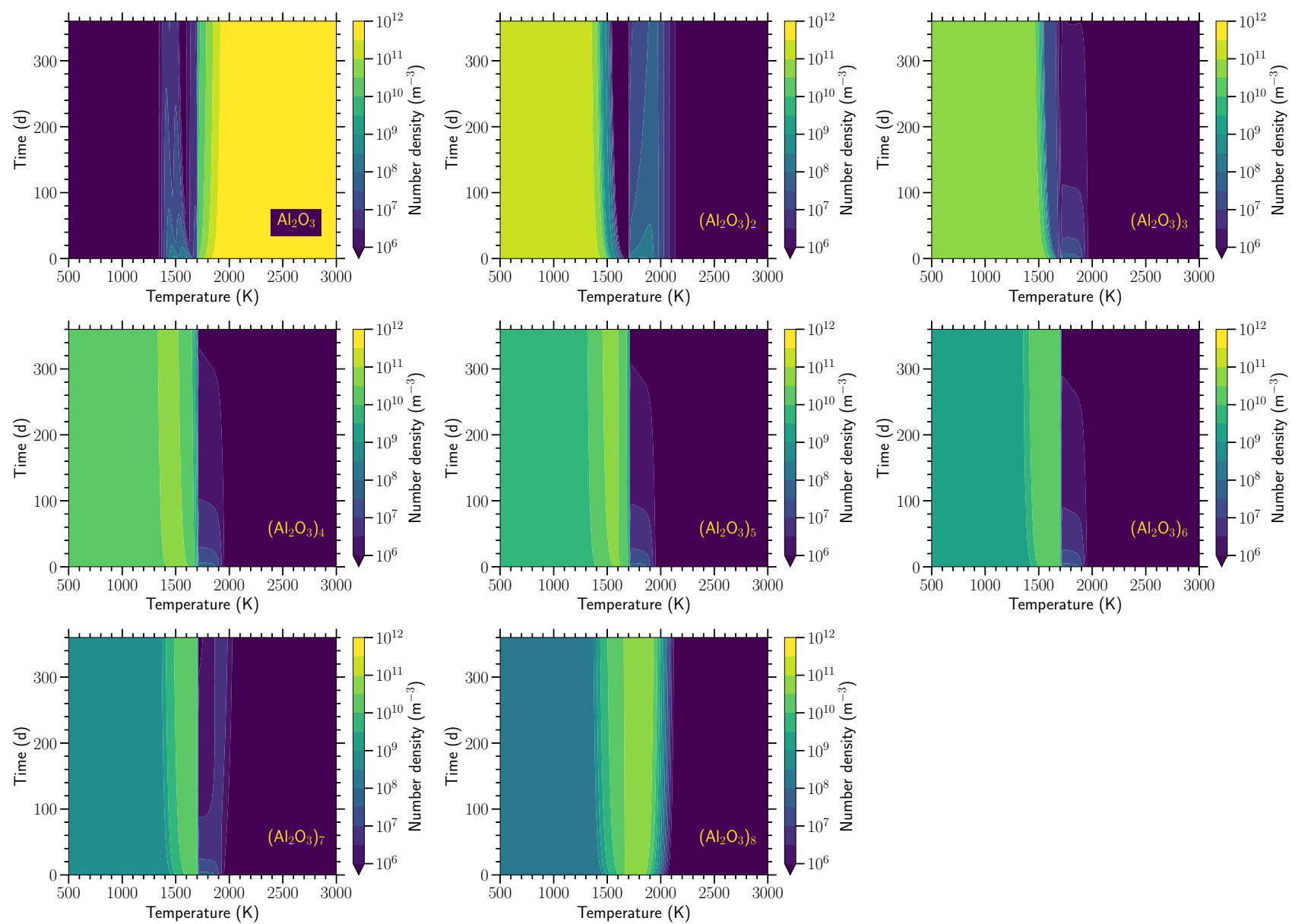

Figure E8. Temporal evolution of the absolute number density of all $\mathrm{Al}_{2} \mathrm{O}_{3}$-clusters at the benchmark total gas density $\rho=1 \cdot 10^{-9} \mathrm{~kg} \mathrm{~m}^{-3}$ for a closed nucleation model using the monomer nucleation description. 

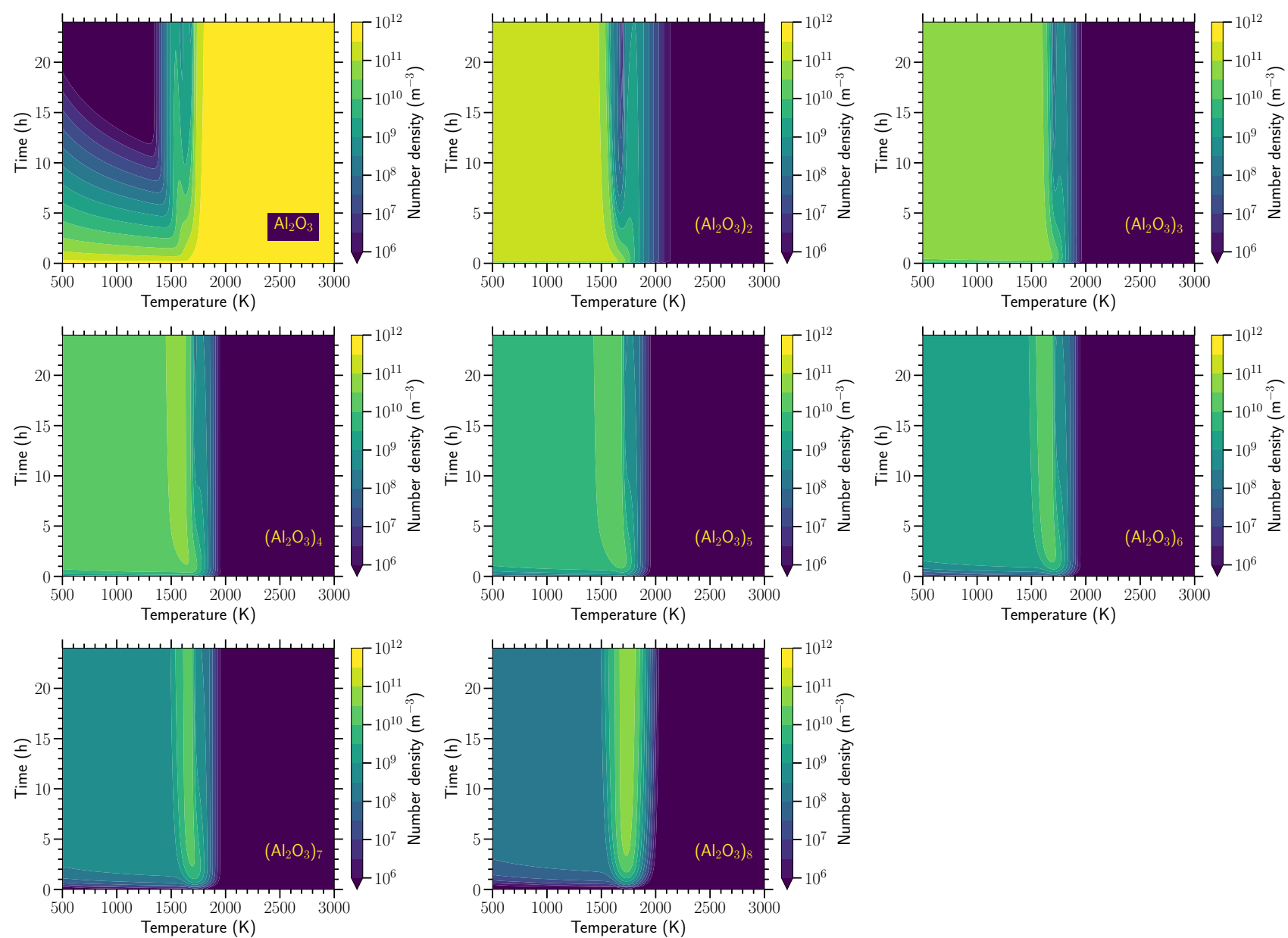

Figure E9. Refined temporal evolution of the absolute number density of all $\mathrm{Al}_{2} \mathrm{O}_{3}$-clusters at the benchmark total gas density $\rho=$ $1 \cdot 10^{-9} \mathrm{~kg} \mathrm{~m}^{-3}$ for a closed nucleation model using the monomer nucleation description. 

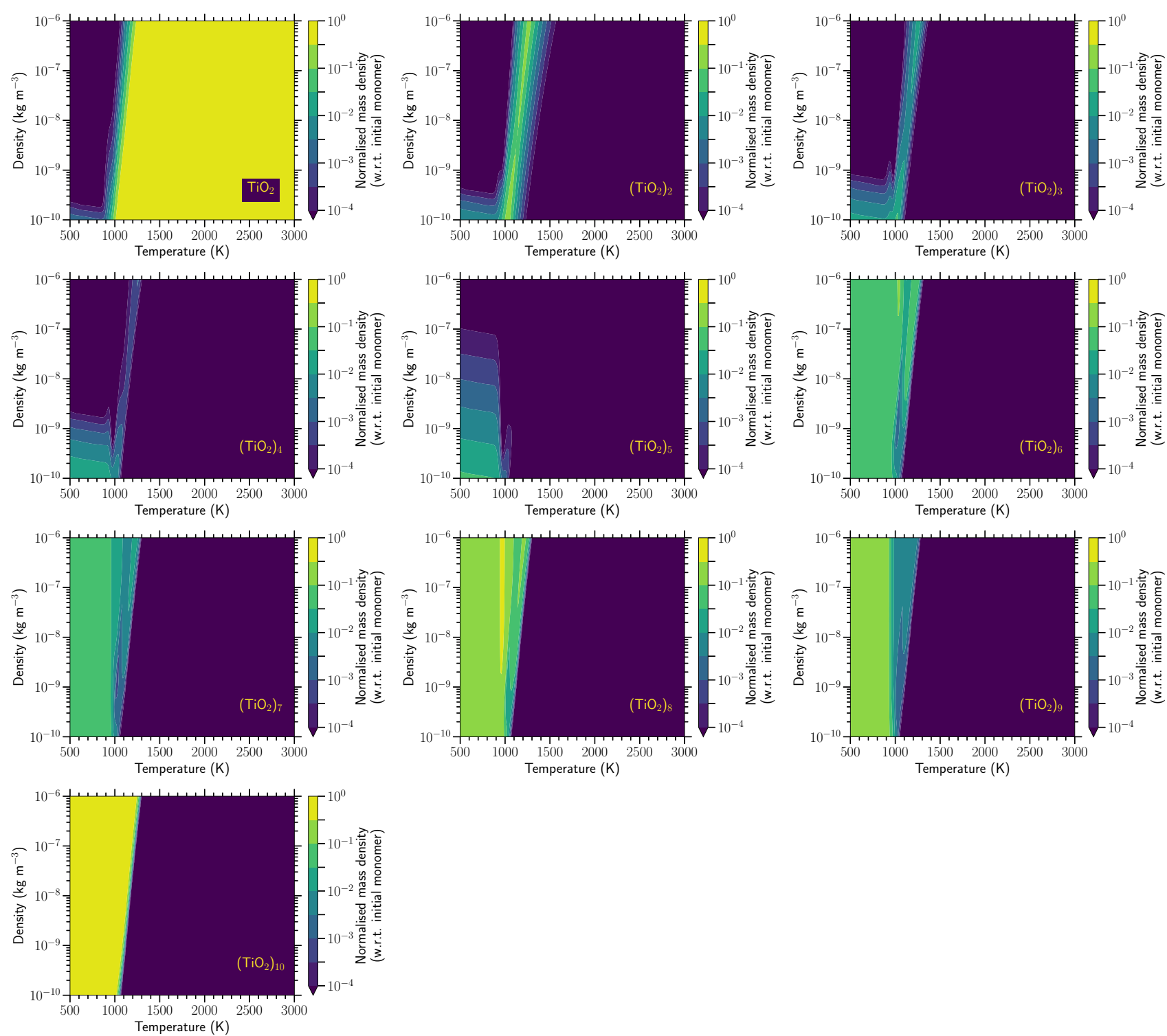

Figure E10. Overview of the normalised mass density after one year of all $\mathrm{TiO}_{2}$-clusters for a closed nucleation model using the polymer nucleation description. 

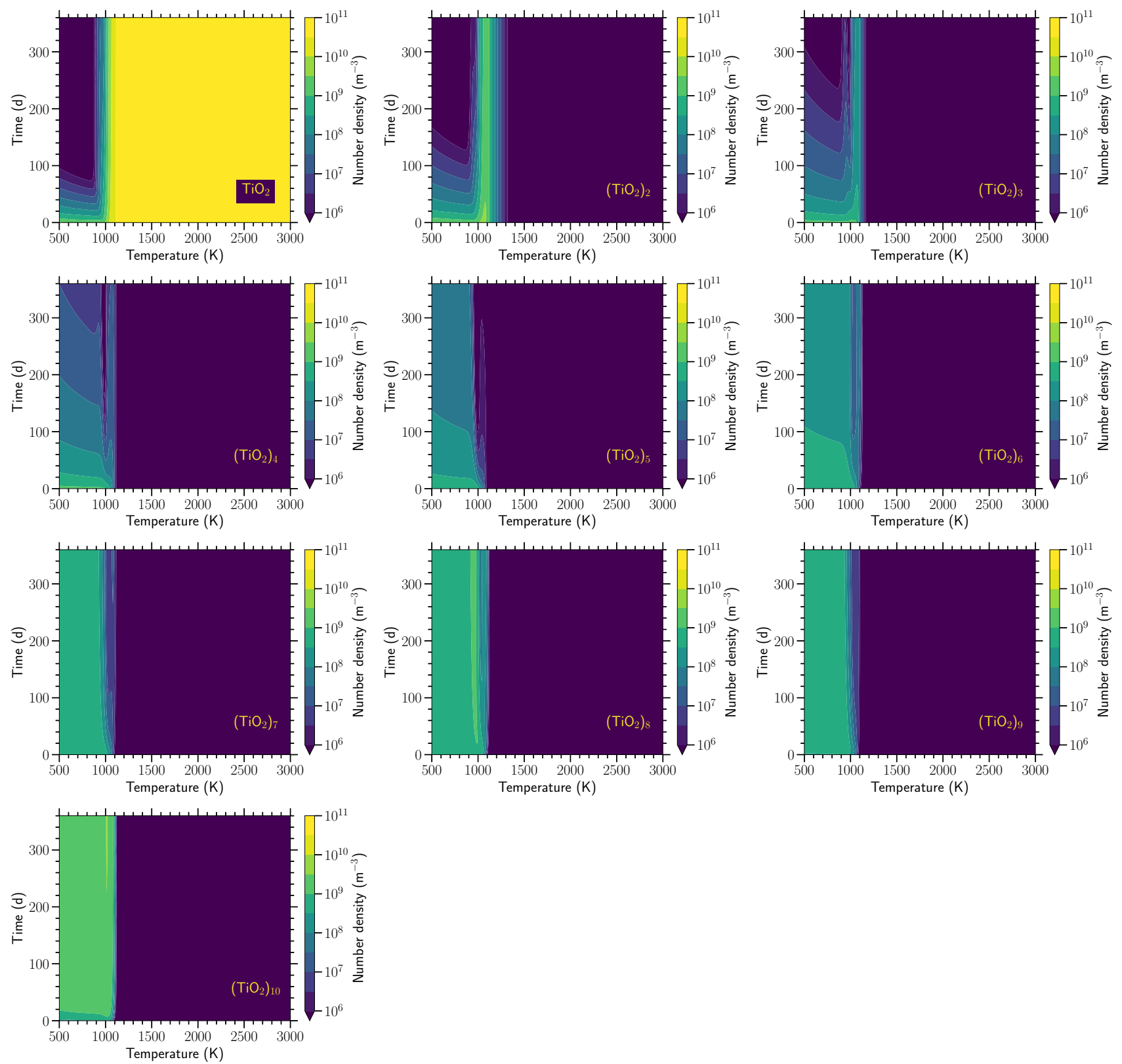

Figure E11. Temporal evolution of the absolute number density of all $\mathrm{TiO}_{2}$-clusters at the benchmark total gas density $\rho=1 \cdot 10^{-9} \mathrm{~kg} \mathrm{~m}^{-3}$ for a closed nucleation model using the polymer nucleation description. 

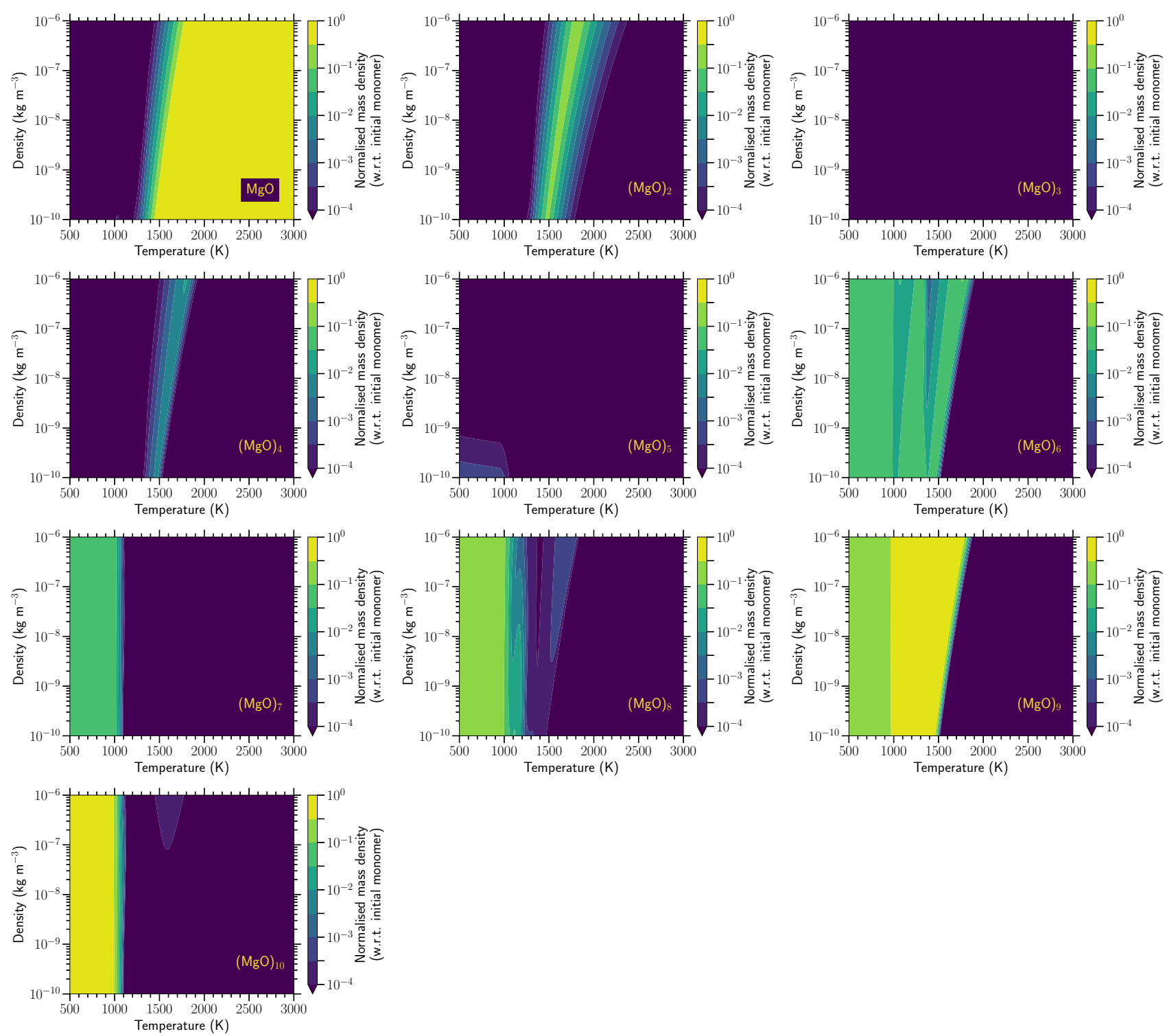

Figure E12. Overview of the normalised mass density after one year of all MgO-clusters for a closed nucleation model using the polymer nucleation description. 

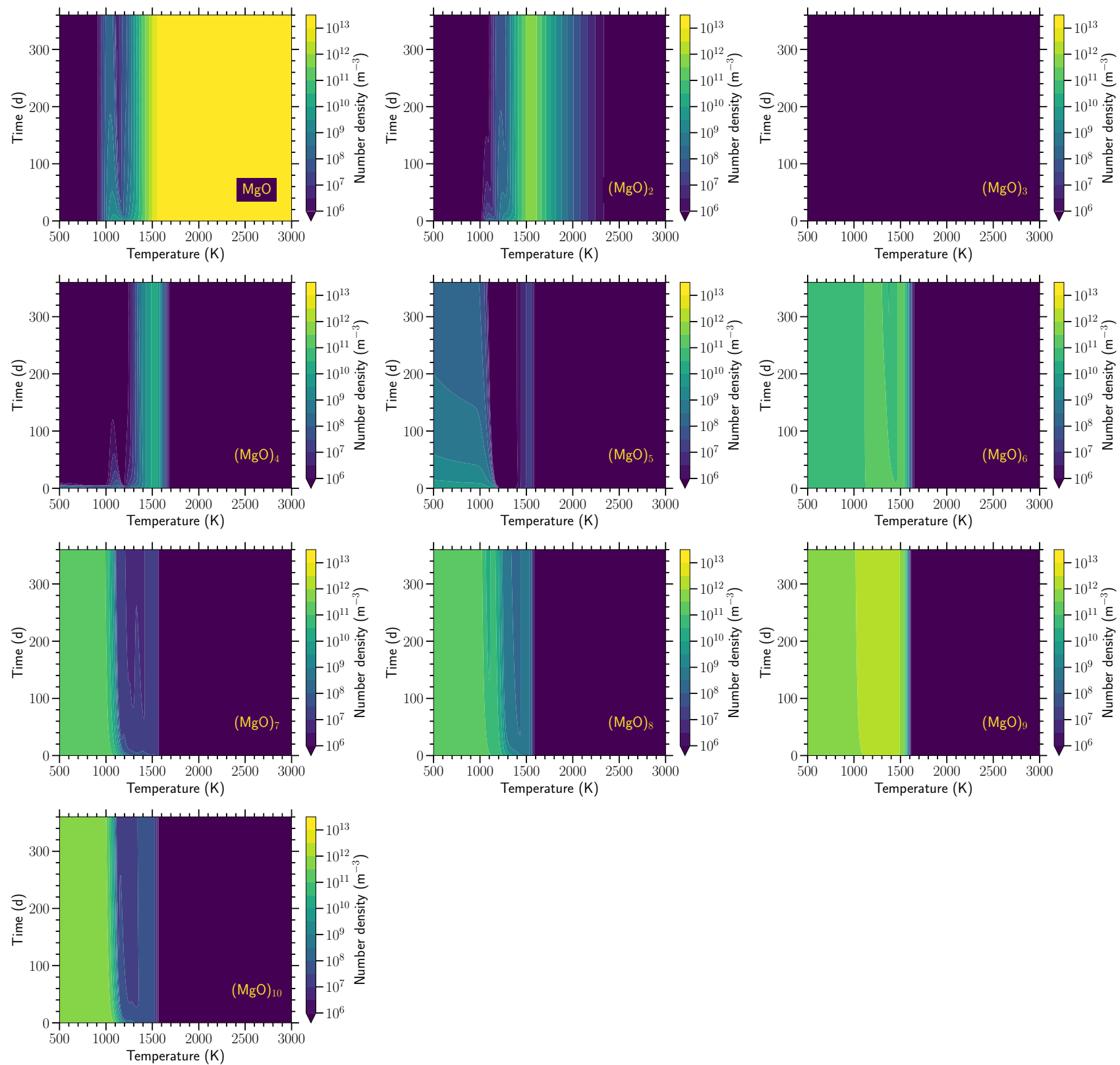

Figure E13. Temporal evolution of the absolute number density of all $\mathrm{MgO}$-clusters at the benchmark total gas density $\rho=1 \cdot 10^{-9} \mathrm{~kg} \mathrm{~m}^{-3}$ for a closed nucleation model using the polymer nucleation description. 

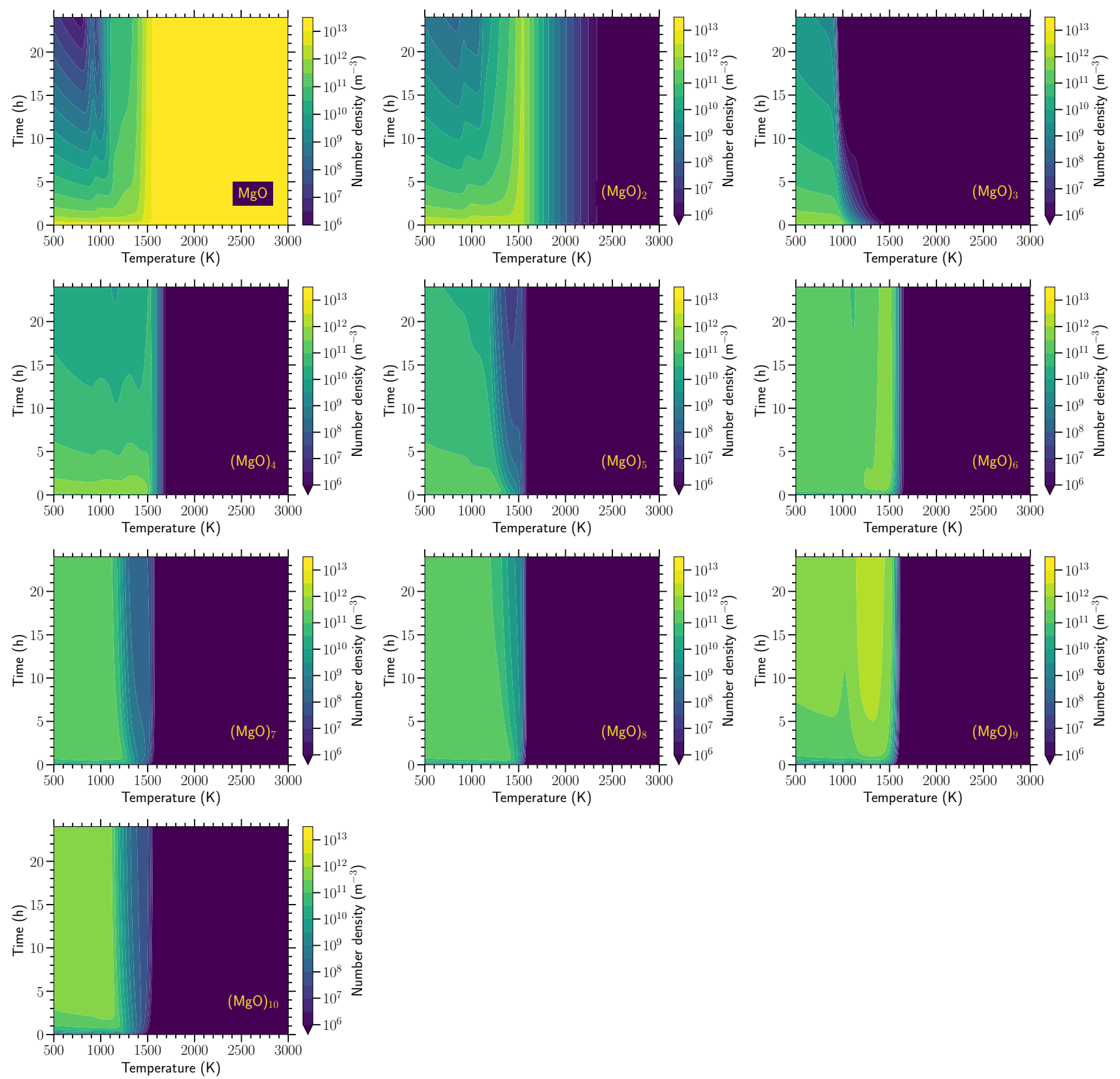

Figure E14. Refined temporal evolution of the absolute number density of all MgO-clusters at the benchmark total gas density $\rho=1 \cdot 10^{-9} \mathrm{~kg} \mathrm{~m}^{-3}$ for a closed nucleation model using the polymer nucleation description. 

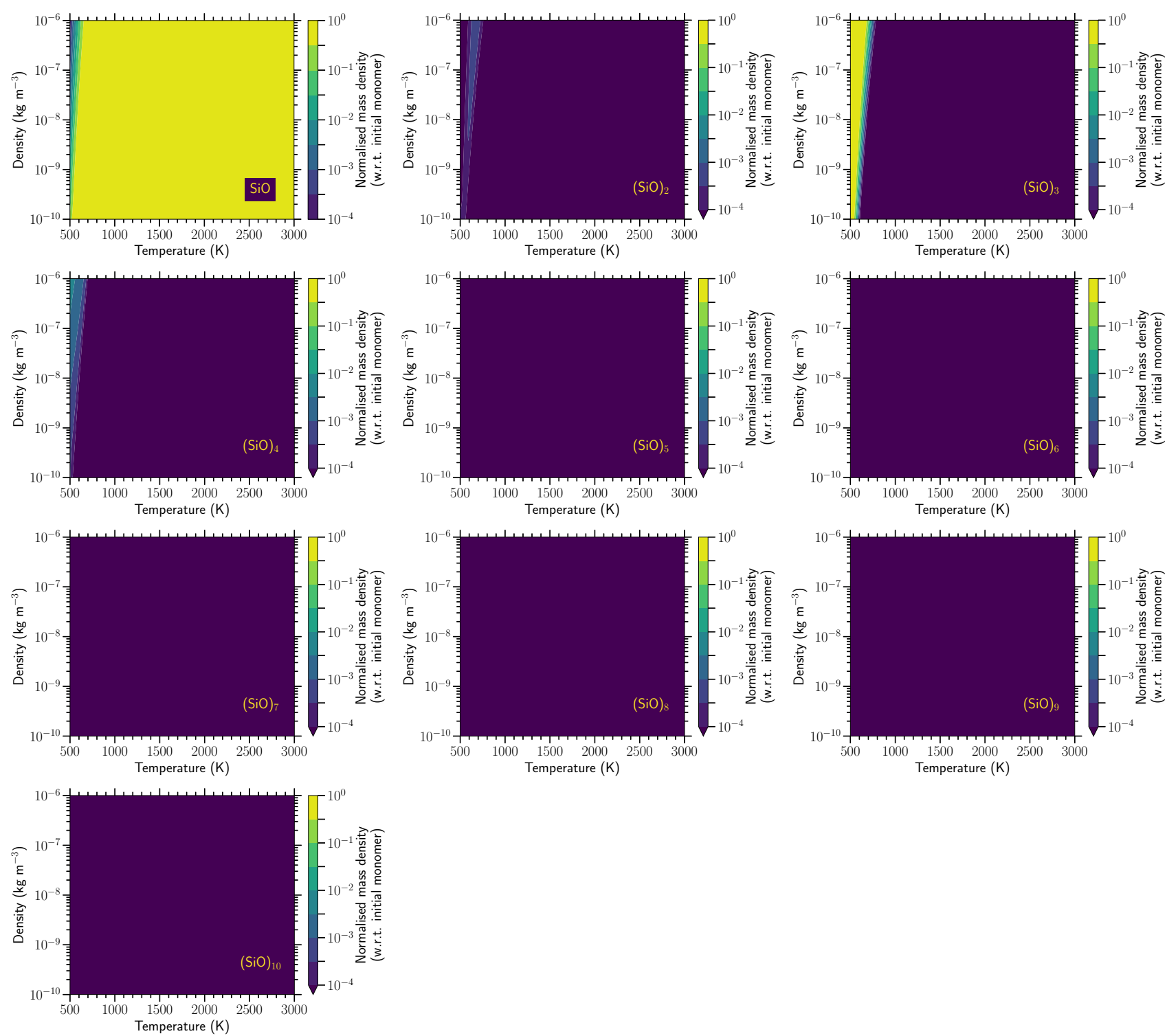

Figure E15. Overview of the normalised mass density after one year of all SiO-clusters for a closed nucleation model using the polymer nucleation description. 

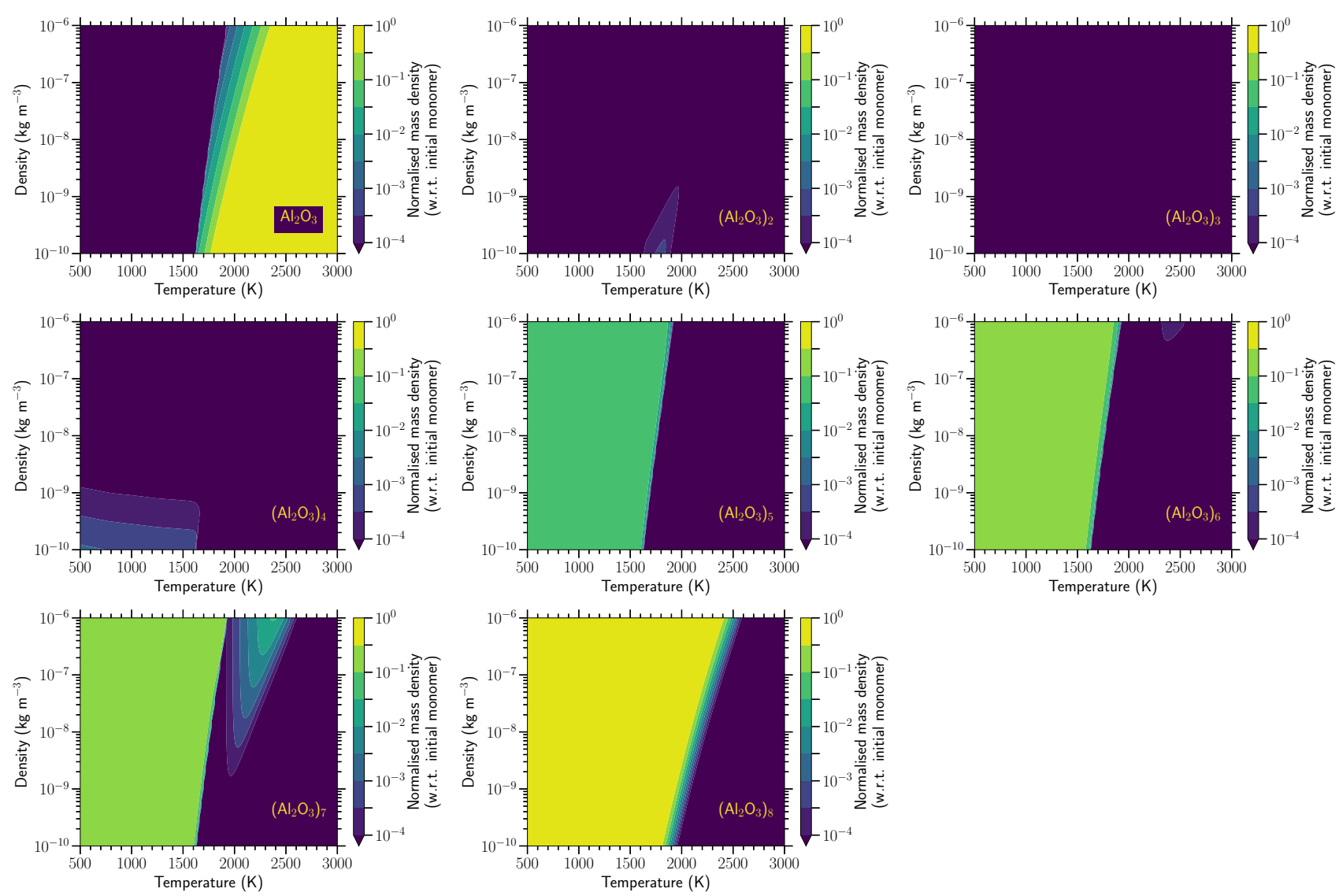

Figure E16. Overview of the normalised mass density after one year of all $\mathrm{Al}_{2} \mathrm{O}_{3}$-clusters for a closed nucleation model using the polymer nucleation description. 

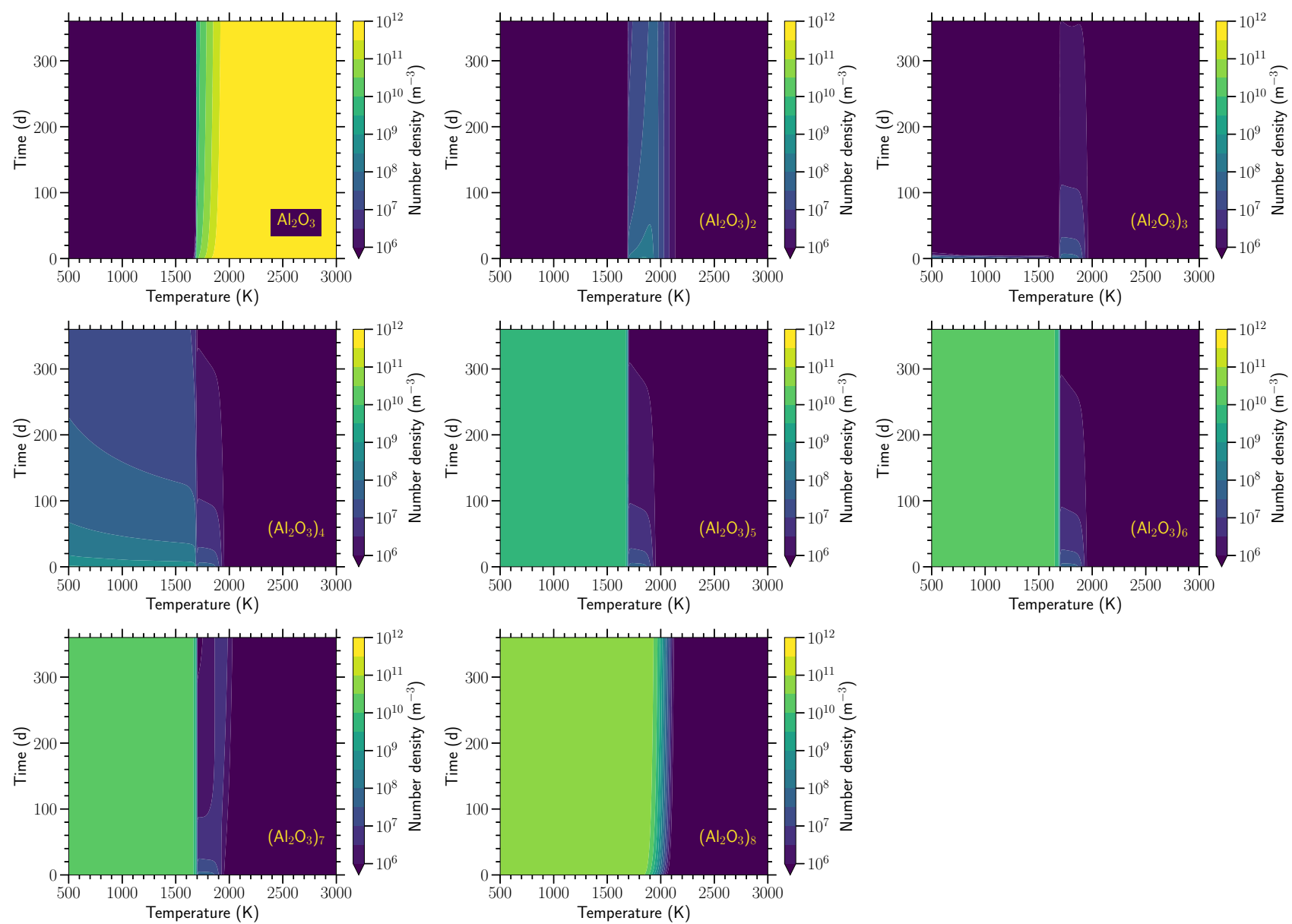

Figure E17. Temporal evolution of the absolute number density of all $\mathrm{Al}_{2} \mathrm{O}_{3}$-clusters at the benchmark total gas density $\rho=$ $1 \cdot 10^{-9} \mathrm{~kg} \mathrm{~m}^{-3}$ for a closed nucleation model using the polymer nucleation description. 

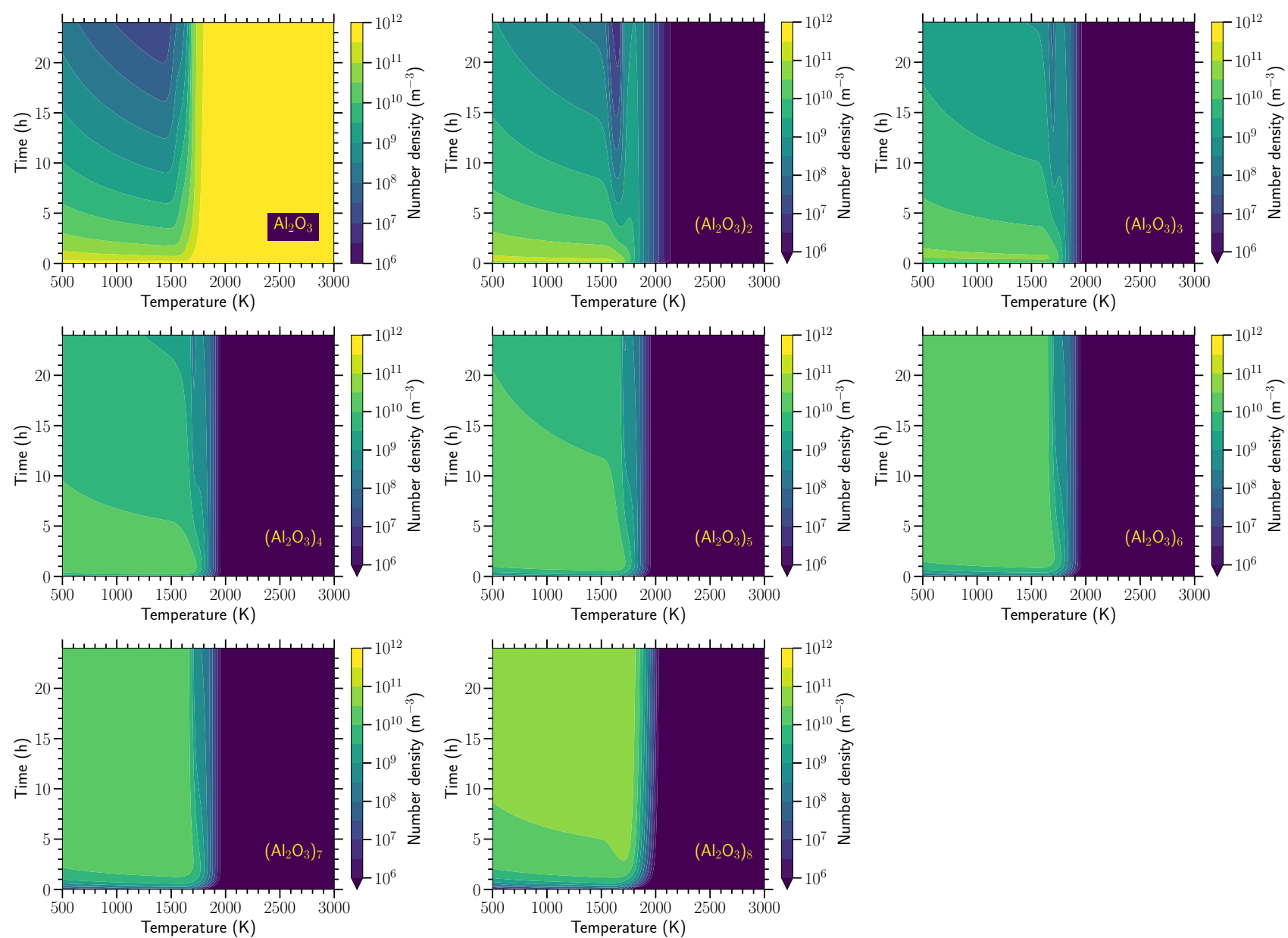

Figure E18. Refined temporal evolution of the absolute number density of all $\mathrm{Al}_{2} \mathrm{O}_{3}$-clusters at the benchmark total gas density $\rho=1 \cdot 10^{-9} \mathrm{~kg} \mathrm{~m}^{-3}$ for a closed nucleation model using the polymer nucleation description. 


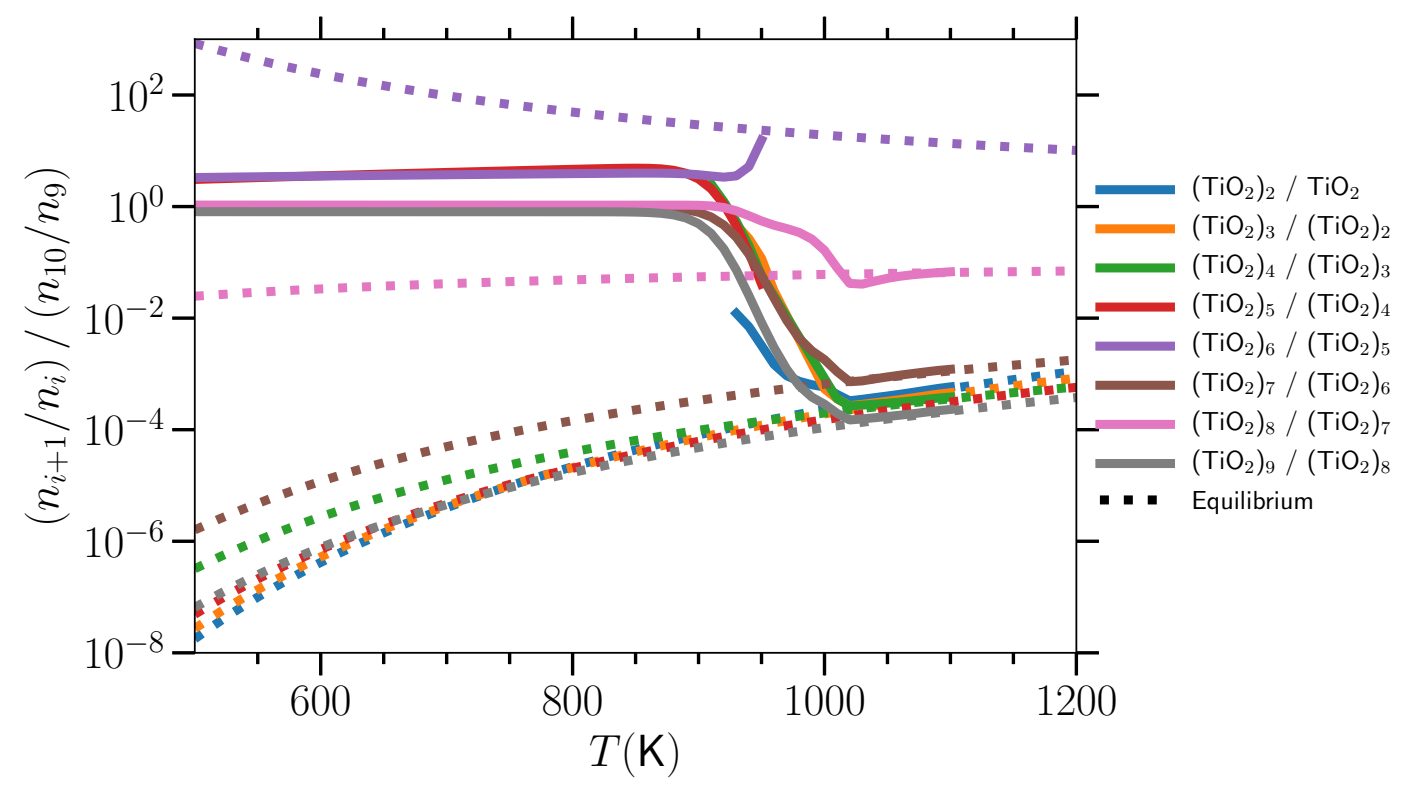

Figure E19. The relative ratios of $\mathrm{TiO}_{2}$-clusters do not reach the equilibrium ratios in the entire temperature range. At the highest temperatures at which the nucleation is feasible, the model results (full lines) correspond to the equilibrium ratios (dotted line). At lower temperatures, the clusters need more time to reach the equilibrium ratios since the interaction probability is lower. This continuous evolution is also visible in Fig. E11. The results are of the closed polymer nucleation model for the benchmark total gas density $\rho=1 \cdot 10^{-9} \mathrm{~kg} \mathrm{~m}^{-3}$ at the final time step (one year). The figure shows the ratios of two clusters w.r.t. the ratio of both largest clusters. If the number density of any of the four clusters is below the numerical solver accuracy of $1 \cdot 10^{-20} \mathrm{~cm}^{-3}$, the ratios are not shown.

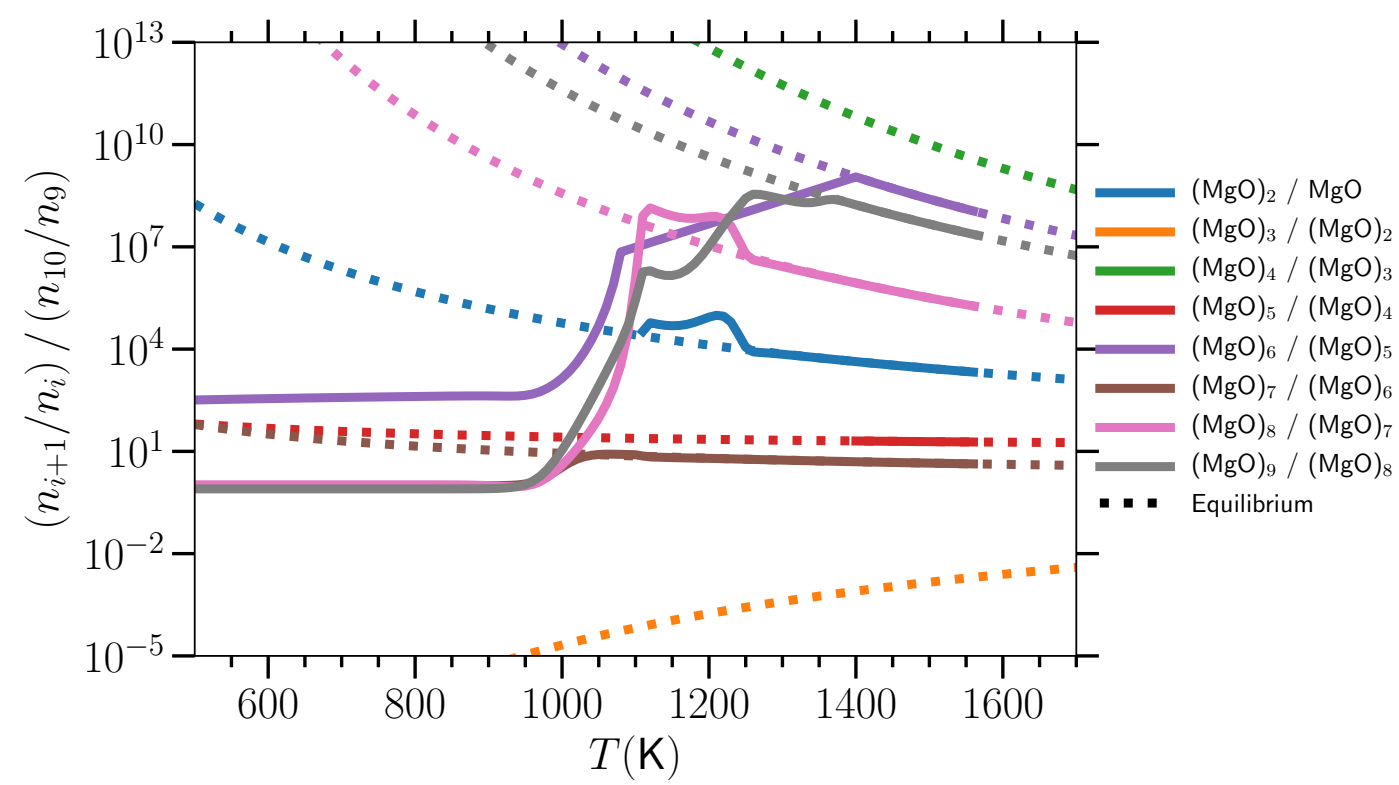

Figure E20. The relative ratios of $\mathrm{MgO}$-clusters do not reach the equilibrium ratios in the entire temperature range. At the highest temperatures at which the nucleation is feasible, the model results (full lines) correspond to the equilibrium ratios (dotted line). At lower temperatures, the clusters need more time to reach the equilibrium ratios since the interaction probability is lower. This transition is visible between 1000 to $1300 \mathrm{~K}$. The continuous evolution is also visible in Fig. E13. The results are of the closed polymer nucleation model for the benchmark total gas density $\rho=1 \cdot 10^{-9} \mathrm{~kg} \mathrm{~m}^{-3}$ at the final time step (one year). The figure shows the ratios of two clusters w.r.t. the ratio of both largest clusters. If the number density of any of the four clusters is below the numerical solver accuracy of $1 \cdot 10^{-20} \mathrm{~cm}^{-3}$, the ratios are not shown. Note that no model results involving $(\mathrm{MgO})_{3}$ are visible since this cluster does not exists under the local conditions. 


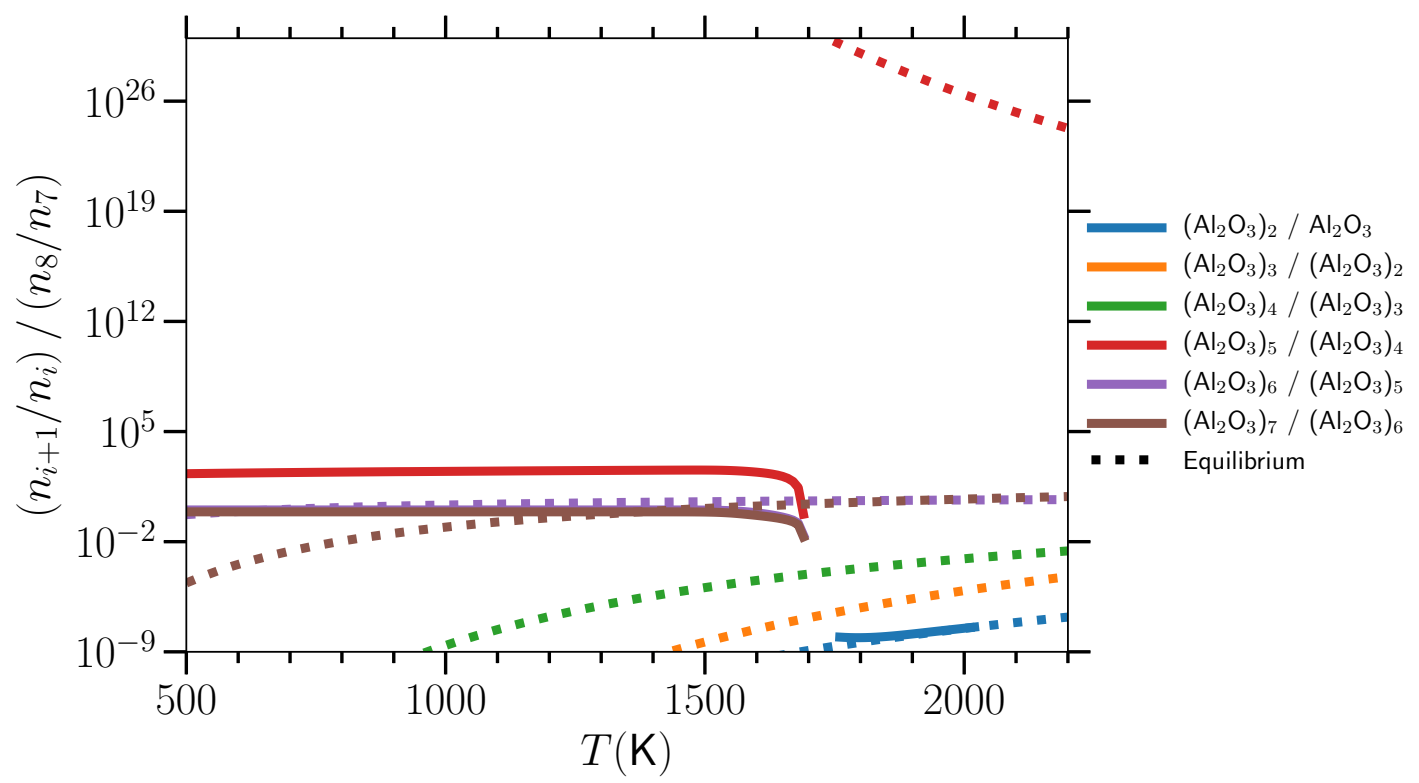

Figure E21. The relative ratios of $\mathrm{Al}_{2} \mathrm{O}_{3}$-clusters (full lines) do not correspond to the equilibrium ratios (dotted line). The figure shows the ratios of two clusters w.r.t. the ratio of both largest clusters. If the number density of any of the four clusters is below the numerical solver accuracy of $1 \cdot 10^{-20} \mathrm{~cm}^{-3}$, the ratios are not shown. Due to the large variation in number densities of the clusters in different temperature regimes (order of magnitude), it is often impossible to compare ratios of the clusters. This variation is more clearly visible in Fig. E17. The results are of the closed polymer nucleation model for the benchmark total gas density $\rho=1 \cdot 10^{-9} \mathrm{~kg} \mathrm{~m}^{-3}$ at the final time step (one year). 

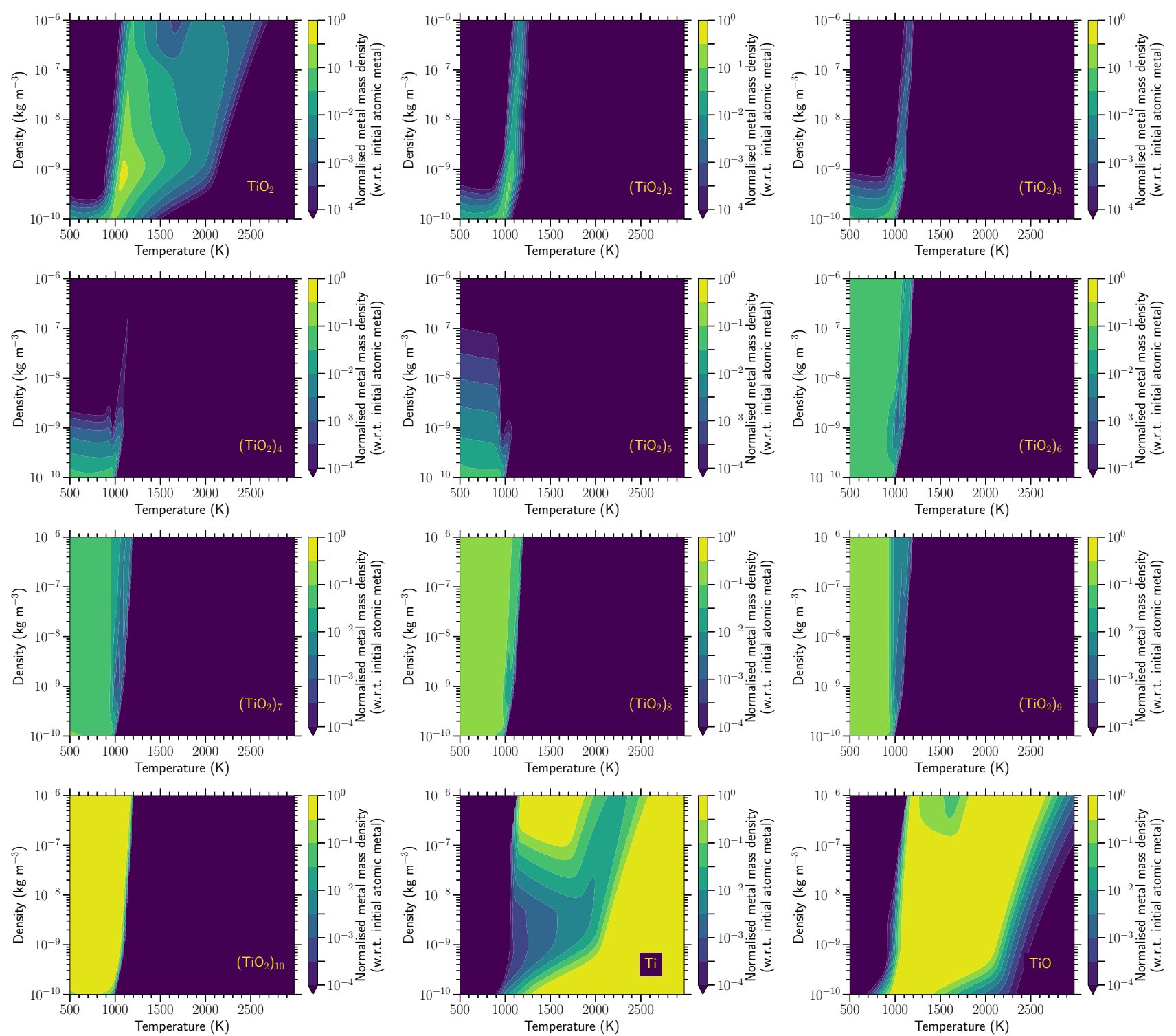

Figure E22. Overview of the normalised mass density after one year of all Ti-bearing species for the comprehensive chemical nucleation model using the polymer nucleation description. 

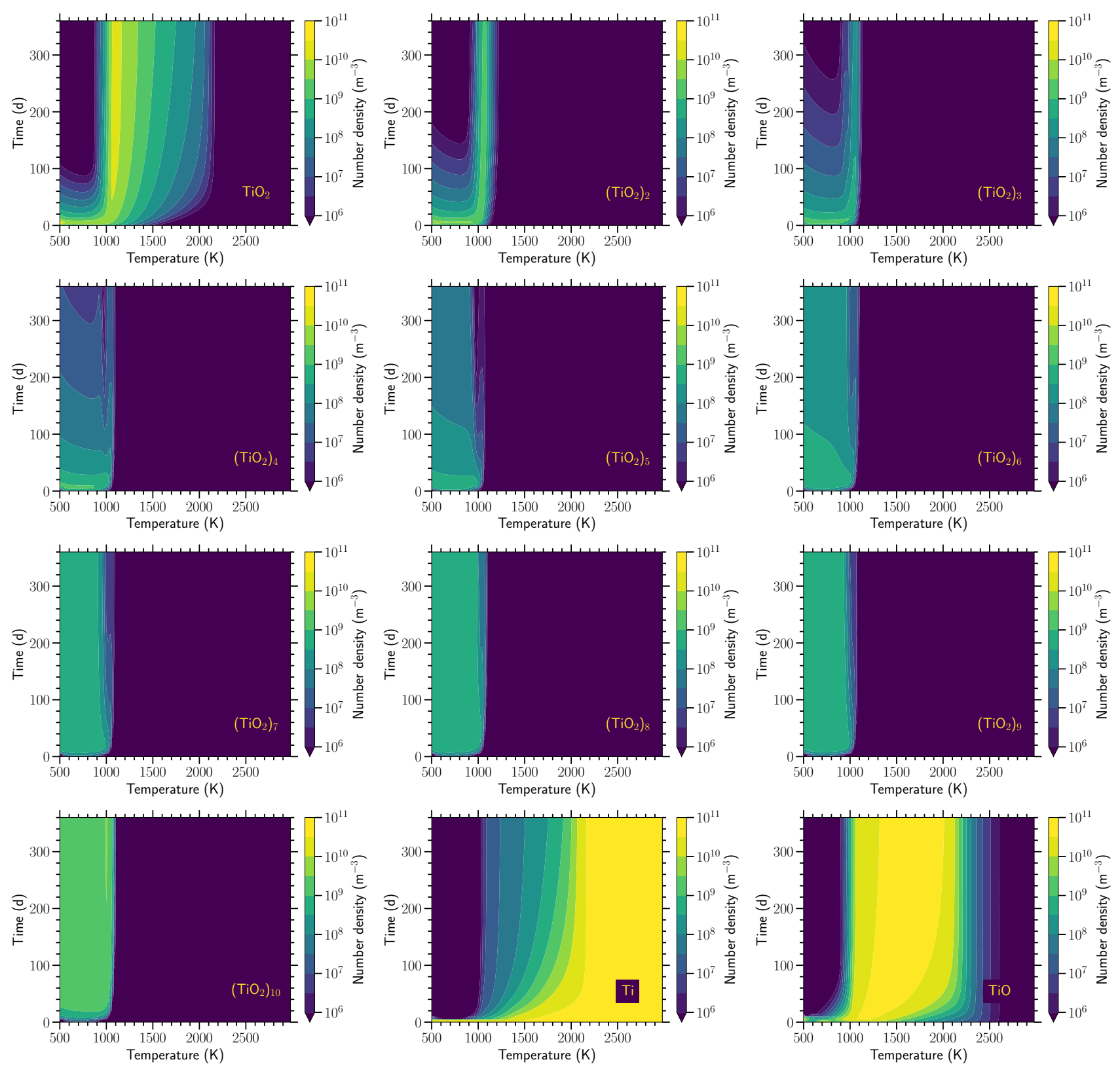

Figure E23. Temporal evolution of the absolute number density of all Ti-bearing species at the benchmark total gas density $\rho=$ $1 \cdot 10^{-9} \mathrm{~kg} \mathrm{~m}^{-3}$ for the comprehensive chemical nucleation model using the polymer nucleation description. 

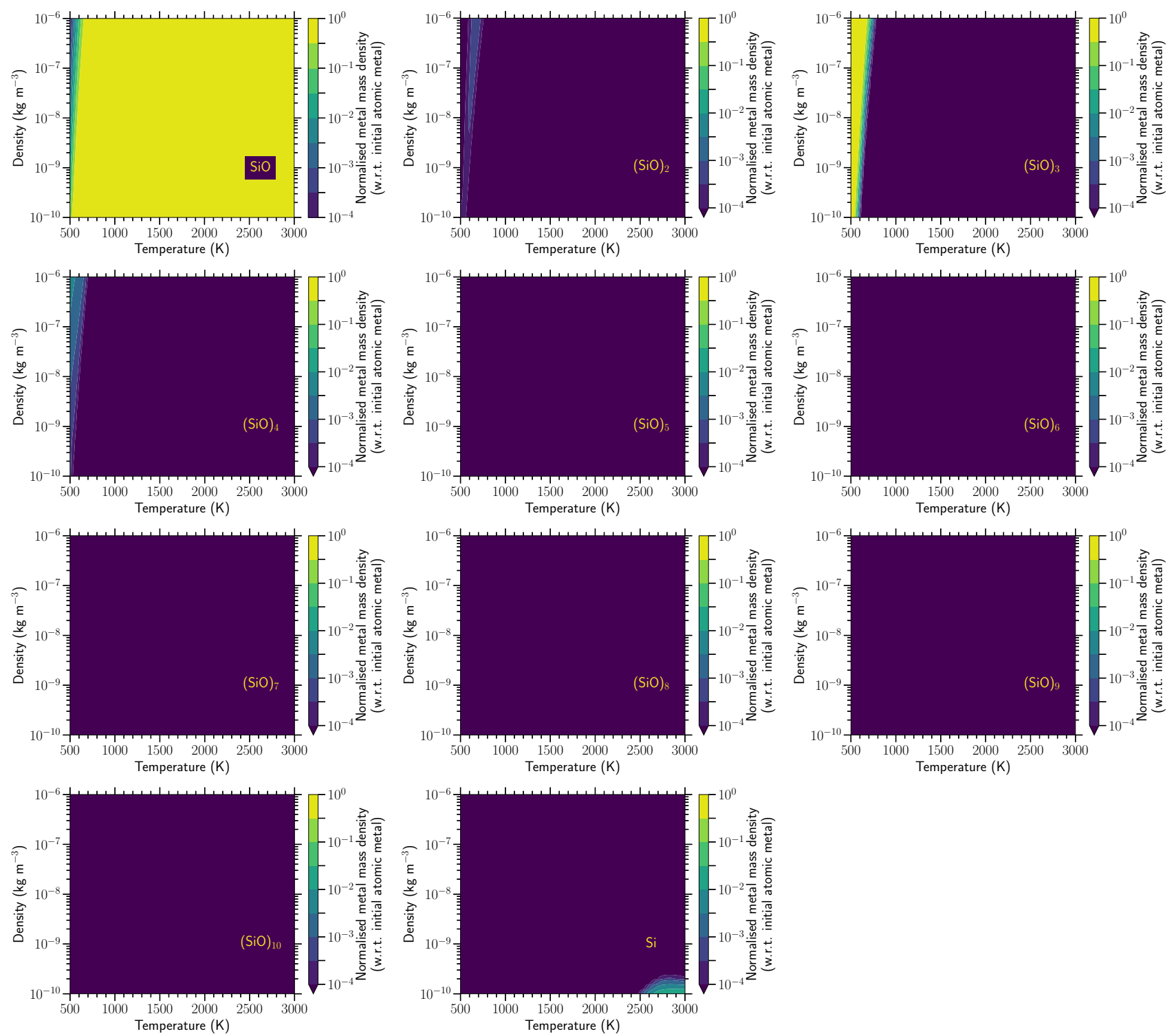

Figure E24. Overview of the normalised mass density of all Si-bearing species for the comprehensive chemical nucleation model using the polymer nucleation description. Species with zero abundance are not shown. 

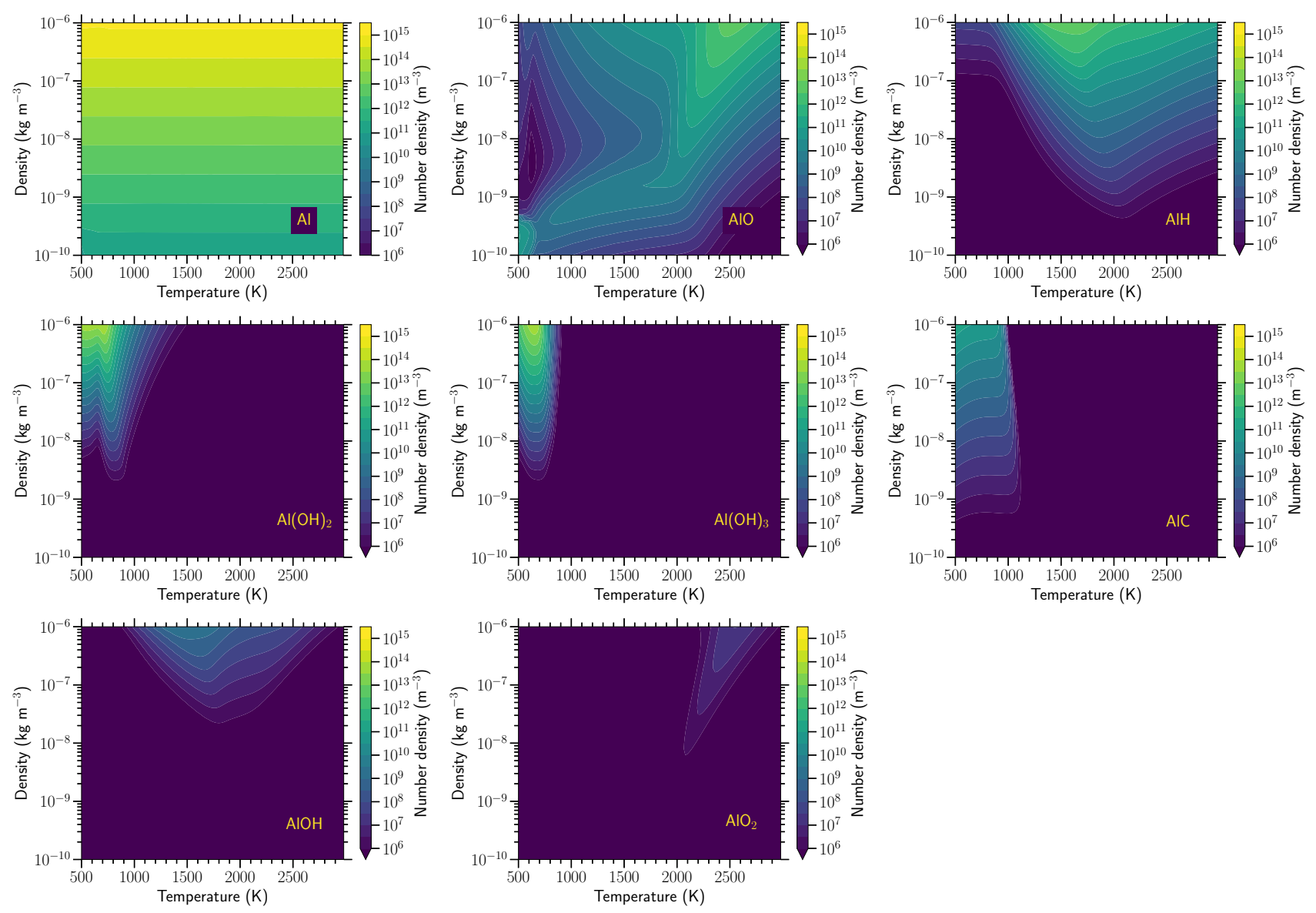

Figure E25. Overview of the absolute number density after one year of all Al-bearing species for the comprehensive chemical nucleation model using the polymer nucleation description. Species with zero abundance are not shown.
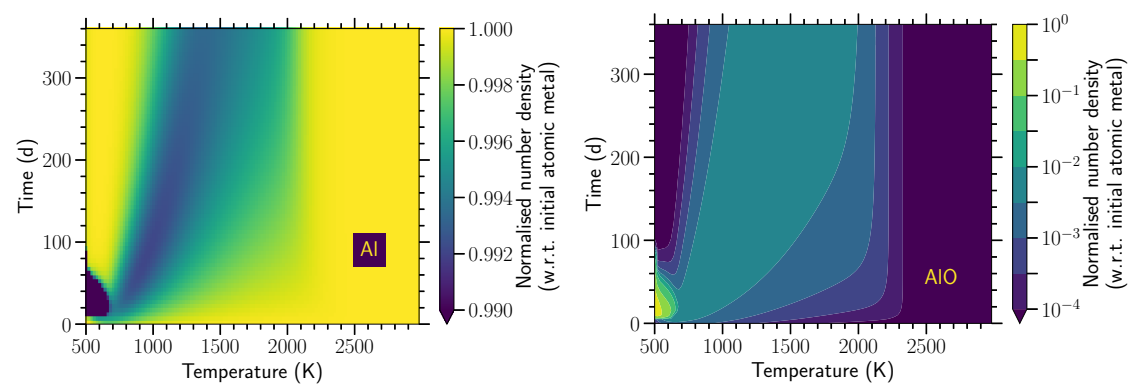

Figure E26. Temporal evolution of the absolute number density of all Al-bearing species at the benchmark total gas density $\rho=$ $1 \cdot 10^{-9} \mathrm{~kg} \mathrm{~m}^{-3}$ for the comprehensive chemical nucleation model using the polymer nucleation description. Species with zero abundance are not shown. 
Table F1: An overview of the comprehensive chemical network. The chemical reactions are listed alphabetically. Additional information on references, parameters, abbreviations, and notes are provided at the bottom of the table.

\begin{tabular}{|c|c|c|c|}
\hline No. & Reaction & Rate coefficient $\left(\mathrm{cm}^{3(N-1)} \mathrm{s}^{-1}\right)$ with $N$ number of reactants & Ref. \\
\hline 1 & $\mathrm{Al}+\mathrm{AlO}_{2}+\mathrm{M} \longrightarrow \mathrm{Al}_{2} \mathrm{O}_{2}+\mathrm{M}$ & $\mathrm{k}_{1}=1.661 \cdot 10^{-9} n_{\text {tot }} \exp \left(-\frac{74937.1}{T}\right) \mathrm{EQR}\left(T,\left\{\mathrm{Al}, \mathrm{AlO}_{2}\right\},\left\{\mathrm{Al}_{2} \mathrm{O}_{2}\right\}\right)$ & 1 \\
\hline 2 & $\mathrm{Al}+\mathrm{C}+\mathrm{M} \longrightarrow \mathrm{AlC}+\mathrm{M}$ & $\mathrm{k}_{2}=9.21 \cdot 10^{-33} T^{0.5} n_{\mathrm{tot}}$ & 2 \\
\hline 3 & $\mathrm{Al}+\mathrm{CO}_{2} \longrightarrow \mathrm{AlO}+\mathrm{CO}$ & $\mathrm{k}_{3}=1.214 \cdot 10^{-11} T^{0.5} \exp \left(-\frac{7470}{T}\right)$ & 2 \\
\hline 4 & $\mathrm{Al}+\mathrm{H}+\mathrm{M} \longrightarrow \mathrm{AlH}+\mathrm{M}$ & $\mathrm{k}_{4}=2.6 \cdot 10^{-33} T^{0.5} n_{\mathrm{tot}}$ & 3 \\
\hline 5 & $\mathrm{Al}+\mathrm{H}_{2} \longrightarrow \mathrm{AlH}+\mathrm{H}$ & $\mathrm{k}_{5}=1.187 \cdot 10^{-10} T^{0.17} \mathrm{EQR}\left(T,\left\{\mathrm{Al}, \mathrm{H}_{2}\right\},\{\mathrm{AlH}, \mathrm{H}\}\right)$ & 3 \\
\hline 6 & $\mathrm{Al}+\mathrm{H}_{2} \mathrm{O} \longrightarrow \mathrm{AlOH}+\mathrm{H}$ & $\mathrm{k}_{6}=3.255 \cdot 10^{-10} \exp \left(-\frac{3744}{T}\right) T^{-0.09}+4.616 \cdot 10^{-18} T^{2.06} \exp \left(-\frac{438}{T}\right)$ & 4 \\
\hline 7 & $\mathrm{Al}+\mathrm{H}_{2} \mathrm{O}+\mathrm{H}_{2} \mathrm{O} \longrightarrow \mathrm{AlO}_{2} \mathrm{H}_{2}+\mathrm{H}_{2}$ & $\mathrm{k}_{7}=3.198 \cdot 10^{-33} T^{0.5}$ & 3 \\
\hline 8 & $\mathrm{Al}+\mathrm{H}_{2} \mathrm{O}+\mathrm{H}_{2} \mathrm{O} \longrightarrow \mathrm{AlOH}+\mathrm{H}+\mathrm{H}_{2} \mathrm{O}$ & $\mathrm{k}_{8}=3.198 \cdot 10^{-33} T^{0.5} \exp \left(-\frac{1260}{T}\right)$ & 3 \\
\hline 9 & $\mathrm{Al}+\mathrm{H}_{2} \mathrm{O}_{2} \longrightarrow \mathrm{AlOH}+\mathrm{OH}$ & $\mathrm{k}_{9}=1.827 \cdot 10^{-11} T^{0.159} \exp \left(\frac{91.1}{T}\right)$ & 5 \\
\hline 10 & $\mathrm{Al}+\mathrm{H}_{2} \mathrm{O}_{2} \longrightarrow \mathrm{AlO}_{2} \mathrm{H}_{2}+\gamma$ & $\mathrm{k}_{10}=1.827 \cdot 10^{-11} T^{0.159} \exp \left(\frac{91.1}{T}\right)$ & 5 \\
\hline 11 & $\mathrm{Al}+\mathrm{HCO} \longrightarrow \mathrm{AlH}+\mathrm{CO}$ & $\mathrm{k}_{11}=4.55 \cdot 10^{-11} T^{0.17}$ & 2 \\
\hline 12 & $\mathrm{Al}+\mathrm{HO}_{2} \longrightarrow \mathrm{AlO}+\mathrm{OH}$ & $\mathrm{k}_{12}=2.209 \cdot 10^{-11} T^{0.17}$ & 2 \\
\hline 13 & $\mathrm{Al}+\mathrm{HO}_{2} \longrightarrow \mathrm{AlH}+\mathrm{O}_{2}$ & $\mathrm{k}_{13}=2.209 \cdot 10^{-11} T^{0.17}$ & 2 \\
\hline 14 & $\mathrm{Al}+\mathrm{O}+\mathrm{H}_{2} \longrightarrow \mathrm{AlO}+\mathrm{H}_{2}$ & $\mathrm{k}_{14}=9.101 \cdot 10^{-31} T^{-1}$ & 1 \\
\hline 15 & $\mathrm{Al}+\mathrm{O}+\mathrm{H}_{2} \mathrm{O} \longrightarrow \mathrm{AlO}+\mathrm{H}_{2} \mathrm{O}$ & $\mathrm{k}_{15}=2.317 \cdot 10^{-31} T^{-1}$ & 1 \\
\hline 16 & $\mathrm{Al}+\mathrm{O}+\mathrm{O}_{2} \longrightarrow \mathrm{AlO}+\mathrm{O}_{2}$ & $\mathrm{k}_{16}=9.101 \cdot 10^{-31} T^{-1}$ & 1 \\
\hline 17 & $\mathrm{Al}+\mathrm{O}_{2} \longrightarrow \mathrm{AlO}+\mathrm{O}$ & $\mathrm{k}_{17}=3.836 \cdot 10^{-11} T^{0.17}$ & 2 \\
\hline 18 & $\mathrm{Al}+\mathrm{OH}+\mathrm{M} \longrightarrow \mathrm{AlOH}+\mathrm{M}$ & $\mathrm{k}_{18}=5.957 \cdot 10^{-33} T^{0.5} n_{\mathrm{tot}}$ & 2 \\
\hline 19 & $\mathrm{Al}_{10} \mathrm{O}_{15} \longrightarrow \mathrm{Al}_{2} \mathrm{O}_{3}+\mathrm{Al}_{8} \mathrm{O}_{12}$ & $\mathrm{k}_{19}=\mathrm{k}_{\mathrm{N}, \mathrm{M}}^{+}\left(\mathrm{Al}_{2} \mathrm{O}_{3}, 1,4, T\right) \mathrm{EQR}\left(T,\left\{\mathrm{Al}_{10} \mathrm{O}_{15}\right\},\left\{\mathrm{Al}_{2} \mathrm{O}_{3}, \mathrm{Al}_{8} \mathrm{O}_{12}\right\}\right)$ & 6 \\
\hline 20 & $\mathrm{Al}_{10} \mathrm{O}_{15} \longrightarrow \mathrm{Al}_{4} \mathrm{O}_{6}+\mathrm{Al}_{6} \mathrm{O}_{9}$ & $\mathrm{k}_{20}=\mathrm{k}_{\mathrm{N}, \mathrm{M}}^{+}\left(\mathrm{Al}_{2} \mathrm{O}_{3}, 2,3, T\right) \mathrm{EQR}\left(T,\left\{\mathrm{Al}_{10} \mathrm{O}_{15}\right\},\left\{\mathrm{Al}_{4} \mathrm{O}_{6}, \mathrm{Al}_{6} \mathrm{O}_{9}\right\}\right)$ & 6 \\
\hline 21 & $\mathrm{Al}_{12} \mathrm{O}_{18} \longrightarrow \mathrm{Al}_{2} \mathrm{O}_{3}+\mathrm{Al}_{10} \mathrm{O}_{15}$ & $\mathrm{k}_{21}=\mathrm{k}_{\mathrm{N}, \mathrm{M}}^{+}\left(\mathrm{Al}_{2} \mathrm{O}_{3}, 1,5, T\right) \mathrm{EQR}\left(T,\left\{\mathrm{Al}_{12} \mathrm{O}_{18}\right\},\left\{\mathrm{Al}_{10} \mathrm{O}_{15}, \mathrm{Al}_{2} \mathrm{O}_{3}\right\}\right)$ & 6 \\
\hline 22 & $\mathrm{Al}_{12} \mathrm{O}_{18} \longrightarrow \mathrm{Al}_{4} \mathrm{O}_{6}+\mathrm{Al}_{8} \mathrm{O}_{12}$ & $\mathrm{k}_{22}=\mathrm{k}_{\mathrm{N}, \mathrm{M}}^{+}\left(\mathrm{Al}_{2} \mathrm{O}_{3}, 2,4, T\right) \mathrm{EQR}\left(T,\left\{\mathrm{Al}_{12} \mathrm{O}_{18}\right\},\left\{\mathrm{Al}_{4} \mathrm{O}_{6}, \mathrm{Al}_{8} \mathrm{O}_{12}\right\}\right)$ & 6 \\
\hline 23 & $\mathrm{Al}_{12} \mathrm{O}_{18} \longrightarrow \mathrm{Al}_{6} \mathrm{O}_{9}+\mathrm{Al}_{6} \mathrm{O}_{9}$ & $\mathrm{k}_{23}=\mathrm{k}_{\mathrm{N}, \mathrm{M}}^{+}\left(\mathrm{Al}_{2} \mathrm{O}_{3}, 3,3, T\right) \mathrm{EQR}\left(T,\left\{\mathrm{Al}_{12} \mathrm{O}_{18}\right\},\left\{\mathrm{Al}_{6} \mathrm{O}_{9}\right\}\right)$ & 6 \\
\hline 24 & $\mathrm{Al}_{14} \mathrm{O}_{21} \longrightarrow \mathrm{Al}_{2} \mathrm{O}_{3}+\mathrm{Al}_{12} \mathrm{O}_{18}$ & $\mathrm{k}_{24}=\mathrm{k}_{\mathrm{N}, \mathrm{M}}^{+}\left(\mathrm{Al}_{2} \mathrm{O}_{3}, 1,6, T\right) \mathrm{EQR}\left(T,\left\{\mathrm{Al}_{14} \mathrm{O}_{21}\right\},\left\{\mathrm{Al}_{12} \mathrm{O}_{18}, \mathrm{Al}_{2} \mathrm{O}_{3}\right\}\right)$ & 6 \\
\hline 25 & $\mathrm{Al}_{14} \mathrm{O}_{21} \longrightarrow \mathrm{Al}_{4} \mathrm{O}_{6}+\mathrm{Al}_{10} \mathrm{O}_{15}$ & $\mathrm{k}_{25}=\mathrm{k}_{\mathrm{N}, \mathrm{M}}^{+}\left(\mathrm{Al}_{2} \mathrm{O}_{3}, 2,5, T\right) \mathrm{EQR}\left(T,\left\{\mathrm{Al}_{14} \mathrm{O}_{21}\right\},\left\{\mathrm{Al}_{10} \mathrm{O}_{15}, \mathrm{Al}_{4} \mathrm{O}_{6}\right\}\right)$ & 6 \\
\hline 26 & $\mathrm{Al}_{14} \mathrm{O}_{21} \longrightarrow \mathrm{Al}_{6} \mathrm{O}_{9}+\mathrm{Al}_{8} \mathrm{O}_{12}$ & $\mathrm{k}_{26}=\mathrm{k}_{\mathrm{N}, \mathrm{M}}^{+}\left(\mathrm{Al}_{2} \mathrm{O}_{3}, 3,4, T\right) \mathrm{EQR}\left(T,\left\{\mathrm{Al}_{14} \mathrm{O}_{21}\right\},\left\{\mathrm{Al}_{6} \mathrm{O}_{9}, \mathrm{Al}_{8} \mathrm{O}_{12}\right\}\right)$ & 6 \\
\hline 27 & $\mathrm{Al}_{16} \mathrm{O}_{24} \longrightarrow \mathrm{Al}_{2} \mathrm{O}_{3}+\mathrm{Al}_{14} \mathrm{O}_{21}$ & $\mathrm{k}_{27}=\mathrm{k}_{\mathrm{N}, \mathrm{M}}^{+}\left(\mathrm{Al}_{2} \mathrm{O}_{3}, 1,7, T\right) \mathrm{EQR}\left(T,\left\{\mathrm{Al}_{16} \mathrm{O}_{24}\right\},\left\{\mathrm{Al}_{14} \mathrm{O}_{21}, \mathrm{Al}_{2} \mathrm{O}_{3}\right\}\right)$ & 6 \\
\hline 28 & $\mathrm{Al}_{16} \mathrm{O}_{24} \longrightarrow \mathrm{Al}_{4} \mathrm{O}_{6}+\mathrm{Al}_{12} \mathrm{O}_{18}$ & $\mathrm{k}_{28}=\mathrm{k}_{\mathrm{N}, \mathrm{M}}^{+}\left(\mathrm{Al}_{2} \mathrm{O}_{3}, 2,6, T\right) \mathrm{EQR}\left(T,\left\{\mathrm{Al}_{16} \mathrm{O}_{24}\right\},\left\{\mathrm{Al}_{12} \mathrm{O}_{18}, \mathrm{Al}_{4} \mathrm{O}_{6}\right\}\right)$ & 6 \\
\hline 29 & $\mathrm{Al}_{16} \mathrm{O}_{24} \longrightarrow \mathrm{Al}_{6} \mathrm{O}_{9}+\mathrm{Al}_{10} \mathrm{O}_{15}$ & $\mathrm{k}_{29}=\mathrm{k}_{\mathrm{N}, \mathrm{M}}^{+}\left(\mathrm{Al}_{2} \mathrm{O}_{3}, 3,5, T\right) \mathrm{EQR}\left(T,\left\{\mathrm{Al}_{16} \mathrm{O}_{24}\right\},\left\{\mathrm{Al}_{10} \mathrm{O}_{15}, \mathrm{Al}_{6} \mathrm{O}_{9}\right\}\right)$ & 6 \\
\hline 30 & $\mathrm{Al}_{16} \mathrm{O}_{24} \longrightarrow \mathrm{Al}_{8} \mathrm{O}_{12}+\mathrm{Al}_{8} \mathrm{O}_{12}$ & $\mathrm{k}_{30}=\mathrm{k}_{\mathrm{N}, \mathrm{M}}^{+}\left(\mathrm{Al}_{2} \mathrm{O}_{3}, 4,4, T\right) \mathrm{EQR}\left(T,\left\{\mathrm{Al}_{16} \mathrm{O}_{24}\right\},\left\{\mathrm{Al}_{8} \mathrm{O}_{12}\right\}\right)$ & 6 \\
\hline 31 & $\mathrm{Al}_{2} \mathrm{O}+\mathrm{M} \longrightarrow \mathrm{AlO}+\mathrm{Al}+\mathrm{M}$ & $\mathrm{k}_{31}=1.661 \cdot 10^{-9} n_{\text {tot }} \exp \left(-\frac{67035.7}{T}\right)$ & 1 \\
\hline 32 & $\mathrm{Al}_{2} \mathrm{O}+\mathrm{O}+\mathrm{M} \longrightarrow \mathrm{Al}_{2} \mathrm{O}_{2}+\mathrm{M}$ & $\mathrm{k}_{32}=1.661 \cdot 10^{-9} n_{\text {tot }} \exp \left(-\frac{52466}{T}\right) \mathrm{EQR}\left(T,\left\{\mathrm{Al}_{2} \mathrm{O}, \mathrm{O}\right\},\left\{\mathrm{Al}_{2} \mathrm{O}_{2}\right\}\right)$ & 1 \\
\hline 33 & $\mathrm{Al}_{2} \mathrm{O}_{2}+\mathrm{M} \longrightarrow \mathrm{AlO}+\mathrm{AlO}+\mathrm{M}$ & $\mathrm{k}_{33}=1.661 \cdot 10^{-9} n_{\mathrm{tot}} \exp \left(-\frac{59335.7}{T}\right)$ & 1 \\
\hline 34 & $\mathrm{Al}_{2} \mathrm{O}_{2}+\mathrm{M} \longrightarrow \mathrm{Al}+\mathrm{AlO}_{2}+\mathrm{M}$ & $\mathrm{k}_{34}=1.661 \cdot 10^{-9} n_{\mathrm{tot}} \exp \left(-\frac{74937.1}{T}\right)$ & 1 \\
\hline 35 & $\mathrm{Al}_{2} \mathrm{O}_{2}+\mathrm{M} \longrightarrow \mathrm{Al}_{2} \mathrm{O}+\mathrm{O}+\mathrm{M}$ & $\mathrm{k}_{35}=1.661 \cdot 10^{-9} n_{\text {tot }} \exp \left(-\frac{52466}{T}\right)$ & 1 \\
\hline 36 & $\mathrm{Al}_{2} \mathrm{O}_{2}+\mathrm{O}+\mathrm{M} \longrightarrow \mathrm{Al}_{2} \mathrm{O}_{3}+\mathrm{M}$ & $\mathrm{k}_{36}=4.982 \cdot 10^{-9} n_{\text {tot }} \exp \left(-\frac{49144.4}{T}\right) \mathrm{EQR}\left(T,\left\{\mathrm{Al}_{2} \mathrm{O}_{2}, \mathrm{O}\right\},\left\{\mathrm{Al}_{2} \mathrm{O}_{3}\right\}\right)$ & 1 \\
\hline 37 & $\mathrm{Al}_{2} \mathrm{O}_{3}+\mathrm{M} \longrightarrow \mathrm{Al}_{2} \mathrm{O}_{2}+\mathrm{O}+\mathrm{M}$ & $\mathrm{k}_{37}=4.982 \cdot 10^{-9} n_{\text {tot }} \exp \left(-\frac{49144.4}{T}\right)$ & 1 \\
\hline
\end{tabular}




\begin{tabular}{|c|c|c|c|}
\hline No. & Reaction & Rate coefficient $\left(\mathrm{cm}^{3(N-1)} \mathrm{s}^{-1}\right)$ with $N$ number of reactants & Ref. \\
\hline 38 & $\mathrm{Al}_{2} \mathrm{O}_{3}+\mathrm{M} \longrightarrow \mathrm{AlO}_{2}+\mathrm{AlO}+\mathrm{M}$ & $\mathrm{k}_{38}=4.982 \cdot 10^{-9} n_{\text {tot }} \exp \left(-\frac{63915.4}{T}\right)$ & 1 \\
\hline 39 & $\mathrm{Al}_{2} \mathrm{O}_{3}+\mathrm{Al}_{10} \mathrm{O}_{15} \longrightarrow \mathrm{Al}_{12} \mathrm{O}_{18}$ & $\mathrm{k}_{39}=\mathrm{k}_{\mathrm{N}, \mathrm{M}}^{+}\left(\mathrm{Al}_{2} \mathrm{O}_{3}, 1,5, T\right)$ & 6 \\
\hline 40 & $\mathrm{Al}_{2} \mathrm{O}_{3}+\mathrm{Al}_{12} \mathrm{O}_{18} \longrightarrow \mathrm{Al}_{14} \mathrm{O}_{21}$ & $\mathrm{k}_{40}=\mathrm{k}_{\mathrm{N}, \mathrm{M}}^{+}\left(\mathrm{Al}_{2} \mathrm{O}_{3}, 1,6, T\right)$ & 6 \\
\hline 41 & $\mathrm{Al}_{2} \mathrm{O}_{3}+\mathrm{Al}_{14} \mathrm{O}_{21} \longrightarrow \mathrm{Al}_{16} \mathrm{O}_{24}$ & $\mathrm{k}_{41}=\mathrm{k}_{\mathrm{N}, \mathrm{M}}^{+}\left(\mathrm{Al}_{2} \mathrm{O}_{3}, 1,7, T\right)$ & 6 \\
\hline 42 & $\mathrm{Al}_{2} \mathrm{O}_{3}+\mathrm{Al}_{2} \mathrm{O}_{3} \longrightarrow \mathrm{Al}_{4} \mathrm{O}_{6}$ & $\mathrm{k}_{42}=\mathrm{k}_{\mathrm{N}, \mathrm{M}}^{+}\left(\mathrm{Al}_{2} \mathrm{O}_{3}, 1,1, T\right)$ & 6 \\
\hline 43 & $\mathrm{Al}_{2} \mathrm{O}_{3}+\mathrm{Al}_{4} \mathrm{O}_{6} \longrightarrow \mathrm{Al}_{6} \mathrm{O}_{9}$ & $\mathrm{k}_{43}=\mathrm{k}_{\mathrm{N}, \mathrm{M}}^{+}\left(\mathrm{Al}_{2} \mathrm{O}_{3}, 1,2, T\right)$ & 6 \\
\hline 44 & $\mathrm{Al}_{2} \mathrm{O}_{3}+\mathrm{Al}_{6} \mathrm{O}_{9} \longrightarrow \mathrm{Al}_{8} \mathrm{O}_{12}$ & $\mathrm{k}_{44}=\mathrm{k}_{\mathrm{N}, \mathrm{M}}^{+}\left(\mathrm{Al}_{2} \mathrm{O}_{3}, 1,3, T\right)$ & 6 \\
\hline 45 & $\mathrm{Al}_{2} \mathrm{O}_{3}+\mathrm{Al}_{8} \mathrm{O}_{12} \longrightarrow \mathrm{Al}_{10} \mathrm{O}_{15}$ & $\mathrm{k}_{45}=\mathrm{k}_{\mathrm{N}, \mathrm{M}}^{+}\left(\mathrm{Al}_{2} \mathrm{O}_{3}, 1,4, T\right)$ & 6 \\
\hline 46 & $\mathrm{Al}_{4} \mathrm{O}_{6} \longrightarrow \mathrm{Al}_{2} \mathrm{O}_{3}+\mathrm{Al}_{2} \mathrm{O}_{3}$ & $\mathrm{k}_{46}=\mathrm{k}_{\mathrm{N}, \mathrm{M}}^{+}\left(\mathrm{Al}_{2} \mathrm{O}_{3}, 1,1, T\right) \mathrm{EQR}\left(T,\left\{\mathrm{Al}_{4} \mathrm{O}_{6}\right\},\left\{\mathrm{Al}_{2} \mathrm{O}_{3}\right\}\right)$ & 6 \\
\hline 47 & $\mathrm{Al}_{4} \mathrm{O}_{6}+\mathrm{Al}_{10} \mathrm{O}_{15} \longrightarrow \mathrm{Al}_{14} \mathrm{O}_{21}$ & $\mathrm{k}_{47}=\mathrm{k}_{\mathrm{N}, \mathrm{M}}^{+}\left(\mathrm{Al}_{2} \mathrm{O}_{3}, 2,5, T\right)$ & 6 \\
\hline 48 & $\mathrm{Al}_{4} \mathrm{O}_{6}+\mathrm{Al}_{12} \mathrm{O}_{18} \longrightarrow \mathrm{Al}_{16} \mathrm{O}_{24}$ & $\mathrm{k}_{48}=\mathrm{k}_{\mathrm{N}, \mathrm{M}}^{+}\left(\mathrm{Al}_{2} \mathrm{O}_{3}, 2,6, T\right)$ & 6 \\
\hline 49 & $\mathrm{Al}_{4} \mathrm{O}_{6}+\mathrm{Al}_{4} \mathrm{O}_{6} \longrightarrow \mathrm{Al}_{8} \mathrm{O}_{12}$ & $\mathrm{k}_{49}=\mathrm{k}_{\mathrm{N}, \mathrm{M}}^{+}\left(\mathrm{Al}_{2} \mathrm{O}_{3}, 2,2, T\right)$ & 6 \\
\hline 50 & $\mathrm{Al}_{4} \mathrm{O}_{6}+\mathrm{Al}_{6} \mathrm{O}_{9} \longrightarrow \mathrm{Al}_{10} \mathrm{O}_{15}$ & $\mathrm{k}_{50}=\mathrm{k}_{\mathrm{N}, \mathrm{M}}^{+}\left(\mathrm{Al}_{2} \mathrm{O}_{3}, 2,3, T\right)$ & 6 \\
\hline 51 & $\mathrm{Al}_{4} \mathrm{O}_{6}+\mathrm{Al}_{8} \mathrm{O}_{12} \longrightarrow \mathrm{Al}_{12} \mathrm{O}_{18}$ & $\mathrm{k}_{51}=\mathrm{k}_{\mathrm{N}, \mathrm{M}}^{+}\left(\mathrm{Al}_{2} \mathrm{O}_{3}, 2,4, T\right)$ & 6 \\
\hline 52 & $\mathrm{Al}_{6} \mathrm{O}_{9} \longrightarrow \mathrm{Al}_{2} \mathrm{O}_{3}+\mathrm{Al}_{4} \mathrm{O}_{6}$ & $\mathrm{k}_{52}=\mathrm{k}_{\mathrm{N}, \mathrm{M}}^{+}\left(\mathrm{Al}_{2} \mathrm{O}_{3}, 1,2, T\right) \mathrm{EQR}\left(T,\left\{\mathrm{Al}_{6} \mathrm{O}_{9}\right\},\left\{\mathrm{Al}_{2} \mathrm{O}_{3}, \mathrm{Al}_{4} \mathrm{O}_{6}\right\}\right)$ & 6 \\
\hline 53 & $\mathrm{Al}_{6} \mathrm{O}_{9}+\mathrm{Al}_{10} \mathrm{O}_{15} \longrightarrow \mathrm{Al}_{16} \mathrm{O}_{24}$ & $\mathrm{k}_{53}=\mathrm{k}_{\mathrm{N}, \mathrm{M}}^{+}\left(\mathrm{Al}_{2} \mathrm{O}_{3}, 3,5, T\right)$ & 6 \\
\hline 54 & $\mathrm{Al}_{6} \mathrm{O}_{9}+\mathrm{Al}_{6} \mathrm{O}_{9} \longrightarrow \mathrm{Al}_{12} \mathrm{O}_{18}$ & $\mathrm{k}_{54}=\mathrm{k}_{\mathrm{N}, \mathrm{M}}^{+}\left(\mathrm{Al}_{2} \mathrm{O}_{3}, 3,3, T\right)$ & 6 \\
\hline 55 & $\mathrm{Al}_{6} \mathrm{O}_{9}+\mathrm{Al}_{8} \mathrm{O}_{12} \longrightarrow \mathrm{Al}_{14} \mathrm{O}_{21}$ & $\mathrm{k}_{55}=\mathrm{k}_{\mathrm{N}, \mathrm{M}}^{+}\left(\mathrm{Al}_{2} \mathrm{O}_{3}, 3,4, T\right)$ & 6 \\
\hline 56 & $\mathrm{Al}_{8} \mathrm{O}_{12} \longrightarrow \mathrm{Al}_{2} \mathrm{O}_{3}+\mathrm{Al}_{6} \mathrm{O}_{9}$ & $\mathrm{k}_{56}=\mathrm{k}_{\mathrm{N}, \mathrm{M}}^{+}\left(\mathrm{Al}_{2} \mathrm{O}_{3}, 1,3, T\right) \mathrm{EQR}\left(T,\left\{\mathrm{Al}_{8} \mathrm{O}_{12}\right\},\left\{\mathrm{Al}_{2} \mathrm{O}_{3}, \mathrm{Al}_{6} \mathrm{O}_{9}\right\}\right)$ & 6 \\
\hline 57 & $\mathrm{Al}_{8} \mathrm{O}_{12} \longrightarrow \mathrm{Al}_{4} \mathrm{O}_{6}+\mathrm{Al}_{4} \mathrm{O}_{6}$ & $\mathrm{k}_{57}=\mathrm{k}_{\mathrm{N}, \mathrm{M}}^{+}\left(\mathrm{Al}_{2} \mathrm{O}_{3}, 2,2, T\right) \mathrm{EQR}\left(T,\left\{\mathrm{Al}_{8} \mathrm{O}_{12}\right\},\left\{\mathrm{Al}_{4} \mathrm{O}_{6}\right\}\right)$ & 6 \\
\hline 58 & $\mathrm{Al}_{8} \mathrm{O}_{12}+\mathrm{Al}_{8} \mathrm{O}_{12} \longrightarrow \mathrm{Al}_{16} \mathrm{O}_{24}$ & $\mathrm{k}_{58}=\mathrm{k}_{\mathrm{N}, \mathrm{M}}^{+}\left(\mathrm{Al}_{2} \mathrm{O}_{3}, 4,4, T\right)$ & 6 \\
\hline 59 & $\mathrm{AlC}+\mathrm{M} \longrightarrow \mathrm{Al}+\mathrm{C}+\mathrm{M}$ & $\mathrm{k}_{59}=9.21 \cdot 10^{-33} T^{0.5} n_{\mathrm{tot}} \mathrm{EQR}(T,\{\mathrm{AlC}\},\{\mathrm{Al}, \mathrm{C}\})$ & 2 \\
\hline 60 & $\mathrm{AlH}+\mathrm{M} \longrightarrow \mathrm{Al}+\mathrm{H}+\mathrm{M}$ & $\mathrm{k}_{60}=2.6 \cdot 10^{-33} T^{0.5} n_{\mathrm{tot}} \mathrm{EQR}(T,\{\mathrm{AlH}\},\{\mathrm{Al}, \mathrm{H}\})$ & 3 \\
\hline 61 & $\mathrm{AlH}+\mathrm{CO} \longrightarrow \mathrm{Al}+\mathrm{HCO}$ & $\mathrm{k}_{61}=4.55 \cdot 10^{-11} T^{0.17} \mathrm{EQR}(T,\{\mathrm{AlH}, \mathrm{CO}\},\{\mathrm{Al}, \mathrm{HCO}\})$ & 2 \\
\hline 62 & $\mathrm{AlH}+\mathrm{H} \longrightarrow \mathrm{Al}+\mathrm{H}_{2}$ & $\mathrm{k}_{62}=1.187 \cdot 10^{-10} T^{0.17}$ & 3 \\
\hline 63 & $\mathrm{AlH}+\mathrm{H}+\mathrm{M} \longrightarrow \mathrm{AlH}_{2}+\mathrm{M}$ & $\begin{aligned} \mathrm{k}_{63}= & \mathrm{k}_{\operatorname{Troe}}\left(1.607 \cdot 10^{-9} \exp \left(-\frac{19962}{T}\right), 2.42 \cdot 10^{-9} \exp \left(-\frac{23376}{T}\right)\right. \\
& \left., \exp \left(-\frac{942}{T}\right)-4.1 \exp (-0.04629 T)+5.1 \exp (-0.00202 T), n_{\text {tot }}\right) \\
& \cdot \operatorname{EQR}\left(T,\{\mathrm{AlH}, \mathrm{H}\},\left\{\mathrm{AlH}_{2}\right\}\right)\end{aligned}$ & 7 \\
\hline 64 & $\mathrm{AlH}+\mathrm{H}_{2}+\mathrm{M} \longrightarrow \mathrm{AlH}_{3}+\mathrm{M}$ & $\begin{aligned} \mathrm{k}_{64}= & \mathrm{k}_{\text {Troe }}\left(1.677 \cdot 10^{-9} \exp \left(-\frac{27089}{T}\right), 2.46 \cdot 10^{-11} \exp \left(-\frac{30756}{T}\right)\right. \\
& \left., \exp \left(-\frac{3807}{T}\right)+0.06 \exp (-0.00181 T)+0.94 \exp (-0.00112 T), n_{\mathrm{tot}}\right) \\
& \cdot \mathrm{EQR}\left(T,\left\{\mathrm{AlH}, \mathrm{H}_{2}\right\},\left\{\mathrm{AlH}_{3}\right\}\right)\end{aligned}$ & 7 \\
\hline 65 & $\mathrm{AlH}+\mathrm{H}_{2} \longrightarrow \mathrm{AlH}_{2}+\mathrm{H}$ & $\mathrm{k}_{65}=3.321 \cdot 10^{-11} \mathrm{EQR}\left(T,\left\{\mathrm{AlH}, \mathrm{H}_{2}\right\},\left\{\mathrm{AlH}_{2}, \mathrm{H}\right\}\right)$ & 7 \\
\hline 66 & $\mathrm{AlH}+\mathrm{HO}_{2} \longrightarrow \mathrm{AlOH}+\mathrm{OH}$ & $\mathrm{k}_{66}=4.948 \cdot 10^{-11} T^{0.167} \exp \left(\frac{0.3}{T}\right)$ & 5 \\
\hline 67 & $\mathrm{AlH}+\mathrm{O}_{2} \longrightarrow \mathrm{Al}+\mathrm{HO}_{2}$ & $\mathrm{k}_{67}=2.209 \cdot 10^{-11} T^{0.17} \mathrm{EQR}\left(T,\left\{\mathrm{AlH}, \mathrm{O}_{2}\right\},\left\{\mathrm{Al}, \mathrm{HO}_{2}\right\}\right)$ & 2 \\
\hline 68 & $\mathrm{AlH}_{2}+\mathrm{M} \longrightarrow \mathrm{AlH}+\mathrm{H}+\mathrm{M}$ & $\begin{aligned} \mathrm{k}_{68}= & \mathrm{k}_{\text {Troe }}\left(1.607 \cdot 10^{-9} \exp \left(-\frac{19962}{T}\right), 2.42 \cdot 10^{-9} \exp \left(-\frac{23376}{T}\right)\right. \\
& \left., \exp \left(-\frac{942}{T}\right)-4.1 \exp (-0.04629 T)+5.1 \exp (-0.00202 T), n_{\text {tot }}\right)\end{aligned}$ & 7 \\
\hline 69 & $\mathrm{AlH}_{2}+\mathrm{H} \longrightarrow \mathrm{AlH}+\mathrm{H}_{2}$ & $\mathrm{k}_{69}=3.321 \cdot 10^{-11}$ & 7 \\
\hline 70 & $\mathrm{AlH}_{2}+\mathrm{H}_{2} \longrightarrow \mathrm{AlH}_{3}+\mathrm{H}$ & $\mathrm{k}_{70}=7.888 \cdot 10^{-15} T^{1.5} \mathrm{EQR}\left(T,\left\{\mathrm{AlH}_{2}, \mathrm{H}_{2}\right\},\left\{\mathrm{AlH}_{3}, \mathrm{H}\right\}\right)$ & 7 \\
\hline
\end{tabular}




\begin{tabular}{|c|c|c|c|}
\hline No. & Reaction & Rate coefficient $\left(\mathrm{cm}^{3(N-1)} \mathrm{s}^{-1}\right)$ with $N$ number of reactants & Ref. \\
\hline 71 & $\mathrm{AlH}_{3}+\mathrm{M} \longrightarrow \mathrm{AlH}+\mathrm{H}_{2}+\mathrm{M}$ & $\begin{aligned} \mathrm{k}_{71}= & \mathrm{k}_{\text {Troe }}\left(1.677 \cdot 10^{-9} \exp \left(-\frac{27089}{T}\right), 2.46 \cdot 10^{-11} \exp \left(-\frac{30756}{T}\right)\right. \\
& \left., \exp \left(-\frac{3807}{T}\right)+0.06 \exp (-0.00181 T)+0.94 \exp (-0.00112 T), n_{\text {tot }}\right)\end{aligned}$ & 7 \\
\hline 72 & $\mathrm{AlH}_{3}+\mathrm{H} \longrightarrow \mathrm{AlH}_{2}+\mathrm{H}_{2}$ & $\mathrm{k}_{72}=7.888 \cdot 10^{-15} T^{1.5}$ & 7 \\
\hline 73 & $\mathrm{AlO}+\mathrm{Al}+\mathrm{M} \longrightarrow \mathrm{Al}_{2} \mathrm{O}+\mathrm{M}$ & $\mathrm{k}_{73}=1.661 \cdot 10^{-9} n_{\text {tot }} \exp \left(-\frac{67035.7}{T}\right) \mathrm{EQR}\left(T,\{\mathrm{Al}, \mathrm{AlO}\},\left\{\mathrm{Al}_{2} \mathrm{O}\right\}\right)$ & 1 \\
\hline 74 & $\mathrm{AlO}+\mathrm{AlH} \longrightarrow \mathrm{AlOH}+\mathrm{Al}$ & $\mathrm{k}_{74}=4.218 \cdot 10^{-11} T^{0.17}$ & 3 \\
\hline 75 & $\mathrm{AlO}+\mathrm{AlO}+\mathrm{M} \longrightarrow \mathrm{Al}_{2} \mathrm{O}_{2}+\mathrm{M}$ & $\mathrm{k}_{75}=1.661 \cdot 10^{-9} n_{\mathrm{tot}} \exp \left(-\frac{59335.7}{T}\right) \mathrm{EQR}\left(T,\{\mathrm{AlO}\},\left\{\mathrm{Al}_{2} \mathrm{O}_{2}\right\}\right)$ & 1 \\
\hline 76 & $\mathrm{AlO}+\mathrm{CO} \longrightarrow \mathrm{Al}+\mathrm{CO}_{2}$ & $\mathrm{k}_{76}=1.214 \cdot 10^{-11} T^{0.5} \exp \left(-\frac{7470}{T}\right) \mathrm{EQR}\left(T,\{\mathrm{AlO}, \mathrm{CO}\},\left\{\mathrm{Al}, \mathrm{CO}_{2}\right\}\right)$ & 2 \\
\hline 77 & $\mathrm{AlO}+\mathrm{CO}_{2} \longrightarrow \mathrm{AlO}_{2}+\mathrm{CO}$ & $\mathrm{k}_{77}=1.187 \cdot 10^{-11} T^{0.5} \exp \left(-\frac{15600}{T}\right)$ & 2 \\
\hline 78 & $\mathrm{AlO}+\mathrm{H}+\mathrm{M} \longrightarrow \mathrm{AlOH}+\mathrm{M}$ & $\mathrm{k}_{78}=5.489 \cdot 10^{-33} T^{0.5} n_{\text {tot }}$ & 2 \\
\hline 79 & $\mathrm{AlO}+\mathrm{H}_{2} \longrightarrow \mathrm{AlOH}+\mathrm{H}$ & $\mathrm{k}_{79}=4.417 \cdot 10^{-16} T^{0.82} \exp \left(-\frac{7844}{T}\right) \mathrm{EQR}\left(T,\left\{\mathrm{AlO}, \mathrm{H}_{2}\right\},\{\mathrm{AlOH}, \mathrm{H}\}\right)$ & 4 \\
\hline 80 & $\mathrm{AlO}+\mathrm{H}_{2} \longrightarrow \mathrm{Al}+\mathrm{O}+\mathrm{H}_{2}$ & $\mathrm{k}_{80}=9.101 \cdot 10^{-31} T^{-1} \mathrm{EQR}(T,\{\mathrm{AlO}\},\{\mathrm{Al}, \mathrm{O}\})$ & 1 \\
\hline 81 & $\mathrm{AlO}+\mathrm{H}_{2} \mathrm{O} \longrightarrow \mathrm{Al}+\mathrm{O}+\mathrm{H}_{2} \mathrm{O}$ & $\mathrm{k}_{81}=2.317 \cdot 10^{-31} T^{-1} \mathrm{EQR}(T,\{\mathrm{AlO}\},\{\mathrm{Al}, \mathrm{O}\})$ & 1 \\
\hline 82 & $\mathrm{AlO}+\mathrm{H}_{2} \mathrm{O}_{2} \longrightarrow \mathrm{AlOH}+\mathrm{HO}_{2}$ & $\mathrm{k}_{82}=6.044 \cdot 10^{-11} T^{0.152} \exp \left(\frac{78.8}{T}\right)$ & 5 \\
\hline 83 & $\mathrm{AlO}+\mathrm{HO}_{2} \longrightarrow \mathrm{AlOH}+\mathrm{O}_{2}$ & $\mathrm{k}_{83}=3.637 \cdot 10^{-10} T^{-0.08} \exp \left(\frac{35}{T}\right)$ & 2 \\
\hline 84 & $\mathrm{AlO}+\mathrm{O} \longrightarrow \mathrm{Al}+\mathrm{O}_{2}$ & $\mathrm{k}_{84}=3.836 \cdot 10^{-11} T^{0.17} \mathrm{EQR}\left(T,\{\mathrm{AlO}, \mathrm{O}\},\left\{\mathrm{Al}, \mathrm{O}_{2}\right\}\right)$ & 2 \\
\hline 85 & $\mathrm{AlO}+\mathrm{O}+\mathrm{M} \longrightarrow \mathrm{AlO}_{2}+\mathrm{M}$ & $\mathrm{k}_{85}=1.661 \cdot 10^{-9} n_{\text {tot }} \exp \left(-\frac{44564.6}{T}\right) \mathrm{EQR}\left(T,\{\mathrm{AlO}, \mathrm{O}\},\left\{\mathrm{AlO}_{2}\right\}\right)$ & 1 \\
\hline 86 & $\mathrm{AlO}+\mathrm{O}_{2} \longrightarrow \mathrm{AlO}_{2}+\mathrm{O}$ & $\mathrm{k}_{86}=1.182 \cdot 10^{-11} T^{0.5} \exp \left(-\frac{13150}{T}\right)$ & 2 \\
\hline 87 & $\mathrm{AlO}+\mathrm{O}_{2} \longrightarrow \mathrm{Al}+\mathrm{O}+\mathrm{O}_{2}$ & $\mathrm{k}_{87}=9.101 \cdot 10^{-31} T^{-1} \mathrm{EQR}(T,\{\mathrm{AlO}\},\{\mathrm{Al}, \mathrm{O}\})$ & 1 \\
\hline 88 & $\mathrm{AlO}+\mathrm{OH}+\mathrm{M} \longrightarrow \mathrm{AlO}_{2} \mathrm{H}+\mathrm{M}$ & $\mathrm{k}_{88}=7.226 \cdot 10^{-33} T^{0.5} n_{\mathrm{tot}}$ & 2 \\
\hline 89 & $\mathrm{AlO}+\mathrm{OH} \longrightarrow \mathrm{AlOH}+\mathrm{O}$ & $\mathrm{k}_{89}=1.251 \cdot 10^{-11} T^{0.5} \exp \left(-\frac{4450}{T}\right) \mathrm{EQR}(T,\{\mathrm{AlO}, \mathrm{OH}\},\{\mathrm{AlOH}, \mathrm{O}\})$ & 2 \\
\hline 90 & $\mathrm{AlO}+\mathrm{OH} \longrightarrow \mathrm{Al}+\mathrm{HO}_{2}$ & $\mathrm{k}_{90}=2.209 \cdot 10^{-11} T^{0.17} \mathrm{EQR}\left(T,\{\mathrm{AlO}, \mathrm{OH}\},\left\{\mathrm{Al}, \mathrm{HO}_{2}\right\}\right)$ & 2 \\
\hline 91 & $\mathrm{AlO}_{2}+\mathrm{M} \longrightarrow \mathrm{AlO}+\mathrm{O}+\mathrm{M}$ & $\mathrm{k}_{91}=1.661 \cdot 10^{-9} n_{\text {tot }} \exp \left(-\frac{44564.6}{T}\right)$ & 1 \\
\hline 92 & $\mathrm{AlO}_{2}+\mathrm{AlO}+\mathrm{M} \longrightarrow \mathrm{Al}_{2} \mathrm{O}_{3}+\mathrm{M}$ & $\mathrm{k}_{92}=4.982 \cdot 10^{-9} n_{\text {tot }} \exp \left(-\frac{63915.4}{T}\right) \mathrm{EQR}\left(T,\left\{\mathrm{AlO}, \mathrm{AlO}_{2}\right\},\left\{\mathrm{Al}_{2} \mathrm{O}_{3}\right\}\right)$ & 1 \\
\hline 93 & $\mathrm{AlO}_{2}+\mathrm{CO} \longrightarrow \mathrm{AlO}+\mathrm{CO}_{2}$ & $\mathrm{k}_{93}=1.187 \cdot 10^{-11} T^{0.5} \exp \left(-\frac{15600}{T}\right) \operatorname{EQR}\left(T,\left\{\mathrm{AlO}_{2}, \mathrm{CO}\right\},\left\{\mathrm{AlO}, \mathrm{CO}_{2}\right\}\right)$ & 2 \\
\hline 94 & $\mathrm{AlO}_{2}+\mathrm{H}+\mathrm{M} \longrightarrow \mathrm{AlO}_{2} \mathrm{H}+\mathrm{M}$ & $\mathrm{k}_{94}=6.04 \cdot 10^{-33} T^{0.5} n_{\mathrm{tot}}$ & 2 \\
\hline 95 & $\mathrm{AlO}_{2}+\mathrm{H}_{2} \longrightarrow \mathrm{AlO}_{2} \mathrm{H}+\mathrm{H}$ & $\mathrm{k}_{95}=7.672 \cdot 10^{-14} T^{1.39} \exp \left(-\frac{2940}{T}\right)$ & 2 \\
\hline 96 & $\mathrm{AlO}_{2}+\mathrm{H}_{2} \mathrm{O} \longrightarrow \mathrm{AlO}_{2} \mathrm{H}+\mathrm{OH}$ & $\mathrm{k}_{96}=4.367 \cdot 10^{-22} T^{3.26} \exp \left(-\frac{3430}{T}\right)$ & 2 \\
\hline 97 & $\mathrm{AlO}_{2}+\mathrm{O} \longrightarrow \mathrm{AlO}+\mathrm{O}_{2}$ & $\mathrm{k}_{97}=1.182 \cdot 10^{-11} T^{0.5} \exp \left(-\frac{13150}{T}\right) \mathrm{EQR}\left(T,\left\{\mathrm{AlO}_{2}, \mathrm{O}\right\},\left\{\mathrm{AlO}, \mathrm{O}_{2}\right\}\right)$ & 2 \\
\hline 98 & $\mathrm{AlO}_{2}+\mathrm{OH} \longrightarrow \mathrm{AlO}_{2} \mathrm{H}+\mathrm{O}$ & $\mathrm{k}_{98}=4.268 \cdot 10^{-11} T^{0.17}$ & 2 \\
\hline 99 & $\mathrm{AlO}_{2} \mathrm{H}+\mathrm{M} \longrightarrow \mathrm{AlO}+\mathrm{OH}+\mathrm{M}$ & $\mathrm{k}_{99}=7.226 \cdot 10^{-33} T^{0.5} n_{\mathrm{tot}} \mathrm{EQR}\left(T,\left\{\mathrm{AlO}_{2} \mathrm{H}\right\},\{\mathrm{AlO}, \mathrm{OH}\}\right)$ & 2 \\
\hline 100 & $\mathrm{AlO}_{2} \mathrm{H}+\mathrm{M} \longrightarrow \mathrm{AlO}_{2}+\mathrm{H}+\mathrm{M}$ & $\mathrm{k}_{100}=6.04 \cdot 10^{-33} T^{0.5} n_{\mathrm{tot}} \mathrm{EQR}\left(T,\left\{\mathrm{AlO}_{2} \mathrm{H}\right\},\left\{\mathrm{AlO}_{2}, \mathrm{H}\right\}\right)$ & 2 \\
\hline 101 & $\mathrm{AlO}_{2} \mathrm{H}+\mathrm{M} \longrightarrow \mathrm{AlOH}+\mathrm{O}+\mathrm{M}$ & $\mathrm{k}_{101}=8.107 \cdot 10^{-33} T^{0.5} n_{\mathrm{tot}} \mathrm{EQR}\left(T,\left\{\mathrm{AlO}_{2} \mathrm{H}\right\},\{\mathrm{AlOH}, \mathrm{O}\}\right)$ & 2 \\
\hline 102 & $\mathrm{AlO}_{2} \mathrm{H}+\mathrm{H} \longrightarrow \mathrm{AlO}_{2} \mathrm{H}_{2}+\gamma$ & $\mathrm{k}_{102}=1.227 \cdot 10^{-10} T^{0.17}$ & 2 \\
\hline 103 & $\mathrm{AlO}_{2} \mathrm{H}+\mathrm{H} \longrightarrow \mathrm{AlO}_{2}+\mathrm{H}_{2}$ & $\mathrm{k}_{103}=7.672 \cdot 10^{-14} T^{1.39} \exp \left(-\frac{2940}{T}\right) \mathrm{EQR}\left(T,\left\{\mathrm{AlO}_{2} \mathrm{H}, \mathrm{H}\right\},\left\{\mathrm{AlO}_{2}, \mathrm{H}_{2}\right\}\right)$ & 2 \\
\hline 104 & $\mathrm{AlO}_{2} \mathrm{H}+\mathrm{H}_{2} \mathrm{O} \longrightarrow \mathrm{AlOH}+\mathrm{H}_{2} \mathrm{O}_{2}$ & $\mathrm{k}_{104}=4.367 \cdot 10^{-11} T^{0.18} \exp \left(\frac{15.4}{T}\right) \operatorname{EQR}\left(T,\left\{\mathrm{AlO}_{2} \mathrm{H}, \mathrm{H}_{2} \mathrm{O}\right\},\left\{\mathrm{AlOH}, \mathrm{H}_{2} \mathrm{O}_{2}\right\}\right)$ & 5 \\
\hline 105 & $\mathrm{AlO}_{2} \mathrm{H}+\mathrm{O} \longrightarrow \mathrm{AlOH}+\mathrm{O}_{2}$ & $\mathrm{k}_{105}=3.554 \cdot 10^{-11} T^{0.17}$ & 2 \\
\hline 106 & $\mathrm{AlO}_{2} \mathrm{H}+\mathrm{O} \longrightarrow \mathrm{AlO}_{2}+\mathrm{OH}$ & $\mathrm{k}_{106}=4.268 \cdot 10^{-11} T^{0.17} \mathrm{EQR}\left(T,\left\{\mathrm{AlO}_{2} \mathrm{H}, \mathrm{O}\right\},\left\{\mathrm{AlO}_{2}, \mathrm{OH}\right\}\right)$ & 2 \\
\hline 107 & $\mathrm{AlO}_{2} \mathrm{H}+\mathrm{OH} \longrightarrow \mathrm{AlO}_{2}+\mathrm{H}_{2} \mathrm{O}$ & $\mathrm{k}_{107}=4.367 \cdot 10^{-22} T^{3.26} \exp \left(-\frac{3430}{T}\right) \mathrm{EQR}\left(T,\left\{\mathrm{AlO}_{2} \mathrm{H}, \mathrm{OH}\right\},\left\{\mathrm{AlO}_{2}, \mathrm{H}_{2} \mathrm{O}\right\}\right)$ & 2 \\
\hline 108 & $\mathrm{AlO}_{2} \mathrm{H}+\mathrm{OH} \longrightarrow \mathrm{AlOH}+\mathrm{HO}_{2}$ & $\mathrm{k}_{108}=6.244 \cdot 10^{-11} T^{0.14} \mathrm{EQR}\left(T,\left\{\mathrm{AlO}_{2} \mathrm{H}, \mathrm{OH}\right\},\left\{\mathrm{AlOH}, \mathrm{HO}_{2}\right\}\right)$ & 2 \\
\hline
\end{tabular}




\begin{tabular}{|c|c|c|c|}
\hline No. & Reaction & Rate coefficient $\left(\mathrm{cm}^{3(N-1)} \mathrm{s}^{-1}\right)$ with $N$ number of reactants & Ref. \\
\hline 109 & $\mathrm{AlO}_{2} \mathrm{H}_{2} \longrightarrow \mathrm{AlO}_{2} \mathrm{H}+\mathrm{H}$ & $\mathrm{k}_{109}=1.227 \cdot 10^{-10} T^{0.17} \mathrm{EQR}\left(T,\left\{\mathrm{AlO}_{2} \mathrm{H}_{2}\right\},\left\{\mathrm{AlO}_{2} \mathrm{H}, \mathrm{H}\right\}\right)$ & 2 \\
\hline 110 & $\mathrm{AlO}_{2} \mathrm{H}_{2} \longrightarrow \mathrm{AlOH}+\mathrm{OH}$ & $\mathrm{k}_{110}=4.118 \cdot 10^{-11} T^{0.16} \exp \left(\frac{23}{T}\right) \mathrm{EQR}\left(T,\left\{\mathrm{AlO}_{2} \mathrm{H}_{2}\right\},\{\mathrm{AlOH}, \mathrm{OH}\}\right)$ & 2 \\
\hline 111 & $\mathrm{AlO}_{2} \mathrm{H}_{2} \longrightarrow \mathrm{Al}+\mathrm{H}_{2} \mathrm{O}_{2}$ & $\mathrm{k}_{111}=1.827 \cdot 10^{-11} T^{0.159} \exp \left(\frac{91.1}{T}\right) \mathrm{EQR}\left(T,\left\{\mathrm{AlO}_{2} \mathrm{H}_{2}\right\},\left\{\mathrm{Al}, \mathrm{H}_{2} \mathrm{O}_{2}\right\}\right)$ & 5 \\
\hline 112 & $\mathrm{AlO}_{2} \mathrm{H}_{2}+\mathrm{H}_{2} \longrightarrow \mathrm{Al}+\mathrm{H}_{2} \mathrm{O}+\mathrm{H}_{2} \mathrm{O}$ & $\mathrm{k}_{112}=3.198 \cdot 10^{-33} T^{0.5} \mathrm{EQR}\left(T,\left\{\mathrm{AlO}_{2} \mathrm{H}_{2}, \mathrm{H}_{2}\right\},\left\{\mathrm{Al}, \mathrm{H}_{2} \mathrm{O}\right\}\right)$ & 3 \\
\hline 113 & $\mathrm{AlO}_{2} \mathrm{H}_{2}+\mathrm{OH} \longrightarrow \mathrm{AlO}_{3} \mathrm{H}_{3}+\gamma$ & $\mathrm{k}_{113}=4.218 \cdot 10^{-11} T^{0.15} \exp \left(\frac{48}{T}\right)$ & 2 \\
\hline 114 & $\mathrm{AlO}_{2} \mathrm{H}_{2}+\mathrm{OH} \longrightarrow \mathrm{AlOH}+\mathrm{H}_{2} \mathrm{O}_{2}$ & $\mathrm{k}_{114}=4.367 \cdot 10^{-11} T^{0.18} \exp \left(\frac{15.4}{T}\right) \mathrm{EQR}\left(T,\left\{\mathrm{AlO}_{2} \mathrm{H}_{2}, \mathrm{OH}\right\},\left\{\mathrm{AlOH}, \mathrm{H}_{2} \mathrm{O}_{2}\right\}\right)$ & 5 \\
\hline 115 & $\mathrm{AlO}_{3} \mathrm{H}_{3} \longrightarrow \mathrm{AlO}_{2} \mathrm{H}_{2}+\mathrm{OH}$ & $\mathrm{k}_{115}=4.218 \cdot 10^{-11} T^{0.15} \exp \left(\frac{48}{T}\right) \mathrm{EQR}\left(T,\left\{\mathrm{AlO}_{3} \mathrm{H}_{3}\right\},\left\{\mathrm{AlO}_{2} \mathrm{H}_{2}, \mathrm{OH}\right\}\right)$ & 2 \\
\hline 116 & $\mathrm{AlO}_{3} \mathrm{H}_{3} \longrightarrow \mathrm{AlOH}+\mathrm{H}_{2} \mathrm{O}_{2}$ & $\mathrm{k}_{116}=4.367 \cdot 10^{-11} T^{0.18} \exp \left(\frac{15.4}{T}\right) \mathrm{EQR}\left(T,\left\{\mathrm{AlO}_{3} \mathrm{H}_{3}\right\},\left\{\mathrm{AlOH}, \mathrm{H}_{2} \mathrm{O}_{2}\right\}\right)$ & 5 \\
\hline 117 & $\mathrm{AlOH}+\mathrm{M} \longrightarrow \mathrm{AlO}+\mathrm{H}+\mathrm{M}$ & $\mathrm{k}_{117}=5.489 \cdot 10^{-33} T^{0.5} n_{\text {tot }} \mathrm{EQR}(T,\{\mathrm{AlOH}\},\{\mathrm{AlO}, \mathrm{H}\})$ & 2 \\
\hline 118 & $\mathrm{AlOH}+\mathrm{M} \longrightarrow \mathrm{Al}+\mathrm{OH}+\mathrm{M}$ & $\mathrm{k}_{118}=5.957 \cdot 10^{-33} T^{0.5} n_{\mathrm{tot}} \mathrm{EQR}(T,\{\mathrm{AlOH}\},\{\mathrm{Al}, \mathrm{OH}\})$ & 2 \\
\hline 119 & $\mathrm{AlOH}+\mathrm{Al} \longrightarrow \mathrm{AlO}+\mathrm{AlH}$ & $\mathrm{k}_{119}=4.218 \cdot 10^{-11} T^{0.17} \mathrm{EQR}(T,\{\mathrm{Al}, \mathrm{AlOH}\},\{\mathrm{AlH}, \mathrm{AlO}\})$ & 3 \\
\hline 120 & $\mathrm{AlOH}+\mathrm{H} \longrightarrow \mathrm{AlO}+\mathrm{H}_{2}$ & $\mathrm{k}_{120}=4.417 \cdot 10^{-16} T^{0.82} \exp \left(-\frac{7844}{T}\right)$ & 4 \\
\hline 121 & $\mathrm{AlOH}+\mathrm{H} \longrightarrow \mathrm{Al}+\mathrm{H}_{2} \mathrm{O}$ & $\begin{aligned} \mathrm{k}_{121}= & {\left[T^{-0.09} 3.255 \cdot 10^{-10} \exp \left(-\frac{3744}{T}\right)+4.616 \cdot 10^{-18} T^{2.06} \exp \left(-\frac{438}{T}\right)\right] } \\
& \cdot \operatorname{EQR}\left(T,\{\mathrm{AlOH}, \mathrm{H}\},\left\{\mathrm{Al}, \mathrm{H}_{2} \mathrm{O}\right\}\right)\end{aligned}$ & 4 \\
\hline 122 & $\mathrm{AlOH}+\mathrm{H}+\mathrm{H}_{2} \mathrm{O} \longrightarrow \mathrm{Al}+\mathrm{H}_{2} \mathrm{O}+\mathrm{H}_{2} \mathrm{O}$ & $\mathrm{k}_{122}=3.198 \cdot 10^{-33} T^{0.5} \exp \left(-\frac{1260}{T}\right) \mathrm{EQR}\left(T,\left\{\mathrm{AlOH}, \mathrm{H}, \mathrm{H}_{2} \mathrm{O}\right\},\left\{\mathrm{Al}, \mathrm{H}_{2} \mathrm{O}\right\}\right)$ & 3 \\
\hline 123 & $\mathrm{AlOH}+\mathrm{H}_{2} \mathrm{O}_{2} \longrightarrow \mathrm{AlO}_{2} \mathrm{H}_{2}+\mathrm{OH}$ & $\mathrm{k}_{123}=4.367 \cdot 10^{-11} T^{0.18} \exp \left(\frac{15.4}{T}\right)$ & 5 \\
\hline 124 & $\mathrm{AlOH}+\mathrm{H}_{2} \mathrm{O}_{2} \longrightarrow \mathrm{AlO}_{3} \mathrm{H}_{3}+\gamma$ & $\mathrm{k}_{124}=4.367 \cdot 10^{-11} T^{0.18} \exp \left(\frac{15.4}{T}\right)$ & 5 \\
\hline 125 & $\mathrm{AlOH}+\mathrm{H}_{2} \mathrm{O}_{2} \longrightarrow \mathrm{AlO}_{2} \mathrm{H}+\mathrm{H}_{2} \mathrm{O}$ & $\mathrm{k}_{125}=4.367 \cdot 10^{-11} T^{0.18} \exp \left(\frac{15.4}{T}\right)$ & 5 \\
\hline 126 & $\mathrm{AlOH}+\mathrm{HO}_{2} \longrightarrow \mathrm{AlO}_{2} \mathrm{H}+\mathrm{OH}$ & $\mathrm{k}_{126}=6.244 \cdot 10^{-11} T^{0.14}$ & 2 \\
\hline 127 & $\mathrm{AlOH}+\mathrm{HO}_{2} \longrightarrow \mathrm{AlO}+\mathrm{H}_{2} \mathrm{O}_{2}$ & $\mathrm{k}_{127}=6.044 \cdot 10^{-11} T^{0.152} \exp \left(\frac{78.8}{T}\right) \mathrm{EQR}\left(T,\left\{\mathrm{AlOH}, \mathrm{HO}_{2}\right\},\left\{\mathrm{AlO}, \mathrm{H}_{2} \mathrm{O}_{2}\right\}\right)$ & 5 \\
\hline 128 & $\mathrm{AlOH}+\mathrm{O} \longrightarrow \mathrm{AlO}+\mathrm{OH}$ & $\mathrm{k}_{128}=1.251 \cdot 10^{-11} T^{0.5} \exp \left(-\frac{4450}{T}\right)$ & 2 \\
\hline 129 & $\mathrm{AlOH}+\mathrm{O}+\mathrm{M} \longrightarrow \mathrm{AlO}_{2} \mathrm{H}+\mathrm{M}$ & $\mathrm{k}_{129}=8.107 \cdot 10^{-33} T^{0.5} n_{\text {tot }}$ & 2 \\
\hline 130 & $\mathrm{AlOH}+\mathrm{O}_{2} \longrightarrow \mathrm{AlO}_{2} \mathrm{H}+\mathrm{O}$ & $\mathrm{k}_{130}=3.554 \cdot 10^{-11} T^{0.17} \mathrm{EQR}\left(T,\left\{\mathrm{AlOH}, \mathrm{O}_{2}\right\},\left\{\mathrm{AlO}_{2} \mathrm{H}, \mathrm{O}\right\}\right)$ & 2 \\
\hline 131 & $\mathrm{AlOH}+\mathrm{O}_{2} \longrightarrow \mathrm{AlO}+\mathrm{HO}_{2}$ & $\mathrm{k}_{131}=T^{-0.08} 3.637 \cdot 10^{-10} \exp \left(\frac{35}{T}\right) \mathrm{EQR}\left(T,\left\{\mathrm{AlOH}, \mathrm{O}_{2}\right\},\left\{\mathrm{AlO}, \mathrm{HO}_{2}\right\}\right)$ & 2 \\
\hline 132 & $\mathrm{AlOH}+\mathrm{OH} \longrightarrow \mathrm{AlO}_{2} \mathrm{H}_{2}+\gamma$ & $\mathrm{k}_{132}=4.118 \cdot 10^{-11} T^{0.16} \exp \left(\frac{23}{T}\right)$ & 2 \\
\hline 133 & $\mathrm{AlOH}+\mathrm{OH} \longrightarrow \mathrm{Al}+\mathrm{H}_{2} \mathrm{O}_{2}$ & $\mathrm{k}_{133}=1.827 \cdot 10^{-11} T^{0.159} \exp \left(\frac{91.1}{T}\right) \mathrm{EQR}\left(T,\{\mathrm{AlOH}, \mathrm{OH}\},\left\{\mathrm{Al}, \mathrm{H}_{2} \mathrm{O}_{2}\right\}\right)$ & 5 \\
\hline 134 & $\mathrm{AlOH}+\mathrm{OH} \longrightarrow \mathrm{AlH}+\mathrm{HO}_{2}$ & $\mathrm{k}_{134}=4.948 \cdot 10^{-11} T^{0.167} \exp \left(\frac{0.3}{T}\right) \mathrm{EQR}\left(T,\{\mathrm{AlOH}, \mathrm{OH}\},\left\{\mathrm{AlH}, \mathrm{HO}_{2}\right\}\right)$ & 5 \\
\hline 135 & $\mathrm{C}+\mathrm{C} \longrightarrow \mathrm{C}_{2}+\gamma$ & $\mathrm{k}_{135}=4.36 \cdot 10^{-18}(T / 300)^{0.35} \exp \left(-\frac{161.3}{T}\right)$ & 8 \\
\hline 136 & $\mathrm{C}+\mathrm{CH} \longrightarrow \mathrm{C}_{2}+\mathrm{H}$ & $\mathrm{k}_{136}=6.59 \cdot 10^{-11}$ & 8 \\
\hline 137 & $\mathrm{C}+\mathrm{CN} \longrightarrow \mathrm{C}_{2}+\mathrm{N}$ & $\mathrm{k}_{137}=4.98 \cdot 10^{-10} \exp \left(-\frac{18116}{T}\right)$ & 8 \\
\hline 138 & $\mathrm{C}+\mathrm{CO} \longrightarrow \mathrm{C}_{2}+\mathrm{O}$ & $\mathrm{k}_{138}=2.94 \cdot 10^{-11}(T / 300)^{0.5} \exp \left(-\frac{58025}{T}\right)$ & 8 \\
\hline 139 & $\mathrm{C} \stackrel{\mathrm{CR}}{\longrightarrow} \mathrm{C}^{+}+\mathrm{e}^{-}$ & $\mathrm{k}_{139}=1.69117 \zeta$ & 8 \\
\hline 140 & $\mathrm{C}+\mathrm{CS} \longrightarrow \mathrm{S}+\mathrm{C}_{2}$ & $\mathrm{k}_{140}=1.44 \cdot 10^{-11}(T / 300)^{0.5} \exp \left(-\frac{20435}{T}\right)$ & 8 \\
\hline 141 & $\mathrm{C}+\mathrm{e}^{-} \longrightarrow \mathrm{C}^{-}+\gamma$ & $\mathrm{k}_{141}=2.25 \cdot 10^{-15}$ & 8 \\
\hline 142 & $\mathrm{C}+\mathrm{HCO}^{+} \longrightarrow \mathrm{CO}+\mathrm{CH}^{+}$ & $\mathrm{k}_{142}=1.1 \cdot 10^{-9}$ & 8 \\
\hline 143 & $\mathrm{C}+\mathrm{HS} \longrightarrow \mathrm{CS}+\mathrm{H}$ & $\mathrm{k}_{143}=1 \cdot 10^{-10}$ & 8 \\
\hline 144 & $\mathrm{C}+\mathrm{HS} \longrightarrow \mathrm{S}+\mathrm{CH}$ & $\mathrm{k}_{144}=1.2 \cdot 10^{-11}(T / 300)^{0.58} \exp \left(-\frac{5880}{T}\right)$ & 8 \\
\hline 145 & $\mathrm{C}+\mathrm{N} \longrightarrow \mathrm{CN}+\gamma$ & $\mathrm{k}_{145}=5.72 \cdot 10^{-19}(T / 300)^{0.37} \exp \left(-\frac{51}{T}\right)$ & 8 \\
\hline
\end{tabular}




\begin{tabular}{|c|c|c|c|}
\hline No. & Reaction & Rate coefficient $\left(\mathrm{cm}^{3(N-1)} \mathrm{s}^{-1}\right)$ with $N$ number of reactants & Ref. \\
\hline 146 & $\mathrm{C}+\mathrm{N}_{2} \longrightarrow \mathrm{CN}+\mathrm{N}$ & $\mathrm{k}_{146}=8.69 \cdot 10^{-11} \exp \left(-\frac{22600}{T}\right)$ & 8 \\
\hline 147 & $\mathrm{C}+\mathrm{NH} \longrightarrow \mathrm{N}+\mathrm{CH}$ & $\mathrm{k}_{147}=1.73 \cdot 10^{-11}(T / 300)^{0.5} \exp \left(-\frac{4000}{T}\right)$ & 8 \\
\hline 148 & $\mathrm{C}+\mathrm{NH} \longrightarrow \mathrm{CN}+\mathrm{H}$ & $\mathrm{k}_{148}=1.2 \cdot 10^{-10}$ & 8 \\
\hline 149 & $\mathrm{C}+\mathrm{NO} \longrightarrow \mathrm{CO}+\mathrm{N}$ & $\mathrm{k}_{149}=9 \cdot 10^{-11}(T / 300)^{-0.16}$ & 8 \\
\hline 150 & $\mathrm{C}+\mathrm{NO} \longrightarrow \mathrm{CN}+\mathrm{O}$ & $\mathrm{k}_{150}=6 \cdot 10^{-11}(T / 300)^{-0.16}$ & 8 \\
\hline 151 & $\mathrm{C}+\mathrm{NS} \longrightarrow \mathrm{S}+\mathrm{CN}$ & $\mathrm{k}_{151}=1.5 \cdot 10^{-10}(T / 300)^{-0.16}$ & 8 \\
\hline 152 & $\mathrm{C}+\mathrm{O} \longrightarrow \mathrm{CO}+\gamma$ & $\mathrm{k}_{152}=4.69 \cdot 10^{-19}(T / 300)^{1.52} \exp \left(\frac{50.5}{T}\right)$ & 8 \\
\hline 153 & $\mathrm{C}+\mathrm{O}_{2} \longrightarrow \mathrm{CO}+\mathrm{O}$ & $\mathrm{k}_{153}=5.56 \cdot 10^{-11}(T / 300)^{0.41} \exp \left(\frac{26.9}{T}\right)$ & 8 \\
\hline 154 & $\mathrm{C}+\mathrm{OH} \longrightarrow \mathrm{O}+\mathrm{CH}$ & $\mathrm{k}_{154}=2.25 \cdot 10^{-11}(T / 300)^{0.5} \exp \left(-\frac{14800}{T}\right)$ & 8 \\
\hline 155 & $\mathrm{C}+\mathrm{OH} \longrightarrow \mathrm{CO}+\mathrm{H}$ & $\mathrm{k}_{155}=1 \cdot 10^{-10}$ & 8 \\
\hline 156 & $\mathrm{C}+\mathrm{S} \longrightarrow \mathrm{CS}+\gamma$ & $\mathrm{k}_{156}=4.36 \cdot 10^{-19}(T / 300)^{0.22}$ & 8 \\
\hline 157 & $\mathrm{C}+\mathrm{SO} \longrightarrow \mathrm{CS}+\mathrm{O}$ & $\mathrm{k}_{157}=3.5 \cdot 10^{-11}$ & 8 \\
\hline 158 & $\mathrm{C}+\mathrm{SO} \longrightarrow \mathrm{S}+\mathrm{CO}$ & $\mathrm{k}_{158}=3.5 \cdot 10^{-11}$ & 8 \\
\hline 159 & $\mathrm{C}+\mathrm{SO}_{2} \longrightarrow \mathrm{CO}+\mathrm{SO}$ & $\mathrm{k}_{159}=7 \cdot 10^{-11}$ & 8 \\
\hline 160 & $\mathrm{C}+\mathrm{SiO}^{+} \longrightarrow \mathrm{Si}^{+}+\mathrm{CO}$ & $\mathrm{k}_{160}=1 \cdot 10^{-9}$ & 8 \\
\hline 161 & $\mathrm{C}^{+}+\mathrm{e}^{-} \longrightarrow \mathrm{C}+\gamma$ & $\mathrm{k}_{161}=2.36 \cdot 10^{-12}(T / 300)^{-0.29} \exp \left(\frac{17.6}{T}\right)$ & 8 \\
\hline 162 & $\mathrm{C}^{+}+\mathrm{Fe} \longrightarrow \mathrm{Fe}^{+}+\mathrm{C}$ & $\mathrm{k}_{162}=2.6 \cdot 10^{-9}$ & 8 \\
\hline 163 & $\mathrm{C}^{+}+\mathrm{Mg} \longrightarrow \mathrm{Mg}^{+}+\mathrm{C}$ & $\mathrm{k}_{163}=1.1 \cdot 10^{-9}$ & 8 \\
\hline 164 & $\mathrm{C}^{+}+\mathrm{Si} \longrightarrow \mathrm{Si}^{+}+\mathrm{C}$ & $\mathrm{k}_{164}=2.1 \cdot 10^{-9}$ & 8 \\
\hline 165 & $\mathrm{C}^{-}+\mathrm{H}^{+} \longrightarrow \mathrm{C}+\mathrm{H}$ & $\mathrm{k}_{165}=7.51 \cdot 10^{-8}(T / 300)^{-0.5}$ & 8 \\
\hline 166 & $\mathrm{C}_{2}+\mathrm{S} \longrightarrow \mathrm{CS}+\mathrm{C}$ & $\mathrm{k}_{166}=1 \cdot 10^{-10}$ & 8 \\
\hline 167 & $\mathrm{CH}+\mathrm{N} \longrightarrow \mathrm{NH}+\mathrm{C}$ & $\mathrm{k}_{167}=3.03 \cdot 10^{-11}(T / 300)^{0.65} \exp \left(-\frac{1207}{T}\right)$ & 8 \\
\hline 168 & $\mathrm{CH}+\mathrm{N} \longrightarrow \mathrm{CN}+\mathrm{H}$ & $\mathrm{k}_{168}=1.66 \cdot 10^{-10}(T / 300)^{-0.09}$ & 8 \\
\hline 169 & $\mathrm{CH}+\mathrm{O} \longrightarrow \mathrm{OH}+\mathrm{C}$ & $\mathrm{k}_{169}=2.52 \cdot 10^{-11} \exp \left(-\frac{2381}{T}\right)$ & 8 \\
\hline 170 & $\mathrm{CH}+\mathrm{O} \longrightarrow \mathrm{CO}+\mathrm{H}$ & $\mathrm{k}_{170}=6.02 \cdot 10^{-11}(T / 300)^{0.1} \exp \left(\frac{4.5}{T}\right)$ & 8 \\
\hline 171 & $\mathrm{CH}+\mathrm{O} \longrightarrow \mathrm{HCO}^{+}+\mathrm{e}^{-}$ & $\mathrm{k}_{171}=1.09 \cdot 10^{-11}(T / 300)^{-2.19} \exp \left(-\frac{165.1}{T}\right)$ & 8 \\
\hline 172 & $\mathrm{CH}+\mathrm{S} \longrightarrow \mathrm{CS}+\mathrm{H}$ & $\mathrm{k}_{172}=5 \cdot 10^{-11}$ & 8 \\
\hline 173 & $\mathrm{CH}+\mathrm{S} \longrightarrow \mathrm{HS}+\mathrm{C}$ & $\mathrm{k}_{173}=1.73 \cdot 10^{-11}(T / 300)^{0.5} \exp \left(-\frac{4000}{T}\right)$ & 8 \\
\hline 174 & $\mathrm{CH}^{+}+\mathrm{e}^{-} \longrightarrow \mathrm{C}+\mathrm{H}$ & $\mathrm{k}_{174}=1.5 \cdot 10^{-7}(T / 300)^{-0.42}$ & 8 \\
\hline 175 & $\mathrm{CN}+\mathrm{O}_{2} \longrightarrow \mathrm{OCN}+\mathrm{O}$ & $\mathrm{k}_{175}=2.02 \cdot 10^{-11}(T / 300)^{-0.19} \exp \left(\frac{31.9}{T}\right)$ & 8 \\
\hline 176 & $\mathrm{CN}+\mathrm{S} \longrightarrow \mathrm{NS}+\mathrm{C}$ & $\mathrm{k}_{176}=5.71 \cdot 10^{-11}(T / 300)^{0.5} \exp \left(-\frac{32010}{T}\right)$ & 8 \\
\hline 177 & $\mathrm{CO} \stackrel{\mathrm{CR}}{\longrightarrow} \mathrm{CO}^{+}+\mathrm{e}^{-}$ & $\mathrm{k}_{177}=2.86764 \zeta$ & 8 \\
\hline 178 & $\mathrm{CO} \stackrel{\mathrm{CR}}{\longrightarrow} \mathrm{C}+\mathrm{O}$ & $\mathrm{k}_{178}=5 \zeta$ & 9 \\
\hline 179 & $\mathrm{CO}^{+}+\mathrm{e}^{-} \longrightarrow \mathrm{O}+\mathrm{C}$ & $\mathrm{k}_{179}=2 \cdot 10^{-7}(T / 300)^{-0.48}$ & 8 \\
\hline 180 & $\mathrm{~F}^{+}+\mathrm{e}^{-} \longrightarrow \mathrm{F}+\gamma$ & $\mathrm{k}_{180}=6.273 \cdot 10^{-13}\left(\frac{10000}{T}\right)^{0.6789}$ & 10 \\
\hline 181 & $\mathrm{Fe}^{+}+\mathrm{e}^{-} \longrightarrow \mathrm{Fe}+\gamma$ & $\mathrm{k}_{181}=2.55 \cdot 10^{-12}(T / 300)^{-0.69}$ & 8 \\
\hline 182 & $\mathrm{H}+\mathrm{C} \longrightarrow \mathrm{CH}+\gamma$ & $\mathrm{k}_{182}=1 \cdot 10^{-17}$ & 8 \\
\hline 183 & $\mathrm{H}+\mathrm{C}^{-} \longrightarrow \mathrm{CH}+\mathrm{e}^{-}$ & $\mathrm{k}_{183}=5 \cdot 10^{-10}$ & 8 \\
\hline 184 & $\mathrm{H}+\mathrm{C}_{2} \longrightarrow \mathrm{CH}+\mathrm{C}$ & $\mathrm{k}_{184}=4.67 \cdot 10^{-10}(T / 300)^{0.5} \exp \left(-\frac{30450}{T}\right)$ & 8 \\
\hline
\end{tabular}




\begin{tabular}{|c|c|c|c|}
\hline No. & Reaction & Rate coefficient $\left(\mathrm{cm}^{3(N-1)} \mathrm{s}^{-1}\right)$ with $N$ number of reactants & Ref. \\
\hline 185 & $\mathrm{H}+\mathrm{CH} \longrightarrow \mathrm{C}+\mathrm{H}_{2}$ & $\mathrm{k}_{185}=1.31 \cdot 10^{-10} \exp \left(-\frac{80}{T}\right)$ & 8 \\
\hline 186 & $\mathrm{H}+\mathrm{CH} \longrightarrow \mathrm{C}+\mathrm{H}+\mathrm{H}$ & $\mathrm{k}_{186}=6 \cdot 10^{-9} \exp \left(-\frac{40200}{T}\right)$ & 8 \\
\hline 187 & $\mathrm{H}+\mathrm{CH}^{+} \longrightarrow \mathrm{C}^{+}+\mathrm{H}_{2}$ & $\mathrm{k}_{187}=9.06 \cdot 10^{-10}(T / 300)^{-0.37} \exp \left(-\frac{29.1}{T}\right)$ & 8 \\
\hline 188 & $\mathrm{H}+\mathrm{CH}_{2} \longrightarrow \mathrm{CH}+\mathrm{H}_{2}$ & $\mathrm{k}_{188}=2.2 \cdot 10^{-10}$ & 8 \\
\hline 189 & $\mathrm{H}+\mathrm{CO} \longrightarrow \mathrm{OH}+\mathrm{C}$ & $\mathrm{k}_{189}=1.1 \cdot 10^{-10}(T / 300)^{0.5} \exp \left(-\frac{77700}{T}\right)$ & 8 \\
\hline 190 & $\mathrm{H}+\mathrm{CO}_{2} \longrightarrow \mathrm{CO}+\mathrm{OH}$ & $\mathrm{k}_{190}=3.38 \cdot 10^{-10} \exp \left(-\frac{13163}{T}\right)$ & 8 \\
\hline 191 & $\mathrm{H} \stackrel{\mathrm{CR}}{\longrightarrow} \mathrm{H}^{+}+\mathrm{e}^{-}$ & $\mathrm{k}_{191}=0.43970 \zeta$ & 8 \\
\hline 192 & $\mathrm{H}+\mathrm{e}^{-} \longrightarrow \mathrm{H}^{-}+\gamma$ & $\mathrm{k}_{192}=3.37 \cdot 10^{-16}(T / 300)^{0.64} \exp \left(-\frac{9.2}{T}\right)$ & 8 \\
\hline \multirow[t]{5}{*}{193} & $\mathrm{H}+\mathrm{e}^{-} \longrightarrow \mathrm{H}^{+}+\mathrm{e}^{-}+\mathrm{e}^{-}$ & $\mathrm{k}_{193}=\exp \left(-2.03914 \cdot 10^{-6} \ln ^{8}\left(T_{\mathrm{e}}\right)\right.$ & 11 \\
\hline & & $+0.00011 \ln ^{7}\left(T_{\mathrm{e}}\right)-0.00263 \ln ^{6}\left(T_{\mathrm{e}}\right)$ & \\
\hline & & $+0.03482 \ln ^{5}\left(T_{\mathrm{e}}\right)-0.28770 \ln ^{4}\left(T_{\mathrm{e}}\right)$ & \\
\hline & & $+1.56315 \ln ^{3}\left(T_{\mathrm{e}}\right)-5.73932 \ln ^{2}\left(T_{\mathrm{e}}\right)$ & \\
\hline & & $\left.+13.53655 \ln \left(T_{\mathrm{e}}\right)-32.71396\right)$ & \\
\hline 194 & $\mathrm{H}+\mathrm{H}+\mathrm{H} \longrightarrow \mathrm{H}_{2}+\mathrm{H}$ & $\mathrm{k}_{194}=2 \cdot 10^{-31} T^{-0.5}+6 \cdot 10^{-32} T^{-0.25}$ & 12 \\
\hline 195 & $\mathrm{H}+\mathrm{H}+\mathrm{He} \longrightarrow \mathrm{H}_{2}+\mathrm{He}$ & $\mathrm{k}_{195}=6.9 \cdot 10^{-32} T^{-0.4}$ & 13 \\
\hline 196 & $\mathrm{H}+\mathrm{H}_{2} \longrightarrow \mathrm{H}+\mathrm{H}+\mathrm{H}$ & $\mathrm{k}_{196}=4.67 \cdot 10^{-7}(T / 300)^{-1} \exp \left(-\frac{55000}{T}\right)$ & 8 \\
\hline 197 & $\mathrm{H}+\mathrm{H}_{2}^{+} \longrightarrow \mathrm{H}_{2}+\mathrm{H}^{+}$ & $\mathrm{k}_{197}=6.4 \cdot 10^{-10}$ & 8 \\
\hline 198 & $\mathrm{H}+\mathrm{H}_{2} \mathrm{O} \longrightarrow \mathrm{OH}+\mathrm{H}+\mathrm{H}$ & $\mathrm{k}_{198}=5.8 \cdot 10^{-9} \exp \left(-\frac{52900}{T}\right)$ & 8 \\
\hline 199 & $\mathrm{H}+\mathrm{H}_{2} \mathrm{O} \longrightarrow \mathrm{OH}+\mathrm{H}_{2}$ & $\mathrm{k}_{199}=1.59 \cdot 10^{-11}(T / 300)^{1.2} \exp \left(-\frac{9610}{T}\right)$ & 8 \\
\hline 200 & $\mathrm{H}+\mathrm{H}_{2} \mathrm{~S} \longrightarrow \mathrm{HS}+\mathrm{H}_{2}$ & $\mathrm{k}_{200}=3.71 \cdot 10^{-12}(T / 300)^{1.94} \exp \left(-\frac{455}{T}\right)$ & 8 \\
\hline 201 & $\mathrm{H}+\mathrm{HCN} \longrightarrow \mathrm{CN}+\mathrm{H}_{2}$ & $\mathrm{k}_{201}=6.2 \cdot 10^{-10} \exp \left(-\frac{12500}{T}\right)$ & 8 \\
\hline 202 & $\mathrm{H}+\mathrm{HCO} \longrightarrow \mathrm{CO}+\mathrm{H}_{2}$ & $\mathrm{k}_{202}=1.5 \cdot 10^{-10}$ & 8 \\
\hline 203 & $\mathrm{H}+\mathrm{HS} \longrightarrow \mathrm{S}+\mathrm{H}_{2}$ & $\mathrm{k}_{203}=2.5 \cdot 10^{-11}$ & 8 \\
\hline 204 & $\mathrm{H}+\mathrm{HS}^{+} \longrightarrow \mathrm{S}^{+}+\mathrm{H}_{2}$ & $\mathrm{k}_{204}=1.1 \cdot 10^{-10}$ & 8 \\
\hline 205 & $\mathrm{H}+\mathrm{He}^{+} \longrightarrow \mathrm{He}+\mathrm{H}^{+}$ & $\mathrm{k}_{205}=1.2 \cdot 10^{-15}(T / 300)^{0.25}$ & 8 \\
\hline 206 & $\mathrm{H}+\mathrm{HeH}^{+} \longrightarrow \mathrm{He}+\mathrm{H}_{2}^{+}$ & $\mathrm{k}_{206}=9.1 \cdot 10^{-10}$ & 8 \\
\hline 207 & $\mathrm{H}+\mathrm{NH} \longrightarrow \mathrm{N}+\mathrm{H}_{2}$ & $\mathrm{k}_{207}=1.73 \cdot 10^{-11}(T / 300)^{0.5} \exp \left(-\frac{2400}{T}\right)$ & 8 \\
\hline 208 & $\mathrm{H}+\mathrm{NH}_{2} \longrightarrow \mathrm{NH}+\mathrm{H}_{2}$ & $\mathrm{k}_{208}=4.56 \cdot 10^{-12}(T / 300)^{1.02} \exp \left(-\frac{2161}{T}\right)$ & 8 \\
\hline 209 & $\mathrm{H}+\mathrm{NO} \longrightarrow \mathrm{OH}+\mathrm{N}$ & $\mathrm{k}_{209}=3.6 \cdot 10^{-10} \exp \left(-\frac{24910}{T}\right)$ & 8 \\
\hline 210 & $\mathrm{H}+\mathrm{NO} \longrightarrow \mathrm{O}+\mathrm{NH}$ & $\mathrm{k}_{210}=9.29 \cdot 10^{-10}(T / 300)^{-0.1} \exp \left(-\frac{35220}{T}\right)$ & 8 \\
\hline 211 & $\mathrm{H}+\mathrm{NS} \longrightarrow \mathrm{HS}+\mathrm{N}$ & $\mathrm{k}_{211}=7.27 \cdot 10^{-11}(T / 300)^{0.5} \exp \left(-\frac{15700}{T}\right)$ & 8 \\
\hline 212 & $\mathrm{H}+\mathrm{NS} \longrightarrow \mathrm{S}+\mathrm{NH}$ & $\mathrm{k}_{212}=7.27 \cdot 10^{-11}(T / 300)^{0.5} \exp \left(-\frac{20735}{T}\right)$ & 8 \\
\hline 213 & $\mathrm{H}+\mathrm{O} \longrightarrow \mathrm{OH}+\gamma$ & $\mathrm{k}_{213}=9.9 \cdot 10^{-19}(T / 300)^{-0.38}$ & 8 \\
\hline 214 & $\mathrm{H}+\mathrm{O}^{+} \longrightarrow \mathrm{O}+\mathrm{H}^{+}$ & $\mathrm{k}_{214}=5.66 \cdot 10^{-10}(T / 300)^{0.36} \exp \left(\frac{8.6}{T}\right)$ & 8 \\
\hline 215 & $\mathrm{H}+\mathrm{O}^{-} \longrightarrow \mathrm{OH}+\mathrm{e}^{-}$ & $\mathrm{k}_{215}=5 \cdot 10^{-10}$ & 8 \\
\hline 216 & $\mathrm{H}+\mathrm{O}_{2} \longrightarrow \mathrm{O}+\mathrm{O}+\mathrm{H}$ & $\mathrm{k}_{216}=6 \cdot 10^{-9} \exp \left(-\frac{52300}{T}\right)$ & 8 \\
\hline 217 & $\mathrm{H}+\mathrm{O}_{2} \longrightarrow \mathrm{OH}+\mathrm{O}$ & $\mathrm{k}_{217}=2.61 \cdot 10^{-10} \exp \left(-\frac{8156}{T}\right)$ & 8 \\
\hline 218 & $\mathrm{H}+\mathrm{O}_{3} \longrightarrow \mathrm{OH}+\mathrm{O}_{2}$ & $\mathrm{k}_{218}=1.4 \cdot 10^{-10} \exp \left(\frac{470}{T}\right)$ & 14 \\
\hline
\end{tabular}




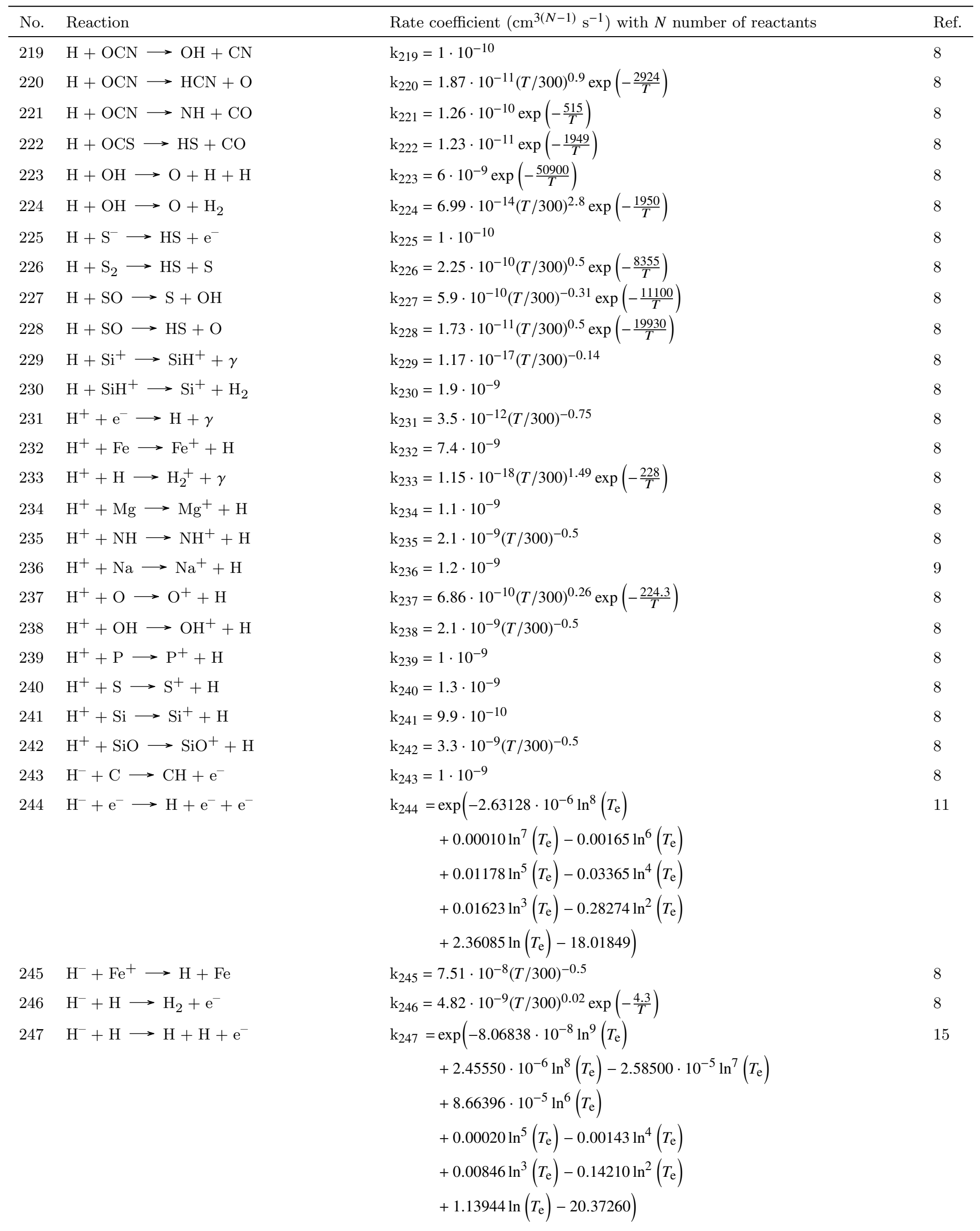




\begin{tabular}{|c|c|c|c|}
\hline No. & Reaction & Rate coefficient $\left(\mathrm{cm}^{3(N-1)} \mathrm{s}^{-1}\right)$ with $N$ number of reactants & Ref. \\
\hline 248 & $\mathrm{H}^{-}+\mathrm{H}^{+} \longrightarrow \mathrm{H}+\mathrm{H}$ & $\mathrm{k}_{248}=7.51 \cdot 10^{-8}(T / 300)^{-0.5}$ & 8 \\
\hline 249 & $\mathrm{H}^{-}+\mathrm{H}^{+} \longrightarrow \mathrm{H}_{2}^{+}+\mathrm{e}^{-}$ & $\mathrm{k}_{249}=1 \cdot 10^{-8} T^{-0.4}$ & 16 \\
\hline 250 & $\mathrm{H}^{-}+\mathrm{Mg}^{+} \longrightarrow \mathrm{H}+\mathrm{Mg}$ & $\mathrm{k}_{250}=7.51 \cdot 10^{-8}(T / 300)^{-0.5}$ & 8 \\
\hline 251 & $\mathrm{H}^{-}+\mathrm{N} \longrightarrow \mathrm{NH}+\mathrm{e}^{-}$ & $\mathrm{k}_{251}=1 \cdot 10^{-9}$ & 8 \\
\hline 252 & $\mathrm{H}^{-}+\mathrm{Na}^{+} \longrightarrow \mathrm{H}+\mathrm{Na}$ & $\mathrm{k}_{252}=7.51 \cdot 10^{-8}(T / 300)^{-0.5}$ & 8 \\
\hline 253 & $\mathrm{H}^{-}+\mathrm{O} \longrightarrow \mathrm{OH}+\mathrm{e}^{-}$ & $\mathrm{k}_{253}=1 \cdot 10^{-9}$ & 8 \\
\hline 254 & $\mathrm{H}^{-}+\mathrm{O}^{+} \longrightarrow \mathrm{H}+\mathrm{O}$ & $\mathrm{k}_{254}=7.51 \cdot 10^{-8}(T / 300)^{-0.5}$ & 8 \\
\hline 255 & $\mathrm{H}^{-}+\mathrm{S}^{+} \longrightarrow \mathrm{H}+\mathrm{S}$ & $\mathrm{k}_{255}=7.51 \cdot 10^{-8}(T / 300)^{-0.5}$ & 8 \\
\hline 256 & $\mathrm{H}^{-}+\mathrm{Si}^{+} \longrightarrow \mathrm{H}+\mathrm{Si}$ & $\mathrm{k}_{256}=7.51 \cdot 10^{-8}(T / 300)^{-0.5}$ & 8 \\
\hline 257 & $\mathrm{H}_{2}+\mathrm{C} \longrightarrow \mathrm{CH}+\mathrm{H}$ & $\mathrm{k}_{257}=6.64 \cdot 10^{-10} \exp \left(-\frac{11700}{T}\right)$ & 8 \\
\hline 258 & $\mathrm{H}_{2}+\mathrm{C} \longrightarrow \mathrm{CH}_{2}+\gamma$ & $\mathrm{k}_{258}=1 \cdot 10^{-17}$ & 8 \\
\hline 259 & $\mathrm{H}_{2}+\mathrm{CH} \longrightarrow \mathrm{CH}_{2}+\mathrm{H}$ & $\mathrm{k}_{259}=5.46 \cdot 10^{-10} \exp \left(-\frac{1943}{T}\right)$ & 8 \\
\hline 260 & $\mathrm{H}_{2}+\mathrm{CN} \longrightarrow \mathrm{HCN}+\mathrm{H}$ & $\mathrm{k}_{260}=4.04 \cdot 10^{-13}(T / 300)^{2.87} \exp \left(-\frac{820}{T}\right)$ & 8 \\
\hline 261 & $\mathrm{H}_{2} \stackrel{\mathrm{CR}}{\longrightarrow} \mathrm{H}^{+}+\mathrm{H}^{-}$ & $\mathrm{k}_{261}=0.00028 \zeta$ & 8 \\
\hline 262 & $\mathrm{H}_{2} \stackrel{\mathrm{CR}}{\longrightarrow} \mathrm{H}^{+}+\mathrm{H}+\mathrm{e}^{-}$ & $\mathrm{k}_{262}=0.02102 \zeta$ & 8 \\
\hline 263 & $\mathrm{H}_{2} \stackrel{\mathrm{CR}}{\longrightarrow} \mathrm{H}+\mathrm{H}$ & $\mathrm{k}_{263}=0.09558 \zeta$ & 8 \\
\hline 264 & $\mathrm{H}_{2} \stackrel{\mathrm{CR}}{\longrightarrow} \mathrm{H}_{2}^{+}+\mathrm{e}^{-}$ & $\mathrm{k}_{264}=0.88235 \zeta$ & 8 \\
\hline 265 & $\mathrm{H}_{2}+\mathrm{e}^{-} \longrightarrow \mathrm{H}+\mathrm{H}+\mathrm{e}^{-}$ & $\mathrm{k}_{265}=3.22 \cdot 10^{-9}(T / 300)^{0.35} \exp \left(-\frac{102000}{T}\right)$ & 8 \\
\hline 266 & $\mathrm{H}_{2}+\mathrm{e}^{-} \longrightarrow \mathrm{H}+\mathrm{H}^{-}$ & $\mathrm{k}_{266}=35.5 T^{-2.28} \exp \left(-\frac{46707}{T}\right)$ & 17 \\
\hline 267 & $\mathrm{H}_{2}+\mathrm{F} \longrightarrow \mathrm{HF}+\mathrm{H}$ & $\mathrm{k}_{267}=1 \cdot 10^{-10} \exp \left(-\frac{400}{T}\right)$ & 8 \\
\hline 268 & $\mathrm{H}_{2}+\mathrm{F}^{+} \longrightarrow \mathrm{H}_{2}^{+}+\mathrm{F}$ & $\mathrm{k}_{268}=6.24 \cdot 10^{-10}$ & 8 \\
\hline 269 & $\mathrm{H}_{2}+\mathrm{H}+\mathrm{H} \longrightarrow \mathrm{H}_{2}+\mathrm{H}_{2}$ & $\mathrm{k}_{269}=2.5 \cdot 10^{-32} T^{-0.5}+T^{-0.25} 7.5 \cdot 10^{-33}$ & 13 \\
\hline \multirow[t]{4}{*}{270} & $\mathrm{H}_{2}+\mathrm{H}^{+} \longrightarrow \mathrm{H}_{2}^{+}+\mathrm{H}$ & $\mathrm{k}_{270}=\left(3.53119 \cdot 10^{-13} \ln ^{7}(T)-1.81714 \cdot 10^{-11} \ln ^{6}(T)\right.$ & 18 \\
\hline & & $+3.97315 \cdot 10^{-10} \ln ^{5}(T)-4.78137 \cdot 10^{-9} \ln ^{4}(T)$ & \\
\hline & & $+3.41728 \cdot 10^{-8} \ln ^{3}(T)-1.44913 \cdot 10^{-7} \ln ^{2}(T)$ & \\
\hline & & $\left.+3.37353 \cdot 10^{-7} \ln (T)-3.32321 \cdot 10^{-7}\right) \exp \left(-\frac{21237.15}{T}\right)$ & \\
\hline 271 & $\mathrm{H}_{2}+\mathrm{HS} \longrightarrow \mathrm{H}_{2} \mathrm{~S}+\mathrm{H}$ & $\mathrm{k}_{271}=6.52 \cdot 10^{-12}(T / 300)^{0.09} \exp \left(-\frac{8050}{T}\right)$ & 8 \\
\hline 272 & $\mathrm{H}_{2}+\mathrm{N} \longrightarrow \mathrm{NH}+\mathrm{H}$ & $\mathrm{k}_{272}=1.69 \cdot 10^{-9} \exp \left(-\frac{18095}{T}\right)$ & 8 \\
\hline 273 & $\mathrm{H}_{2}+\mathrm{NH} \longrightarrow \mathrm{NH}_{2}+\mathrm{H}$ & $\mathrm{k}_{273}=5.96 \cdot 10^{-11} \exp \left(-\frac{7782}{T}\right)$ & 8 \\
\hline 274 & $\mathrm{H}_{2}+\mathrm{O} \longrightarrow \mathrm{OH}+\mathrm{H}$ & $\mathrm{k}_{274}=3.14 \cdot 10^{-13}(T / 300)^{2.7} \exp \left(-\frac{3150}{T}\right)$ & 8 \\
\hline 275 & $\mathrm{H}_{2}+\mathrm{O}^{+} \longrightarrow \mathrm{OH}^{+}+\mathrm{H}$ & $\mathrm{k}_{275}=1.7 \cdot 10^{-9}$ & 8 \\
\hline 276 & $\mathrm{H}_{2}+\mathrm{O}_{2} \longrightarrow \mathrm{OH}+\mathrm{OH}$ & $\mathrm{k}_{276}=3.16 \cdot 10^{-10} \exp \left(-\frac{21890}{T}\right)$ & 8 \\
\hline 277 & $\mathrm{H}_{2}+\mathrm{OH} \longrightarrow \mathrm{H}_{2} \mathrm{O}+\mathrm{H}$ & $\mathrm{k}_{277}=2.05 \cdot 10^{-12}(T / 300)^{1.52} \exp \left(-\frac{1736}{T}\right)$ & 8 \\
\hline 278 & $\mathrm{H}_{2}+\mathrm{S} \longrightarrow \mathrm{HS}+\mathrm{H}$ & $\mathrm{k}_{278}=1.76 \cdot 10^{-13}(T / 300)^{2.88} \exp \left(-\frac{6126}{T}\right)$ & 8 \\
\hline 279 & $\mathrm{H}_{2}+\mathrm{S}^{+} \longrightarrow \mathrm{HS}^{+}+\mathrm{H}$ & $\mathrm{k}_{279}=1.1 \cdot 10^{-10} \exp \left(-\frac{9860}{T}\right)$ & 8 \\
\hline 280 & $\mathrm{H}_{2}^{+}+\mathrm{C} \longrightarrow \mathrm{CH}^{+}+\mathrm{H}$ & $\mathrm{k}_{280}=2.4 \cdot 10^{-9}$ & 8 \\
\hline 281 & $\mathrm{H}_{2}^{+}+\mathrm{e}^{-} \longrightarrow \mathrm{H}+\mathrm{H}$ & $\mathrm{k}_{281}=1.6 \cdot 10^{-8}(T / 300)^{-0.43}$ & 8 \\
\hline 282 & $\mathrm{H}_{2}^{+}+\mathrm{He} \longrightarrow \mathrm{HeH}^{+}+\mathrm{H}$ & $\mathrm{k}_{282}=1.3 \cdot 10^{-10}$ & 8 \\
\hline 283 & $\mathrm{H}_{2}^{+}+\mathrm{O} \longrightarrow \mathrm{OH}^{+}+\mathrm{H}$ & $\mathrm{k}_{283}=1.5 \cdot 10^{-9}$ & 8 \\
\hline
\end{tabular}




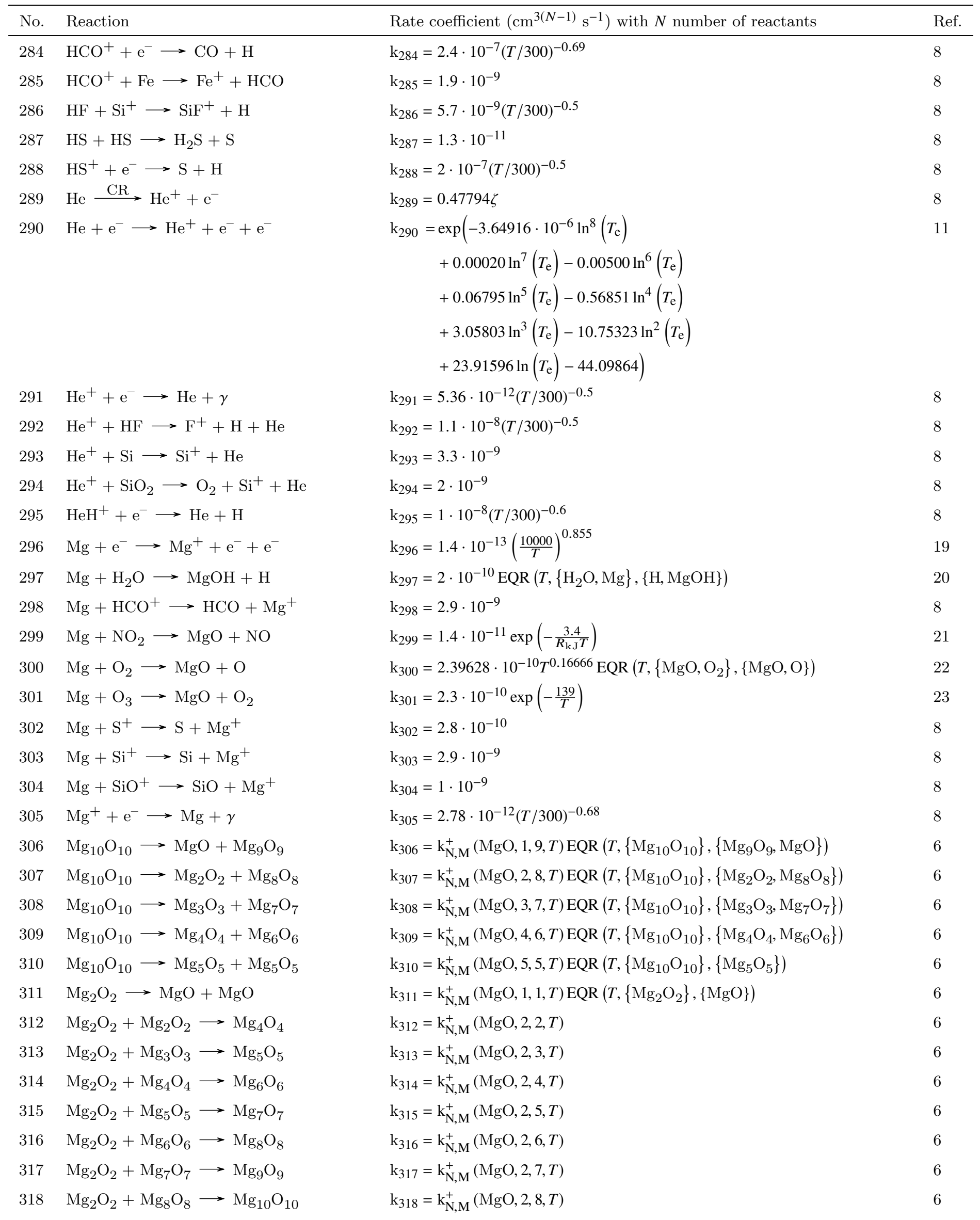




\begin{tabular}{|c|c|c|c|}
\hline No. & Reaction & Rate coefficient $\left(\mathrm{cm}^{3(N-1)} \mathrm{s}^{-1}\right)$ with $N$ number of reactants & Ref. \\
\hline 319 & $\mathrm{Mg}_{3} \mathrm{O}_{3} \longrightarrow \mathrm{MgO}+\mathrm{Mg}_{2} \mathrm{O}_{2}$ & $\mathrm{k}_{319}=\mathrm{k}_{\mathrm{N}, \mathrm{M}}^{+}(\mathrm{MgO}, 1,2, T) \mathrm{EQR}\left(T,\left\{\mathrm{Mg}_{3} \mathrm{O}_{3}\right\},\left\{\mathrm{Mg}_{2} \mathrm{O}_{2}, \mathrm{MgO}\right\}\right)$ & 6 \\
\hline 320 & $\mathrm{Mg}_{3} \mathrm{O}_{3}+\mathrm{Mg}_{3} \mathrm{O}_{3} \longrightarrow \mathrm{Mg}_{6} \mathrm{O}_{6}$ & $\mathrm{k}_{320}=\mathrm{k}_{\mathrm{N}, \mathrm{M}}^{+}(\mathrm{MgO}, 3,3, T)$ & 6 \\
\hline 321 & $\mathrm{Mg}_{3} \mathrm{O}_{3}+\mathrm{Mg}_{4} \mathrm{O}_{4} \longrightarrow \mathrm{Mg}_{7} \mathrm{O}_{7}$ & $\mathrm{k}_{321}=\mathrm{k}_{\mathrm{N}, \mathrm{M}}^{+}(\mathrm{MgO}, 3,4, T)$ & 6 \\
\hline 322 & $\mathrm{Mg}_{3} \mathrm{O}_{3}+\mathrm{Mg}_{5} \mathrm{O}_{5} \longrightarrow \mathrm{Mg}_{8} \mathrm{O}_{8}$ & $\mathrm{k}_{322}=\mathrm{k}_{\mathrm{N}, \mathrm{M}}^{+}(\mathrm{MgO}, 3,5, T)$ & 6 \\
\hline 323 & $\mathrm{Mg}_{3} \mathrm{O}_{3}+\mathrm{Mg}_{6} \mathrm{O}_{6} \longrightarrow \mathrm{Mg}_{9} \mathrm{O}_{9}$ & $\mathrm{k}_{323}=\mathrm{k}_{\mathrm{N}, \mathrm{M}}^{+}(\mathrm{MgO}, 3,6, T)$ & 6 \\
\hline 324 & $\mathrm{Mg}_{3} \mathrm{O}_{3}+\mathrm{Mg}_{7} \mathrm{O}_{7} \longrightarrow \mathrm{Mg}_{10} \mathrm{O}_{10}$ & $\mathrm{k}_{324}=\mathrm{k}_{\mathrm{N}, \mathrm{M}}^{+}(\mathrm{MgO}, 3,7, T)$ & 6 \\
\hline 325 & $\mathrm{Mg}_{4} \mathrm{O}_{4} \longrightarrow \mathrm{MgO}+\mathrm{Mg}_{3} \mathrm{O}_{3}$ & $\mathrm{k}_{325}=\mathrm{k}_{\mathrm{N}, \mathrm{M}}^{+}(\mathrm{MgO}, 1,3, T) \mathrm{EQR}\left(T,\left\{\mathrm{Mg}_{4} \mathrm{O}_{4}\right\},\left\{\mathrm{Mg}_{3} \mathrm{O}_{3}, \mathrm{MgO}\right\}\right)$ & 6 \\
\hline 326 & $\mathrm{Mg}_{4} \mathrm{O}_{4} \longrightarrow \mathrm{Mg}_{2} \mathrm{O}_{2}+\mathrm{Mg}_{2} \mathrm{O}_{2}$ & $\mathrm{k}_{326}=\mathrm{k}_{\mathrm{N}, \mathrm{M}}^{+}(\mathrm{MgO}, 2,2, T) \mathrm{EQR}\left(T,\left\{\mathrm{Mg}_{4} \mathrm{O}_{4}\right\},\left\{\mathrm{Mg}_{2} \mathrm{O}_{2}\right\}\right)$ & 6 \\
\hline 327 & $\mathrm{Mg}_{4} \mathrm{O}_{4}+\mathrm{Mg}_{4} \mathrm{O}_{4} \longrightarrow \mathrm{Mg}_{8} \mathrm{O}_{8}$ & $\mathrm{k}_{327}=\mathrm{k}_{\mathrm{N}, \mathrm{M}}^{+}(\mathrm{MgO}, 4,4, T)$ & 6 \\
\hline 328 & $\mathrm{Mg}_{4} \mathrm{O}_{4}+\mathrm{Mg}_{5} \mathrm{O}_{5} \longrightarrow \mathrm{Mg}_{9} \mathrm{O}_{9}$ & $\mathrm{k}_{328}=\mathrm{k}_{\mathrm{N}, \mathrm{M}}^{+}(\mathrm{MgO}, 4,5, T)$ & 6 \\
\hline 329 & $\mathrm{Mg}_{4} \mathrm{O}_{4}+\mathrm{Mg}_{6} \mathrm{O}_{6} \longrightarrow \mathrm{Mg}_{10} \mathrm{O}_{10}$ & $\mathrm{k}_{329}=\mathrm{k}_{\mathrm{N}, \mathrm{M}}^{+}(\mathrm{MgO}, 4,6, T)$ & 6 \\
\hline 330 & $\mathrm{Mg}_{5} \mathrm{O}_{5} \longrightarrow \mathrm{MgO}+\mathrm{Mg}_{4} \mathrm{O}_{4}$ & $\mathrm{k}_{330}=\mathrm{k}_{\mathrm{N}, \mathrm{M}}^{+}(\mathrm{MgO}, 1,4, T) \mathrm{EQR}\left(T,\left\{\mathrm{Mg}_{5} \mathrm{O}_{5}\right\},\left\{\mathrm{Mg}_{4} \mathrm{O}_{4}, \mathrm{MgO}\right\}\right)$ & 6 \\
\hline 331 & $\mathrm{Mg}_{5} \mathrm{O}_{5} \longrightarrow \mathrm{Mg}_{2} \mathrm{O}_{2}+\mathrm{Mg}_{3} \mathrm{O}_{3}$ & $\mathrm{k}_{331}=\mathrm{k}_{\mathrm{N}, \mathrm{M}}^{+}(\mathrm{MgO}, 2,3, T) \mathrm{EQR}\left(T,\left\{\mathrm{Mg}_{5} \mathrm{O}_{5}\right\},\left\{\mathrm{Mg}_{2} \mathrm{O}_{2}, \mathrm{Mg}_{3} \mathrm{O}_{3}\right\}\right)$ & 6 \\
\hline 332 & $\mathrm{Mg}_{5} \mathrm{O}_{5}+\mathrm{Mg}_{5} \mathrm{O}_{5} \longrightarrow \mathrm{Mg}_{10} \mathrm{O}_{10}$ & $\mathrm{k}_{332}=\mathrm{k}_{\mathrm{N}, \mathrm{M}}^{+}(\mathrm{MgO}, 5,5, T)$ & 6 \\
\hline 333 & $\mathrm{Mg}_{6} \mathrm{O}_{6} \longrightarrow \mathrm{MgO}+\mathrm{Mg}_{5} \mathrm{O}_{5}$ & $\mathrm{k}_{333}=\mathrm{k}_{\mathrm{N}, \mathrm{M}}^{+}(\mathrm{MgO}, 1,5, T) \mathrm{EQR}\left(T,\left\{\mathrm{Mg}_{6} \mathrm{O}_{6}\right\},\left\{\mathrm{Mg}_{5} \mathrm{O}_{5}, \mathrm{MgO}\right\}\right)$ & 6 \\
\hline 334 & $\mathrm{Mg}_{6} \mathrm{O}_{6} \longrightarrow \mathrm{Mg}_{2} \mathrm{O}_{2}+\mathrm{Mg}_{4} \mathrm{O}_{4}$ & $\mathrm{k}_{334}=\mathrm{k}_{\mathrm{N}, \mathrm{M}}^{+}(\mathrm{MgO}, 2,4, T) \mathrm{EQR}\left(T,\left\{\mathrm{Mg}_{6} \mathrm{O}_{6}\right\},\left\{\mathrm{Mg}_{2} \mathrm{O}_{2}, \mathrm{Mg}_{4} \mathrm{O}_{4}\right\}\right)$ & 6 \\
\hline 335 & $\mathrm{Mg}_{6} \mathrm{O}_{6} \longrightarrow \mathrm{Mg}_{3} \mathrm{O}_{3}+\mathrm{Mg}_{3} \mathrm{O}_{3}$ & $\mathrm{k}_{335}=\mathrm{k}_{\mathrm{N}, \mathrm{M}}^{+}(\mathrm{MgO}, 3,3, T) \mathrm{EQR}\left(T,\left\{\mathrm{Mg}_{6} \mathrm{O}_{6}\right\},\left\{\mathrm{Mg}_{3} \mathrm{O}_{3}\right\}\right)$ & 6 \\
\hline 336 & $\mathrm{Mg}_{7} \mathrm{O}_{7} \longrightarrow \mathrm{MgO}+\mathrm{Mg}_{6} \mathrm{O}_{6}$ & $\mathrm{k}_{336}=\mathrm{k}_{\mathrm{N}, \mathrm{M}}^{+}(\mathrm{MgO}, 1,6, T) \mathrm{EQR}\left(T,\left\{\mathrm{Mg}_{7} \mathrm{O}_{7}\right\},\left\{\mathrm{Mg}_{6} \mathrm{O}_{6}, \mathrm{MgO}\right\}\right)$ & 6 \\
\hline 337 & $\mathrm{Mg}_{7} \mathrm{O}_{7} \longrightarrow \mathrm{Mg}_{2} \mathrm{O}_{2}+\mathrm{Mg}_{5} \mathrm{O}_{5}$ & $\mathrm{k}_{337}=\mathrm{k}_{\mathrm{N}, \mathrm{M}}^{+}(\mathrm{MgO}, 2,5, T) \mathrm{EQR}\left(T,\left\{\mathrm{Mg}_{7} \mathrm{O}_{7}\right\},\left\{\mathrm{Mg}_{2} \mathrm{O}_{2}, \mathrm{Mg}_{5} \mathrm{O}_{5}\right\}\right)$ & 6 \\
\hline 338 & $\mathrm{Mg}_{7} \mathrm{O}_{7} \longrightarrow \mathrm{Mg}_{3} \mathrm{O}_{3}+\mathrm{Mg}_{4} \mathrm{O}_{4}$ & $\mathrm{k}_{338}=\mathrm{k}_{\mathrm{N}, \mathrm{M}}^{+}(\mathrm{MgO}, 3,4, T) \mathrm{EQR}\left(T,\left\{\mathrm{Mg}_{7} \mathrm{O}_{7}\right\},\left\{\mathrm{Mg}_{3} \mathrm{O}_{3}, \mathrm{Mg}_{4} \mathrm{O}_{4}\right\}\right)$ & 6 \\
\hline 339 & $\mathrm{Mg}_{8} \mathrm{O}_{8} \longrightarrow \mathrm{MgO}+\mathrm{Mg}_{7} \mathrm{O}_{7}$ & $\mathrm{k}_{339}=\mathrm{k}_{\mathrm{N}, \mathrm{M}}^{+}(\mathrm{MgO}, 1,7, T) \mathrm{EQR}\left(T,\left\{\mathrm{Mg}_{8} \mathrm{O}_{8}\right\},\left\{\mathrm{Mg}_{7} \mathrm{O}_{7}, \mathrm{MgO}\right\}\right)$ & 6 \\
\hline 340 & $\mathrm{Mg}_{8} \mathrm{O}_{8} \longrightarrow \mathrm{Mg}_{2} \mathrm{O}_{2}+\mathrm{Mg}_{6} \mathrm{O}_{6}$ & $\mathrm{k}_{340}=\mathrm{k}_{\mathrm{N}, \mathrm{M}}^{+}(\mathrm{MgO}, 2,6, T) \mathrm{EQR}\left(T,\left\{\mathrm{Mg}_{8} \mathrm{O}_{8}\right\},\left\{\mathrm{Mg}_{2} \mathrm{O}_{2}, \mathrm{Mg}_{6} \mathrm{O}_{6}\right\}\right)$ & 6 \\
\hline 341 & $\mathrm{Mg}_{8} \mathrm{O}_{8} \longrightarrow \mathrm{Mg}_{3} \mathrm{O}_{3}+\mathrm{Mg}_{5} \mathrm{O}_{5}$ & $\mathrm{k}_{341}=\mathrm{k}_{\mathrm{N}, \mathrm{M}}^{+}(\mathrm{MgO}, 3,5, T) \mathrm{EQR}\left(T,\left\{\mathrm{Mg}_{8} \mathrm{O}_{8}\right\},\left\{\mathrm{Mg}_{3} \mathrm{O}_{3}, \mathrm{Mg}_{5} \mathrm{O}_{5}\right\}\right)$ & 6 \\
\hline 342 & $\mathrm{Mg}_{8} \mathrm{O}_{8} \longrightarrow \mathrm{Mg}_{4} \mathrm{O}_{4}+\mathrm{Mg}_{4} \mathrm{O}_{4}$ & $\mathrm{k}_{342}=\mathrm{k}_{\mathrm{N}, \mathrm{M}}^{+}(\mathrm{MgO}, 4,4, T) \mathrm{EQR}\left(T,\left\{\mathrm{Mg}_{8} \mathrm{O}_{8}\right\},\left\{\mathrm{Mg}_{4} \mathrm{O}_{4}\right\}\right)$ & 6 \\
\hline 343 & $\mathrm{Mg}_{9} \mathrm{O}_{9} \longrightarrow \mathrm{MgO}+\mathrm{Mg}_{8} \mathrm{O}_{8}$ & $\mathrm{k}_{343}=\mathrm{k}_{\mathrm{N}, \mathrm{M}}^{+}(\mathrm{MgO}, 1,8, T) \mathrm{EQR}\left(T,\left\{\mathrm{Mg}_{9} \mathrm{O}_{9}\right\},\left\{\mathrm{Mg}_{8} \mathrm{O}_{8}, \mathrm{MgO}\right\}\right)$ & 6 \\
\hline 344 & $\mathrm{Mg}_{9} \mathrm{O}_{9} \longrightarrow \mathrm{Mg}_{2} \mathrm{O}_{2}+\mathrm{Mg}_{7} \mathrm{O}_{7}$ & $\mathrm{k}_{344}=\mathrm{k}_{\mathrm{N}, \mathrm{M}}^{+}(\mathrm{MgO}, 2,7, T) \mathrm{EQR}\left(T,\left\{\mathrm{Mg}_{9} \mathrm{O}_{9}\right\},\left\{\mathrm{Mg}_{2} \mathrm{O}_{2}, \mathrm{Mg}_{7} \mathrm{O}_{7}\right\}\right)$ & 6 \\
\hline 345 & $\mathrm{Mg}_{9} \mathrm{O}_{9} \longrightarrow \mathrm{Mg}_{3} \mathrm{O}_{3}+\mathrm{Mg}_{6} \mathrm{O}_{6}$ & $\mathrm{k}_{345}=\mathrm{k}_{\mathrm{N}, \mathrm{M}}^{+}(\mathrm{MgO}, 3,6, T) \mathrm{EQR}\left(T,\left\{\mathrm{Mg}_{9} \mathrm{O}_{9}\right\},\left\{\mathrm{Mg}_{3} \mathrm{O}_{3}, \mathrm{Mg}_{6} \mathrm{O}_{6}\right\}\right)$ & 6 \\
\hline 346 & $\mathrm{Mg}_{9} \mathrm{O}_{9} \longrightarrow \mathrm{Mg}_{4} \mathrm{O}_{4}+\mathrm{Mg}_{5} \mathrm{O}_{5}$ & $\mathrm{k}_{346}=\mathrm{k}_{\mathrm{N}, \mathrm{M}}^{+}(\mathrm{MgO}, 4,5, T) \mathrm{EQR}\left(T,\left\{\mathrm{Mg}_{9} \mathrm{O}_{9}\right\},\left\{\mathrm{Mg}_{4} \mathrm{O}_{4}, \mathrm{Mg}_{5} \mathrm{O}_{5}\right\}\right)$ & 6 \\
\hline 347 & $\mathrm{MgCO}_{3}+\mathrm{M} \longrightarrow \mathrm{MgO}+\mathrm{CO}_{2}+\mathrm{M}$ & 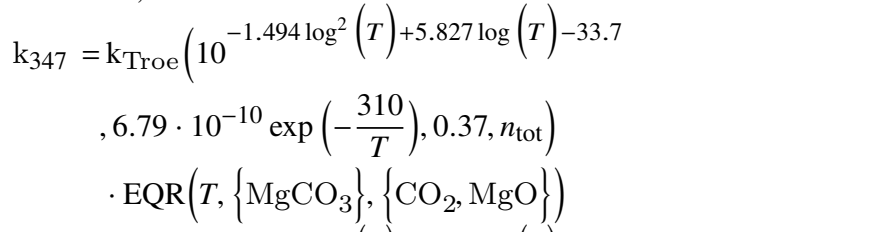 & 24 \\
\hline 348 & $\mathrm{MgO}+\mathrm{CO}_{2}+\mathrm{M} \longrightarrow \mathrm{MgCO}_{3}+\mathrm{M}$ & $\begin{aligned} \mathrm{k}_{348}= & \mathrm{k}_{\text {Troe }}\left(10^{-1.494 \log ^{2}(T)+5.827 \log (T)-33.7}\right. \\
& \left., 6.79 \cdot 10^{-10} \exp \left(-\frac{310}{T}\right), 0.37, n_{\text {tot }}\right)\end{aligned}$ & 24 \\
\hline 349 & $\mathrm{MgO}+\mathrm{H}_{2} \mathrm{O}+\mathrm{M} \longrightarrow \mathrm{MgO}_{2} \mathrm{H}_{2}+\mathrm{M}$ & $\begin{aligned} \mathrm{k}_{349}= & \mathrm{k}_{\text {Troe }}\left(10^{-2.127 \log ^{2}(T)+7.894 \log (T)-32.75}\right. \\
& \left., 3.52 \cdot 10^{-10} \exp \left(-\frac{334}{T}\right), 0.28, n_{\text {tot }}\right)\end{aligned}$ & 24 \\
\hline 350 & $\mathrm{MgO}+\mathrm{Mg}_{2} \mathrm{O}_{2} \longrightarrow \mathrm{Mg}_{3} \mathrm{O}_{3}$ & $\mathrm{k}_{350}=\mathrm{k}_{\mathrm{N}, \mathrm{M}}^{+}(\mathrm{MgO}, 1,2, T)$ & 6 \\
\hline 351 & $\mathrm{MgO}+\mathrm{Mg}_{3} \mathrm{O}_{3} \longrightarrow \mathrm{Mg}_{4} \mathrm{O}_{4}$ & $\mathrm{k}_{351}=\mathrm{k}_{\mathrm{N}, \mathrm{M}}^{+}(\mathrm{MgO}, 1,3, T)$ & 6 \\
\hline 352 & $\mathrm{MgO}+\mathrm{Mg}_{4} \mathrm{O}_{4} \longrightarrow \mathrm{Mg}_{5} \mathrm{O}_{5}$ & $\mathrm{k}_{352}=\mathrm{k}_{\mathrm{N}, \mathrm{M}}^{+}(\mathrm{MgO}, 1,4, T)$ & 6 \\
\hline
\end{tabular}




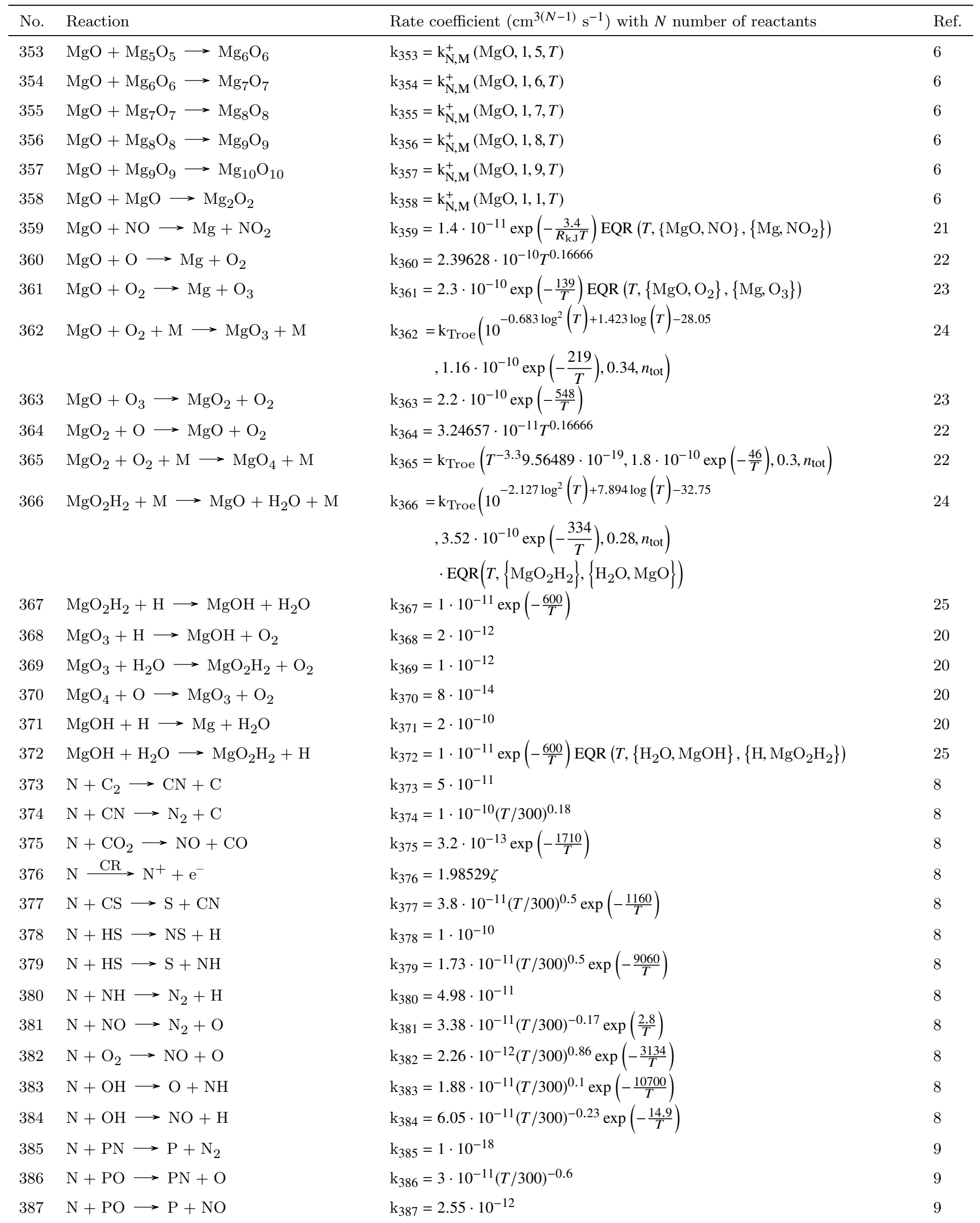




\begin{tabular}{|c|c|c|c|}
\hline No. & Reaction & Rate coefficient $\left(\mathrm{cm}^{3(N-1)} \mathrm{s}^{-1}\right)$ with $N$ number of reactants & Ref. \\
\hline 388 & $\mathrm{~N}+\mathrm{SO} \longrightarrow \mathrm{NS}+\mathrm{O}$ & $\mathrm{k}_{388}=4.68 \cdot 10^{-11}(T / 300)^{0.5} \exp \left(-\frac{8254}{T}\right)$ & 8 \\
\hline 389 & $\mathrm{~N}+\mathrm{SO} \longrightarrow \mathrm{S}+\mathrm{NO}$ & $\mathrm{k}_{389}=1.73 \cdot 10^{-11}(T / 300)^{0.5} \exp \left(-\frac{750}{T}\right)$ & 8 \\
\hline 390 & $\mathrm{~N}+\mathrm{SiO}^{+} \longrightarrow \mathrm{NO}+\mathrm{Si}^{+}$ & $\mathrm{k}_{390}=2.1 \cdot 10^{-10}$ & 8 \\
\hline 391 & $\mathrm{~N}^{+}+\mathrm{e}^{-} \longrightarrow \mathrm{N}+\gamma$ & $\mathrm{k}_{391}=3.5 \cdot 10^{-12}(T / 300)^{-0.53} \exp \left(\frac{3.2}{T}\right)$ & 8 \\
\hline 392 & $\mathrm{~N}_{2} \stackrel{\mathrm{CR}}{\longrightarrow} \mathrm{N}+\mathrm{N}$ & $\mathrm{k}_{392}=5 \zeta$ & 9 \\
\hline 393 & $\mathrm{NH}+\mathrm{O} \longrightarrow \mathrm{OH}+\mathrm{N}$ & $\mathrm{k}_{393}=1.16 \cdot 10^{-11}$ & 8 \\
\hline 394 & $\mathrm{NH}+\mathrm{O} \longrightarrow \mathrm{NO}+\mathrm{H}$ & $\mathrm{k}_{394}=6.6 \cdot 10^{-11}$ & 8 \\
\hline 395 & $\mathrm{NH}+\mathrm{S} \longrightarrow \mathrm{NS}+\mathrm{H}$ & $\mathrm{k}_{395}=1 \cdot 10^{-10}$ & 8 \\
\hline 396 & $\mathrm{NH}+\mathrm{S} \longrightarrow \mathrm{HS}+\mathrm{N}$ & $\mathrm{k}_{396}=1.73 \cdot 10^{-11}(T / 300)^{0.5} \exp \left(-\frac{4000}{T}\right)$ & 8 \\
\hline 397 & $\mathrm{NH}^{+}+\mathrm{e}^{-} \longrightarrow \mathrm{N}+\mathrm{H}$ & $\mathrm{k}_{397}=4.3 \cdot 10^{-8}(T / 300)^{-0.5}$ & 8 \\
\hline 398 & $\mathrm{Na}+\mathrm{Fe}^{+} \longrightarrow \mathrm{Fe}+\mathrm{Na}^{+}$ & $\mathrm{k}_{398}=1 \cdot 10^{-11}$ & 8 \\
\hline 399 & $\mathrm{Na}+\mathrm{Mg}^{+} \longrightarrow \mathrm{Mg}+\mathrm{Na}^{+}$ & $\mathrm{k}_{399}=1 \cdot 10^{-11}$ & 8 \\
\hline 400 & $\mathrm{Na}+\mathrm{S}^{+} \longrightarrow \mathrm{S}+\mathrm{Na}^{+}$ & $\mathrm{k}_{400}=2.6 \cdot 10^{-10}$ & 8 \\
\hline 401 & $\mathrm{Na}+\mathrm{Si}^{+} \longrightarrow \mathrm{Si}+\mathrm{Na}^{+}$ & $\mathrm{k}_{401}=2.7 \cdot 10^{-9}$ & 8 \\
\hline 402 & $\mathrm{Na}^{+}+\mathrm{e}^{-} \longrightarrow \mathrm{Na}+\gamma$ & $\mathrm{k}_{402}=2.76 \cdot 10^{-12}(T / 300)^{-0.68}$ & 8 \\
\hline 403 & $\mathrm{O}+\mathrm{C}_{2} \longrightarrow \mathrm{CO}+\mathrm{C}$ & $\mathrm{k}_{403}=2 \cdot 10^{-10}(T / 300)^{-0.12}$ & 8 \\
\hline 404 & $\mathrm{O}+\mathrm{CN} \longrightarrow \mathrm{NO}+\mathrm{C}$ & $\mathrm{k}_{404}=5.37 \cdot 10^{-11} \exp \left(-\frac{13800}{T}\right)$ & 8 \\
\hline 405 & $\mathrm{O}+\mathrm{CN} \longrightarrow \mathrm{CO}+\mathrm{N}$ & $\mathrm{k}_{405}=2.54 \cdot 10^{-11}$ & 8 \\
\hline 406 & $\mathrm{O} \stackrel{\mathrm{CR}}{\longrightarrow} \mathrm{O}^{+}+\mathrm{e}^{-}$ & $\mathrm{k}_{406}=2.5 \zeta$ & 8 \\
\hline 407 & $\mathrm{O}+\mathrm{CS} \longrightarrow \mathrm{SO}+\mathrm{C}$ & $\mathrm{k}_{407}=4.68 \cdot 10^{-11}(T / 300)^{0.5} \exp \left(-\frac{28940}{T}\right)$ & 8 \\
\hline 408 & $\mathrm{O}+\mathrm{CS} \longrightarrow \mathrm{S}+\mathrm{CO}$ & $\mathrm{k}_{408}=2.48 \cdot 10^{-10}(T / 300)^{-0.65} \exp \left(-\frac{783}{T}\right)$ & 8 \\
\hline 409 & $\mathrm{O}+\mathrm{e}^{-} \longrightarrow \mathrm{O}^{-}+\gamma$ & $\mathrm{k}_{409}=1.5 \cdot 10^{-15}$ & 8 \\
\hline 410 & $\mathrm{O}+\mathrm{H}_{2} \mathrm{O} \longrightarrow \mathrm{OH}+\mathrm{OH}$ & $\mathrm{k}_{410}=1.85 \cdot 10^{-11}(T / 300)^{0.95} \exp \left(-\frac{8571}{T}\right)$ & 8 \\
\hline 411 & $\mathrm{O}+\mathrm{HCN} \longrightarrow \mathrm{CO}+\mathrm{NH}$ & $\mathrm{k}_{411}=7.3 \cdot 10^{-13}(T / 300)^{1.14} \exp \left(-\frac{3742}{T}\right)$ & 8 \\
\hline 412 & $\mathrm{O}+\mathrm{HCN} \longrightarrow \mathrm{CN}+\mathrm{OH}$ & $\mathrm{k}_{412}=6.21 \cdot 10^{-10} \exp \left(-\frac{12439}{T}\right)$ & 8 \\
\hline 413 & $\mathrm{O}+\mathrm{HCN} \longrightarrow \mathrm{OCN}+\mathrm{H}$ & $\mathrm{k}_{413}=1.36 \cdot 10^{-12}(T / 300)^{1.38} \exp \left(-\frac{3693}{T}\right)$ & 8 \\
\hline 414 & $\mathrm{O}+\mathrm{HS} \longrightarrow \mathrm{S}+\mathrm{OH}$ & $\mathrm{k}_{414}=1.74 \cdot 10^{-11}(T / 300)^{0.67} \exp \left(-\frac{956}{T}\right)$ & 8 \\
\hline 415 & $\mathrm{O}+\mathrm{HS} \longrightarrow \mathrm{SO}+\mathrm{H}$ & $\mathrm{k}_{415}=1.74 \cdot 10^{-10}(T / 300)^{-0.2} \exp \left(-\frac{5.7}{T}\right)$ & 8 \\
\hline 416 & $\mathrm{O}+\mathrm{N}_{2} \longrightarrow \mathrm{NO}+\mathrm{N}$ & $\mathrm{k}_{416}=2.51 \cdot 10^{-10} \exp \left(-\frac{38602}{T}\right)$ & 8 \\
\hline 417 & $\mathrm{O}+\mathrm{NS} \longrightarrow \mathrm{S}+\mathrm{NO}$ & $\mathrm{k}_{417}=1 \cdot 10^{-10}$ & 8 \\
\hline 418 & $\mathrm{O}+\mathrm{O} \longrightarrow \mathrm{O}_{2}+\gamma$ & $\mathrm{k}_{418}=4.9 \cdot 10^{-20}(T / 300)^{1.58}$ & 8 \\
\hline 419 & $\mathrm{O}+\mathrm{O}_{2}+\mathrm{O}_{2} \longrightarrow \mathrm{O}_{3}+\mathrm{O}_{2}$ & $\mathrm{k}_{419}=1.65449 \cdot 10^{-27} T^{-2.6}$ & 26 \\
\hline 420 & $\mathrm{O}+\mathrm{OH} \longrightarrow \mathrm{O}_{2}+\mathrm{H}$ & $\mathrm{k}_{420}=3.69 \cdot 10^{-11}(T / 300)^{-0.27} \exp \left(-\frac{12.9}{T}\right)$ & 8 \\
\hline 421 & $\mathrm{O}+\mathrm{SO} \longrightarrow \mathrm{S}+\mathrm{O}_{2}$ & $\mathrm{k}_{421}=6.6 \cdot 10^{-13} \exp \left(-\frac{2760}{T}\right)$ & 8 \\
\hline 422 & $\mathrm{O}+\mathrm{SO}_{2} \longrightarrow \mathrm{SO}+\mathrm{O}_{2}$ & $\mathrm{k}_{422}=9.01 \cdot 10^{-12} \exp \left(-\frac{9837}{T}\right)$ & 8 \\
\hline 423 & $\mathrm{O}+\mathrm{Si} \longrightarrow \mathrm{SiO}+\gamma$ & $\mathrm{k}_{423}=5.52 \cdot 10^{-18}(T / 300)^{0.31}$ & 8 \\
\hline 424 & $\mathrm{O}+\mathrm{SiO}^{+} \longrightarrow \mathrm{O}_{2}+\mathrm{Si}^{+}$ & $\mathrm{k}_{424}=2 \cdot 10^{-10}$ & 8 \\
\hline 425 & $\mathrm{O}^{+}+\mathrm{e}^{-} \longrightarrow \mathrm{O}+\gamma$ & $\mathrm{k}_{425}=3.24 \cdot 10^{-12}(T / 300)^{-0.66}$ & 8 \\
\hline 426 & $\mathrm{O}^{+}+\mathrm{Fe} \longrightarrow \mathrm{Fe}^{+}+\mathrm{O}$ & $\mathrm{k}_{426}=2.9 \cdot 10^{-9}$ & 8 \\
\hline
\end{tabular}




\begin{tabular}{|c|c|c|c|}
\hline No. & Reaction & Rate coefficient $\left(\mathrm{cm}^{3(N-1)} \mathrm{s}^{-1}\right)$ with $N$ number of reactants & Ref. \\
\hline 427 & $\mathrm{O}^{-}+\mathrm{Fe}^{+} \longrightarrow \mathrm{O}+\mathrm{Fe}$ & $\mathrm{k}_{427}=7.51 \cdot 10^{-8}(T / 300)^{-0.5}$ & 8 \\
\hline 428 & $\mathrm{O}^{-}+\mathrm{H}^{+} \longrightarrow \mathrm{O}+\mathrm{H}$ & $\mathrm{k}_{428}=7.51 \cdot 10^{-8}(T / 300)^{-0.5}$ & 8 \\
\hline 429 & $\mathrm{O}^{-}+\mathrm{Mg}^{+} \longrightarrow \mathrm{O}+\mathrm{Mg}$ & $\mathrm{k}_{429}=7.51 \cdot 10^{-8}(T / 300)^{-0.5}$ & 8 \\
\hline 430 & $\mathrm{O}_{2}+\mathrm{S} \longrightarrow \mathrm{SO}+\mathrm{O}$ & $\mathrm{k}_{430}=1.76 \cdot 10^{-12}(T / 300)^{0.81} \exp \left(\frac{30.8}{T}\right)$ & 8 \\
\hline 431 & $\mathrm{O}_{3}+\mathrm{O} \longrightarrow \mathrm{O}_{2}+\mathrm{O}_{2}$ & $\mathrm{k}_{431}=8 \cdot 10^{-12} \exp \left(-\frac{2060}{T}\right)$ & 26 \\
\hline 432 & $\mathrm{OH}+\mathrm{CN} \longrightarrow \mathrm{HCN}+\mathrm{O}$ & $\mathrm{k}_{432}=1 \cdot 10^{-11} \exp \left(-\frac{1000}{T}\right)$ & 8 \\
\hline 433 & $\mathrm{OH}+\mathrm{CN} \longrightarrow \mathrm{OCN}+\mathrm{H}$ & $\mathrm{k}_{433}=7 \cdot 10^{-11}$ & 8 \\
\hline 434 & $\mathrm{OH}+\mathrm{CO} \longrightarrow \mathrm{CO}_{2}+\mathrm{H}$ & $\mathrm{k}_{434}=2.81 \cdot 10^{-13} \exp \left(-\frac{176}{T}\right)$ & 8 \\
\hline 435 & $\mathrm{OH}+\mathrm{CS} \longrightarrow \mathrm{CO}+\mathrm{HS}$ & $\mathrm{k}_{435}=3 \cdot 10^{-11}$ & 8 \\
\hline 436 & $\mathrm{OH}+\mathrm{CS} \longrightarrow \mathrm{H}+\mathrm{OCS}$ & $\mathrm{k}_{436}=1.7 \cdot 10^{-10}$ & 8 \\
\hline 437 & $\mathrm{OH}+\mathrm{F} \longrightarrow \mathrm{HF}+\mathrm{O}$ & $\mathrm{k}_{437}=1.6 \cdot 10^{-10}$ & 8 \\
\hline 438 & $\mathrm{OH}+\mathrm{H}_{2} \mathrm{~S} \longrightarrow \mathrm{HS}+\mathrm{H}_{2} \mathrm{O}$ & $\mathrm{k}_{438}=6.3 \cdot 10^{-12} \exp \left(-\frac{80}{T}\right)$ & 8 \\
\hline 439 & $\mathrm{OH}+\mathrm{OH} \longrightarrow \mathrm{H}_{2} \mathrm{O}+\mathrm{O}$ & $\mathrm{k}_{439}=1.65 \cdot 10^{-12}(T / 300)^{1.14} \exp \left(-\frac{50}{T}\right)$ & 8 \\
\hline 440 & $\mathrm{OH}+\mathrm{S} \longrightarrow \mathrm{SO}+\mathrm{H}$ & $\mathrm{k}_{440}=6.6 \cdot 10^{-11}$ & 8 \\
\hline 441 & $\mathrm{OH}+\mathrm{SO} \longrightarrow \mathrm{SO}_{2}+\mathrm{H}$ & $\mathrm{k}_{441}=8.6 \cdot 10^{-11}$ & 8 \\
\hline 442 & $\mathrm{OH}+\mathrm{Si} \longrightarrow \mathrm{SiO}+\mathrm{H}$ & $\mathrm{k}_{442}=1 \cdot 10^{-10}$ & 8 \\
\hline 443 & $\mathrm{OH}+\mathrm{Si}^{+} \longrightarrow \mathrm{SiO}^{+}+\mathrm{H}$ & $\mathrm{k}_{443}=6.3 \cdot 10^{-10}(T / 300)^{-0.5}$ & 8 \\
\hline 444 & $\mathrm{OH}+\mathrm{SiO} \longrightarrow \mathrm{SiO}_{2}+\mathrm{H}$ & $\mathrm{k}_{444}=2 \cdot 10^{-12}$ & 8 \\
\hline 445 & $\mathrm{OH}^{+}+\mathrm{e}^{-} \longrightarrow \mathrm{O}+\mathrm{H}$ & $\mathrm{k}_{445}=3.75 \cdot 10^{-8}(T / 300)^{-0.5}$ & 8 \\
\hline 446 & $\mathrm{P}+\mathrm{O}_{2} \longrightarrow \mathrm{PO}+\mathrm{O}$ & $\mathrm{k}_{446}=1 \cdot 10^{-13}$ & 9 \\
\hline 447 & $\mathrm{P}^{+}+\mathrm{e}^{-} \longrightarrow \mathrm{P}+\gamma$ & $\mathrm{k}_{447}=3.41 \cdot 10^{-12}(T / 300)^{-0.65}$ & 8 \\
\hline 448 & $\mathrm{~S}+\mathrm{e}^{-} \longrightarrow \mathrm{S}^{-}+\gamma$ & $\mathrm{k}_{448}=5 \cdot 10^{-15}$ & 8 \\
\hline 449 & $\mathrm{~S}+\mathrm{HS} \longrightarrow \mathrm{S}_{2}+\mathrm{H}$ & $\mathrm{k}_{449}=4.5 \cdot 10^{-11}$ & 8 \\
\hline 450 & $\mathrm{~S}+\mathrm{SO}_{2} \longrightarrow \mathrm{SO}+\mathrm{SO}$ & $\mathrm{k}_{450}=9.76 \cdot 10^{-12} \exp \left(-\frac{4545}{T}\right)$ & 8 \\
\hline 451 & $\mathrm{~S}^{+}+\mathrm{e}^{-} \longrightarrow \mathrm{S}+\gamma$ & $\mathrm{k}_{451}=5.49 \cdot 10^{-12}(T / 300)^{-0.59}$ & 8 \\
\hline 452 & $\mathrm{~S}^{+}+\mathrm{Fe} \longrightarrow \mathrm{Fe}^{+}+\mathrm{S}$ & $\mathrm{k}_{452}=1.8 \cdot 10^{-10}$ & 8 \\
\hline 453 & $\mathrm{Si}+\mathrm{CO} \longrightarrow \mathrm{SiO}+\mathrm{C}$ & $\mathrm{k}_{453}=1.3 \cdot 10^{-9} \exp \left(-\frac{34513}{T}\right)$ & 8 \\
\hline 454 & $\mathrm{Si}+\mathrm{CO}_{2} \longrightarrow \mathrm{SiO}+\mathrm{CO}$ & $\mathrm{k}_{454}=2.72 \cdot 10^{-11} \exp \left(-\frac{282}{T}\right)$ & 8 \\
\hline 455 & $\mathrm{Si}+\mathrm{HCO}^{+} \longrightarrow \mathrm{SiH}^{+}+\mathrm{CO}$ & $\mathrm{k}_{455}=1.6 \cdot 10^{-9}$ & 8 \\
\hline 456 & $\mathrm{Si}+\mathrm{NO} \longrightarrow \mathrm{SiO}+\mathrm{N}$ & $\mathrm{k}_{456}=9 \cdot 10^{-11}(T / 300)^{-0.96} \exp \left(-\frac{28}{T}\right)$ & 8 \\
\hline 457 & $\mathrm{Si}+\mathrm{O}_{2} \longrightarrow \mathrm{SiO}+\mathrm{O}$ & $\mathrm{k}_{457}=1.72 \cdot 10^{-10}(T / 300)^{-0.53} \exp \left(-\frac{17}{T}\right)$ & 8 \\
\hline 458 & $\mathrm{Si}+\mathrm{P}^{+} \longrightarrow \mathrm{P}+\mathrm{Si}^{+}$ & $\mathrm{k}_{458}=1 \cdot 10^{-9}$ & 8 \\
\hline 459 & $\mathrm{Si}+\mathrm{S}^{+} \longrightarrow \mathrm{S}+\mathrm{Si}^{+}$ & $\mathrm{k}_{459}=1.6 \cdot 10^{-9}$ & 8 \\
\hline 460 & $\mathrm{Si}^{+}+\mathrm{e}^{-} \longrightarrow \mathrm{Si}+\gamma$ & $\mathrm{k}_{460}=4.26 \cdot 10^{-12}(T / 300)^{-0.62}$ & 8 \\
\hline 461 & $\mathrm{Si}^{+}+\mathrm{Fe} \longrightarrow \mathrm{Fe}^{+}+\mathrm{Si}$ & $\mathrm{k}_{461}=1.9 \cdot 10^{-9}$ & 8 \\
\hline 462 & $\mathrm{Si}_{10} \mathrm{O}_{10} \longrightarrow \mathrm{SiO}+\mathrm{Si}_{9} \mathrm{O}_{9}$ & $\mathrm{k}_{462}=\mathrm{k}_{\mathrm{N}, \mathrm{M}}^{+}(\mathrm{SiO}, 1,9, T) \mathrm{EQR}\left(T,\left\{\mathrm{Si}_{10} \mathrm{O}_{10}\right\},\left\{\mathrm{Si}_{9} \mathrm{O}_{9}, \mathrm{SiO}\right\}\right)$ & 6 \\
\hline 463 & $\mathrm{Si}_{10} \mathrm{O}_{10} \longrightarrow \mathrm{Si}_{2} \mathrm{O}_{2}+\mathrm{Si}_{8} \mathrm{O}_{8}$ & $\mathrm{k}_{463}=\mathrm{k}_{\mathrm{N}, \mathrm{M}}^{+}(\mathrm{SiO}, 2,8, T) \mathrm{EQR}\left(T,\left\{\mathrm{Si}_{10} \mathrm{O}_{10}\right\},\left\{\mathrm{Si}_{2} \mathrm{O}_{2}, \mathrm{Si}_{8} \mathrm{O}_{8}\right\}\right)$ & 6 \\
\hline 464 & $\mathrm{Si}_{10} \mathrm{O}_{10} \longrightarrow \mathrm{Si}_{3} \mathrm{O}_{3}+\mathrm{Si}_{7} \mathrm{O}_{7}$ & $\mathrm{k}_{464}=\mathrm{k}_{\mathrm{N}, \mathrm{M}}^{+}(\mathrm{SiO}, 3,7, T) \mathrm{EQR}\left(T,\left\{\mathrm{Si}_{10} \mathrm{O}_{10}\right\},\left\{\mathrm{Si}_{3} \mathrm{O}_{3}, \mathrm{Si}_{7} \mathrm{O}_{7}\right\}\right)$ & 6 \\
\hline 465 & $\mathrm{Si}_{10} \mathrm{O}_{10} \longrightarrow \mathrm{Si}_{4} \mathrm{O}_{4}+\mathrm{Si}_{6} \mathrm{O}_{6}$ & $\mathrm{k}_{465}=\mathrm{k}_{\mathrm{N}, \mathrm{M}}^{+}(\mathrm{SiO}, 4,6, T) \mathrm{EQR}\left(T,\left\{\mathrm{Si}_{10} \mathrm{O}_{10}\right\},\left\{\mathrm{Si}_{4} \mathrm{O}_{4}, \mathrm{Si}_{6} \mathrm{O}_{6}\right\}\right)$ & 6 \\
\hline
\end{tabular}




\begin{tabular}{|c|c|c|c|}
\hline No. & Reaction & Rate coefficient $\left(\mathrm{cm}^{3(N-1)} \mathrm{s}^{-1}\right)$ with $N$ number of reactants & Ref. \\
\hline 466 & $\mathrm{Si}_{10} \mathrm{O}_{10} \longrightarrow \mathrm{Si}_{5} \mathrm{O}_{5}+\mathrm{Si}_{5} \mathrm{O}_{5}$ & $\mathrm{k}_{466}=\mathrm{k}_{\mathrm{N}, \mathrm{M}}^{+}(\mathrm{SiO}, 5,5, T) \mathrm{EQR}\left(T,\left\{\mathrm{Si}_{10} \mathrm{O}_{10}\right\},\left\{\mathrm{Si}_{5} \mathrm{O}_{5}\right\}\right)$ & 6 \\
\hline 467 & $\mathrm{Si}_{2} \mathrm{O}_{2} \longrightarrow \mathrm{SiO}+\mathrm{SiO}$ & $\mathrm{k}_{467}=\mathrm{k}_{\mathrm{N}, \mathrm{M}}^{+}(\mathrm{SiO}, 1,1, T) \mathrm{EQR}\left(T,\left\{\mathrm{Si}_{2} \mathrm{O}_{2}\right\},\{\mathrm{SiO}\}\right)$ & 6 \\
\hline 468 & $\mathrm{Si}_{2} \mathrm{O}_{2}+\mathrm{Si}_{2} \mathrm{O}_{2} \longrightarrow \mathrm{Si}_{4} \mathrm{O}_{4}$ & $\mathrm{k}_{468}=\mathrm{k}_{\mathrm{N}, \mathrm{M}}^{+}(\mathrm{SiO}, 2,2, T)$ & 6 \\
\hline 469 & $\mathrm{Si}_{2} \mathrm{O}_{2}+\mathrm{Si}_{3} \mathrm{O}_{3} \longrightarrow \mathrm{Si}_{5} \mathrm{O}_{5}$ & $\mathrm{k}_{469}=\mathrm{k}_{\mathrm{N}, \mathrm{M}}^{+}(\mathrm{SiO}, 2,3, T)$ & 6 \\
\hline 470 & $\mathrm{Si}_{2} \mathrm{O}_{2}+\mathrm{Si}_{4} \mathrm{O}_{4} \longrightarrow \mathrm{Si}_{6} \mathrm{O}_{6}$ & $\mathrm{k}_{470}=\mathrm{k}_{\mathrm{N}, \mathrm{M}}^{+}(\mathrm{SiO}, 2,4, T)$ & 6 \\
\hline 471 & $\mathrm{Si}_{2} \mathrm{O}_{2}+\mathrm{Si}_{5} \mathrm{O}_{5} \longrightarrow \mathrm{Si}_{7} \mathrm{O}_{7}$ & $\mathrm{k}_{471}=\mathrm{k}_{\mathrm{N}, \mathrm{M}}^{+}(\mathrm{SiO}, 2,5, T)$ & 6 \\
\hline 472 & $\mathrm{Si}_{2} \mathrm{O}_{2}+\mathrm{Si}_{6} \mathrm{O}_{6} \longrightarrow \mathrm{Si}_{8} \mathrm{O}_{8}$ & $\mathrm{k}_{472}=\mathrm{k}_{\mathrm{N}, \mathrm{M}}^{+}(\mathrm{SiO}, 2,6, T)$ & 6 \\
\hline 473 & $\mathrm{Si}_{2} \mathrm{O}_{2}+\mathrm{Si}_{7} \mathrm{O}_{7} \longrightarrow \mathrm{Si}_{9} \mathrm{O}_{9}$ & $\mathrm{k}_{473}=\mathrm{k}_{\mathrm{N}, \mathrm{M}}^{+}(\mathrm{SiO}, 2,7, T)$ & 6 \\
\hline 474 & $\mathrm{Si}_{2} \mathrm{O}_{2}+\mathrm{Si}_{8} \mathrm{O}_{8} \longrightarrow \mathrm{Si}_{10} \mathrm{O}_{10}$ & $\mathrm{k}_{474}=\mathrm{k}_{\mathrm{N}, \mathrm{M}}^{+}(\mathrm{SiO}, 2,8, T)$ & 6 \\
\hline 475 & $\mathrm{Si}_{3} \mathrm{O}_{3} \longrightarrow \mathrm{SiO}+\mathrm{Si}_{2} \mathrm{O}_{2}$ & $\mathrm{k}_{475}=\mathrm{k}_{\mathrm{N}, \mathrm{M}}^{+}(\mathrm{SiO}, 1,2, T) \mathrm{EQR}\left(T,\left\{\mathrm{Si}_{3} \mathrm{O}_{3}\right\},\left\{\mathrm{Si}_{2} \mathrm{O}_{2}, \mathrm{SiO}\right\}\right)$ & 6 \\
\hline 476 & $\mathrm{Si}_{3} \mathrm{O}_{3}+\mathrm{Si}_{3} \mathrm{O}_{3} \longrightarrow \mathrm{Si}_{6} \mathrm{O}_{6}$ & $\mathrm{k}_{476}=\mathrm{k}_{\mathrm{N}, \mathrm{M}}^{+}(\mathrm{SiO}, 3,3, T)$ & 6 \\
\hline 477 & $\mathrm{Si}_{3} \mathrm{O}_{3}+\mathrm{Si}_{4} \mathrm{O}_{4} \longrightarrow \mathrm{Si}_{7} \mathrm{O}_{7}$ & $\mathrm{k}_{477}=\mathrm{k}_{\mathrm{N}, \mathrm{M}}^{+}(\mathrm{SiO}, 3,4, T)$ & 6 \\
\hline 478 & $\mathrm{Si}_{3} \mathrm{O}_{3}+\mathrm{Si}_{5} \mathrm{O}_{5} \longrightarrow \mathrm{Si}_{8} \mathrm{O}_{8}$ & $\mathrm{k}_{478}=\mathrm{k}_{\mathrm{N}, \mathrm{M}}^{+}(\mathrm{SiO}, 3,5, T)$ & 6 \\
\hline 479 & $\mathrm{Si}_{3} \mathrm{O}_{3}+\mathrm{Si}_{6} \mathrm{O}_{6} \longrightarrow \mathrm{Si}_{9} \mathrm{O}_{9}$ & $\mathrm{k}_{479}=\mathrm{k}_{\mathrm{N}, \mathrm{M}}^{+}(\mathrm{SiO}, 3,6, T)$ & 6 \\
\hline 480 & $\mathrm{Si}_{3} \mathrm{O}_{3}+\mathrm{Si}_{7} \mathrm{O}_{7} \longrightarrow \mathrm{Si}_{10} \mathrm{O}_{10}$ & $\mathrm{k}_{480}=\mathrm{k}_{\mathrm{N}, \mathrm{M}}^{+}(\mathrm{SiO}, 3,7, T)$ & 6 \\
\hline 481 & $\mathrm{Si}_{4} \mathrm{O}_{4} \longrightarrow \mathrm{SiO}+\mathrm{Si}_{3} \mathrm{O}_{3}$ & $\mathrm{k}_{481}=\mathrm{k}_{\mathrm{N}, \mathrm{M}}^{+}(\mathrm{SiO}, 1,3, T) \mathrm{EQR}\left(T,\left\{\mathrm{Si}_{4} \mathrm{O}_{4}\right\},\left\{\mathrm{Si}_{3} \mathrm{O}_{3}, \mathrm{SiO}\right\}\right)$ & 6 \\
\hline 482 & $\mathrm{Si}_{4} \mathrm{O}_{4} \longrightarrow \mathrm{Si}_{2} \mathrm{O}_{2}+\mathrm{Si}_{2} \mathrm{O}_{2}$ & $\mathrm{k}_{482}=\mathrm{k}_{\mathrm{N}, \mathrm{M}}^{+}(\mathrm{SiO}, 2,2, T) \mathrm{EQR}\left(T,\left\{\mathrm{Si}_{4} \mathrm{O}_{4}\right\},\left\{\mathrm{Si}_{2} \mathrm{O}_{2}\right\}\right)$ & 6 \\
\hline 483 & $\mathrm{Si}_{4} \mathrm{O}_{4}+\mathrm{Si}_{4} \mathrm{O}_{4} \longrightarrow \mathrm{Si}_{8} \mathrm{O}_{8}$ & $\mathrm{k}_{483}=\mathrm{k}_{\mathrm{N}, \mathrm{M}}^{+}(\mathrm{SiO}, 4,4, T)$ & 6 \\
\hline 484 & $\mathrm{Si}_{4} \mathrm{O}_{4}+\mathrm{Si}_{5} \mathrm{O}_{5} \longrightarrow \mathrm{Si}_{9} \mathrm{O}_{9}$ & $\mathrm{k}_{484}=\mathrm{k}_{\mathrm{N}, \mathrm{M}}^{+}(\mathrm{SiO}, 4,5, T)$ & 6 \\
\hline 485 & $\mathrm{Si}_{4} \mathrm{O}_{4}+\mathrm{Si}_{6} \mathrm{O}_{6} \longrightarrow \mathrm{Si}_{10} \mathrm{O}_{10}$ & $\mathrm{k}_{485}=\mathrm{k}_{\mathrm{N}, \mathrm{M}}^{+}(\mathrm{SiO}, 4,6, T)$ & 6 \\
\hline 486 & $\mathrm{Si}_{5} \mathrm{O}_{5} \longrightarrow \mathrm{SiO}+\mathrm{Si}_{4} \mathrm{O}_{4}$ & $\mathrm{k}_{486}=\mathrm{k}_{\mathrm{N}, \mathrm{M}}^{+}(\mathrm{SiO}, 1,4, T) \mathrm{EQR}\left(T,\left\{\mathrm{Si}_{5} \mathrm{O}_{5}\right\},\left\{\mathrm{Si}_{4} \mathrm{O}_{4}, \mathrm{SiO}\right\}\right)$ & 6 \\
\hline 487 & $\mathrm{Si}_{5} \mathrm{O}_{5} \longrightarrow \mathrm{Si}_{2} \mathrm{O}_{2}+\mathrm{Si}_{3} \mathrm{O}_{3}$ & $\mathrm{k}_{487}=\mathrm{k}_{\mathrm{N}, \mathrm{M}}^{+}(\mathrm{SiO}, 2,3, T) \mathrm{EQR}\left(T,\left\{\mathrm{Si}_{5} \mathrm{O}_{5}\right\},\left\{\mathrm{Si}_{2} \mathrm{O}_{2}, \mathrm{Si}_{3} \mathrm{O}_{3}\right\}\right)$ & 6 \\
\hline 488 & $\mathrm{Si}_{5} \mathrm{O}_{5}+\mathrm{Si}_{5} \mathrm{O}_{5} \longrightarrow \mathrm{Si}_{10} \mathrm{O}_{10}$ & $\mathrm{k}_{488}=\mathrm{k}_{\mathrm{N}, \mathrm{M}}^{+}(\mathrm{SiO}, 5,5, T)$ & 6 \\
\hline 489 & $\mathrm{Si}_{6} \mathrm{O}_{6} \longrightarrow \mathrm{SiO}+\mathrm{Si}_{5} \mathrm{O}_{5}$ & $\mathrm{k}_{489}=\mathrm{k}_{\mathrm{N}, \mathrm{M}}^{+}(\mathrm{SiO}, 1,5, T) \mathrm{EQR}\left(T,\left\{\mathrm{Si}_{6} \mathrm{O}_{6}\right\},\left\{\mathrm{Si}_{5} \mathrm{O}_{5}, \mathrm{SiO}\right\}\right)$ & 6 \\
\hline 490 & $\mathrm{Si}_{6} \mathrm{O}_{6} \longrightarrow \mathrm{Si}_{2} \mathrm{O}_{2}+\mathrm{Si}_{4} \mathrm{O}_{4}$ & $\mathrm{k}_{490}=\mathrm{k}_{\mathrm{N}, \mathrm{M}}^{+}(\mathrm{SiO}, 2,4, T) \mathrm{EQR}\left(T,\left\{\mathrm{Si}_{6} \mathrm{O}_{6}\right\},\left\{\mathrm{Si}_{2} \mathrm{O}_{2}, \mathrm{Si}_{4} \mathrm{O}_{4}\right\}\right)$ & 6 \\
\hline 491 & $\mathrm{Si}_{6} \mathrm{O}_{6} \longrightarrow \mathrm{Si}_{3} \mathrm{O}_{3}+\mathrm{Si}_{3} \mathrm{O}_{3}$ & $\mathrm{k}_{491}=\mathrm{k}_{\mathrm{N}, \mathrm{M}}^{+}(\mathrm{SiO}, 3,3, T) \mathrm{EQR}\left(T,\left\{\mathrm{Si}_{6} \mathrm{O}_{6}\right\},\left\{\mathrm{Si}_{3} \mathrm{O}_{3}\right\}\right)$ & 6 \\
\hline 492 & $\mathrm{Si}_{7} \mathrm{O}_{7} \longrightarrow \mathrm{SiO}+\mathrm{Si}_{6} \mathrm{O}_{6}$ & $\mathrm{k}_{492}=\mathrm{k}_{\mathrm{N}, \mathrm{M}}^{+}(\mathrm{SiO}, 1,6, T) \mathrm{EQR}\left(T,\left\{\mathrm{Si}_{7} \mathrm{O}_{7}\right\},\left\{\mathrm{Si}_{6} \mathrm{O}_{6}, \mathrm{SiO}\right\}\right)$ & 6 \\
\hline 493 & $\mathrm{Si}_{7} \mathrm{O}_{7} \longrightarrow \mathrm{Si}_{2} \mathrm{O}_{2}+\mathrm{Si}_{5} \mathrm{O}_{5}$ & $\mathrm{k}_{493}=\mathrm{k}_{\mathrm{N}, \mathrm{M}}^{+}(\mathrm{SiO}, 2,5, T) \mathrm{EQR}\left(T,\left\{\mathrm{Si}_{7} \mathrm{O}_{7}\right\},\left\{\mathrm{Si}_{2} \mathrm{O}_{2}, \mathrm{Si}_{5} \mathrm{O}_{5}\right\}\right)$ & 6 \\
\hline 494 & $\mathrm{Si}_{7} \mathrm{O}_{7} \longrightarrow \mathrm{Si}_{3} \mathrm{O}_{3}+\mathrm{Si}_{4} \mathrm{O}_{4}$ & $\mathrm{k}_{494}=\mathrm{k}_{\mathrm{N}, \mathrm{M}}^{+}(\mathrm{SiO}, 3,4, T) \mathrm{EQR}\left(T,\left\{\mathrm{Si}_{7} \mathrm{O}_{7}\right\},\left\{\mathrm{Si}_{3} \mathrm{O}_{3}, \mathrm{Si}_{4} \mathrm{O}_{4}\right\}\right)$ & 6 \\
\hline 495 & $\mathrm{Si}_{8} \mathrm{O}_{8} \longrightarrow \mathrm{SiO}+\mathrm{Si}_{7} \mathrm{O}_{7}$ & $\mathrm{k}_{495}=\mathrm{k}_{\mathrm{N}, \mathrm{M}}^{+}(\mathrm{SiO}, 1,7, T) \mathrm{EQR}\left(T,\left\{\mathrm{Si}_{8} \mathrm{O}_{8}\right\},\left\{\mathrm{Si}_{7} \mathrm{O}_{7}, \mathrm{SiO}\right\}\right)$ & 6 \\
\hline 496 & $\mathrm{Si}_{8} \mathrm{O}_{8} \longrightarrow \mathrm{Si}_{2} \mathrm{O}_{2}+\mathrm{Si}_{6} \mathrm{O}_{6}$ & $\mathrm{k}_{496}=\mathrm{k}_{\mathrm{N}, \mathrm{M}}^{+}(\mathrm{SiO}, 2,6, T) \mathrm{EQR}\left(T,\left\{\mathrm{Si}_{8} \mathrm{O}_{8}\right\},\left\{\mathrm{Si}_{2} \mathrm{O}_{2}, \mathrm{Si}_{6} \mathrm{O}_{6}\right\}\right)$ & 6 \\
\hline 497 & $\mathrm{Si}_{8} \mathrm{O}_{8} \longrightarrow \mathrm{Si}_{3} \mathrm{O}_{3}+\mathrm{Si}_{5} \mathrm{O}_{5}$ & $\mathrm{k}_{497}=\mathrm{k}_{\mathrm{N}, \mathrm{M}}^{+}(\mathrm{SiO}, 3,5, T) \mathrm{EQR}\left(T,\left\{\mathrm{Si}_{8} \mathrm{O}_{8}\right\},\left\{\mathrm{Si}_{3} \mathrm{O}_{3}, \mathrm{Si}_{5} \mathrm{O}_{5}\right\}\right)$ & 6 \\
\hline 498 & $\mathrm{Si}_{8} \mathrm{O}_{8} \longrightarrow \mathrm{Si}_{4} \mathrm{O}_{4}+\mathrm{Si}_{4} \mathrm{O}_{4}$ & $\mathrm{k}_{498}=\mathrm{k}_{\mathrm{N}, \mathrm{M}}^{+}(\mathrm{SiO}, 4,4, T) \mathrm{EQR}\left(T,\left\{\mathrm{Si}_{8} \mathrm{O}_{8}\right\},\left\{\mathrm{Si}_{4} \mathrm{O}_{4}\right\}\right)$ & 6 \\
\hline 499 & $\mathrm{Si}_{9} \mathrm{O}_{9} \longrightarrow \mathrm{SiO}+\mathrm{Si}_{8} \mathrm{O}_{8}$ & $\mathrm{k}_{499}=\mathrm{k}_{\mathrm{N}, \mathrm{M}}^{+}(\mathrm{SiO}, 1,8, T) \mathrm{EQR}\left(T,\left\{\mathrm{Si}_{9} \mathrm{O}_{9}\right\},\left\{\mathrm{Si}_{8} \mathrm{O}_{8}, \mathrm{SiO}\right\}\right)$ & 6 \\
\hline 500 & $\mathrm{Si}_{9} \mathrm{O}_{9} \longrightarrow \mathrm{Si}_{2} \mathrm{O}_{2}+\mathrm{Si}_{7} \mathrm{O}_{7}$ & $\mathrm{k}_{500}=\mathrm{k}_{\mathrm{N}, \mathrm{M}}^{+}(\mathrm{SiO}, 2,7, T) \mathrm{EQR}\left(T,\left\{\mathrm{Si}_{9} \mathrm{O}_{9}\right\},\left\{\mathrm{Si}_{2} \mathrm{O}_{2}, \mathrm{Si}_{7} \mathrm{O}_{7}\right\}\right)$ & 6 \\
\hline 501 & $\mathrm{Si}_{9} \mathrm{O}_{9} \longrightarrow \mathrm{Si}_{3} \mathrm{O}_{3}+\mathrm{Si}_{6} \mathrm{O}_{6}$ & $\mathrm{k}_{501}=\mathrm{k}_{\mathrm{N}, \mathrm{M}}^{+}(\mathrm{SiO}, 3,6, T) \mathrm{EQR}\left(T,\left\{\mathrm{Si}_{9} \mathrm{O}_{9}\right\},\left\{\mathrm{Si}_{3} \mathrm{O}_{3}, \mathrm{Si}_{6} \mathrm{O}_{6}\right\}\right)$ & 6 \\
\hline 502 & $\mathrm{Si}_{9} \mathrm{O}_{9} \longrightarrow \mathrm{Si}_{4} \mathrm{O}_{4}+\mathrm{Si}_{5} \mathrm{O}_{5}$ & $\mathrm{k}_{502}=\mathrm{k}_{\mathrm{N}, \mathrm{M}}^{+}(\mathrm{SiO}, 4,5, T) \mathrm{EQR}\left(T,\left\{\mathrm{Si}_{9} \mathrm{O}_{9}\right\},\left\{\mathrm{Si}_{4} \mathrm{O}_{4}, \mathrm{Si}_{5} \mathrm{O}_{5}\right\}\right)$ & 6 \\
\hline 503 & $\mathrm{SiF}^{+}+\mathrm{e}^{-} \longrightarrow \mathrm{Si}+\mathrm{F}$ & $\mathrm{k}_{503}=2 \cdot 10^{-7}(T / 300)^{-0.5}$ & 8 \\
\hline 504 & $\mathrm{SiH}^{+}+\mathrm{e}^{-} \longrightarrow \mathrm{Si}+\mathrm{H}$ & $\mathrm{k}_{504}=2 \cdot 10^{-7}(T / 300)^{-0.5}$ & 8 \\
\hline 505 & $\mathrm{SiO}+\mathrm{Si}_{2} \mathrm{O}_{2} \longrightarrow \mathrm{Si}_{3} \mathrm{O}_{3}$ & $\mathrm{k}_{505}=\mathrm{k}_{\mathrm{N}, \mathrm{M}}^{+}(\mathrm{SiO}, 1,2, T)$ & 6 \\
\hline
\end{tabular}




\begin{tabular}{|c|c|c|c|}
\hline No. & Reaction & Rate coefficient $\left(\mathrm{cm}^{3(N-1)} \mathrm{s}^{-1}\right)$ with $N$ number of reactants & Ref. \\
\hline 506 & $\mathrm{SiO}+\mathrm{Si}_{3} \mathrm{O}_{3} \longrightarrow \mathrm{Si}_{4} \mathrm{O}_{4}$ & $\mathrm{k}_{506}=\mathrm{k}_{\mathrm{N}, \mathrm{M}}^{+}(\mathrm{SiO}, 1,3, T)$ & 6 \\
\hline 507 & $\mathrm{SiO}+\mathrm{Si}_{4} \mathrm{O}_{4} \longrightarrow \mathrm{Si}_{5} \mathrm{O}_{5}$ & $\mathrm{k}_{507}=\mathrm{k}_{\mathrm{N}, \mathrm{M}}^{+}(\mathrm{SiO}, 1,4, T)$ & 6 \\
\hline 508 & $\mathrm{SiO}+\mathrm{Si}_{5} \mathrm{O}_{5} \longrightarrow \mathrm{Si}_{6} \mathrm{O}_{6}$ & $\mathrm{k}_{508}=\mathrm{k}_{\mathrm{N}, \mathrm{M}}^{+}(\mathrm{SiO}, 1,5, T)$ & 6 \\
\hline 509 & $\mathrm{SiO}+\mathrm{Si}_{6} \mathrm{O}_{6} \longrightarrow \mathrm{Si}_{7} \mathrm{O}_{7}$ & $\mathrm{k}_{509}=\mathrm{k}_{\mathrm{N}, \mathrm{M}}^{+}(\mathrm{SiO}, 1,6, T)$ & 6 \\
\hline 510 & $\mathrm{SiO}+\mathrm{Si}_{7} \mathrm{O}_{7} \longrightarrow \mathrm{Si}_{8} \mathrm{O}_{8}$ & $\mathrm{k}_{510}=\mathrm{k}_{\mathrm{N}, \mathrm{M}}^{+}(\mathrm{SiO}, 1,7, T)$ & 6 \\
\hline 511 & $\mathrm{SiO}+\mathrm{Si}_{8} \mathrm{O}_{8} \longrightarrow \mathrm{Si}_{9} \mathrm{O}_{9}$ & $\mathrm{k}_{511}=\mathrm{k}_{\mathrm{N}, \mathrm{M}}^{+}(\mathrm{SiO}, 1,8, T)$ & 6 \\
\hline 512 & $\mathrm{SiO}+\mathrm{Si}_{9} \mathrm{O}_{9} \longrightarrow \mathrm{Si}_{10} \mathrm{O}_{10}$ & $\mathrm{k}_{512}=\mathrm{k}_{\mathrm{N}, \mathrm{M}}^{+}(\mathrm{SiO}, 1,9, T)$ & 6 \\
\hline 513 & $\mathrm{SiO}+\mathrm{SiO} \longrightarrow \mathrm{Si}_{2} \mathrm{O}_{2}$ & $\mathrm{k}_{513}=\mathrm{k}_{\mathrm{N}, \mathrm{M}}^{+}(\mathrm{SiO}, 1,1, T)$ & 6 \\
\hline 514 & $\mathrm{SiO}^{+}+\mathrm{e}^{-} \longrightarrow \mathrm{Si}+\mathrm{O}$ & $\mathrm{k}_{514}=2 \cdot 10^{-7}(T / 300)^{-0.5}$ & 8 \\
\hline 515 & $\mathrm{SiO}^{+}+\mathrm{Fe} \longrightarrow \mathrm{Fe}^{+}+\mathrm{SiO}$ & $\mathrm{k}_{515}=1 \cdot 10^{-9}$ & 8 \\
\hline 516 & $\mathrm{SiO}_{2}+\mathrm{H} \longrightarrow \mathrm{SiO}+\mathrm{OH}$ & $\mathrm{k}_{516}=2 \cdot 10^{-12} \mathrm{EQR}\left(T,\left\{\mathrm{SiO}_{2}, \mathrm{H}\right\},\{\mathrm{SiO}, \mathrm{OH}\}\right)$ & 8 \\
\hline 517 & $\mathrm{Ti}+\mathrm{CO}_{2} \longrightarrow \mathrm{TiO}+\mathrm{CO}$ & $\mathrm{k}_{517}=7 \cdot 10^{-11} \exp \left(-\frac{14.9}{R_{\mathrm{kJ}} T}\right)$ & 27 \\
\hline 518 & $\mathrm{Ti}+\mathrm{N}_{2} \mathrm{O} \longrightarrow \mathrm{TiO}+\mathrm{N}_{2}$ & $\mathrm{k}_{518}=1.74 \cdot 10^{-10} \exp \left(-\frac{14.3}{R_{\mathrm{kJ} J} T}\right)$ & 27 \\
\hline 519 & $\mathrm{Ti}+\mathrm{NO} \longrightarrow \mathrm{TiO}+\mathrm{N}$ & $\mathrm{k}_{519}=3.28 \cdot 10^{-11} \exp \left(-\frac{3.62}{R_{\mathrm{kJ}} T}\right)$ & 27 \\
\hline 520 & $\mathrm{Ti}+\mathrm{NO}_{2} \longrightarrow \mathrm{TiO}+\mathrm{NO}$ & $\mathrm{k}_{520}=9 \cdot 10^{-11}$ & 27 \\
\hline 521 & $\mathrm{Ti}+\mathrm{O}_{2} \longrightarrow \mathrm{TiO}+\mathrm{O}$ & $\mathrm{k}_{521}=1.69 \cdot 10^{-10} \exp \left(-\frac{11.6}{R_{\mathrm{kJ}} T}\right)$ & 27 \\
\hline 522 & $\mathrm{Ti}+\mathrm{SO}_{2} \longrightarrow \mathrm{TiO}+\mathrm{SO}$ & $\mathrm{k}_{522}=1.7 \cdot 10^{-10} \exp \left(-\frac{2.66}{R_{\mathrm{kJ} J} T}\right)$ & 27 \\
\hline 523 & $\mathrm{Ti}_{10} \mathrm{O}_{20} \longrightarrow \mathrm{TiO}_{2}+\mathrm{Ti}_{9} \mathrm{O}_{18}$ & $\mathrm{k}_{523}=\mathrm{k}_{\mathrm{N}, \mathrm{M}}^{+}\left(\mathrm{TiO}_{2}, 1,9, T\right) \mathrm{EQR}\left(T,\left\{\mathrm{Ti}_{10} \mathrm{O}_{20}\right\},\left\{\mathrm{Ti}_{9} \mathrm{O}_{18}, \mathrm{TiO}_{2}\right\}\right)$ & 6 \\
\hline 524 & $\mathrm{Ti}_{10} \mathrm{O}_{20} \longrightarrow \mathrm{Ti}_{2} \mathrm{O}_{4}+\mathrm{Ti}_{8} \mathrm{O}_{16}$ & $\mathrm{k}_{524}=\mathrm{k}_{\mathrm{N}, \mathrm{M}}^{+}\left(\mathrm{TiO}_{2}, 2,8, T\right) \mathrm{EQR}\left(T,\left\{\mathrm{Ti}_{10} \mathrm{O}_{20}\right\},\left\{\mathrm{Ti}_{2} \mathrm{O}_{4}, \mathrm{Ti}_{8} \mathrm{O}_{16}\right\}\right)$ & 6 \\
\hline 525 & $\mathrm{Ti}_{10} \mathrm{O}_{20} \longrightarrow \mathrm{Ti}_{3} \mathrm{O}_{6}+\mathrm{Ti}_{7} \mathrm{O}_{14}$ & $\mathrm{k}_{525}=\mathrm{k}_{\mathrm{N}, \mathrm{M}}^{+}\left(\mathrm{TiO}_{2}, 3,7, T\right) \mathrm{EQR}\left(T,\left\{\mathrm{Ti}_{10} \mathrm{O}_{20}\right\},\left\{\mathrm{Ti}_{3} \mathrm{O}_{6}, \mathrm{Ti}_{7} \mathrm{O}_{14}\right\}\right)$ & 6 \\
\hline 526 & $\mathrm{Ti}_{10} \mathrm{O}_{20} \longrightarrow \mathrm{Ti}_{4} \mathrm{O}_{8}+\mathrm{Ti}_{6} \mathrm{O}_{12}$ & $\mathrm{k}_{526}=\mathrm{k}_{\mathrm{N}, \mathrm{M}}^{+}\left(\mathrm{TiO}_{2}, 4,6, T\right) \mathrm{EQR}\left(T,\left\{\mathrm{Ti}_{10} \mathrm{O}_{20}\right\},\left\{\mathrm{Ti}_{4} \mathrm{O}_{8}, \mathrm{Ti}_{6} \mathrm{O}_{12}\right\}\right)$ & 6 \\
\hline 527 & $\mathrm{Ti}_{10} \mathrm{O}_{20} \longrightarrow \mathrm{Ti}_{5} \mathrm{O}_{10}+\mathrm{Ti}_{5} \mathrm{O}_{10}$ & $\mathrm{k}_{527}=\mathrm{k}_{\mathrm{N}, \mathrm{M}}^{+}\left(\mathrm{TiO}_{2}, 5,5, T\right) \mathrm{EQR}\left(T,\left\{\mathrm{Ti}_{10} \mathrm{O}_{20}\right\},\left\{\mathrm{Ti}_{5} \mathrm{O}_{10}\right\}\right)$ & 6 \\
\hline 528 & $\mathrm{Ti}_{2} \mathrm{O}_{4} \longrightarrow \mathrm{TiO}_{2}+\mathrm{TiO}_{2}$ & $\mathrm{k}_{528}=\mathrm{k}_{\mathrm{N}, \mathrm{M}}^{+}\left(\mathrm{TiO}_{2}, 1,1, T\right) \mathrm{EQR}\left(T,\left\{\mathrm{Ti}_{2} \mathrm{O}_{4}\right\},\left\{\mathrm{TiO}_{2}\right\}\right)$ & 6 \\
\hline 529 & $\mathrm{Ti}_{2} \mathrm{O}_{4}+\mathrm{Ti}_{2} \mathrm{O}_{4} \longrightarrow \mathrm{Ti}_{4} \mathrm{O}_{8}$ & $\mathrm{k}_{529}=\mathrm{k}_{\mathrm{N}, \mathrm{M}}^{+}\left(\mathrm{TiO}_{2}, 2,2, T\right)$ & 6 \\
\hline 530 & $\mathrm{Ti}_{2} \mathrm{O}_{4}+\mathrm{Ti}_{3} \mathrm{O}_{6} \longrightarrow \mathrm{Ti}_{5} \mathrm{O}_{10}$ & $\mathrm{k}_{530}=\mathrm{k}_{\mathrm{N}, \mathrm{M}}^{+}\left(\mathrm{TiO}_{2}, 2,3, T\right)$ & 6 \\
\hline 531 & $\mathrm{Ti}_{2} \mathrm{O}_{4}+\mathrm{Ti}_{4} \mathrm{O}_{8} \longrightarrow \mathrm{Ti}_{6} \mathrm{O}_{12}$ & $\mathrm{k}_{531}=\mathrm{k}_{\mathrm{N}, \mathrm{M}}^{+}\left(\mathrm{TiO}_{2}, 2,4, T\right)$ & 6 \\
\hline 532 & $\mathrm{Ti}_{2} \mathrm{O}_{4}+\mathrm{Ti}_{5} \mathrm{O}_{10} \longrightarrow \mathrm{Ti}_{7} \mathrm{O}_{14}$ & $\mathrm{k}_{532}=\mathrm{k}_{\mathrm{N}, \mathrm{M}}^{+}\left(\mathrm{TiO}_{2}, 2,5, T\right)$ & 6 \\
\hline 533 & $\mathrm{Ti}_{2} \mathrm{O}_{4}+\mathrm{Ti}_{6} \mathrm{O}_{12} \longrightarrow \mathrm{Ti}_{8} \mathrm{O}_{16}$ & $\mathrm{k}_{533}=\mathrm{k}_{\mathrm{N}, \mathrm{M}}^{+}\left(\mathrm{TiO}_{2}, 2,6, T\right)$ & 6 \\
\hline 534 & $\mathrm{Ti}_{2} \mathrm{O}_{4}+\mathrm{Ti}_{7} \mathrm{O}_{14} \longrightarrow \mathrm{Ti}_{9} \mathrm{O}_{18}$ & $\mathrm{k}_{534}=\mathrm{k}_{\mathrm{N}, \mathrm{M}}^{+}\left(\mathrm{TiO}_{2}, 2,7, T\right)$ & 6 \\
\hline 535 & $\mathrm{Ti}_{2} \mathrm{O}_{4}+\mathrm{Ti}_{8} \mathrm{O}_{16} \longrightarrow \mathrm{Ti}_{10} \mathrm{O}_{20}$ & $\mathrm{k}_{535}=\mathrm{k}_{\mathrm{N}, \mathrm{M}}^{+}\left(\mathrm{TiO}_{2}, 2,8, T\right)$ & 6 \\
\hline 536 & $\mathrm{Ti}_{3} \mathrm{O}_{6} \longrightarrow \mathrm{TiO}_{2}+\mathrm{Ti}_{2} \mathrm{O}_{4}$ & $\mathrm{k}_{536}=\mathrm{k}_{\mathrm{N}, \mathrm{M}}^{+}\left(\mathrm{TiO}_{2}, 1,2, T\right) \mathrm{EQR}\left(T,\left\{\mathrm{Ti}_{3} \mathrm{O}_{6}\right\},\left\{\mathrm{Ti}_{2} \mathrm{O}_{4}, \mathrm{TiO}_{2}\right\}\right)$ & 6 \\
\hline 537 & $\mathrm{Ti}_{3} \mathrm{O}_{6}+\mathrm{Ti}_{3} \mathrm{O}_{6} \longrightarrow \mathrm{Ti}_{6} \mathrm{O}_{12}$ & $\mathrm{k}_{537}=\mathrm{k}_{\mathrm{N}, \mathrm{M}}^{+}\left(\mathrm{TiO}_{2}, 3,3, T\right)$ & 6 \\
\hline 538 & $\mathrm{Ti}_{3} \mathrm{O}_{6}+\mathrm{Ti}_{4} \mathrm{O}_{8} \longrightarrow \mathrm{Ti}_{7} \mathrm{O}_{14}$ & $\mathrm{k}_{538}=\mathrm{k}_{\mathrm{N}, \mathrm{M}}^{+}\left(\mathrm{TiO}_{2}, 3,4, T\right)$ & 6 \\
\hline 539 & $\mathrm{Ti}_{3} \mathrm{O}_{6}+\mathrm{Ti}_{5} \mathrm{O}_{10} \longrightarrow \mathrm{Ti}_{8} \mathrm{O}_{16}$ & $\mathrm{k}_{539}=\mathrm{k}_{\mathrm{N}, \mathrm{M}}^{+}\left(\mathrm{TiO}_{2}, 3,5, T\right)$ & 6 \\
\hline 540 & $\mathrm{Ti}_{3} \mathrm{O}_{6}+\mathrm{Ti}_{6} \mathrm{O}_{12} \longrightarrow \mathrm{Ti}_{9} \mathrm{O}_{18}$ & $\mathrm{k}_{540}=\mathrm{k}_{\mathrm{N}, \mathrm{M}}^{+}\left(\mathrm{TiO}_{2}, 3,6, T\right)$ & 6 \\
\hline 541 & $\mathrm{Ti}_{3} \mathrm{O}_{6}+\mathrm{Ti}_{7} \mathrm{O}_{14} \longrightarrow \mathrm{Ti}_{10} \mathrm{O}_{20}$ & $\mathrm{k}_{541}=\mathrm{k}_{\mathrm{N}, \mathrm{M}}^{+}\left(\mathrm{TiO}_{2}, 3,7, T\right)$ & 6 \\
\hline 542 & $\mathrm{Ti}_{4} \mathrm{O}_{8} \longrightarrow \mathrm{TiO}_{2}+\mathrm{Ti}_{3} \mathrm{O}_{6}$ & $\mathrm{k}_{542}=\mathrm{k}_{\mathrm{N}, \mathrm{M}}^{+}\left(\mathrm{TiO}_{2}, 1,3, T\right) \mathrm{EQR}\left(T,\left\{\mathrm{Ti}_{4} \mathrm{O}_{8}\right\},\left\{\mathrm{Ti}_{3} \mathrm{O}_{6}, \mathrm{TiO}_{2}\right\}\right)$ & 6 \\
\hline 543 & $\mathrm{Ti}_{4} \mathrm{O}_{8} \longrightarrow \mathrm{Ti}_{2} \mathrm{O}_{4}+\mathrm{Ti}_{2} \mathrm{O}_{4}$ & $\mathrm{k}_{543}=\mathrm{k}_{\mathrm{N}, \mathrm{M}}^{+}\left(\mathrm{TiO}_{2}, 2,2, T\right) \mathrm{EQR}\left(T,\left\{\mathrm{Ti}_{4} \mathrm{O}_{8}\right\},\left\{\mathrm{Ti}_{2} \mathrm{O}_{4}\right\}\right)$ & 6 \\
\hline 544 & $\mathrm{Ti}_{4} \mathrm{O}_{8}+\mathrm{Ti}_{4} \mathrm{O}_{8} \longrightarrow \mathrm{Ti}_{8} \mathrm{O}_{16}$ & $\mathrm{k}_{544}=\mathrm{k}_{\mathrm{N}, \mathrm{M}}^{+}\left(\mathrm{TiO}_{2}, 4,4, T\right)$ & 6 \\
\hline 545 & $\mathrm{Ti}_{4} \mathrm{O}_{8}+\mathrm{Ti}_{5} \mathrm{O}_{10} \longrightarrow \mathrm{Ti}_{9} \mathrm{O}_{18}$ & $\mathrm{k}_{545}=\mathrm{k}_{\mathrm{N}, \mathrm{M}}^{+}\left(\mathrm{TiO}_{2}, 4,5, T\right)$ & 6 \\
\hline
\end{tabular}




\begin{tabular}{|c|c|c|c|}
\hline No. & Reaction & Rate coefficient $\left(\mathrm{cm}^{3(N-1)} \mathrm{s}^{-1}\right)$ with $N$ number of reactants & Ref. \\
\hline 546 & $\mathrm{Ti}_{4} \mathrm{O}_{8}+\mathrm{Ti}_{6} \mathrm{O}_{12} \longrightarrow \mathrm{Ti}_{10} \mathrm{O}_{20}$ & $\mathrm{k}_{546}=\mathrm{k}_{\mathrm{N}, \mathrm{M}}^{+}\left(\mathrm{TiO}_{2}, 4,6, T\right)$ & 6 \\
\hline 547 & $\mathrm{Ti}_{5} \mathrm{O}_{10} \longrightarrow \mathrm{TiO}_{2}+\mathrm{Ti}_{4} \mathrm{O}_{8}$ & $\mathrm{k}_{547}=\mathrm{k}_{\mathrm{N}, \mathrm{M}}^{+}\left(\mathrm{TiO}_{2}, 1,4, T\right) \mathrm{EQR}\left(T,\left\{\mathrm{Ti}_{5} \mathrm{O}_{10}\right\},\left\{\mathrm{Ti}_{4} \mathrm{O}_{8}, \mathrm{TiO}_{2}\right\}\right)$ & 6 \\
\hline 548 & $\mathrm{Ti}_{5} \mathrm{O}_{10} \longrightarrow \mathrm{Ti}_{2} \mathrm{O}_{4}+\mathrm{Ti}_{3} \mathrm{O}_{6}$ & $\mathrm{k}_{548}=\mathrm{k}_{\mathrm{N}, \mathrm{M}}^{+}\left(\mathrm{TiO}_{2}, 2,3, T\right) \mathrm{EQR}\left(T,\left\{\mathrm{Ti}_{5} \mathrm{O}_{10}\right\},\left\{\mathrm{Ti}_{2} \mathrm{O}_{4}, \mathrm{Ti}_{3} \mathrm{O}_{6}\right\}\right)$ & 6 \\
\hline 549 & $\mathrm{Ti}_{5} \mathrm{O}_{10}+\mathrm{Ti}_{5} \mathrm{O}_{10} \longrightarrow \mathrm{Ti}_{10} \mathrm{O}_{20}$ & $\mathrm{k}_{549}=\mathrm{k}_{\mathrm{N}, \mathrm{M}}^{+}\left(\mathrm{TiO}_{2}, 5,5, T\right)$ & 6 \\
\hline 550 & $\mathrm{Ti}_{6} \mathrm{O}_{12} \longrightarrow \mathrm{TiO}_{2}+\mathrm{Ti}_{5} \mathrm{O}_{10}$ & $\mathrm{k}_{550}=\mathrm{k}_{\mathrm{N}, \mathrm{M}}^{+}\left(\mathrm{TiO}_{2}, 1,5, T\right) \mathrm{EQR}\left(T,\left\{\mathrm{Ti}_{6} \mathrm{O}_{12}\right\},\left\{\mathrm{Ti}_{5} \mathrm{O}_{10}, \mathrm{TiO}_{2}\right\}\right)$ & 6 \\
\hline 551 & $\mathrm{Ti}_{6} \mathrm{O}_{12} \longrightarrow \mathrm{Ti}_{2} \mathrm{O}_{4}+\mathrm{Ti}_{4} \mathrm{O}_{8}$ & $\mathrm{k}_{551}=\mathrm{k}_{\mathrm{N}, \mathrm{M}}^{+}\left(\mathrm{TiO}_{2}, 2,4, T\right) \mathrm{EQR}\left(T,\left\{\mathrm{Ti}_{6} \mathrm{O}_{12}\right\},\left\{\mathrm{Ti}_{2} \mathrm{O}_{4}, \mathrm{Ti}_{4} \mathrm{O}_{8}\right\}\right)$ & 6 \\
\hline 552 & $\mathrm{Ti}_{6} \mathrm{O}_{12} \longrightarrow \mathrm{Ti}_{3} \mathrm{O}_{6}+\mathrm{Ti}_{3} \mathrm{O}_{6}$ & $\mathrm{k}_{552}=\mathrm{k}_{\mathrm{N}, \mathrm{M}}^{+}\left(\mathrm{TiO}_{2}, 3,3, T\right) \mathrm{EQR}\left(T,\left\{\mathrm{Ti}_{6} \mathrm{O}_{12}\right\},\left\{\mathrm{Ti}_{3} \mathrm{O}_{6}\right\}\right)$ & 6 \\
\hline 553 & $\mathrm{Ti}_{7} \mathrm{O}_{14} \longrightarrow \mathrm{TiO}_{2}+\mathrm{Ti}_{6} \mathrm{O}_{12}$ & $\mathrm{k}_{553}=\mathrm{k}_{\mathrm{N}, \mathrm{M}}^{+}\left(\mathrm{TiO}_{2}, 1,6, T\right) \mathrm{EQR}\left(T,\left\{\mathrm{Ti}_{7} \mathrm{O}_{14}\right\},\left\{\mathrm{Ti}_{6} \mathrm{O}_{12}, \mathrm{TiO}_{2}\right\}\right)$ & 6 \\
\hline 554 & $\mathrm{Ti}_{7} \mathrm{O}_{14} \longrightarrow \mathrm{Ti}_{2} \mathrm{O}_{4}+\mathrm{Ti}_{5} \mathrm{O}_{10}$ & $\mathrm{k}_{554}=\mathrm{k}_{\mathrm{N}, \mathrm{M}}^{+}\left(\mathrm{TiO}_{2}, 2,5, T\right) \mathrm{EQR}\left(T,\left\{\mathrm{Ti}_{7} \mathrm{O}_{14}\right\},\left\{\mathrm{Ti}_{2} \mathrm{O}_{4}, \mathrm{Ti}_{5} \mathrm{O}_{10}\right\}\right)$ & 6 \\
\hline 555 & $\mathrm{Ti}_{7} \mathrm{O}_{14} \longrightarrow \mathrm{Ti}_{3} \mathrm{O}_{6}+\mathrm{Ti}_{4} \mathrm{O}_{8}$ & $\mathrm{k}_{555}=\mathrm{k}_{\mathrm{N}, \mathrm{M}}^{+}\left(\mathrm{TiO}_{2}, 3,4, T\right) \mathrm{EQR}\left(T,\left\{\mathrm{Ti}_{7} \mathrm{O}_{14}\right\},\left\{\mathrm{Ti}_{3} \mathrm{O}_{6}, \mathrm{Ti}_{4} \mathrm{O}_{8}\right\}\right)$ & 6 \\
\hline 556 & $\mathrm{Ti}_{8} \mathrm{O}_{16} \longrightarrow \mathrm{TiO}_{2}+\mathrm{Ti}_{7} \mathrm{O}_{14}$ & $\mathrm{k}_{556}=\mathrm{k}_{\mathrm{N}, \mathrm{M}}^{+}\left(\mathrm{TiO}_{2}, 1,7, T\right) \mathrm{EQR}\left(T,\left\{\mathrm{Ti}_{8} \mathrm{O}_{16}\right\},\left\{\mathrm{Ti}_{7} \mathrm{O}_{14}, \mathrm{TiO}_{2}\right\}\right)$ & 6 \\
\hline 557 & $\mathrm{Ti}_{8} \mathrm{O}_{16} \longrightarrow \mathrm{Ti}_{2} \mathrm{O}_{4}+\mathrm{Ti}_{6} \mathrm{O}_{12}$ & $\mathrm{k}_{557}=\mathrm{k}_{\mathrm{N}, \mathrm{M}}^{+}\left(\mathrm{TiO}_{2}, 2,6, T\right) \mathrm{EQR}\left(T,\left\{\mathrm{Ti}_{8} \mathrm{O}_{16}\right\},\left\{\mathrm{Ti}_{2} \mathrm{O}_{4}, \mathrm{Ti}_{6} \mathrm{O}_{12}\right\}\right)$ & 6 \\
\hline 558 & $\mathrm{Ti}_{8} \mathrm{O}_{16} \longrightarrow \mathrm{Ti}_{3} \mathrm{O}_{6}+\mathrm{Ti}_{5} \mathrm{O}_{10}$ & $\mathrm{k}_{558}=\mathrm{k}_{\mathrm{N}, \mathrm{M}}^{+}\left(\mathrm{TiO}_{2}, 3,5, T\right) \mathrm{EQR}\left(T,\left\{\mathrm{Ti}_{8} \mathrm{O}_{16}\right\},\left\{\mathrm{Ti}_{3} \mathrm{O}_{6}, \mathrm{Ti}_{5} \mathrm{O}_{10}\right\}\right)$ & 6 \\
\hline 559 & $\mathrm{Ti}_{8} \mathrm{O}_{16} \longrightarrow \mathrm{Ti}_{4} \mathrm{O}_{8}+\mathrm{Ti}_{4} \mathrm{O}_{8}$ & $\mathrm{k}_{559}=\mathrm{k}_{\mathrm{N}, \mathrm{M}}^{+}\left(\mathrm{TiO}_{2}, 4,4, T\right) \mathrm{EQR}\left(T,\left\{\mathrm{Ti}_{8} \mathrm{O}_{16}\right\},\left\{\mathrm{Ti}_{4} \mathrm{O}_{8}\right\}\right)$ & 6 \\
\hline 560 & $\mathrm{Ti}_{9} \mathrm{O}_{18} \longrightarrow \mathrm{TiO}_{2}+\mathrm{Ti}_{8} \mathrm{O}_{16}$ & $\mathrm{k}_{560}=\mathrm{k}_{\mathrm{N}, \mathrm{M}}^{+}\left(\mathrm{TiO}_{2}, 1,8, T\right) \mathrm{EQR}\left(T,\left\{\mathrm{Ti}_{9} \mathrm{O}_{18}\right\},\left\{\mathrm{Ti}_{8} \mathrm{O}_{16}, \mathrm{TiO}_{2}\right\}\right)$ & 6 \\
\hline 561 & $\mathrm{Ti}_{9} \mathrm{O}_{18} \longrightarrow \mathrm{Ti}_{2} \mathrm{O}_{4}+\mathrm{Ti}_{7} \mathrm{O}_{14}$ & $\mathrm{k}_{561}=\mathrm{k}_{\mathrm{N}, \mathrm{M}}^{+}\left(\mathrm{TiO}_{2}, 2,7, T\right) \mathrm{EQR}\left(T,\left\{\mathrm{Ti}_{9} \mathrm{O}_{18}\right\},\left\{\mathrm{Ti}_{2} \mathrm{O}_{4}, \mathrm{Ti}_{7} \mathrm{O}_{14}\right\}\right)$ & 6 \\
\hline 562 & $\mathrm{Ti}_{9} \mathrm{O}_{18} \longrightarrow \mathrm{Ti}_{3} \mathrm{O}_{6}+\mathrm{Ti}_{6} \mathrm{O}_{12}$ & $\mathrm{k}_{562}=\mathrm{k}_{\mathrm{N}, \mathrm{M}}^{+}\left(\mathrm{TiO}_{2}, 3,6, T\right) \mathrm{EQR}\left(T,\left\{\mathrm{Ti}_{9} \mathrm{O}_{18}\right\},\left\{\mathrm{Ti}_{3} \mathrm{O}_{6}, \mathrm{Ti}_{6} \mathrm{O}_{12}\right\}\right)$ & 6 \\
\hline 563 & $\mathrm{Ti}_{9} \mathrm{O}_{18} \longrightarrow \mathrm{Ti}_{4} \mathrm{O}_{8}+\mathrm{Ti}_{5} \mathrm{O}_{10}$ & $\mathrm{k}_{563}=\mathrm{k}_{\mathrm{N}, \mathrm{M}}^{+}\left(\mathrm{TiO}_{2}, 4,5, T\right) \mathrm{EQR}\left(T,\left\{\mathrm{Ti}_{9} \mathrm{O}_{18}\right\},\left\{\mathrm{Ti}_{4} \mathrm{O}_{8}, \mathrm{Ti}_{5} \mathrm{O}_{10}\right\}\right)$ & 6 \\
\hline 564 & $\mathrm{TiO}+\mathrm{CO} \longrightarrow \mathrm{Ti}+\mathrm{CO}_{2}$ & $\mathrm{k}_{564}=7 \cdot 10^{-11} \exp \left(-\frac{14.9}{R_{\mathrm{k} J} T}\right) \mathrm{EQR}\left(T,\{\mathrm{CO}, \mathrm{TiO}\},\left\{\mathrm{CO}_{2}, \mathrm{Ti}\right\}\right)$ & 27 \\
\hline 565 & $\mathrm{TiO}+\mathrm{N} \longrightarrow \mathrm{Ti}+\mathrm{NO}$ & $\mathrm{k}_{565}=3.28 \cdot 10^{-11} \exp \left(-\frac{3.62}{R_{\mathrm{k} J} T}\right) \mathrm{EQR}(T,\{\mathrm{~N}, \mathrm{TiO}\},\{\mathrm{NO}, \mathrm{Ti}\})$ & 27 \\
\hline 566 & $\mathrm{TiO}+\mathrm{N}_{2} \longrightarrow \mathrm{Ti}+\mathrm{N}_{2} \mathrm{O}$ & $\mathrm{k}_{566}=1.74 \cdot 10^{-10} \exp \left(-\frac{14.3}{R_{\mathrm{kJ}} T}\right) \mathrm{EQR}\left(T,\left\{\mathrm{~N}_{2}, \mathrm{TiO}\right\},\left\{\mathrm{N}_{2} \mathrm{O}, \mathrm{Ti}\right\}\right)$ & 27 \\
\hline 567 & $\mathrm{TiO}+\mathrm{NO} \longrightarrow \mathrm{Ti}+\mathrm{NO}_{2}$ & $\mathrm{k}_{567}=9 \cdot 10^{-11} \mathrm{EQR}\left(T,\{\mathrm{NO}, \mathrm{TiO}\},\left\{\mathrm{NO}_{2}, \mathrm{Ti}\right\}\right)$ & 27 \\
\hline 568 & $\mathrm{TiO}+\mathrm{NO} \longrightarrow \mathrm{TiO}_{2}+\mathrm{N}$ & $\mathrm{k}_{568}=2.2 \cdot 10^{-12}$ & 28 \\
\hline 569 & $\mathrm{TiO}+\mathrm{O} \longrightarrow \mathrm{Ti}+\mathrm{O}_{2}$ & $\mathrm{k}_{569}=1.69 \cdot 10^{-10} \exp \left(-\frac{11.6}{R_{\mathrm{k} J} T}\right) \mathrm{EQR}\left(T,\{\mathrm{O}, \mathrm{TiO}\},\left\{\mathrm{O}_{2}, \mathrm{Ti}\right\}\right)$ & 27 \\
\hline 570 & $\mathrm{TiO}+\mathrm{O}_{2} \longrightarrow \mathrm{TiO}_{2}+\mathrm{O}$ & $\mathrm{k}_{570}=7.07 \cdot 10^{-12}$ & 29 \\
\hline 571 & $\mathrm{TiO}+\mathrm{OH} \longrightarrow \mathrm{TiO}_{2}+\mathrm{H}$ & $\mathrm{k}_{571}=2.07075 \cdot 10^{-10}(T)^{0.39}$ & 30 \\
\hline 572 & $\mathrm{TiO}+\mathrm{SO} \longrightarrow \mathrm{Ti}+\mathrm{SO}_{2}$ & $\mathrm{k}_{572}=1.7 \cdot 10^{-10} \exp \left(-\frac{2.66}{R_{\mathrm{kJ}} T}\right) \mathrm{EQR}\left(T,\{\mathrm{SO}, \mathrm{TiO}\},\left\{\mathrm{SO}_{2}, \mathrm{Ti}\right\}\right)$ & 27 \\
\hline 573 & $\mathrm{TiO}_{2}+\mathrm{H} \longrightarrow \mathrm{TiO}+\mathrm{OH}$ & $\mathrm{k}_{573}=5 \cdot 10^{-10} \exp \left(-\frac{15570}{T}\right)$ & 30 \\
\hline 574 & $\mathrm{TiO}_{2}+\mathrm{N} \longrightarrow \mathrm{TiO}+\mathrm{NO}$ & $\mathrm{k}_{574}=2.2 \cdot 10^{-12} \mathrm{EQR}\left(T,\left\{\mathrm{~N}, \mathrm{TiO}_{2}\right\},\{\mathrm{NO}, \mathrm{TiO}\}\right)$ & 28 \\
\hline 575 & $\mathrm{TiO}_{2}+\mathrm{O} \longrightarrow \mathrm{TiO}+\mathrm{O}_{2}$ & $\mathrm{k}_{575}=7.07 \cdot 10^{-12} \mathrm{EQR}\left(T,\left\{\mathrm{O}, \mathrm{TiO}_{2}\right\},\left\{\mathrm{O}_{2}, \mathrm{TiO}\right\}\right)$ & 29 \\
\hline 576 & $\mathrm{TiO}_{2}+\mathrm{Ti}_{2} \mathrm{O}_{4} \longrightarrow \mathrm{Ti}_{3} \mathrm{O}_{6}$ & $\mathrm{k}_{576}=\mathrm{k}_{\mathrm{N}, \mathrm{M}}^{+}\left(\mathrm{TiO}_{2}, 1,2, T\right)$ & 6 \\
\hline 577 & $\mathrm{TiO}_{2}+\mathrm{Ti}_{3} \mathrm{O}_{6} \longrightarrow \mathrm{Ti}_{4} \mathrm{O}_{8}$ & $\mathrm{k}_{577}=\mathrm{k}_{\mathrm{N}, \mathrm{M}}^{+}\left(\mathrm{TiO}_{2}, 1,3, T\right)$ & 6 \\
\hline 578 & $\mathrm{TiO}_{2}+\mathrm{Ti}_{4} \mathrm{O}_{8} \longrightarrow \mathrm{Ti}_{5} \mathrm{O}_{10}$ & $\mathrm{k}_{578}=\mathrm{k}_{\mathrm{N}, \mathrm{M}}^{+}\left(\mathrm{TiO}_{2}, 1,4, T\right)$ & 6 \\
\hline 579 & $\mathrm{TiO}_{2}+\mathrm{Ti}_{5} \mathrm{O}_{10} \longrightarrow \mathrm{Ti}_{6} \mathrm{O}_{12}$ & $\mathrm{k}_{579}=\mathrm{k}_{\mathrm{N}, \mathrm{M}}^{+}\left(\mathrm{TiO}_{2}, 1,5, T\right)$ & 6 \\
\hline 580 & $\mathrm{TiO}_{2}+\mathrm{Ti}_{6} \mathrm{O}_{12} \longrightarrow \mathrm{Ti}_{7} \mathrm{O}_{14}$ & $\mathrm{k}_{580}=\mathrm{k}_{\mathrm{N}, \mathrm{M}}^{+}\left(\mathrm{TiO}_{2}, 1,6, T\right)$ & 6 \\
\hline 581 & $\mathrm{TiO}_{2}+\mathrm{Ti}_{7} \mathrm{O}_{14} \longrightarrow \mathrm{Ti}_{8} \mathrm{O}_{16}$ & $\mathrm{k}_{581}=\mathrm{k}_{\mathrm{N}, \mathrm{M}}^{+}\left(\mathrm{TiO}_{2}, 1,7, T\right)$ & 6 \\
\hline 582 & $\mathrm{TiO}_{2}+\mathrm{Ti}_{8} \mathrm{O}_{16} \longrightarrow \mathrm{Ti}_{9} \mathrm{O}_{18}$ & $\mathrm{k}_{582}=\mathrm{k}_{\mathrm{N}, \mathrm{M}}^{+}\left(\mathrm{TiO}_{2}, 1,8, T\right)$ & 6 \\
\hline 583 & $\mathrm{TiO}_{2}+\mathrm{Ti}_{9} \mathrm{O}_{18} \longrightarrow \mathrm{Ti}_{10} \mathrm{O}_{20}$ & $\mathrm{k}_{583}=\mathrm{k}_{\mathrm{N}, \mathrm{M}}^{+}\left(\mathrm{TiO}_{2}, 1,9, T\right)$ & 6 \\
\hline 584 & $\mathrm{TiO}_{2}+\mathrm{TiO}_{2} \longrightarrow \mathrm{Ti}_{2} \mathrm{O}_{4}$ & $\mathrm{k}_{584}=\mathrm{k}_{\mathrm{N}, \mathrm{M}}^{+}\left(\mathrm{TiO}_{2}, 1,1, T\right)$ & 6 \\
\hline
\end{tabular}




\section{Parameters:}

$$
\begin{aligned}
T_{e} & =T / 11604.525 \mathrm{eV} \mathrm{K}^{-1} \text { is the gas temperature in electron volt } \\
\zeta & =1.36 \cdot 10^{-17} \mathrm{~s}^{-1} \text { is the cosmic ray }(\mathrm{CR}) \text { flux } \\
n_{\mathrm{tot}} & \text { is the total number density of the gas } \\
R_{\mathrm{kJ}} & \text { is the universal gas constant in } \mathrm{kJ} \mathrm{K}^{-1} \mathrm{~mol}^{-1} \\
\mathrm{k}_{\mathrm{N}, \mathrm{M}}^{+}(X, N, M, T) & =\pi\left(N^{1 / 3} r_{X}+M^{1 / 3} r_{X}\right)^{2} \sqrt{\frac{8 k_{\mathrm{B}} T}{\pi \mu_{N, M}}}, \quad \mu_{N, M}=\frac{m_{X_{N}} m_{X_{M}}}{m_{X_{N}}+m_{X_{M}}} \\
\mathrm{EQR}(T, \mathcal{R}, \mathcal{P}) & =\left(\frac{P^{\circ}}{k_{\mathrm{B}} T}\right)^{\Delta s} \exp \left(\frac{\sum_{r \in \mathcal{R}} G_{r}^{\circ}-\sum_{p \in \mathcal{P}} G_{p}^{\circ}}{R_{\mathrm{kJ}} T}\right), \quad \Delta s=|\mathcal{P}|-|\mathcal{R}|, \quad P^{\circ}=10^{5} \mathrm{~Pa} \\
\mathrm{k}_{\text {Troe }}\left(k_{0}, k_{\infty}, F_{C}, n_{\mathrm{tot}}\right) & =\frac{k_{0} n_{\mathrm{tot}}}{1+\frac{k_{0} n_{\mathrm{tot}}}{k_{\infty}}} F_{c}^{\beta}, \quad \beta=\frac{1}{1+\left(\log \frac{k_{0} n_{\mathrm{tot}}}{k_{\infty}}\right)^{2}}
\end{aligned}
$$

References: (1) Washburn et al. (2008), (2) Sharipov et al. (2012), (3) Starik et al. (2014), (4) Sharipov et al. (2011), (5) Sharipov \& Starik (2016), (6) This work, (7) Swihart et al. (2003), (8) UMIST database McElroy et al. (2013) , (9) KIDA database Wakelam et al. (2012), (10) Verner \& Ferland (1996), (11) Janev et al. (1987), (12) Forrey (2013), (13) Glover \& Abel (2008), (14) DeMore et al. (1997), (15) Abel et al. (1997), (16) Poulaert et al. (1978), (17) Capitelli et al. (2007), (18) Glover et al. (2010), (19) Verner \& Ferland (1996), (20) Plane et al. (2015), (21) Whalley et al. (2011), (22) Plane \& Whalley (2012), (23) Plane \& Helmer (1995), (24) Rollason \& Plane (2001), (25) Langowski et al. (2015), (26) Atkinson et al. (2004), (27) Campbell \& McClean (1993), (28) Ritter \& Weisshaar (1989), (29) Higuchi et al. (2008) and (30) Plane (2013)

Notes: The reactants $\mathrm{M}$ act as catalyists and can be any species. Therefore the total number density of the gas $n_{\text {tot }}$ is used as its density. References of reactions that contain the equilibrium ratio function EQR refer to the references of the reversed reaction. Not all reaction rate coefficients are valid in the considered temperature range. However, due to a lack of literature data, those coeffiecients are extrapolated in temperature when necessary. 